\title{
MEASURING ENERGY-SAVING RETROFITS: \\ EXPERIENCES \\ from the \\ TEXAS LoanSTAR PROGRAM
}

Prepared by

J.S. Haberl

T. A. Reddy

D. E. Claridge

W. D. Turner

D. L. O'Neal

W. M. Heffington

February 1996

Energy Systems Laboratory

Mechanical Engineering Department

Texas A\&M University

for the

Existing Buildings Research Program

Office of Building Energy Research

U.S. Department of Energy

OAK RIDGE NATIONAL LABORATORY

managed by Lockheed Martin Energy Research Corp.

for the U.S. Department of Energy

under contract number DE-AC05-960R22464 



\section{TABLE OF CONTENTS}

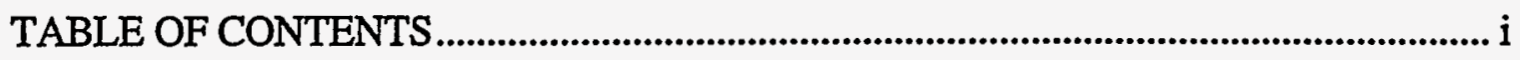

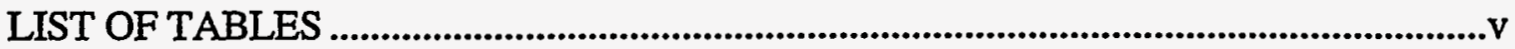

LIST OF FIGURES................................................................................................................... vi

PREFACE ......................................................................................................................... viii

DISCLAIMER .................................................................................................................. ix

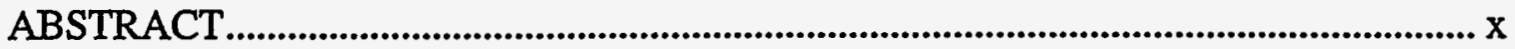

EXECUTIVE SUMMARY......................................................................................................... xi

Purpose and Objectives of the Program............................................................................. xi

Tasking.............................................................................................................................

Development of Monitoring Levels .............................................................................. xii

Measuring the Energy Use................................................................................................... xii

Acquiring and Processing the Data............................................................................... xii

Monitoring Requirements - Why Did We Monitor What We Did? ............................ xiii

Analysis Approach - How Did We Intend to Calculate the Savings?........................... xiii

Energy Savings....................................................................................................................... xiv

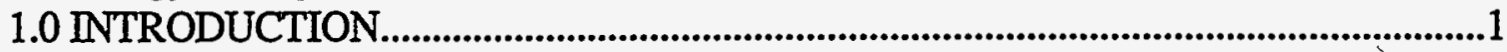

2.0 LOanSTAR PROJECT OVERVIEW, OBJECTIVES, AND

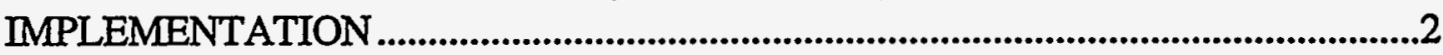

2.1 LoanSTAR Overview .....................................................................................................2

2.2 Objectives of the LoanSTAR Monitoring and Analysis Program ................................

2.3 Implementing the LoanSTAR Program ........................................................................4

2.3.1 Tasking....................................................................................................................4

2.3.1.1 Task 1: Audit Review and Assignment .....................................................4

2.3.1.2 Task 2: Selection and Installation of Monitoring Systems .....................5

2.3.1.3 Task 3: Calibration Laboratory ................................................................6

2.3.1.4 Task 4: Testing of Systems Communications, and Computer

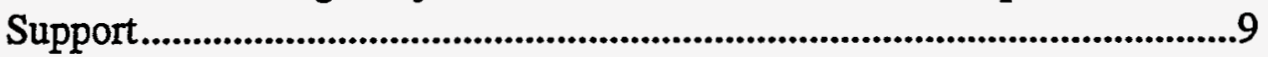

2.3.1.5 Task 5: Monitoring Plans, Analysis, and Reports................................10

2.3.1.6 Task 6: Improved Energy Audits ............................................................11

2.4 Development of Monitoring Levels ...............................................................................11

2.4.1 Level 0: Facility/Whole-building(s) Utility Data..........................................11

2.4.2 Level 1: Whole-building and Limited Sub-metered Hourly Data..................11

2.4.3 Level 2: Moderate Sub-metered Hourly Data.....................................................12

2.4.4 Level 3: Detailed Sub-metered Hourly Data.....................................................12

2.5 Budgeting for the Measurement of Energy Conservation Retrofits........................12

3.0 ACQUIRING, ARCHIVING, HANDLING, AND REPORTING THE DATA ..........38

3.1 Measuring the Energy Use .................................................................................38

3.2 General Information on Acquiring, Archiving, Handling, and Reporting

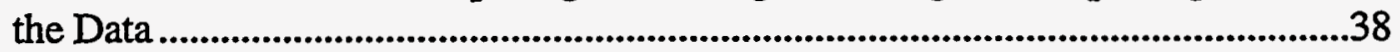

3.3 Basics of Electricity Monitoring ..................................................................................39

3.3.1 The Watt-hour Meter .................................................................................39

3.3.1.1 Connecting a Computer to a Watt-hour meter.......................................39 
3.3.1.2 Measuring Demand With a Watt-hour Meter ........................................40

3.3.1.3 The Watt/Watt-hour Transducer.............................................................40

3.4 Measuring Thermal Energy....................................................................................41

3.4.1 Thermal Energy Meters................................................................................41

3.4.2 Thermal Energy Meters Used in the LoanSTAR Program ........................42

3.4.3 Insertion Flow Meters ....................................................................................44

3.5 Polling and Retrieving Data.....................................................................................45

3.5.1 Processing/Plotting Synergistics Data..........................................................46

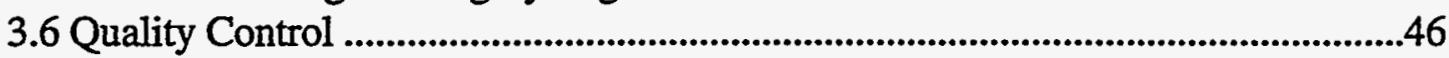

3.7 Weekly Report Generation............................................................................................48

3.8 Reporting the Data ............................................................................................4.48

3.8.1 Monthly Energy Consumption Reports .............................................................49

3.9 Data Exploration Software.........................................................................................51

3.10 Summary of LoanSTAR Data Management .............................................................51

3.10.1 Review of Polling Logs.............................................................................52

3.10.2 Recorder Parameter Set Revision Control ...................................................52

3.10.3 Automated Initial Verification ..........................................................................52

3.10.4 Automated Handling of Missing Records......................................................53

3.10.5 Generation and Review of Inspection Plots......................................................53

3.10.6 Controlled Data Release ..................................................................................53

3.10.7 Marking, Filling and Reconditioning In Database .......................................54

4.0 CHARACTERIZATION OF THE ANALYSIS OF RETROFIT MEASURES .........68

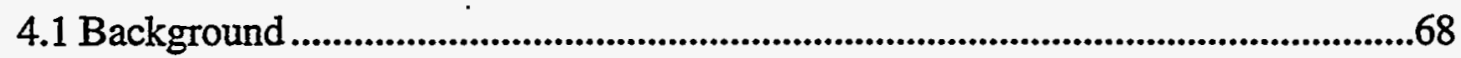

4.2 Monitoring Requirements - Why did we monitor what we did? ..............................68

4.2.1 Types of Retrofits......................................................................................68

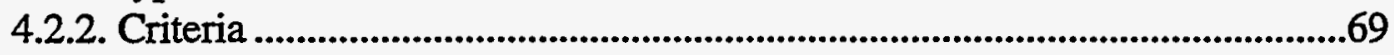

4.3 Analysis Approach - How did we intend to calculate savings? ................................70

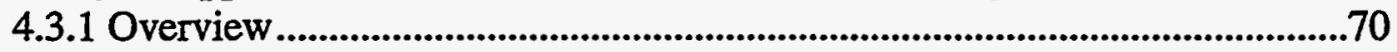

4.3.2 Savings Methodology ............................................................................................71

4.3.3 Statistical Models Used....................................................................................73

4.4 Allied Issues Regarding Modeling...............................................................................76

4.4.1. Effect of Short Pre-retrofit Data Sets ............................................................76

4.4.2. Uncertainty in Savings Determination .............................................................76

4.4.3. Simplified Systems Model Approach ..........................................................78

4.4.4 Mixed billing and monitored data......................................................................78

5.0 RESULTS FROM THE FIRST TWO YEARS OF MONITORING ...........................88

5.1 Verifying Energy and Audit Dollar Savings of Retrofits........................................88

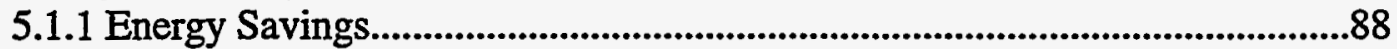

5.1.2 Demand Savings ...........................................................................................8

5.2 Reducing Energy Costs by Identifying O\&M Problems...........................................89

6.0 RECOMMENDATIONS FROM THE FIRST TWO YEARS OF

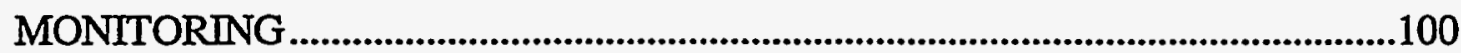

6.1 Recommendations from Task 1 .......................................................................100

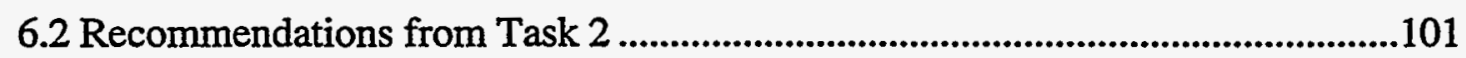

6.2.1 Administrative Guidelines for Task 2 ..........................................................101 
6.2.2 Equipment Recommendations .......................................................................102

6.2.2.1 Thermal Metering ...............................................................................102

6.2.2.2 Electrical Metering..................................................................................103

6.2.2.3 Other Instrumentation Problems ......................................................104

6.2.3 Equipment Installation ...............................................................................105

6.2.3.1 Thermal Metering ..................................................................................105

6.2.3.2 Electrical Metering..................................................................................107

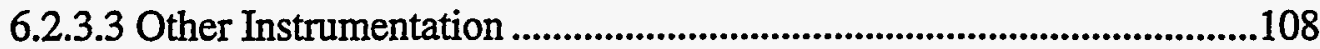

6.2.4 Equipment Maintenance ...............................................................................108

6.3 Recommendations from Task 3 ...................................................................................110

6.3.1 Equipment................................................................................................110

6.3.1.1 Electrical Metering..................................................................................110

6.3.1.2 Thermal Metering ..........................................................................................111

6.3.1.3 Other Equipment................................................................................111

6.3.2 Installation .......................................................................................................111

6.3.2.1 Thermal Metering ...............................................................................111

6.3.2.2 Electrical Metering.....................................................................................111

6.3.2.3 Other Equipment.................................................................................112

6.3.3 Maintenance....................................................................................................112

6.3.3.1 Thermal Metering ...........................................................................112

6.3.3.2 Electrical ...................................................................................................113

6.3.3.3 Other Equipment..................................................................................113

6.4 Recommendations From Task 4 .............................................................................113

6.4.1 Acquiring the data................................................................................................114

6.4.2 Data quality control..........................................................................................115

6.4.3 Hardware issues ......................................................................................116

6.5 Recommendations from Task 5 ..............................................................................116

6.5.1 Agency Contact and Site Description ...........................................................116

6.5.2 Pre-screening of Data.........................................................................................117

6.5.3 Modeling and Analysis ...................................................................................117

6.5.4 Savings Calculation .......................................................................................118

6.5.5 Savings Reporting and Follow-up.....................................................................118

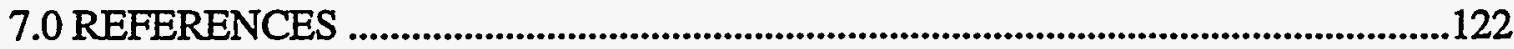

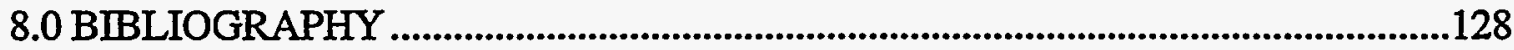

9.0 ACKNOWLEDGMENTS .....................................................................................135

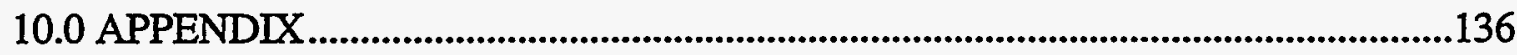

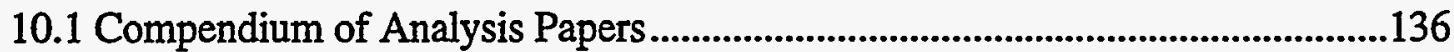

10.2 Helpful Hints about Polling and Retrieving Data ............................................142

10.2.1 Processing/Plotting Synergistics Data........................................................142

10.2.1.1 Preparing Data from Time Series Channels from Raw

Synergistics Data with R2A.BAT ...............................................................143

10.2.1.2 Using GRAPHER to Create an Individual Graph............................146

10.2.1.3 Creating Graphs Using 101GRAPH.BAT ......................................147

10.2.2 Modification of Routines ..............................................................................148 
10.2.3 Creation of Summary Pages From Raw Synergistics Data and Area

Weather Data

10.2.3.1 Modification of Summary Plot Routines

10.2.4 Creating a-3-D Graph Using Lotus 123 and Intex Solutions 3D

Graph..

10.2.5 Using the COLROW3D Columnar to Row Data Processing Routine 


\section{LIST OF TABLES}

Table 2.1: Summary of ECRMs for Buildings Monitored as of May 1993.....................14

Table 2.2: Energy Conservation Monitored in Buildings under the LoanSTAR program as of May 1993 ...................................................................................................14

Table 2.3: Guidelines for the LoanSTAR Metering Experiments ...................................15

Table 2.4: List of Potential Sensors for Calibration...........................................................15

Table 2.5: Ranges and Accuracies of the Calibration Facility ...........................................16

Table 2.6: Summary of Flow Meter Characteristics .............................................................17

Table 2.7: Budget Breakdown for the First Year Monitoring Program .............................18

Table 5.1: Comparison of Audit and Measured Savings on an Individual Building Basis for the 24 Buildings Currently Reporting Savings as of March 1993.

Table 5.2: Energy Conservation Identified in Buildings Monitored Under

LoanSTAR Program as of May 1993. . .93

Table 5.3: O\&M Opportunities identified at six sites......................................................94

Table 5.4: Summary of Potential O\&M Savings at Six LoanSTAR Sites.........................95

Table 6.1: Category IECRMs...........................................................................................120

Table 10.1: Example Output 10192168.DAT From RAW2DAT Program.....................158

Table 10.2: Example Output 10192168.DAT From RAW2DAT Program......................159

Table 10.3: Example Channel Table For the 10190001.CHT ARCHIVE Program......160

Table 10.4: Example .LOG File From the ARCHIVE Program ........................................161

Table 10.5: Summary of GRAPHER Instructions for Graph T1017.GRF ......................162

Table 10.6: T1017.GRF GRAPHER File ........................................................................163

Table 10.7: Example Output from the ARCHIVE Program, File 10192168.ACH ........164

Table 10.8: Example Input Data File for COLROW3D .....................................................165

Table 10.9: Example Output Data File for COLROW3D...................................................166

Table 10.10: An Example .LOG File for COLROW3D .....................................................167

Table 10.11: Decimal Date Reference Table for COLROW3D ........................................168

Table 10.12: Intex Solutions 3DGRAPH Plotting Instructions for 3D Surface

Plot SAMPLEM1.3DP 169 


\section{LIST OF FIGURES}

Figure 2.1: LoanSTAR Monitoring and Analysis Task Planning.....................................19

Figure 2.2: Distribution of LoanSTAR Loans by Percent of Functional Area .................20

Figure 2.3: Geographic Distribution of LoanSTAR Sites in Texas..................................21

Figure 2.4: Audit Estimated Retrofit Costs and Savings ......................................................22

Figure 2.5: Estimated Cost of Retrofits ..................................................................................23

Figure 2.6: $2 \mathrm{MW}$ of Measured Electric Demand Reduction ...............................................24

Figure 2.7: Typical LoanSTAR Level 1 Monitoring ...........................................................25

Figure 2.8: Typical LoanSTAR Level 2 Monitoring ........................................................26

Figure 2.9: Typical LoanSTAR Level 3 Thermal Monitoring...........................................27

Figure 2.10: Typical LoanSTAR Level $3 \mathrm{kWh}$ Monitoring ...............................................28

Figure 2.11: Preliminary Results for Calibration of RH Sensors ......................................29

Figure 2.12: Diagram of the Liquid Flow Loop Calibration Facility..................................30

Figure 2. 13: Preliminary Results from Tangential Paddlewheel Flow meters .................31

Figure 2.14: LoanSTAR Monitoring and Analysis Program Network ..............................32

Figure 2.15: DOS-UNIX ASCII Flat File Method for Archiving and Distributing

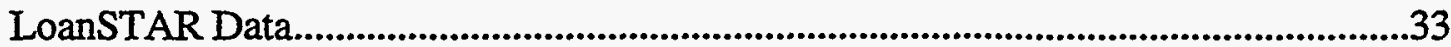

Figure 2.16: DOS-UNIX Relational Method for Archiving and Distributing

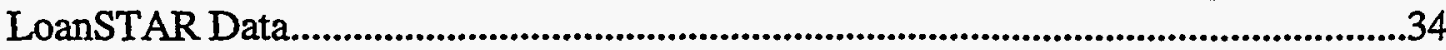

Figure 2.17: LoanSTAR Database Structure ...........................................................................35

Figure 2.18: LoanSTAR Centralized Commenting and Logging Facility --

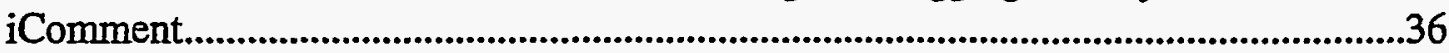

Figure 2.19: Before-After Analysis of Energy Conservation and Savings ........................37

Figure 3.1: Electrical and thermal monitoring diagram for a typical LoanSTAR

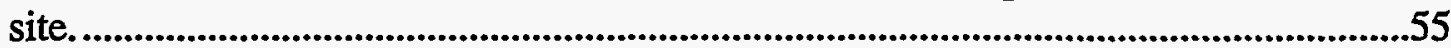

Figure 3.2: Diagram of an example logger set-up. ..........................................................56

Figure 3.3: Typical logger set-up to measure three phase whole-building

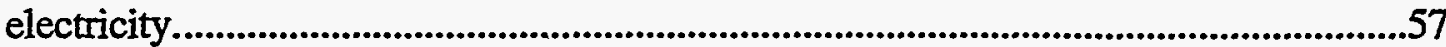

Figure 3.4: Typical thermal energy meter set-up............................................................58

Figure 3.5: Typical hot-tap flow meter installation. .......................................................59

Figure 3.6: Weather cross-plots of LoanSTAR vs. National Weather Service..................60

Figure 3.7: Typical weekly inspection plot for a LoanSTAR site. ...................................61

Figure 3.8: Summary page (page 1) from the August 1993 energy consumption report.

Figure 3.9: Page 2 of the Monthly Energy Consumption Report (MECR). .....................63

Figure 3.10: Page 3 of the Monthly Energy Consumption Report (MECR). ...................64

Figure 3.11: Page 4 of the Monthly Energy Consumption Report (MECR). ....................65

Figure 3.12: Page 5 of the Monthly Energy Consumption Report (MECR). ....................66

Figure 3.13: LoanSTAR browsing software. ...................................................................67

Figure 4.1: Pump and Air-handler Electricity Use at LoanSTAR Building .....................80

Figure 4.2: Pre-Retrofit Chilled-Water Use with Model and Savings.................................81

Figure 4.3: One, Two and Four Parameter Baseline Models for Savings Measurements 
Figure 4.4: Examples of Four-parameter Change-point Models for Hot Water and Chilled Water Energy Use. . .83

Figure 4.5: Flow Chart Summarizing Model Fitting Procedure .........................................84

Figure 4.6: Schematic of Savings Estimation Procedure..................................................85

Figure 4.7: Schematic of the HVAC and Building Zone Interaction Assumed in the Simplified Systems Model Approach ........................................................................86

Figure 4.8: Schematic of the Simulation Procedure ...........................................................87

Figure 5.1: Cumulative Savings from LoanSTAR Retrofits: March 1993 .......................96

Figure 5.2: Electricity Savings from HVAC Retrofits.......................................................97

Figure 5.3: AHU Electric Demand Reduction.....................................................................98

Figure 5.4: O\&M Identification Procedure Flow Chart.......................................................99

Figure 10.1: Flow Chart for R2A.BAT Plotting Procedure.............................................170

Figure 10.2: Example plot of the first 12 channels from Site 101..................................171

Figure 10.3: Example plot of the remaining channels from Site 101.............................172

Figure 10.4: Flow Chart for the GRAPHER Program...................................................173

Figure 10.5: Graph created with T1017.GRF and T101.DAT Data File........................174

Figure 10.6: Flow chart for 101GRAPH.BAT................................................................175

Figure 10.7: Example summary plot for Site 101............................................................176

Figure 10.8: Flow chart for summary page UTSUMM.BAT. ..........................................177

Figure 10.9: Basic flow chart for producing 3-D plots.....................................................178

Figure 10.10: Example .PIC plots using the COLROW3D software packages..............179 


\section{PREFACE}

This report has been prepared for the Existing Buildings Research Program of the Office of Building Energy Research at the U.S. Department of Energy. The purpose of this report is to document, for the benefit of others, the monitoring and analysis methods used in the Texas LoanSTAR program. It describes monitoring procedures and data analysis routines and software developed for the Texas LoanSTAR program that are copyrighted for distribution in the public domain. Software mentioned in this report and additional software used in the LoanSTAR program may be obtained by contacting the authors.

This report has been prepared by Drs. Jeff Haberl and Agami Reddy and includes significant input from Drs. David Claridge, W. Dan Turner, Dennis L. O'Neal, and Warren M. Heffington.

Mailing address: Energy Systems Laboratory, Mechanical Engineering Department, Texas A\&M University, College Station, Texas, 77843-3123, (409)845-6065, fax (409)862-2457. Dr. Haberl can be reached via e-mail at: JSH4037@TAMSIGMA, or jhaberl@loanstar.tamu.edu. 


\section{DISCLAIMER}

This report was prepared by the Energy Systems Laboratory (ESL) of the Texas Engineering Experiment Station (TEES) and was sponsored by the Office of Building Energy Research through the Existing Buildings Research Program at the U.S. Department of Energy (DOE). Neither the ESL, TEES, DOE, or Oak Ridge National Laboratory (ORNL), or any of their employees, makes any warranty, express or implied, or assumes any legal liability or responsibility for the accuracy, completeness, or usefulness of any information, apparatus, product, or process disclosed, or represents that its use would not infringe on privately-owned rights.

Reference herein to any specific commercial product, process, or service by trade name, trademark, manufacturer, or otherwise, does not necessarily constitute or imply its endorsement, recommendation, or favoring by the ESL, TEES, DOE, ORNL, or any agency thereof. The views and opinions of the authors expressed herein do not necessarily state or reflect those of the ESL, TEES, DOE or ORNL or any agency thereof.

Lotus and 1-2-3 are registered trademarks of Lotus Development Corporation located at 55 Cambridge Parkway, Cambridge, MA, 02142. Intex Solution's 3D-Graphics is a trademark of 4-5-6 World Ltd. located at 161 Highland Ave., Needham, MA, 02194. Grapher and Surfer are registered trademarks of Golden Software, 809 14th Street, Golden, CO. Postscript is a registered trademark of Adobe Systems, Inc. Synergistics is a registered trademark of Synergistic Control Systems, 5725 Bundy Road, New Orleans, LA 70127. CR1O and 21X are registered trademarks of Campbell Scientific, Inc., P.O. Box 551, Logan, Utah 84321. 


\section{ABSTRACT}

In 1988 the Governor's Energy Management Center of Texas received approval from the U.S. Department of Energy to establish a $\$ 98.6$ million state-wide retrofit demonstration revolving loan program to fund energy-conserving retrofits in state, public school, and local government buildings. As part of this program, a first-of-its-kind, statewide Monitoring and Analysis Program (MAP) was established to verify energy and dollar savings of the retrofits, reduce energy costs by identifying operational and maintenance improvements, improve retrofit selection in future rounds of the LoanSTAR program, and initiate a data base of energy use in institutional and commercial buildings located in Texas. This report discusses the LoanSTAR MAP with an emphasis on the process of acquiring and analyzing data to measure savings from energy conservation retrofits when budgets are a constraint.

This report includes a discussion of the program structure, basic measurement techniques, data archiving and handling, data reporting and analysis, and includes selected examples from LoanSTAR agencies. A summary of the program results for the first two years of monitoring is also included. 


\section{EXECUTIVE SUMMARY}

This report discusses the procedures developed in the Texas LoanSTAR (Loans to Save Taxes and Resources) program for acquiring and analyzing data to measure savings from energy conservation retrofits when budgets are a constraint. This report presents how the data were collected and how savings from energy conservation retrofits in the Texas LoanSTAR program were measured and reported.

\section{Purpose and Objectives of the Program}

The LoanSTAR Monitoring and Analysis Program (MAP) was designed to serve the differing needs of the many participants in the \$98 million LoanSTAR revolving loan program. Four primary objectives were to be accomplished by the LoanSTAR MAP. The energy monitoring program's first objective is to determine whether retrofits save as much as estimated in the energy audits. Verification of savings includes measurement of consumption data before and after the retrofit and analysis of the data to account for weather, changes in operation of the building, and so on. In effect the LoanSTAR MAP was created to serve as a quality assurance measure for agencies purchasing retrofits. The savings reports produced by the MAP were developed to show that real savings from those retrofits were occurring and, when savings did not occur, to investigate and recommend measures to make sure that the savings do occur.

The second objective of the LoanSTAR MAP is to reduce energy costs in a building by evaluating its energy-using characteristics and recommending operations and maintenance (O\&M) procedures to reduce energy costs.

The third objective is to increase the cost-effectiveness of future rounds of the LoanSTAR program by screening out ineffective retrofits. Some retrofits prove to be more effective and others less effective than expected. Knowledge gained in the LoanSTAR program is intended to enable engineers who perform audits to make more cost-effective recommendations.

The fourth and final objective of the LoanSTAR MAP is to establish a state-wide enduse data base for institutional and commercial buildings in Texas. Such a data base is expected to supplement existing data bases, such as ELCAP, BECA, and those in use by the United States Department of Energy Information Agency (EIA) and the Electric Power Research Institute's Center for Electric End-Use Data (CEED). These data are intended for use by utility planners, building research scientists, and government policy makers.

\section{Tasking}

In order to accomplish these objectives, the LoanSTAR MAP was divided into six tasks with the following responsibilities: Task 1, performing audit reviews and assignments, Task 2 , installing hardware and selecting vendors, Task 3 , running a calibration facility, Task 4, providing computer support, Task 5, analyzing and reporting 
savings, and Task 6, improving energy audits. Each of the six primary tasks also utilized subcontractors as needed to complete the work in a timely fashion.

\section{Development of Monitoring Levels}

Four levels of metering were developed for the energy monitoring program. These levels were intended to accommodate the necessary data requirements with the funds available for monitoring the retrofits, as follows:

1) Level 0: facility whole-building(s) utility data.

2) Level 1: whole-building and limited sub-metered hourly data. Typically, this represents four channels of data from a building, usually electricity and thermal loads.

3) Level 2: moderate sub-metered hourly data. This includes Level 1 plus submetered data for air-handling units or motor control centers.

4) Level 3: detailed sub-metered hourly data. This typically includes 20 or more channels of data and is reserved for the most extensive sites.

Level 1 monitoring applies to retrofits of $\$ 50,000$ to $\$ 100,0000$ and costs about $\$ 3,000$ to install. Level 2 monitoring applies to retrofits costing $\$ 100,000$ to $\$ 300,000$ and costs roughly $\$ 10,000$ to $\$ 30,000$ to install. Level 3 is reserved for buildings with retrofits costing more than $\$ 300,000$ and costs $\$ 30,000$ or more to install. These cost levels were developed to keep monitoring budgets within $3 \%$ of the retrofit costs. Level 0 costs essentially nothing to install since it relies on monthly utility billing data.

\section{Measuring the Energy Use}

The primary uses of energy in buildings involve the time-varying measurements of electricity and thermal energy use, usually on an hourly basis. In the LoanSTAR program, most of the electricity monitoring was accomplished with current transducers, potential transducers, and digital watt-hour transducers, or by piggy-backing on the existing utility meters through the use of a KYZ dry contact pulse.

Thermal energy monitoring, used to measure the chilled water and steam or hot water energy use, was accomplished with thermal energy meters or Btu meters. Btu meters are electronic devices that are used to calculate chilled water or hot water energy use. Each Btu meter requires three input signals: a flow meter signal and a temperature signal for both the supply and return lines.

\section{Acquiring and Processing the Data}

The LoanSTAR MAP data management consists of five major functions: 1) polling the data from the remote data acquisition systems; 2) processing the data from various sites into a reasonably generic format; 3) controlling data quality; 4) generating reports; and 5) retrieving data for analysis. By August 1994, the LoanSTAR MAP was retrieving data from over 81 field recorders and 68 National Weather Service (NWS) weather stations. One of the objectives of the data-gathering aspects of the program was to develop public domain routines that could be useful to others. LoanSTAR has faithfully 
accomplished this task by developing modular routines to poll and process data, and placing these routines in the public domain.

\section{Monitoring Requirements - Why Did We Monitor What We Did?}

As of September 1994, energy savings in 19 LoanSTAR loans (a total of 89 buildings) were being reported, while monitoring was under way at 81 sites. The majority are institutional buildings, while a few are school districts and thermal energy plants. Ranging in size from $50,000 \mathrm{ft}^{2}$ to $500,000 \mathrm{ft}^{2}$, The primary retrofits in these buildings were to the lighting and HVAC systems, which required that both thermal and electrical energy use be analyzed.

If a retrofit was expected to reduce lighting, heating, or cooling energy use, then the energy used by these subsystems was (for the most part) monitored and recorded before and after the retrofit. In most instances, monitoring of whole-building electricity, thermal energy use, and selected electrical submetering on the large electrical loads was sufficient to capture $90 \%$ of the energy used by these systems. Typically, the following channels were used during retrofit savings calculations: chilled water use, hot water use, wholebuilding electricity use, air handler electricity use, pump electricity use, and climate variables (ambient temperature, relative humidity, wind speed and global horizontal solar radiation).

\section{Analysis Approach - How Did We Intend to Calculate the Savings?}

In the simplest cases, retrofit savings can be measured by directly comparing the unadjusted pre-retrofit energy use to the post-retrofit energy use. Unfortunately, this simple comparison can introduce as much as $10-20 \%$ error in buildings that have varying schedules and/or experienced different weather conditions during the pre/post periods. In the LoanSTAR program, for the larger retrofits, hourly data were measured during the pre-retrofit period to construct a baseline model. This model was then used to predict what the building would have consumed in the post-retrofit period had the retrofit not been implemented.

The basic modeling approaches used in the LoanSTAR program can be grouped into two generic types: regression models and calibrated engineering models. The regression models use billing and/or monitored data and employ one-, two-, three-, and fourparameter change-point models, or multiple regression models. The calibrated engineering models ranged from sophisticated DOE-2 calibrated models to calibrated simplified HVAC system models. In each case it was important to identify the pre-retrofit period, construction period, and post-retrofit period. Then, depending on the type of model, hourly data were then converted to average daily data prior to performing the regressions. Statistical models were then applied and the model that demonstrated the best goodness of fit was chosen. Usually, to ensure completeness, all models were applied to all buildings and the best model was chosen. The statistical models were then used to project the baseline use in the post-retrofit period. Savings were then calculated by comparing the differences between the post-retrofit baseline energy use and the measured

Texas LoanSTAR Program

Texas Engineering Experiment Station
Energy Systems Laboratory Texas A\&M University 
post-retrofit energy use. In cases where substantial post-retrofit data were missing a post retrofit model was created and substituted for the missing post-retrofit data.

\section{Energy Savings}

As of September 1994, the cumulative measured savings from the 19 LoanSTAR loan sites that had completed retrofits were $\$ 12.2$ million, of which $34.6 \%$ is in electricity savings, $47.5 \%$ in cooling energy savings, and the remainder (18\%) in heating energy savings. The value of the monitoring performed as part of the LoanSTAR program can be appreciated by noting that the program-wide savings agree to within $5 \%$ of the audit estimated savings -- a feat rarely accomplished in other programs. O\&M savings have increased these values considerably and have also played a significant role in the program. Demand reduction has also been significant across the LoanSTAR sites -- an unexpected feature for variable speed drives. In four of the sites, demand reductions of $30 \%$ were observed. The total reduction for all sites as of December 1993 approaches 2 MW, of which roughly $37 \%$ is in lighting, $60 \%$ in HVAC-related equipment, and $3 \%$ in thermal energy storage.

The remainder of this report discusses the procedures developed in the Texas LoanSTAR program for acquiring and analyzing data to measure savings from energy conservation retrofits when budgets are a constraint. 


\subsection{INTRODUCTION}

This report discusses the process of acquiring and analyzing data to measure savings from energy conservation retrofits when budgets are a constraint. ${ }^{1}$ This report discusses how the data were collected and how savings from energy conservation retrofits in the Texas LoanSTAR program were measured and reported.

In the first section, the objectives of the LoanSTAR program and how it was structured and implemented are described, including the development of monitoring levels and budgeting. This is followed by a discussion of the basic techniques that were employed to measure the energy savings in the agencies participating in the LoanSTAR program, and a discussion of the procedures that were used to archive, handle, and report hourly data from thousands of data channels.

Next, the analysis procedures that have either been adopted or developed for analyzing the savings from energy conservation retrofits in the LoanSTAR program are discussed, including selected examples of the applications of these procedures from LoanSTAR sites.

Preliminary measured results from the first year of monitoring 24 LoanSTAR agencies are also included. The final section of the report summarizes the lessons learned and makes recommendations for other large-scale monitoring projects.

${ }^{1}$ In the LoanSTAR program the budgets were constrained as follows: $3 \%$ of the retrofit costs were to cover the installation of metering equipment, and 2-3\% per year were to cover the analysis and reporting. Since the LoanSTAR numbers indicate Texas state interagency transfers these numbers would need to be adjusted to account for overhead and profit. 


\subsection{LOanSTAR PROJECT OVERVIEW, OBJECTIVES, AND IMPLEMENTATION}

\subsection{LoanSTAR Overview}

In 1988, the Governor's Energy Management Center (GEMC) ${ }^{2}$ of Texas received approval from the U.S. Department of Energy to establish a $\$ 98.6$ million statewide retrofit demonstration revolving loan program, the LoanSTAR (Loans to $\underline{S} a v e \underline{T}$ axes and Resources) program. The LoanSTAR program uses a revolving loan financing mechanism to fund energy-conserving retrofits in state, public school, and local government buildings. Retrofit projects are identified by energy audits conducted by engineering teams under contract to the GEMC. Each retrofit competes for funds on the basis of the estimated payback period, ability to repay the loan through energy savings, engineering assessment of the viability of the retrofit, and the feasibility of metering the project effectively. The program began in 1988. Public sector institutions participating in the program must repay the loans according to estimated energy savings in four years or less (Verdict et al. 1990).

As part of this program, a statewide energy Monitoring and Analysis Program (MAP) was established. The major objectives of the LoanSTAR MAP are as follows (Turner et al. 1990; Claridge et al. 1991):

1) to verify the energy. and dollar savings of the retrofits,

2) to reduce energy costs by identifying operational and maintenance improvements,

3) to improve retrofit selection in future rounds of the LoanSTAR program, and

4) to initiate a data base of energy use in institutional and commercial buildings located in Texas.

The LoanSTAR program is being implemented in two phases. Phase I targets state agencies and institutions that received energy audits in 1984-86. Capital intensive energyconserving improvements totaling $\$ 40$ million are candidates for funding in this phase. Public schools and local governments are targeted for Phase $I I$ of the LoanSTAR program. Previous engineering audits of these facilities conducted under the Institutional Conservation Program (ICP) revealed potential energy savings similar to those in state buildings.

The projects funded by LoanSTAR primarily include retrofits to lighting, HVAC systems, the building shell, electric motors, energy management and control systems, boilers, and thermal energy recovery systems. Retrofits using alternative or renewable energy systems and load management also are considered.

2 In 1990 the center was renamed the Governor's Energy Office. In 1993 it was again renamed the Texas Energy Office; it was given its current name, the State Energy Conservation Office, late in 1993. 
The maximum loan amount to a local government or independent school district is $\$ 1.2$ million. The maximum loan for state agencies and universities is $\$ 4.8$ million. Repayments are made semi-annually at an annual interest rate of $4.04 \%$. The length of the loan is determined by the combined estimated simple payback of the project(s). Loan proceeds are used to pay for the retrofits, engineering and design, and installation expenses. The cost of the on-site metering and energy analysis is paid from the interestincome derived from the program. Total metering costs must not exceed $3 \%$ of all retrofit costs.

\subsection{Objectives of the LoanSTAR Monitoring and Analysis Program}

The LoanSTAR Monitoring and Analysis Program (MAP) was designed to serve the differing needs of the many participants in the LoanSTAR revolving loan program. The energy monitoring program's first objective is to determine whether retrofits save as much as estimated in audits. When necessary, a monitoring plan is developed for each retrofitted facility to verify savings. Verification of savings includes measurement of consumption data before and after the retrofit and analysis of the data to account for weather, changes in the operation of the building, and so on. This is a quality assurance measure to ensure that agencies purchasing retrofits receive real savings from the LoanSTAR retrofits.

The second objective of the MAP is to reduce energy costs of a building by evaluating its energy-using characteristics. Previous experience at several universities and at a large federal office building in Washington, D.C., has demonstrated that continuous energy monitoring and analysis can lead to changes in operation and maintenance that can substantially reduce energy use in a building (Haberl and Claridge, 1987; Haberl and Vajda, 1988; Haberl and Komor, 1989).

Some retrofits may prove more or less effective than expected. This knowledge enables engineers who perform future audits to make more cost-effective recommendations. Hence, the third objective is to increase the cost-effectiveness of future rounds of the LoanSTAR program by screening out ineffective retrofits.

The final major objective of energy monitoring is the establishment of an end-use data base for institutional and commercial buildings in Texas. The number and types of buildings in LoanSTAR for which detailed data will be available will be limited. Therefore, data gathered in the framework of the LoanSTAR program should be considered a supplement to existing data bases, such as ELCAP, BECA, and data bases used by Energy Information Agency (EIA). It will include data to evaluate retrofit effectiveness in a large number of buildings in hot and humid climates. These data can be used by utility planners, building research scientists, and government policy makers. A more detailed description of the energy monitoring and analysis program is available in Claridge et al. (1991). 


\subsection{Implementing the LoanSTAR Program}

The LoanSTAR MAP is administered through the State Energy Conservation Office (SECO) of Texas and is conducted primarily at the Energy Systems Laboratory at Texas A\&M University. A Monitoring and Analysis Review Committee (MARC) has been established to provide ongoing contact with other energy monitoring and analysis efforts to ensure incorporation of applicable techniques and results from those efforts. Organizations with participants on the MARC include the U.S. Department of Energy, the Electric Power Research Institute, Lawrence Berkeley Laboratory, Oak Ridge National Laboratory, Pacific Northwest Labs, National Renewable Energy Laboratory, Princeton University, Massachusetts Institute of Technology, the University of Texas, Pacific Gas \& Electric Co., and a Texas utility. ${ }^{3}$

\subsubsection{Tasking}

The primary work for the MAP has been divided into six tasks (Figure 2.1) with the following responsibilities: Task 1, performing audit reviews and assignments; Task 2 , installing hardware and selecting vendors; Task 3 , running a calibration facility; Task 4, providing computer support; Task 5, analyzing and reporting savings; and Task 6 , improving energy audits. ${ }^{4}$ Each of the six primary tasks utilizes subcontractors as needed to complete the work in a timely fashion.

\subsubsection{Task 1: Audit Review and Assignment}

The SECO has contracted with engineering consulting firms to conduct audits for the LoanSTAR program. An audit firm is assigned to each building based on expertise, geographical location and workload. Task 1 personnel then conduct an independent review of all energy audit reports submitted by the consulting engineering firms under contract to the SECO. Reports are reviewed for use of appropriate technology, conceptual correctness, adequacy of implementation cost data, numerical accuracy, and compliance with program guidelines. The major functions of this task include review of preliminary on-site screening reports, desktop audit reviews, conducting meetings with the engineering consulting firms, and the development of audit format training workshops (Heffington et al., 1987; Nutter et al., 1990; Heffington et al., April 1992; Heffington et al., May 1992.)

Figure 2.2 shows the distribution of the LoanSTAR loans by percent floor area of functional use. The largest portion of floor area is in medical facilities, followed by buildings that are being monitored at university campuses. Figure 2.3 shows the geographical distribution of the LoanSTAR sites around the state of Texas. Clearly, the largest number of buildings are in Austin at the State Capitol and University of Texas at Austin campus. The other buildings are spread around the state as shown.

${ }^{3}$ This is current as of June 1993.

4 Originally, there were 5 tasks. Task 6 was added in 1992.

Texas LoanSTAR Program

Texas Engineering Experiment Station

Energy Systems Laboratory

Texas A\&M University 
Figure 2.4 shows the audit estimated retrofit costs and savings. HVAC system retrofits are by far the largest percent of retrofit costs, followed by variable speed drives and lighting retrofits. One interesting feature to point out is the importance of funding. boiler and steam system retrofits. These types of retrofits have been very cost effective with almost twice the savings potential of other retrofits. Table 2.1 gives a summary of energy cost reduction measures (ECRMs) for buildings monitored as of May 1993. The estimated $\$ 32.5$ million implementation cost will generate $\$ 9.6$ million annual savings for an estimated 3.4 year simple payback. Roughly 199 buildings containing 18.3 million square feet of conditioned space will have been affected by various retrofits, ranging from variable speed drives to lighting replacements. Typically, it takes 6 months from the time an agency applies for an audit until a loan is approved.

Figure 2.5 lists the estimated costs of the completed retrofits in the program as of May 1993. As indicated, at any given time, different numbers of participating LoanSTAR agencies are at different stages in the program. As of May 1993, 24 sites (36 buildings) 5 had completed their retrofits and were having their savings reported by the ESL, 11 additional sites had recently completed their retrofits and have yet to report savings. Thirty-four more sites, for a total of 69 sites (199 buildings) are being monitored by the ESL as of May 1993.

As of May 1993, the LoanSTAR program has identified energy source ${ }^{6}$ savings of 2.5 trillion Btu (2.5 x 1012) as shown in Table 2.2. Electricity represents the largest source of Btu savings at $52.9 \%$, followed by chilled water at $17.4 \%$ and steam/hot water at $17.1 \%$. Natural gas savings represent $12.7 \%$.

The installed retrofits have also produced over $2 \mathrm{MW}$ in electric demand savings as well, as shown in Figure 2.6. Over 60\% of these savings have been in HVAC retrofits, followed by $37 \%$ in lighting retrofits and $3 \%$ in thermal storage retrofits.

\subsubsection{Task 2: Selection and Installation of Monitoring Systems}

This task ensures that adequate, reliable and affordable data are collected to monitor energy use of the buildings participating in the LoanSTAR program. Data collected from the buildings serve as the basis for determining the cost-effectiveness of different retrofits as well as providing indices of how well an individual building is performing. The major functions in this task include determination of metering requirements, data acquisition system subcontractor qualification and selection, and installation and maintenance of metering systems.

Four levels of metering systems have been developed for the energy monitoring program. These accommodate the necessary data requirements with the funds available for monitoring retrofits. The levels also are compatible with different hardware available

\footnotetext{
${ }^{5}$ The number of sites usually represents a data logger. Since several buildings can be monitored by one logger there are more buildings than sites.

${ }^{6}$ Btu savings calculated on the basis of source Btus (i.e., 11,600 Btu/kWh, 1,030,000 Btu/MCF, boiler efficiency of $75 \%$ and $12,000 \mathrm{Btu} / \mathrm{ton}-\mathrm{hr}$ ). 
on the market as of May 1993. Table 2.3 contains guidelines for the energy monitoring levels. These levels include 1) Level 0 : facility whole-building(s) utility data, 2) Level 1: whole-building and limited sub-metered hourly data, 3) Level 2: moderate sub-metered hourly data, 4) Level 3: detailed sub-metered hourly data. Additional information about the four levels of monitoring is discussed in section 2.4 .

Figure 2.7 shows a typical LoanSTAR Level 1 monitoring setup as installed in the $\mathrm{T}$. S. Painter Building on the University of Texas at Austin campus. This Level 1 monitoring provides whole-building electricity, whole-building chilled water and whole-building steam condensate use. Figure 2.8 shows a typical Level 2 monitoring plan as installed in the UTC Building on the University of Texas at Austin campus. In this case, Level 2 monitoring provides whole-building electricity $(\mathrm{kWh})$, whole-building chilled water, whole-building steam condensate, and sub-metered electricity use for the building's airhandling units and pumps.

Figure 2.9 illustrates a Level 3 thermal monitoring setup as installed in the S. F. Austin building at the Texas State Capitol complex. In general most Level 3 monitoring experiments are complex and require a metering plan that is specially tailored to each retrofit. The S. F. Austin building contains a central boiler/chiller complex that feeds several other buildings and a weather station. Figure 2.10 shows a Level 3 electricity monitoring setup as installed in the S. F. Austin building at the Texas State Capitol complex. The intent of this monitoring plan is to isolate electricity use in the boiler/chiller plant.

In general, a separate monitoring diagram is developed for each LoanSTAR site during the initial site visit by the LoanSTAR field engineer. The purpose of this diagram is to ensure that the intended retrofit's energy use is being recorded properly and to develop a simple diagram that can be understood by all parties involved, including the field engineer, agency contact, and LoanSTAR analyst who will later rely on the diagram to help explain what has been monitored and how it relates to the retrofit.

\subsubsection{Task 3: Calibration Laboratory}

The accuracy of the installed sensors is key to a successful energy monitoring project. Data obtained for such a project must be accurate to maintain confidence and reliability. In order to ensure that accurate data are collected, a National Institute of Standards and Technology (NIST)-traceable calibration laboratory has been established at the Energy Systems Laboratory at Texas A\&M University (Turner et al., 1992).

The objectives of the calibration laboratory are to 1) construct a NIST-traceable facility, which will be used to test sensors and verify their compatibility with selected energy monitoring systems; 2) establish a facility for troubleshooting faulty sensors found in the field; 3 ) construct a portable calibration system for in-situ field testing, troubleshooting, calibration, and validation; 4) have a facility to bench-test and prequalify proposed sensors and hardware prior to approval for installation in the field; and 5) develop improved calibration procedures for in-situ field testing. 
A list of potential calibration sensors is shown in Table 2.4. All of the sensors in the LoanSTAR program are calibrated yearly using the calibration laboratory. This calibration facility includes the capability to measure dry-bulb, wet-bulb, and dew-point temperature, humidity, air and hydraulic pressure, air and liquid mass flow rates, air velocity, rpm, illumination levels, electrical energy, power factor, and solar radiation, as shown in Table 2.5. Typically, the calibration accuracy is two to ten times more accurate than the sensors being tested (as recommended by national calibration standards).

Two of the more useful calibration stations have turned out to be the temperaturehumidity station and the flow meter calibration facility. The humidity calibration standard consists of a temperature chamber, a multi-bore glass flask and a variety of salt solutions. Saturated salt solutions of known proportions are placed in the flask along with the candidate sensor and several 1,000 Ohm RTD sensors. The temperature of the chamber is then varied and the readings are compared with NIST published data for the salt solutions, using NIST procedures.

The following salt solutions are currently being used: lithium chloride ( $11 \% \mathrm{RH})$; magnesium chloride ( $32 \% \mathrm{RH})$; magnesium nitrate ( $54 \% \mathrm{RH})$; sodium chloride ( $75 \%$ $\mathrm{RH})$; potassium chloride ( $85 \% \mathrm{RH})$; and potassium sulfate $(97 \% \mathrm{RH})$. The secondary calibration standard for the station is a chilled-mirror dew point sensor.

The measurement of humidity (and its derived variables: enthalpy, specific humidity, dewpoint temperature, etc.) can play an important role in buildings when the analysis of latent cooling loads is undertaken. Unfortunately, the long-term hourly measurement of humidity at remote sites can be characterized as problematic at best. For example, in very humid locations such as the Gulf coast, humidity sensors saturate (and stay saturated) for hours on end. Such sensors require special attention when it comes to calibration. Preliminary results from calibration efforts with bulk polymer-type sensors have been developed. The basic procedure employed involves a constant pressure, sealed flask where the candidate sensors are suspended in the saturated vapor above the salt solution in the bottom of the flask. Then, the entire flask (and sensors) are heated to a beginning temperature and stepped-down through a series of predetermined temperatures, pausing long enough at each temperature for all signals to stabilize.

Figure 2.11 shows the results from tests performed on two RH sensors. Using equations developed by Greenspan (1977), the tests show clearly that one sensor consistently overstates the humidity when compared to the theoretical humidity that is predicted by saturated conditions at a given temperature. Both candidate sensors are bulkpolymer $\mathrm{RH}$ sensors with a stated accuracy of $\pm 2 \%$ at $25 \mathrm{C}(77 \mathrm{~F})$ that were taken "offthe-shelf' from LoanSTAR inventories from the same manufacturer. The preliminary tests clearly indicate that temperature and humidity-dependent corrections will need to be developed for each individual sensor to obtain the highest accuracy. 
Liquid velocity measurements are calibrated with a dynamic weight flow loop. The flow loop consists of 37,800 liter (10,000 gallon) supply and receiving tanks, a parallel pumping configuration using $3.2,9.5$, and $41 \mathrm{l} / \mathrm{s}(50,150$ and $650 \mathrm{gpm})$ pumps, a return pump, assorted valves, and a flow test section, currently with a $15.2 \mathrm{~cm}$ ( 6 inch) pipe as shown in Figure 2.12. The receiving tank is mounted on four Sensortronics Model 65016 $(11,342 \mathrm{~kg}(25,000 \mathrm{lb}$.) each) load cells. This provides a dynamic weighing system for bulk fluid velocity measurements (ASME MFC-9M-1988; Baker and Hurley 1984; Miller 1989; Olsen 1974). The load cells were calibrated by the Department of Agriculture Weights and Measures Division, State of Texas, using NIST-traceable dead weights. In addition to this primary standard, a series of interchangeable orifice plates is installed to provide a secondary standard. In addition, the calibration facility is equipped with interchangeable $20.3 \mathrm{~cm}$ ( 8 inch) and $25.4 \mathrm{~cm}$ (10 inch) pipe test sections as well as a $15.2 \mathrm{~cm}$ ( 6 inch) clear test section. The flow loop is also equipped with a $10.2 \mathrm{~cm}$ (4 inch) return line that can also be used for calibration tests.

Both the liquid flow loop station and the temperature-humidity station are being used in a production mode to calibrate sensors for the program. Preliminary tests of some of the sensors with these stations have already provided some interesting and quite unexpected data that confirm the need for a facility such as this.

One of the first problems investigated in the flow loop was the sensitivity of the insertion-type tangential paddlewheel flow meters to the insertion depth into the fluidcarrying pipe (Haberl et al. 1992). These tests showed that care must be taken when installing flow meters in pipes to ensure that they are installed at the proper insertion depth. This problem is further compounded by the fact that different manufacturers recommend different insertion depths. Without careful documentation, the insertion depth can vary slightly from installation to installation. It can. also be changed by the agency . operators. These flow meters also have an axial alignment requirement; hence, the sensitivity to off-axis installation also needs to be measured.

In Figure 2.13 preliminary results from tests performed on magnetic and nonmagnetic paddlewheel flow meters in a 6" pipe are presented. The results show the velocity measurements by one manufacturer's magnetic-type paddlewheel meter were $15 \%$ low on average due to an erroneous pulse-per-gallon constant. In addition the signal from the magnetic-type paddlewheel meter went to zero for velocities below $2 \mathrm{ft} / \mathrm{s}$. The failure of the meter below $2 \mathrm{ft} / \mathrm{s}$ confirmed the observations that had been made at some of the field installations. However, when the data were closely examined, it was discovered that the flow meter was still rotating and producing electronic pulses but the strength of the pulses had dropped below the sensitivity threshold of the Btu meter. ${ }^{7}$ To remedy this, a pre-amplifier was inserted between the flow meter and the Btu meter that significantly improved the low flow results in the laboratory tests. ${ }^{8}$ In Figure 2.13 the

\footnotetext{
7 Subsequent tests showed that the threshold varies with the type of Btu meter.

8 However, such a pre-amplifier is not used by the manufacturer of this flow meter. Tests were performed to confirm the minimum flowrate that this meter would operate under. 
"mag meter corrected" symbol represents the results that were obtained once the preamplifier had been installed and the pulse-per-gallon reading had been adjusted. As shown, the meter comes within $\pm 5 \%$ of the flow rate for velocities above $2 \mathrm{ft} / \mathrm{s}$.

A second type of paddlewheel meter was tested, which uses a "non-magnetic" metering technology. Although this type of technology is about twice as expensive than the magnetic technology, it seems to consistently produce more accurate data, as shown in Figure 2.13. The results from the non-magnetic paddlewheel meter appear to be within \pm $5 \%$ from $2 \mathrm{ft} / \mathrm{s}$ and up, and $\pm 10 \%$ from $1 / 2$ to $2 \mathrm{ft} / \mathrm{s}$. The pulse-per-gallon factor also appears to be correct. This type of technology also does not suffer from the degradation that the magnetic technology incurs when metal filings accumulate on the magnets and retard the rotation.

Choosing a flow meter for a particular application requires a knowledge of what type of fluid is being measured, how dirty or clean that fluid is, what the lowest expected flow velocities are, and what type of budget one has available, as shown in Table 2.6. This table represents results from an informal survey of flow meter manufacturers and includes installed costs from experiences with the LoanSTAR program.

\subsubsection{Task 4: Testing of Systems Communications, and Computer Support}

The purpose of this task is to conduct bench-mark communications testing of all field Data Acquisition Systems (DASs) for the LoanSTAR MAP. This includes testing the compatibility of sensors, DASs and the host computer. Public domain software, using open communications protocol, has been developed for polling, translating and analyzing the field data. Data acquisition systems that adequately satisfy the testing were approved for use in the program. The primary functions of this task include the communications bench-test and the software design, development, and testing.

Figure 2.14 shows the LoanSTAR Monitoring and Analysis Program Network (MAPNet) that has been developed for polling, archiving and analyzing building energy data. As of May 1993, 1,020 hourly channels of data are polled weekly from 77 loggers at 69 sites, which account for 199 buildings. One hundred fifty hourly channels of data are also collected from the NWS Aviation Weather Observation, converted to LoanSTAR format and merged with the LoanSTAR data. Once in the MAPNet, the data are kept on a Data General Aviion AV-4020 RISC server with 64 MB of RAM and 3.5 Gbytes of disk space. Analysts then have access to the data via the campus internet through one of 64 workstations scattered about the campus.

Originally, data were collected with DOS-based computers, processed for missing data and high-low bounds, and then stored as flat ASCII files (.ACS) as shown in Figure 2.15. Inspection Plot Notebooks (IPNs) and Voyager files were then produced on DOSbased computers and distributed to LoanSTAR analysis workstations via the campus internet. Flat ASCII files were also kept on the UNIX-based server where Monthly Energy Consumption Reports (MECR) and Annual Energy Consumption Reports 
(AECR) were produced, as well as data being made available for analysis. This system was chosen mainly because of ease of use, and the ability to use existing data processing tools, such as ARCHIVE (Feuerman and Kempton 1987). However, handling hourly data comprising about 1,000 channels from 50 sites became too unwieldy using the flat-file ASCII scheme that required concatenating 52 files to look at one year's worth of data. Hence, a relational system was chosen to update the data management system at this stage of the project.

After a lengthy selection process the Informix relational data base was chosen and installed on the UNIX server. Figure 2.16 shows the basic data flow scheme that resulted. With the relational system, flat ASCII files were loaded into Informix after IPNs were produced with the traditional DOS-based scheme. Once in Informix, the data could then be retrieved and used for any one of a number of processing requirements as shown in Figure 2.17. As of May 1993 there are 1,020 channels of building energy data, which includes over 12 million individual readings. Each week about 162,000 records, or roughly 2.5 million bytes, are added to the data base. To date about $2 \%$ of the data have been marked bad. ${ }^{9}$ About $6 \%$ of the data have required some sort of correction after they were collected. Most of the corrections to date involve the flow meter corrections.

Another feature that is being developed is a relational commenting system. At various points in the data stream, analysts and LoanSTAR staff have the opportunity to comment on the data and can insert their comments into the permanent LoanSTAR relational database. This process leaves a paper trail for other analysts so that specific facts about a site can be made available without the various parties involved with the installation, maintenance, data collection, programming, and data administration having to meet in person. The system developed is being called iComment, as shown in Figure 2.18. iComment receives comments from a number of different inputs, including the IPN, MECR, AECR, calibration lab, and automatic comments from several routines. iComment then automatically sorts the comments and archives them appropriately. iComment can automatically deliver messages to field engineers in cases where sensors are down and/or need replacing. Before the development of iComment, all commenting was performed on paper; photocopied and distributed, sometimes resulting in missed communications -- a potential problem that can create serious questions about data integrity problems.

\subsubsection{Task 5: Monitoring Plans, Analysis, and Reports}

This task analyzes collected data in order to determine the energy and dollar savings of the retrofits and reduce energy costs by identifying operational and maintenance improvements. This task also includes development of improved analysis methods, preparation of the overall project monitoring plan, the development of a LoanSTAR MAP computer network to conduct the analysis, the verification of audit assumptions through

9 The use of the term "bad" means that the data cannot be restored and are replaced with -99 , the marker for missing data. 
the analysis of energy use and site data, and the interaction and feedback to agencies and operators through ongoing analysis of the data.

\subsubsection{Task 6: Improved Energy Audits}

This task seeks to improve the energy auditing methods used in commercial and institutional buildings. The primary focus of this task is to incorporate monitored data as feedback to the energy auditor as the audit progresses, with the goal of improving the accuracy of the audit. This is accomplished through the development of the LoanSTAR Monitoring Workshop and accompanying Workbook, and through the use of prescreening indices. The intention of the workshop (Haberl 1992) was to deliver the basic LoanSTAR data collection and plotting routines to energy auditors in complete enough form that they could be used during the audit process.

Prescreening indices are also under development that allow for the screening of facilities based on monthly utility billing data and a minimum amount of site description information. The prescreening indices are based on the previous work by Haberl and Komor (1989) and basically include weather-normalized $\mathrm{W} / \mathrm{ft}^{2}$ and $\mathrm{Btu} / \mathrm{ft}^{2}$-hr comparative values for energy usage and demand that can point to potential problem areas in a building prior to the site visit.

\subsection{Development of Monitoring Levels}

Four levels of metering systems have been developed for the energy monitoring program. These accommodate the necessary data requirements with the funds available for monitoring retrofits. The levels also are compatible with different hardware available on the market. As the project progresses, the definition of the levels and associated hardware requirements typically change. Table 2.3 contains the financial guidelines for the energy monitoring levels. These levels include 1) Level 0: facility whole-building(s) utility data, 2) Level 1: whole-building and limited sub-metered hourly data, 3) Level 2: moderate sub-metered hourly data, and 4) Level 3: detailed sub-metered hourly data.

\subsubsection{Level 0: Facility/Whole-building(s) Utility Data}

These data range from monthly consumption data, based on utility bills, to weekly or daily utility metered data. Such data are useful for separating consumption into heating, cooling, and non-weather related consumption (e.g., water heating). A substantial portion of retrofits in schools and local government buildings is expected to fall within this category.

\subsubsection{Level 1: Whole-building and Limited Sub-metered Hourly Data}

Level 1 utilizes one- to four-channel Data Acquisition Systems (DAS), and captures hourly whole-building thermal and electric measurements. In some cases, limited submetering is also being included. It is anticipated that portable equipment will also be used to collect hourly data for a one- to two-month period as needed for short-term energy monitoring. 


\subsubsection{Level 2: Moderate Sub-metered Hourly Data}

This level has all the capabilities of the first two levels and also enables more detailed analysis for identifying the savings from specific retrofits and pinpointing building operational problems. Moderate sub-metered DASs are simple four to twenty channel recorders.

\subsubsection{Level 3: Detailed Sub-metered Hourly Data.}

These systems typically include at least 20 channels of data. Given current costs for these systems, they are expected to be cost-effective only in large buildings and groups of smaller buildings.

In general, the LoanSTAR analysis relies on before-after energy measurements. Prior to the installation of each retrofit, data loggers are installed in each building to record the baseline energy use. For each site, before-after point-in-time and time-sequenced information, influencing parameters, and system requirements are evaluated to determine if energy savings match those of the audit estimates, as shown in Figure 2.19. When measured savings do not match audit estimates, a problem flag is generated so that corrective action can be taken to remedy the difference. Feedback to owners and operators also plays an important role in assuring that energy conservation retrofits remain on-track.

\subsection{Budgeting for the Measurement of Energy Conservation Retrofits}

From the beginning, the LoanSTAR program was designed to put strict limits on the amount of money that could be spent on the monitoring and analysis. This amounted to roughly 3 to $5 \%$ of the retrofit cost, which paid for the monitoring equipment, and 2 to $3 \%$ of the retrofit cost to pay for the recording of the data, analysis, and reporting. ${ }^{10}$ Budget breakdowns for the first year of monitoring are given in Table 2.7.

- As discussed earlier, four levels of monitoring were established to roughly conform with data acquisition equipment that was available on the market. Financed at 3\%, this converts roughly into the dollar values that are shown in Table 2.3. This means that Level 1 monitoring can be justified in a site where the retrofit cost is in the $\$ 50,000$ to $\$ 100,000$ range, Level 2 monitoring in the $\$ 100,000$ to $\$ 300,000$ retrofit cost range, and so forth. This equates to roughly $\$ 3,000$ for Level 1 , and up to $\$ 10,000$ for the installation of a Level 2 system, etc.

Because the LoanSTAR data are also being used to find and resolve O\&M problems, it has been shown that 5 to $15 \%$ of many building's energy can be saved if these problems can be identified and fixed. Therefore, based on O\&M savings Level 1 monitoring can be

10 Since monies were transferred from one state agency to another there were limited overhead charges. It has been estimated that these would have raised these figure to $6 \%$ of the retrofit costs for installation and $4 \%$ for annual recording, analysis and reporting. The cost will probably drop as the technology matures and becomes more cost effective. 
justified in buildings where the annual energy costs are $\$ 30,000$ to $\$ 60,000$, and so forth. Throughout the program these guidelines have been strictly adhered to. 
Table 2.1: Summary of ECRMs for Buildings Monitored as of May 1993.

\begin{tabular}{|l|l|l|l|l|l||}
\hline \multicolumn{1}{|c|}{$\begin{array}{c}\text { ECRM } \\
\text { Recommendations }\end{array}$} & $\begin{array}{c}\text { Impl. } \\
\text { Cost } \\
\$\end{array}$ & $\begin{array}{c}\text { Total Impl. } \\
\text { Cost } \\
\%\end{array}$ & $\begin{array}{c}\text { Cost } \\
\text { Savings } \\
\$\end{array}$ & $\begin{array}{c}\text { Total Cost } \\
\text { Savings } \\
\%\end{array}$ & $\begin{array}{c}\text { Simple } \\
\text { Payback } \\
\text { Yrs. }\end{array}$ \\
\hline HVAC System Retrofits & $\$ 10,504,625$ & 32.3 & $\$ 3,256,227$ & 34.0 & 3.2 \\
\hline $\begin{array}{l}\text { Boiler and Steam } \\
\text { Retrofits }\end{array}$ & $1,439,646$ & 4.4 & $1,116,516$ & 11.7 & 1.3 \\
\hline $\begin{array}{l}\text { Motor/VSD/VSP } \\
\text { Conversion }\end{array}$ & $4,679,163$ & 14.4 & $1,172,166$ & 12.3 & 4.0 \\
\hline Chiller \& CHW Retrofits & $1,936,886$ & 6.0 & 362,643 & 3.8 & 5.3 \\
\hline Lighting Retrofits & $4,841,987$ & 14.9 & $1,605,062$ & 16.8 & 3.0 \\
\hline EMC Systems & $3,368,158$ & 10.4 & 736,918 & 7.7 & 4.6 \\
\hline Pumping Sys. Retrofits & $1,752,647$ & 5.4 & 655,057 & 6.9 & 6.0 \\
\hline Others & $3,997,383$ & 12.3 & 662,291 & 6.9 & 6.0 \\
\hline & & & & & \\
\hline TOTALS & $\$ 32,520,495$ & 100 & $\$ 9,566,880$ & 100 & 3.4 \\
\hline
\end{tabular}

Table 2.2: Energy Conservation Measures Monitored in Buildings under the LoanSTAR program as of May 1993.

\begin{tabular}{|c|c|c|c|c|c|}
\hline $\begin{array}{c}\text { Purchased } \\
\text { Utility } \\
\text { Category }\end{array}$ & Site Energy & $\begin{array}{c}\text { Site Energy*** } \\
\text { (million } \\
\text { Btu/yr) }\end{array}$ & $\begin{array}{c}\text { Source } \\
\text { Energy* } \\
\text { (mil. Btu/yr) }\end{array}$ & $\begin{array}{c}\text { Fractional Site } \\
\text { Energy Savings } \\
(\%)\end{array}$ & $\begin{array}{c}\text { Fractional } \\
\text { Source Energy } \\
\text { Savings (\%) }\end{array}$ \\
\hline Electricity & $\begin{array}{l}113,282,528 \\
(\mathrm{kWh} / \mathrm{yr})\end{array}$ & 386,520 & $1,314,077$ & 26.6 & 52.9 \\
\hline Natural Gas & $\begin{array}{l}305,274 \\
\text { (MCF/yr) }\end{array}$ & 314,432 & 314,432 & 21.7 & 12.7 \\
\hline $\begin{array}{l}\text { Steam/Hot } \\
\text { Water }\end{array}$ & $\begin{array}{l}318,237 \text { (million } \\
\text { Btu/yr) }\end{array}$ & 318,237 & 424,316 & 21.9 & 17.1 \\
\hline $\begin{array}{l}\text { Chilled } \\
\text { Water }\end{array}$ & $\begin{array}{l}35,986,682 \text { (Ton- } \\
\mathrm{hr} / \mathrm{yr} \text { ) }\end{array}$ & 431,840 & 431,840 & 29.8 & 17.4 \\
\hline Totals & & $1,451,029$ & $2,484,666$ & 100 & 100 \\
\hline
\end{tabular}

**Btu savings calculated on the basis of site Btus (i.e., 3,412 Btu/kWh, 1,030,000 Btu/MCF and $12,000 \mathrm{Btu} / \mathrm{ton}-\mathrm{hr}$ )

*Btu savings calculated on the basis of source Btus (i.e., 11,600 Btu/kWh, 1,030,000 Btu/MCF, boiler efficiency of $75 \%$ and 12,000 , Btu/ton-hr) 
Table 2.3: Guidelines for the LoanSTAR Metering Experiments.

\begin{tabular}{||l|l|l|l||}
\hline Monitoring Level: & \multicolumn{1}{|c|}{ Retrofit Costs: } & \multicolumn{1}{|c|}{$\begin{array}{c}\text { Annual } \\
\text { Energy Costs: }\end{array}$} & \multicolumn{1}{c|}{$\begin{array}{c}\text { Monitoring } \\
\text { Budget: }\end{array}$} \\
\hline $\begin{array}{l}\text { Level 0: } \\
\text { Monthly Utility Data }\end{array}$ & $\$ 20 \mathrm{k}-\$ 50 \mathrm{k}$ & $\$ 10 \mathrm{k}-\$ 30 \mathrm{k}$ & $\$ 0$ \\
\hline $\begin{array}{l}\text { Level 1: } \\
1-4 \text { channels }\end{array}$ & $\$ 50 \mathrm{k}-\$ 100 \mathrm{k}$ & $\$ 30 \mathrm{k}-\$ 60 \mathrm{k}$ & $\$ 3 \mathrm{k}$ \\
\hline $\begin{array}{l}\text { Level 2: } \\
4-20 \text { channels }\end{array}$ & $\$ 100 \mathrm{k}-\$ 300 \mathrm{k}$ & $\$ 60 \mathrm{k}-\$ 200 \mathrm{k}$ & $\$ 10 \mathrm{k}$ \\
\hline $\begin{array}{l}\text { Level 3: } \\
20+\text { channels }\end{array}$ & $\$ 300 \mathrm{k}+$ & $\$ 500 \mathrm{k}+$ & $\$ 30 \mathrm{k}+$ \\
\hline
\end{tabular}

Table 2.4: List of Potential Sensors for Calibration. This table provides a list of possible sensors that might need to be calibrated in a large monitoring program (Turner et al. 1992).

\begin{tabular}{|c|c|c|c|}
\hline Liguid Flow & Temperature & Hydraulic Pressure & Air Pressure \\
\hline $\begin{array}{l}\text { 1. Orifice } \\
\text { 2. Venturi } \\
\text { 3. Flow Nozzle } \\
\text { 4. Turbine } \\
\text { 5. Vortex } \\
\text { 6. Magnetic } \\
\text { 7. Ultrasonic } \\
\text { 8. Paddlewheel } \\
\text { 9. Impact } \\
\text { 10. Mass - Coriolis } \\
\text { 11. Mass - Thermal } \\
\text { 12. Transducers } \\
\text { (kJ or Btu) }\end{array}$ & $\begin{array}{l}\text { 1. Thermometer } \\
\text { 2. Thermocouple } \\
\text { 3. RTD } \\
\text { 4. Temperature } \\
\text { portion of } \\
\text { Humidity sensor } \\
\text { 5. Thermistor } \\
\text { 6. I.C. Temperature } \\
\text { Sensor }\end{array}$ & $\begin{array}{l}\text { 1. Pressure Gauge } \\
\text { 2. Pressure } \\
\text { Transducer }\end{array}$ & $\begin{array}{l}\text { 1. Pressure Gauge } \\
\text { 2. Manometer } \\
\text { 3. Pressure } \\
\text { Transducer }\end{array}$ \\
\hline Humidity & Electrical Power & Electrical Current & Electrical Voltage \\
\hline $\begin{array}{l}\text { 1. Dew/Frost Point } \\
\text { Sensor } \\
\text { 2. Psychrometer } \\
\text { 3. Thin Film Polymer } \\
\text { 4. Mechanical } \\
\text { (Dimensional) } \\
\text { 5. Dielectric Crystal }\end{array}$ & $\begin{array}{l}\text { 1. Watt-hour meters } \\
\text { 2. Watt transducers }\end{array}$ & $\begin{array}{l}\text { 1. Clamp-on } \\
\text { Amp Meter } \\
\text { 2. Current } \\
\text { Transformer }\end{array}$ & $\begin{array}{l}\text { 1. Voltmeter } \\
\text { 2. Multimeter } \\
\text { 3. Potential } \\
\text { Transformer }\end{array}$ \\
\hline Air Flow & Rotational Speed & Solar Radiation & Ilumination Levels \\
\hline $\begin{array}{l}\text { 1. Pitot Tube } \\
\text { 2. Hot-wire } \\
\text { Thermo- } \\
\text { anemometer } \\
\text { 3. Rotary Device } \\
\text { 4. Flow nozzles }\end{array}$ & $\begin{array}{l}\text { 1. Contact } \\
\text { Tachometers } \\
\text { 2. Non-contact } \\
\text { Tachometers } \\
\text { 3. Strobes } \\
\text { 4. Reflective } \\
\text { Tachometer } \\
\end{array}$ & $\begin{array}{l}\text { 1. Pyranometer } \\
\text { 2. Pyrhelio meter }\end{array}$ & 1. Light Meter \\
\hline
\end{tabular}


Table 2.5: Ranges and Accuracies of the Calibration Facility. This table provides a summary of the intended range and accuracies of each of the calibration stations at the facility (Turner et al. 1992).

\begin{tabular}{|c|c|c|c|}
\hline Liquid Flow & Temperature & Hydraulic Pressure & Air Pressure \\
\hline $\begin{array}{l}\text { Range: } 5 \text { to } 950 \mathrm{gpm} \\
0.3 \text { to } 59.9 \mathrm{l} / \mathrm{s}\end{array}$ & $\begin{array}{l}\text { Range: }-40 \text { to } 500 \mathrm{~F} \\
-40 \text { to } 260 \mathrm{C}\end{array}$ & $\begin{array}{l}\text { Range: } 0 \text { to } 500 \text { PSI } \\
0 \text { to } 3.5 \mathrm{MPa}\end{array}$ & $\begin{array}{l}\text { Range: } 0 \text { to } \pm 24 \\
\text { inches WG } \\
0 \text { to } \pm 609 \mathrm{~mm} \mathrm{WG}\end{array}$ \\
\hline $\begin{array}{l}\text { Accuracy: } \\
\pm 1 \% \text { of reading }\end{array}$ & $\begin{array}{l}\text { Accuracy: } \\
\pm 0.4^{\circ} \mathrm{F} \\
\pm 0.2^{\circ} \mathrm{C} \\
\end{array}$ & $\begin{array}{l}\text { Accuracy: } \\
\pm 0.25 \% \text { Reading }\end{array}$ & $\begin{array}{l}\text { Accuracy: } \\
\pm 0.01 \text { inches WG } \\
\pm 0.25 \mathrm{~mm} \text { WG }\end{array}$ \\
\hline Humidity & Electrical Power & Electrical Current & Electrical Voltage \\
\hline $\begin{array}{l}\text { Range: } 10 \text { to } 95 \% \\
\text { RH } 32 \text { to } 125{ }^{\circ} \mathrm{F} \\
0 \text { to } 52^{\circ} \mathrm{C}\end{array}$ & $\begin{array}{l}\text { Range: } \\
0 \text { to } 100 \mathrm{Amps} \\
0 \text { to } 5 \mathrm{MW} \\
\end{array}$ & $\begin{array}{l}\text { Range: } \\
0 \text { to } 1000 \text { Amp }\end{array}$ & $\begin{array}{l}\text { Range: } \\
0 \text { to } 600 \text { VAC } \\
0 \text { to } 600 \text { VDC }\end{array}$ \\
\hline $\begin{array}{l}\text { Accuracy: } \\
\pm 1.5 \% \mathrm{RH}, \pm 1.0 \mathrm{~F}, \\
\pm 0.65 \mathrm{C}\end{array}$ & $\begin{array}{l}\text { Accuracy: } \\
\pm 0.5 \% \text { Full Scale }\end{array}$ & $\begin{array}{l}\text { Accuracy: } \\
\pm 0.5 \% \text { Full Scale }\end{array}$ & $\begin{array}{l}\text { Accuracy: } \\
\pm 0.5 \% \text { Full Scale }\end{array}$ \\
\hline Air Flow & Rotational Speed & Solar Radiation & Illumination Levels \\
\hline $\begin{array}{l}\text { Range: } \\
0 \text { to } 8000 \mathrm{ft} / \mathrm{m} \\
0 \text { to } 46.7 \mathrm{~m} / \mathrm{s}\end{array}$ & $\begin{array}{l}\text { Range: } \\
0 \text { to } 3600 \mathrm{RPM}\end{array}$ & $\begin{array}{l}\text { Range: } \\
0 \text { to } 500 \mathrm{Btu} / \mathrm{ft}^{2} \\
0 \text { to } 1.5 \mathrm{~kW} / \mathrm{m}^{2}\end{array}$ & $\begin{array}{l}\text { Range: } \\
0 \text { to } 1000 \text { FC }\end{array}$ \\
\hline $\begin{array}{l}\text { Accuracy: } \\
\pm 10 \mathrm{ft} / \mathrm{m} \\
\pm .05 \mathrm{~m} / \mathrm{s}\end{array}$ & $\begin{array}{l}\text { Accuracy: } \\
\pm 2 \text { RPM }\end{array}$ & $\begin{array}{l}\text { Accuracy: } \\
\pm 2 \% \text { Reading }\end{array}$ & $\begin{array}{l}\text { Accuracy: } \\
\pm 1 \% \text { Reading }\end{array}$ \\
\hline
\end{tabular}


Table 2.6: Summary of Flow Meter Characteristics. This table presents a summary of flow meter characteristics, which has been assembled from experiences gained in the LoanSTAR monitoring program and other useful sources.

\begin{tabular}{|c|c|c|c|c|c|c|c|c|}
\hline $\begin{array}{c}\text { FLOW } \\
\text { METER }\end{array}$ & $\begin{array}{l}\mathbf{D} \\
\mathbf{I} \\
\mathbf{R} \\
\mathbf{T} \\
\mathbf{Y}\end{array}$ & $\begin{array}{l}\mathbf{C} \\
\mathbf{L} \\
\mathbf{E} \\
\mathbf{A} \\
\mathbf{N}\end{array}$ & RANGE & $\begin{array}{c}\text { LOW } \\
\mathbf{F} \\
\mathbf{L} \\
\mathbf{0} \\
\mathbf{W}\end{array}$ & $\begin{array}{l}\text { PURCHASE } \\
\text { COSTS (\$) }\end{array}$ & $\begin{array}{l}\text { INSTALL } \\
\text { COST (\$) }\end{array}$ & $\begin{array}{c}\text { ACCURACY } \\
\text { UNCALIBRATED } \\
\text { (INCLUDING } \\
\text { TRANSMITTER) } \\
\text { (note 1) } \\
\end{array}$ & APPLICATIONS \\
\hline $\begin{array}{l}\text { ORIFICE } \\
\text { PLATE }\end{array}$ & $\mathbf{A}$ & $\mathbf{G}$ & $\begin{array}{l}\text { THE RANGE } \\
\text { OF ALL THE } \\
\text { DIFFERENTIA } \\
\text { L }\end{array}$ & G & $\$ 800$ & $\$ 1500$ & $\begin{array}{l} \pm 1-2 \% \text { FULL } \\
\text { RANGE SCALE } \\
\text { (FRS) }\end{array}$ & $\begin{array}{l}\text { GOOD FOR LOW } \\
\text { FLOWS IN } \\
\text { CLEAN WATER }\end{array}$ \\
\hline $\begin{array}{l}\text { VENTURI } \\
\text { TUBE }\end{array}$ & $\overline{\mathbf{G}}$ & $\mathbf{G}$ & $\begin{array}{l}\text { MEIERS IS } \\
\text { LIMITED BY } \\
\text { THE } \\
\text { PRESSURE }\end{array}$ & G & $\$ 1500$ & $\$ 1500$ & $\pm 1-2 \%$ FRS & $\begin{array}{l}\text { GOOD FOR } \\
\text { CONTROLS \& } \\
\text { MONITORING IF } \\
\text { PRESENT }\end{array}$ \\
\hline NOZZLE & $\mathbf{G}$ & $\mathbf{G}$ & $\begin{array}{l}\text { TRANSDUCER } \\
\text { IN USE }\end{array}$ & G & $\$ 2000$ & $\$ 2000$ & $\pm 1-2 \%$ FRS & $\begin{array}{l}\text { GOOD FOR } \\
\text { STEAM AND } \\
\text { HIGH PRESSURE } \\
\text { GASSES } \\
\end{array}$ \\
\hline PITOT TUBE & $\mathbf{P}$ & G & & $\mathbf{G}$ & $\$ 500$ & $\$ 500$ & $\pm 5 \%$ FRS & $\begin{array}{l}\text { GOOD FOR } \\
\text { SPOT CHECKS } \\
\text { IN CLEAN } \\
\text { FLUID } \\
\end{array}$ \\
\hline ANNUBAR & $\mathbf{P}$ & G & & G & $\$ 1500$ & $\$ 500$ & $\pm 1 \%$ OF RATE & $\begin{array}{l}\text { VERY GOOD } \\
\text { FOR LOW FLOW } \\
\text { IN CLEAN } \\
\text { FLUID } \\
\end{array}$ \\
\hline TURBINE & $\mathbf{P}$ & $\mathbf{G}$ & $1-30 \mathrm{FPS}$ & $\mathbf{P}$ & $\$ 1500$ & $\$ 1500$ & $\pm 1 \%$ OF RATE & $\begin{array}{l}\text { VERY GOOD } \\
\text { METER IN } \\
\text { CLEAN FLOW } \\
\end{array}$ \\
\hline VORTEX & $\mathbf{G}$ & $\mathbf{G}$ & 1-30 FPS & $\bar{G}$ & $\$ 3500$ & $\$ 1500$ & $\begin{array}{l} \pm .5-1.5 \% \text { OF } \\
\text { RATE }\end{array}$ & $\begin{array}{l}\text { GOOD MULTI } \\
\text { PURPOSE } \\
\text { METER } \\
\end{array}$ \\
\hline $\begin{array}{l}\text { TANGENTIAL } \\
\text { PADDLE- } \\
\text { WHEEL }\end{array}$ & A & G & 1-30 FPS & $\mathbf{P}$ & $\$ 500$ & $\$ 500$ & $\pm 2.5 \%$ OF RATE & $\begin{array}{l}\text { GOOD FOR } \\
\text { MONITORING }\end{array}$ \\
\hline $\begin{array}{l}\text { INSERTION } \\
\text { TURBINE }\end{array}$ & $\mathbf{P}$ & $\bar{G}$ & 1-30 FPS & $\mathbf{P}$ & $\$ 1500$ & $\$ 500$ & $\pm 1 \%$ OF RATE & $\begin{array}{l}\text { GOOD FOR } \\
\text { MONITORING } \\
\end{array}$ \\
\hline TARGET & $\mathbf{A}$ & $\overline{\mathbf{G}}$ & 1-30 FPS & $\mathbf{P}$ & $\$ 1500$ & $\$ 500$ & $\pm 1.5-5 \%$ FRS & $\begin{array}{l}\text { GOOD FOR } \\
\text { MONITORING } \\
\end{array}$ \\
\hline $\begin{array}{l}\text { ULTRASONIC } \\
\text { TIME OF } \\
\text { FLIGHT } \\
\text { DOPPLER }\end{array}$ & $\begin{array}{l}\mathbf{G} \\
\mathbf{G}\end{array}$ & $\begin{array}{l}\mathbf{G} \\
\mathbf{G}\end{array}$ & $\begin{array}{l}.5-30 \mathrm{FPS} \\
.5-30 \mathrm{FPS}\end{array}$ & A & $\$ 2000-\$ 3500$ & $\$ 500$ & $\begin{array}{l} \pm 5 \% \text { FRS } \\
\pm 5 \% \text { FRS }\end{array}$ & $\begin{array}{l}\text { GOOD FOR } \\
\text { SPOT CHECKS }\end{array}$ \\
\hline MAGNETIC & $\mathbf{G}$ & $\mathbf{G}$ & $.5-30 \mathrm{FPS}$ & $\mathbf{G}$ & $\$ 3000$ & $\$ 1500$ & $\pm 1 \%$ FRS & $\begin{array}{l}\text { GOOD METER IF } \\
\text { BUDGET IS NOT } \\
\text { A FACTOR } \\
\end{array}$ \\
\hline MASS FLOW & $\bar{A}$ & $\mathbf{G}$ & $.5-30$ FPS & G & $\$ 3500$ & $\$ 1500$ & $\pm .2-1 \%$ FRS & $\begin{array}{l}\text { GOOD IN LOW } \\
\text { CLEAN FLOW } \\
\text { AND SMALLER } \\
\text { PIPES }\end{array}$ \\
\hline
\end{tabular}


Table 2.7: Budget Breakdown for the First Year Monitoring Program.

\begin{tabular}{|c|c|r|r|r|}
\hline Task & $\begin{array}{c}\text { Person- } \\
\text { months }\end{array}$ & $\begin{array}{c}\text { Personnel } \\
(\$)\end{array}$ & $\begin{array}{c}\text { Travel, } \\
\text { supplies. } \mathbf{( \$ )}\end{array}$ & \multicolumn{1}{c|}{$\begin{array}{c}\text { Total } \\
(\$)\end{array}$} \\
\hline 1 & 29 & $\$ 103,000$ & $\$ 2,500$ & $\$ 105,500$ \\
\hline 2 & 37 & $\$ 103,000$ & $\$ 4,500$ & $\$ 107,000$ \\
\hline 3 & 14 & $\$ 44,000$ & $\$ 30,000$ & $\$ 74,000$ \\
\hline 4 & 21 & $\$ 59,000$ & $\$ 21,000$ & $\$ 80,000$ \\
\hline 5 & 65 & $\$ 166,000$ & $\$ 105,000$ & $\$ 271,000$ \\
\hline & - & - & - & - \\
\hline Total & 166 & $\$ 475,000$ & $\$ 163,000$ & $\$ 638,000$ \\
\hline
\end{tabular}

NOTE:

1) Additional first year costs to establish the LoanSTAR Monitoring Analysis and Review Committee were $\$ 110,000$.

2) Includes $\$ 81,000$ for computer hardware and software, and includes a matching contribution by Texas A\&M.

3) Estimated hardware to monitor $\$ 26$ million in retrofits is $\$ 780,000$.

4) Because the LoanSTAR program was carried out by a Texas state agency these costs do not include overhead and profit. 
Figure 2.1: LoanSTAR Monitoring and Analysis Task Planning.

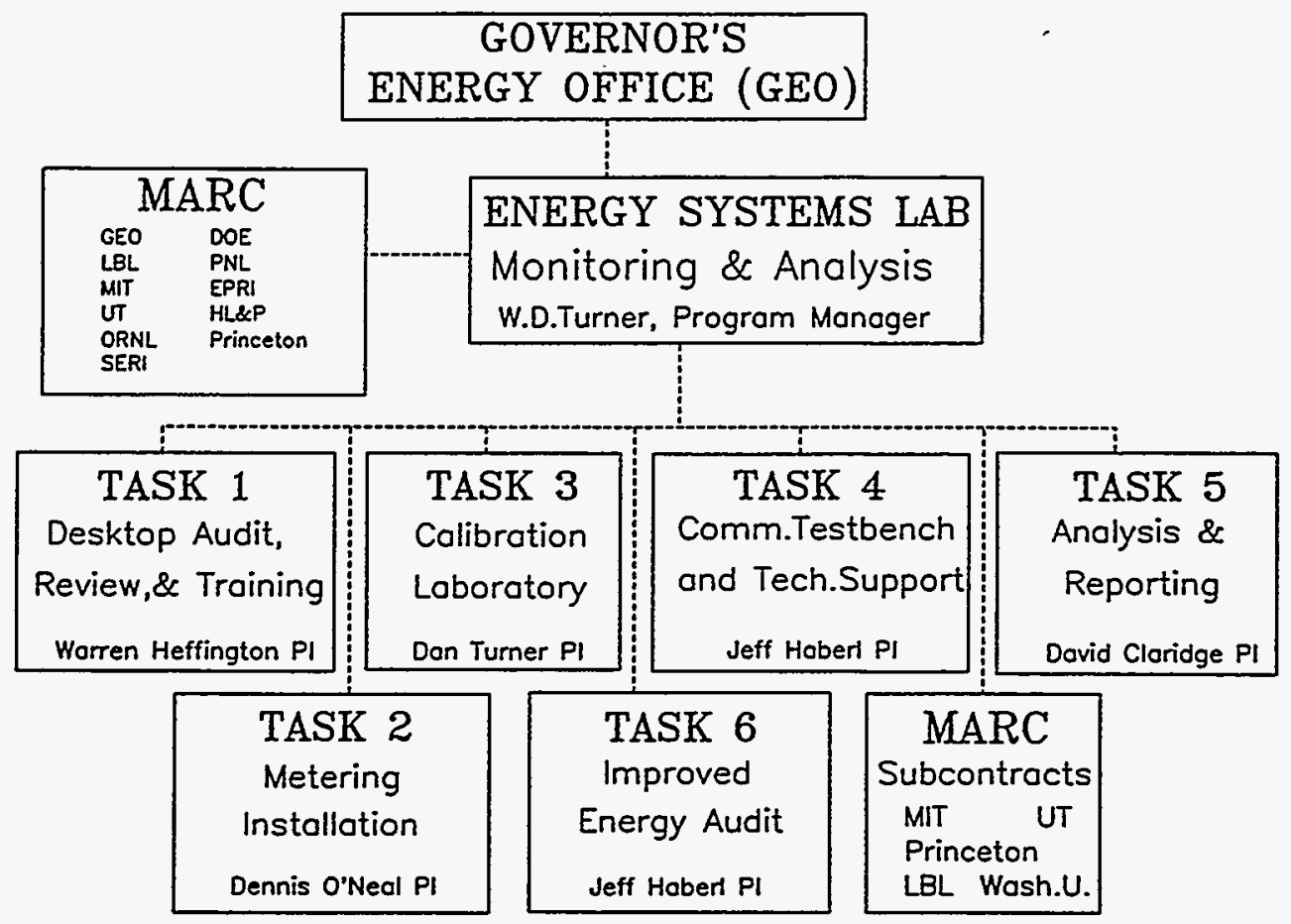


Figure 2.2: Distribution of LoanSTAR Loans by Percent of Functional Area.

\section{Percent Area by Functional Use \\ Buildings Monitored as of April, 1993}

Total Area Monitored Under LoanSTAR Program: 18.27 Million sq.ft.

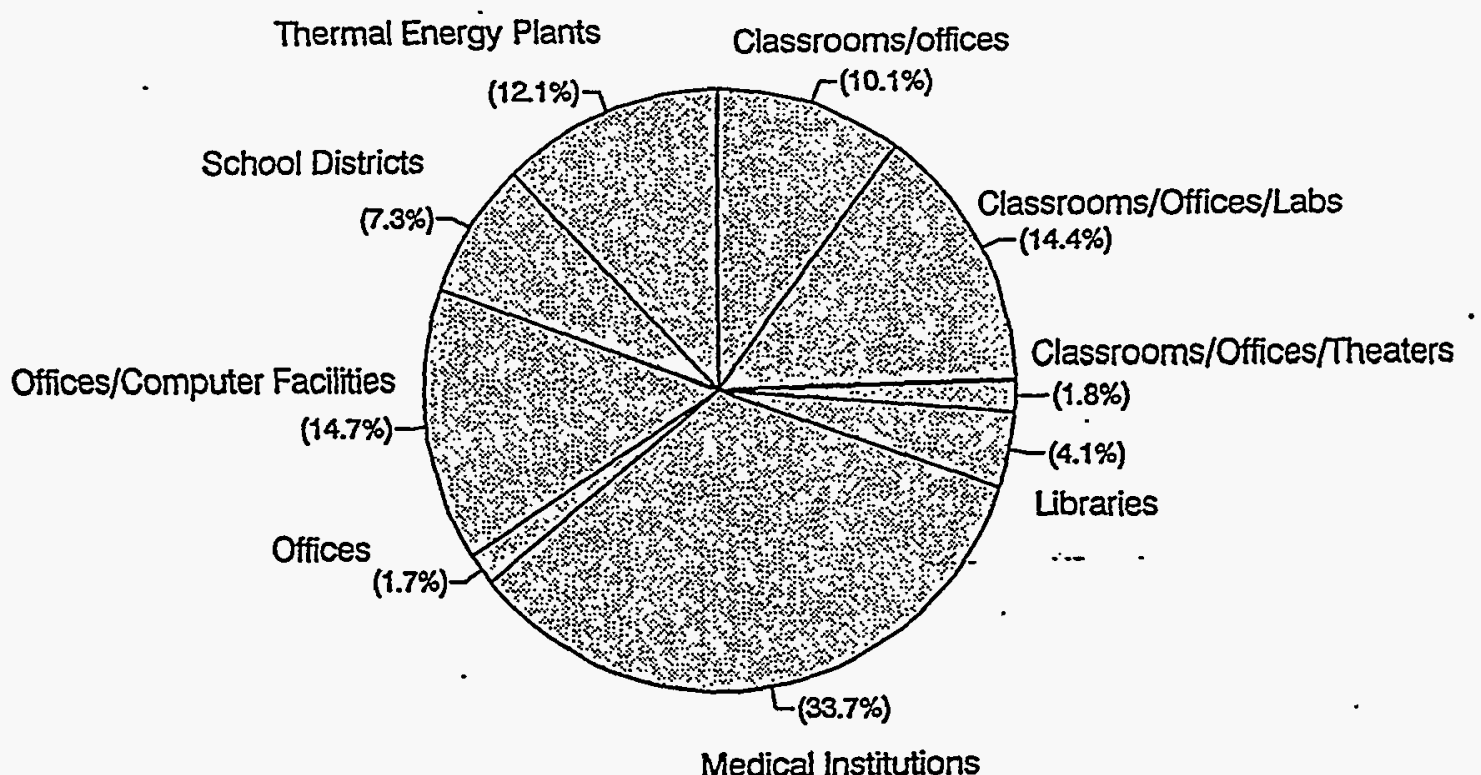

Medical Institutions 
Figure 2.3: Geographic Distribution of LoanSTAR Sites in Texas.

STIES MONITORED UNDER LOANSTAR PROGRAM AS OF MAY 1993

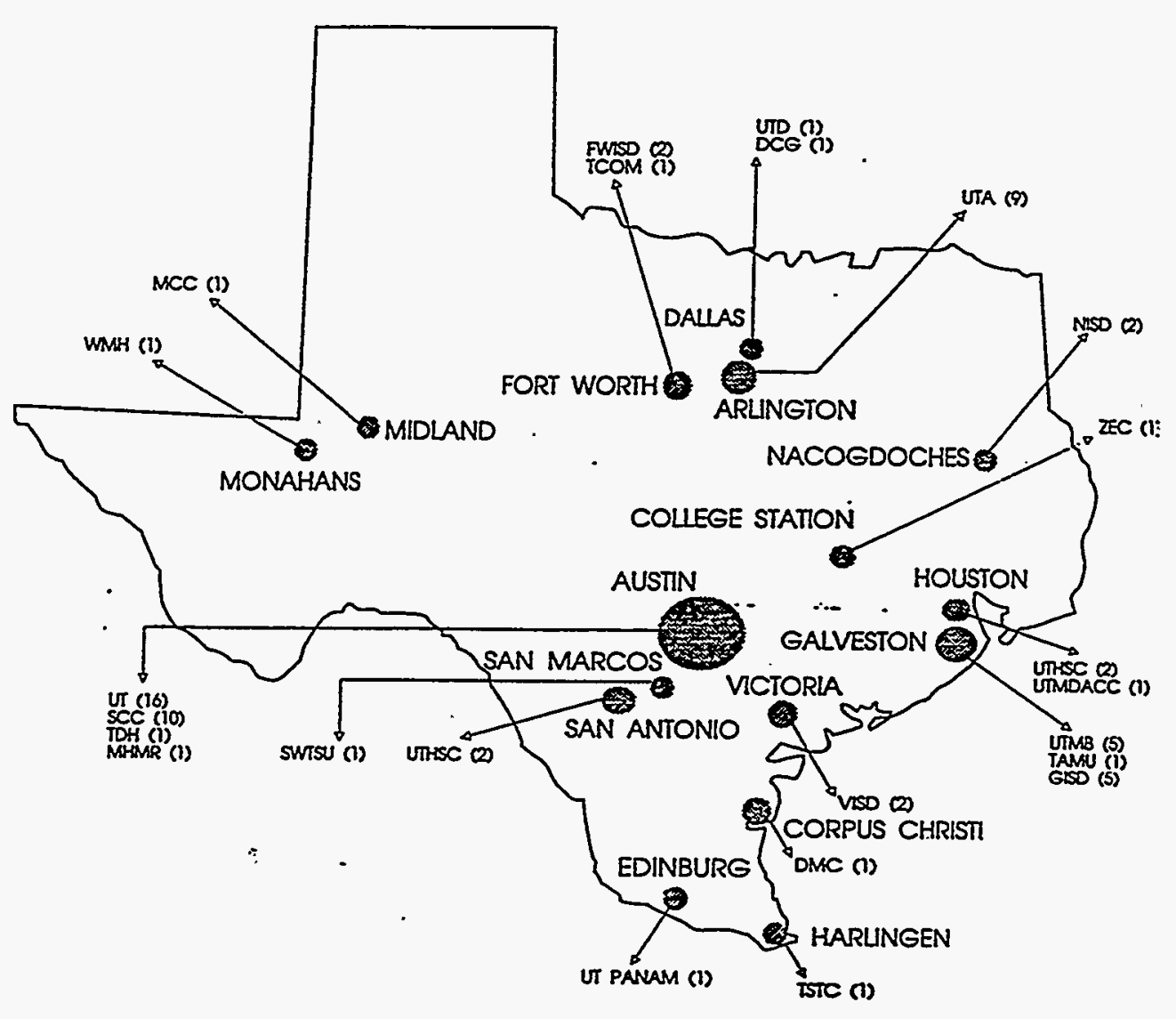


Figure 2.4: Audit Estimated Retrofit Costs and Savings.

\section{Audit Estimated Retrofit Cost}

69 Sites/199 Buildings Monitored as of May 1993

Total Estimated Retrofit Cost: $\$ 32.5$ Million

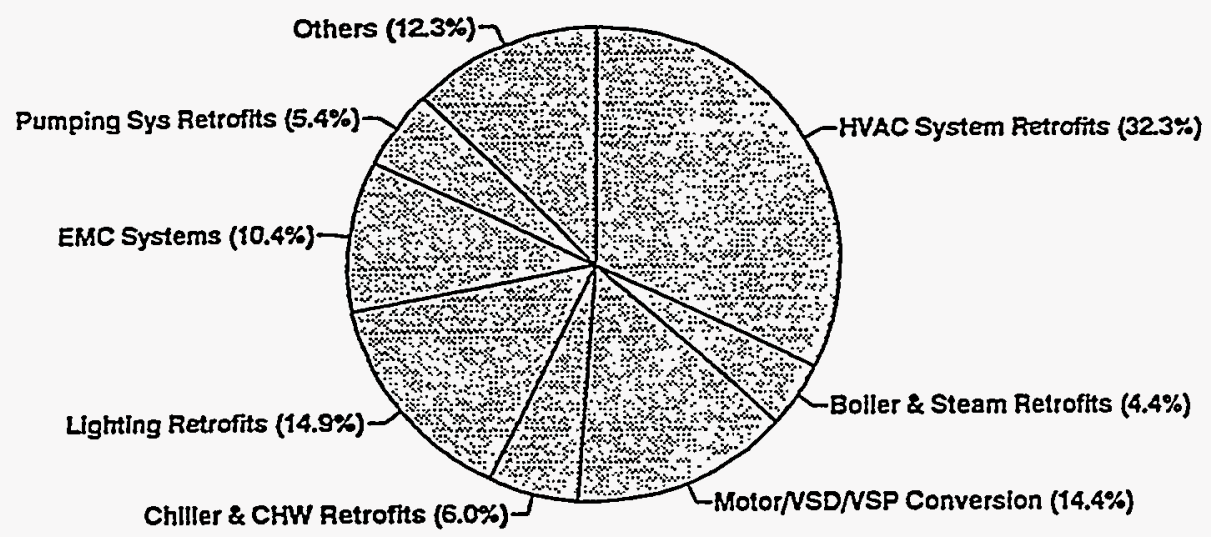

Audit Estimated Cost Savings

69 Sites/199 Buldings Monitored as of May 1993

Annual Cost Savings: $\$ 9.6$ Million

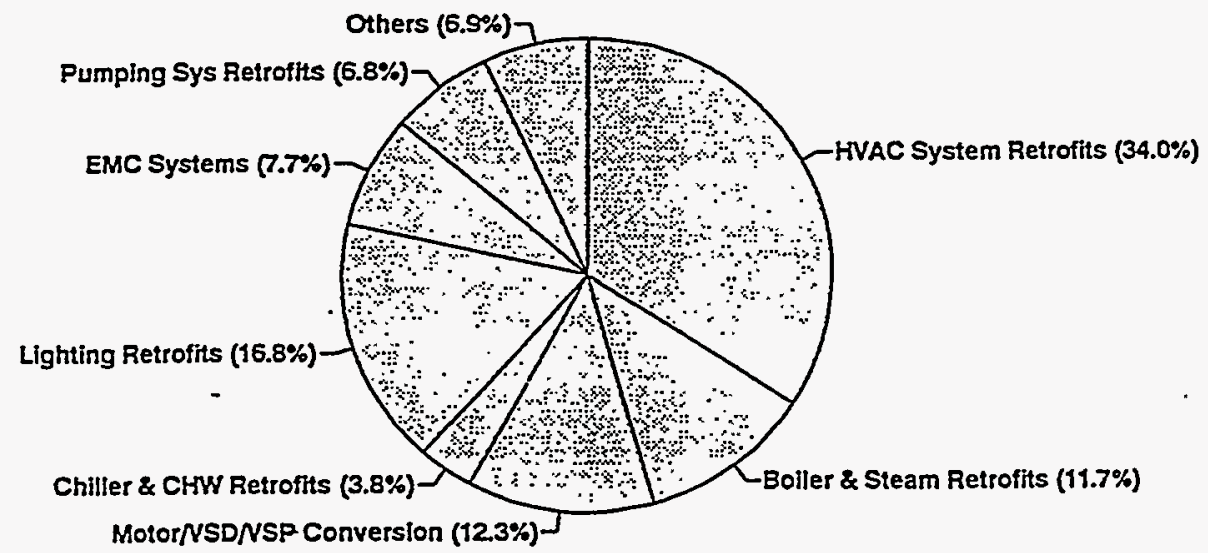


Figure 2.5: Estimated Cost of Retrofits.

\section{Estimated Cost of Retrofits}

As of May, 1993

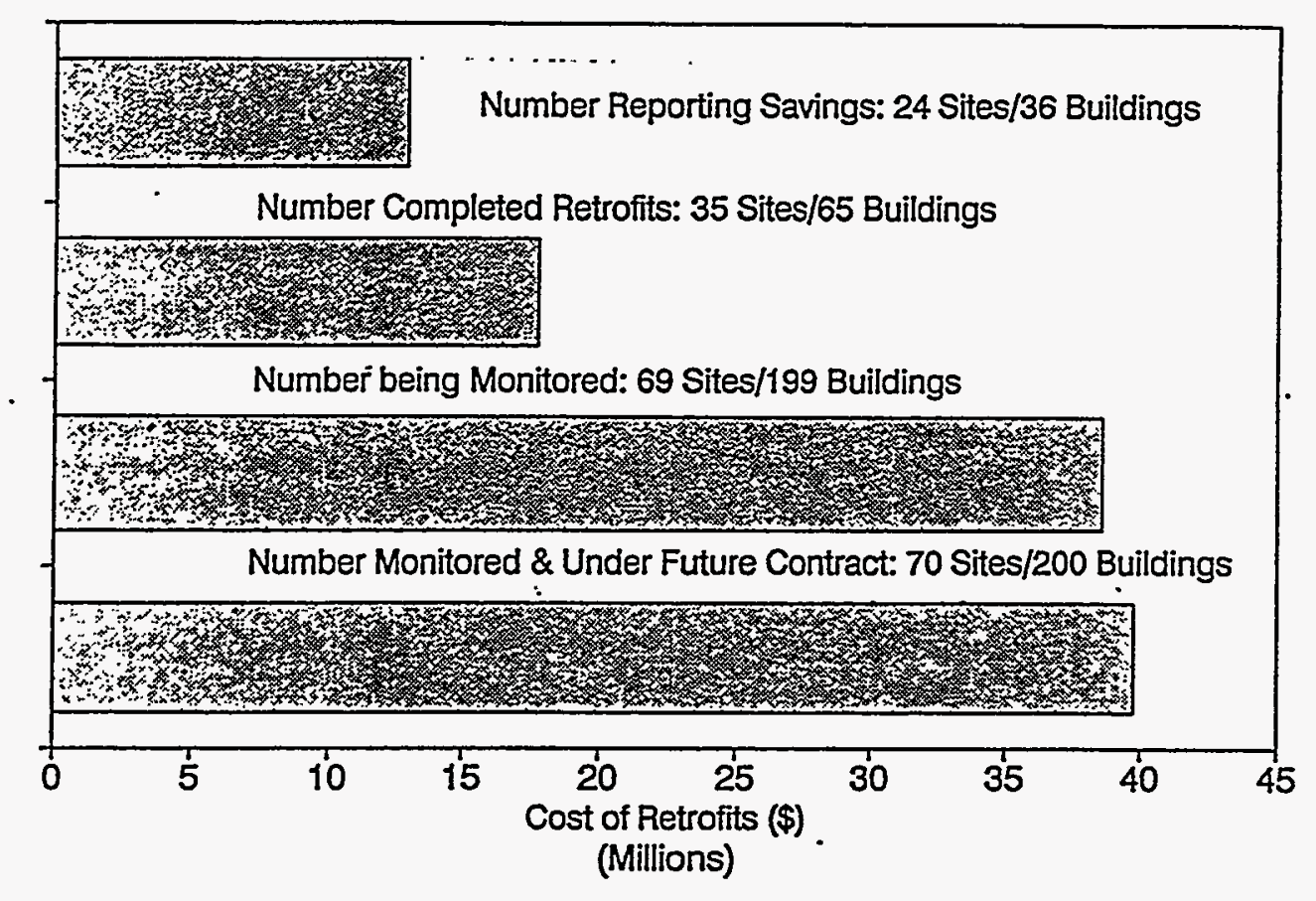


Figure 2.6: Total of Measured Electric Demand Reduction.

\section{Total Measured Reduction in Electricity Demand (2 MW)}

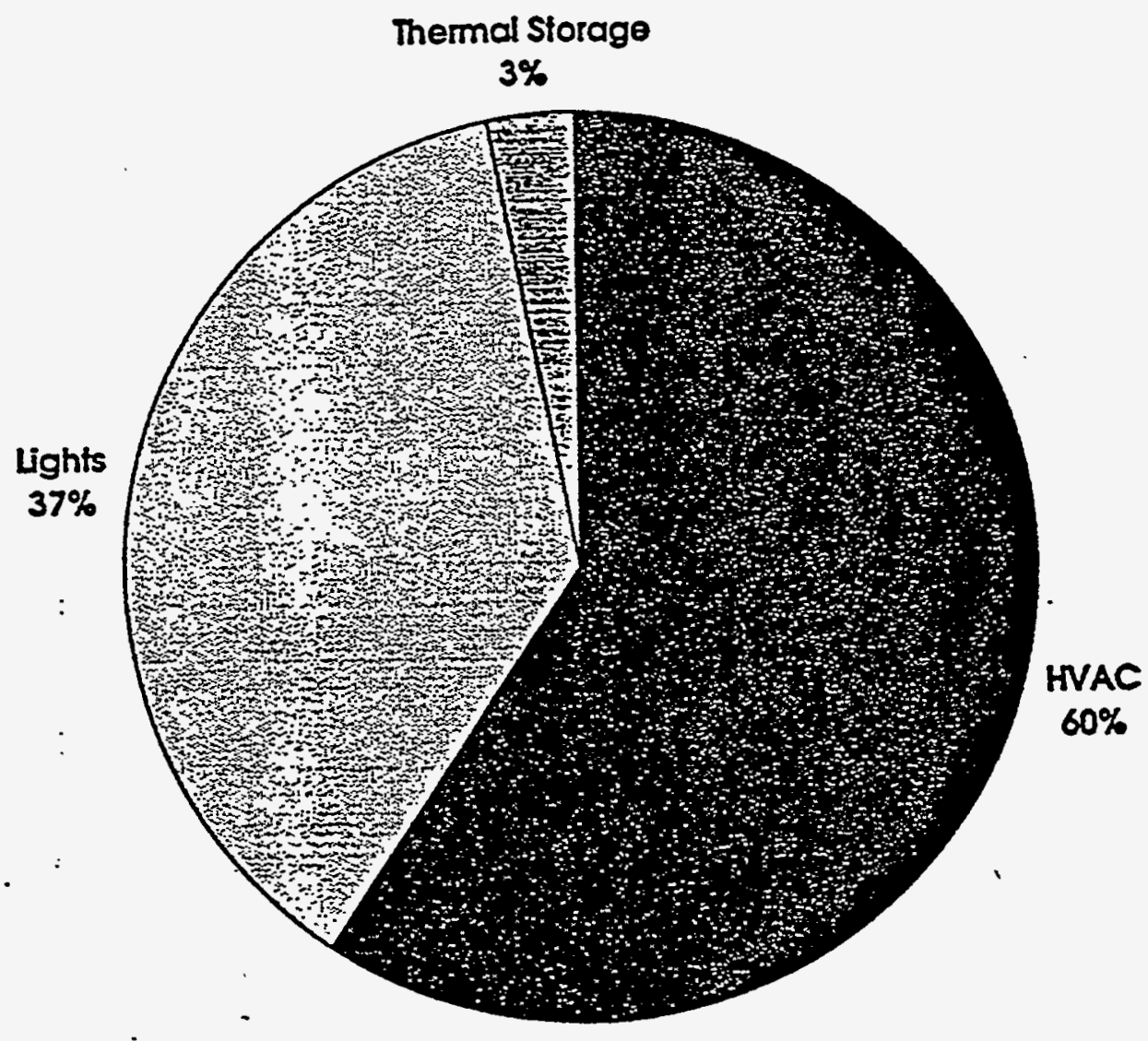


Figure 2.7: Typical LoanSTAR Level 1 Monitoring. This diagram illustrates a typical Level 1 monitoring setup as installed in the T.S. Painter Building on the University of Texas at Austin campus. This Level 1 monitoring provides whole-building electricity use, whole-building chilled water use, and whole-building steam condensate use. Channel numbers (e.g. CH 8) are usually included for each site to help identify data channels.
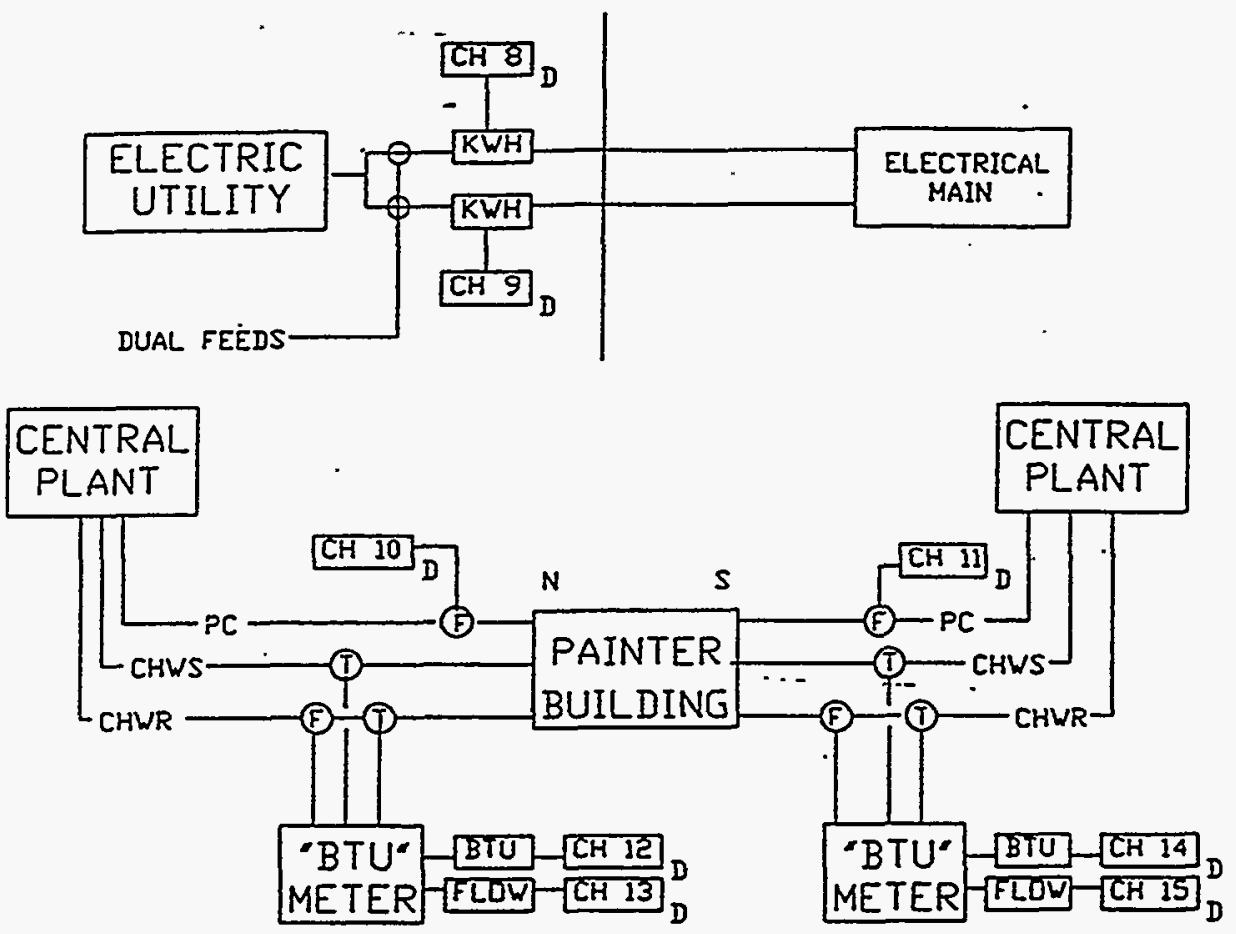
Figure 2.8: Typical LoanSTAR Level 2 Monitoring. This figure shows a typical Level 2 monitoring experiment plan as installed in the UTC Building on the University of Texas at Austin campus. In this case Level 2 monitoring provides whole-building electricity $(\mathrm{kWh})$, whole-building chilled water use [Btu, flow $(\mathrm{F})$, temperature $(\mathrm{T})]$, whole-building steam condensate use ( $\mathrm{PC}$ or $\mathrm{AC}$ ), and sub-metered electricity use for the building's air-handling units (AHUs) and pumps (CHWP).
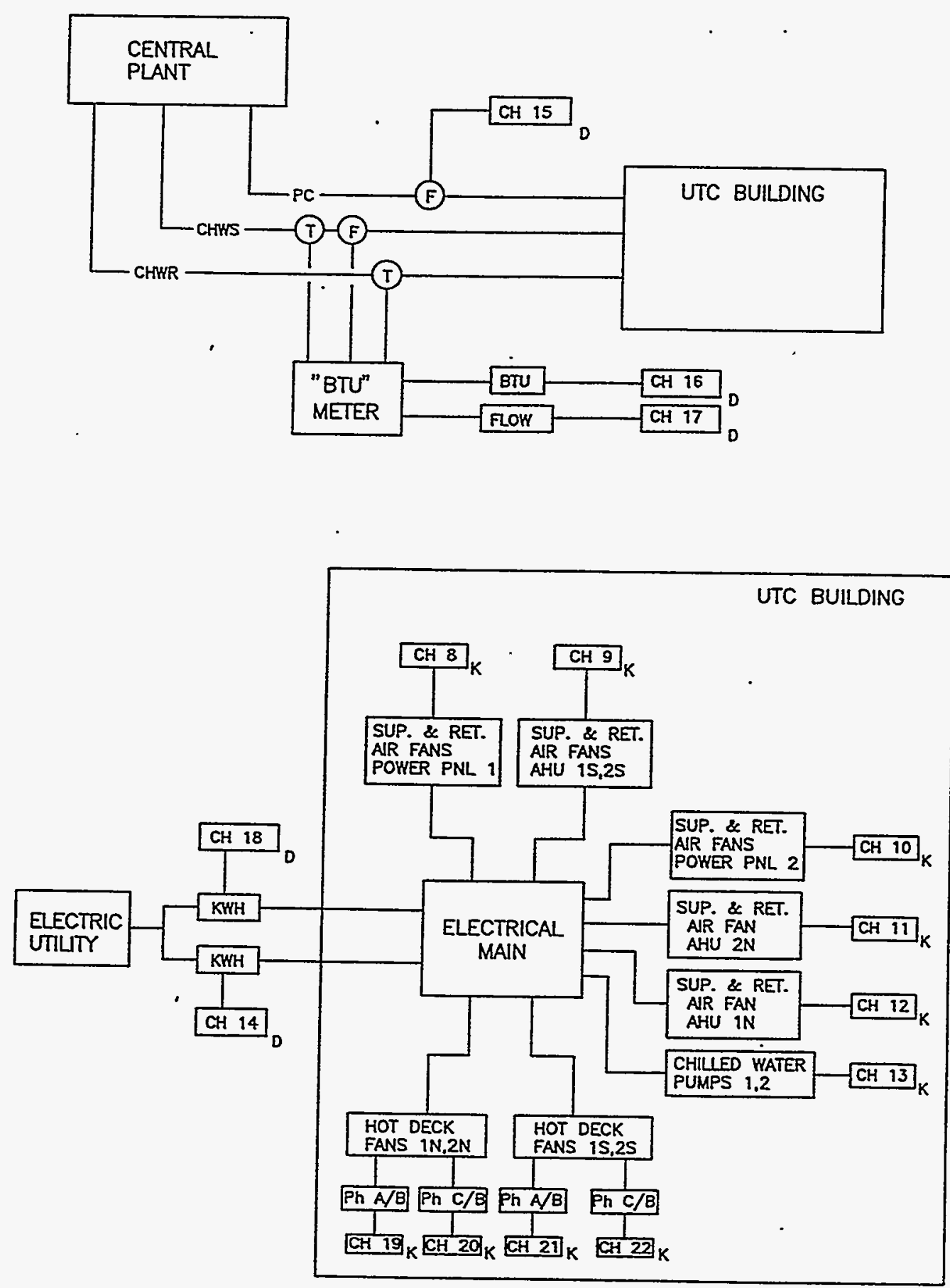
Figure 2.9: Typical LoanSTAR Level 3 Thermal Monitoring. This diagram illustrates a Level 3 thermal monitoring setup as installed in the S.F. Austin building at the Texas State Capitol complex. In general most Level 3 monitoring experiments are complex and require a metering plan that is specially tailored to each experiment. The S. F. Austin building contains a central boiler/chiller complex that feeds several other buildings and a weather station.

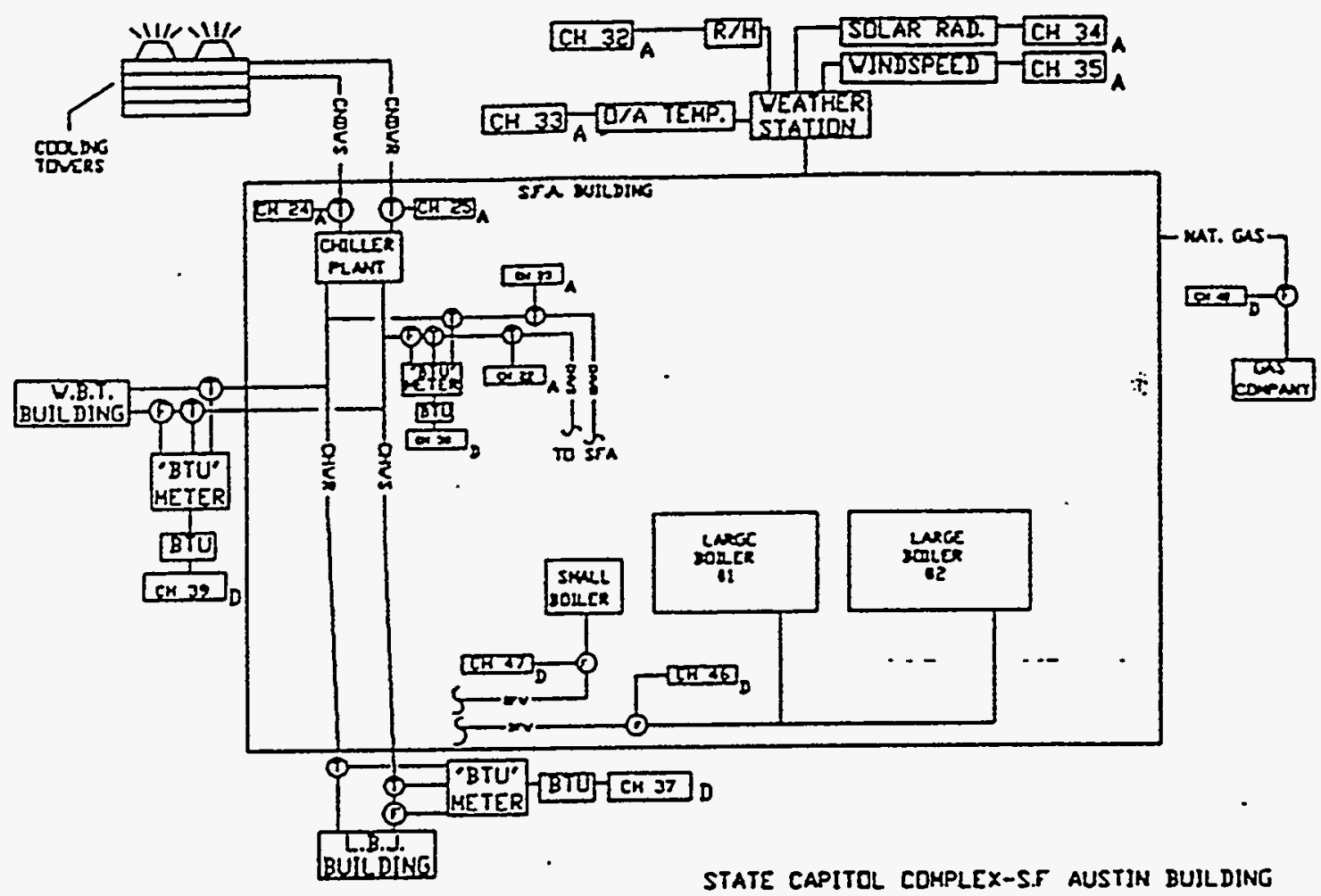


Figure 2.10: Typical LoanSTAR Level $3 \mathrm{kWh}$ Monitoring. This diagram illustrates a Level 1 electricity monitoring setup as installed in the S. F. Austin building at the Texas State Capitol complex. The intent of this monitoring plan is to isolate electricity use in the boiler/chiller plant.

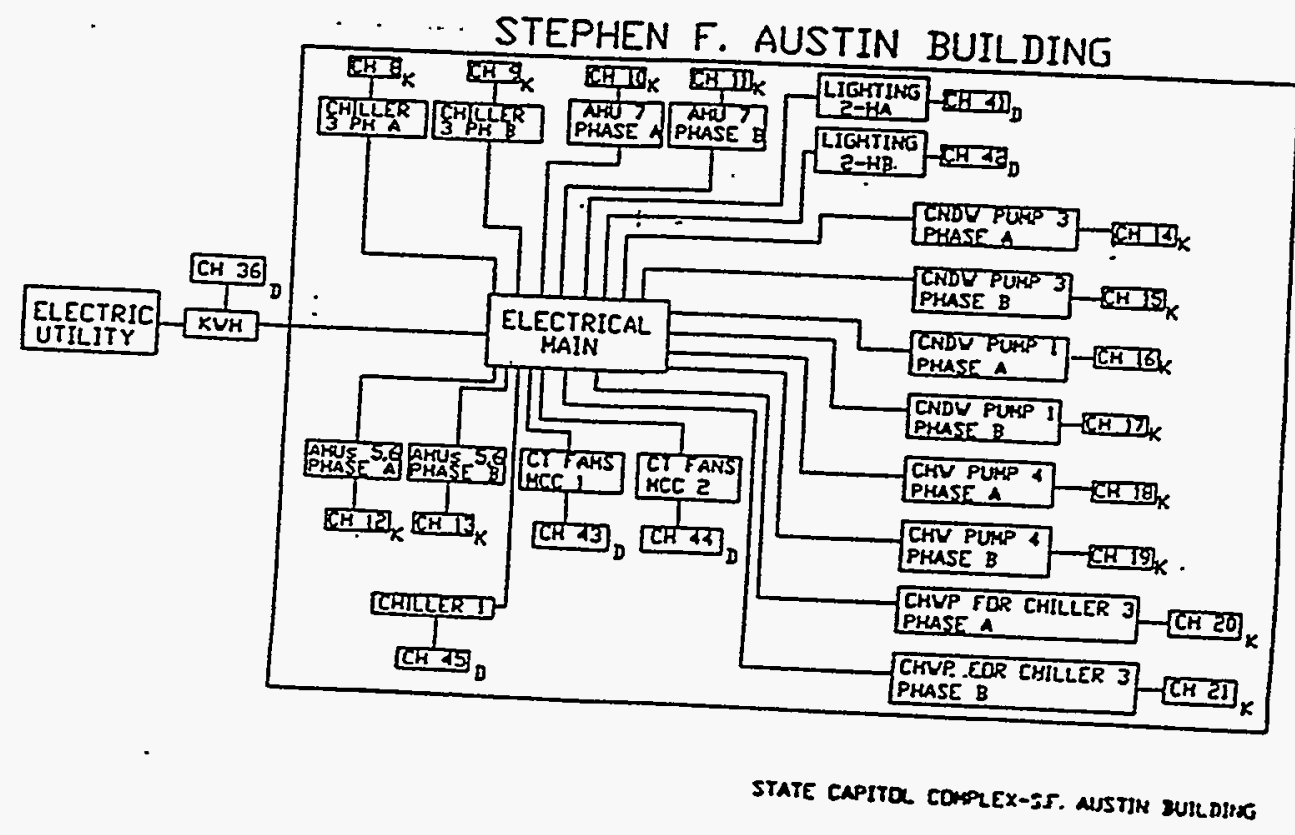


Figure 2.11: Preliminary Results for Calibration of RH Sensors. These figures contain results from tests performed with three salt solutions over a varying range of temperatures as recommended by Greenspan (1977) and Huang (1991). Figure 2.11a presents the results for the calibration of two candidate sensors using lithium chloride $(\mathrm{LiCl})$ over a varying range of temperatures. Figure $2.11 \mathrm{~b}$ presents the results for calibrations using magnesium chloride $(\mathrm{MgCl})$, and Figure $2.11 \mathrm{c}$ presents results using sodium chloride $(\mathrm{NaCl})$. Time series data are presented to illustrate the long length of time needed to perform these calibrations.
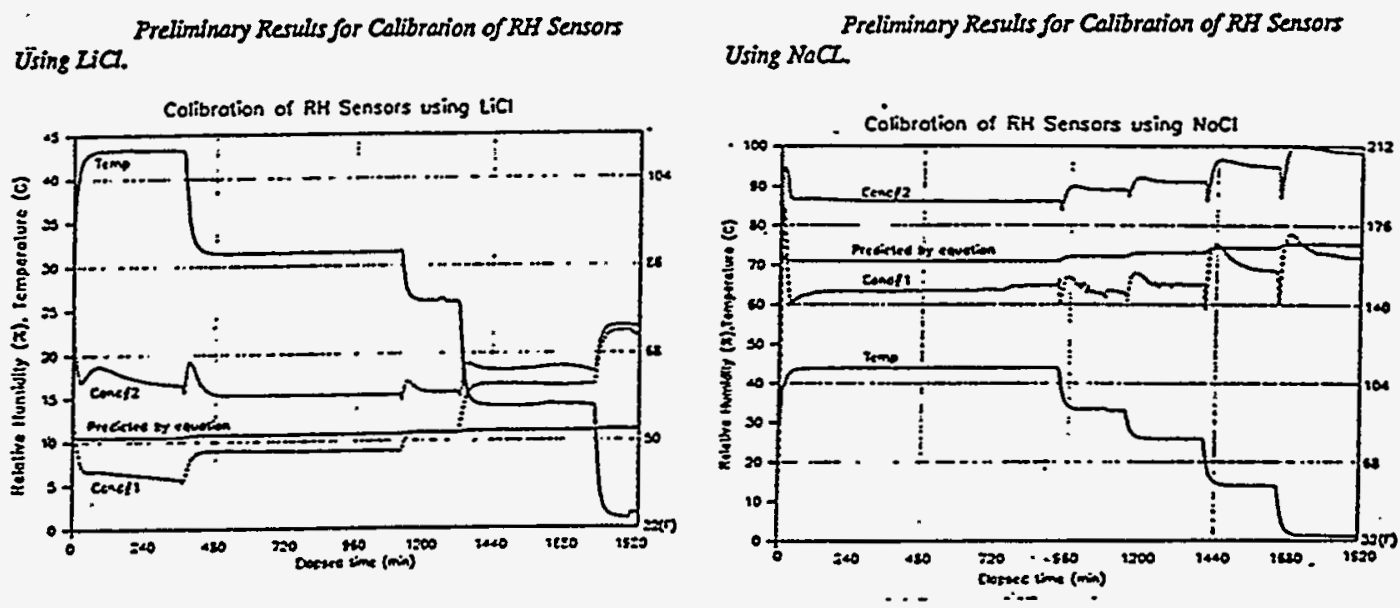

$$
\text { Using } \text { SgCT. }_{\text {Preliminary Results for Calibration of RH Sensors }}
$$

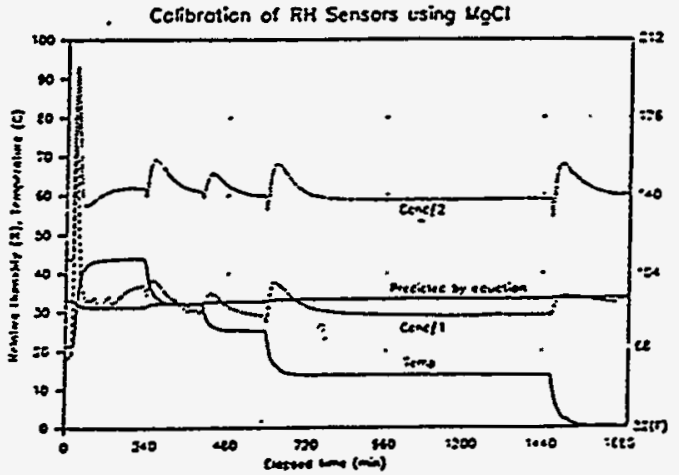


Figure 2.12: Diagram of the Liquid Flow Loop Calibration Facility. This figure is a diagram of the dynamic weight, liquid velocity flow loop that is in the upper portion of the schematic diagram of the calibration facility. Water at varying flow velocities is drawn from the supply tank, pumped through the $6.1 \mathrm{~m}$ ( $20 \mathrm{ft}$ ) long test section, and diffused into the receiving tank where the changing weight of the water is compared to the manufacturer's flow velocity.

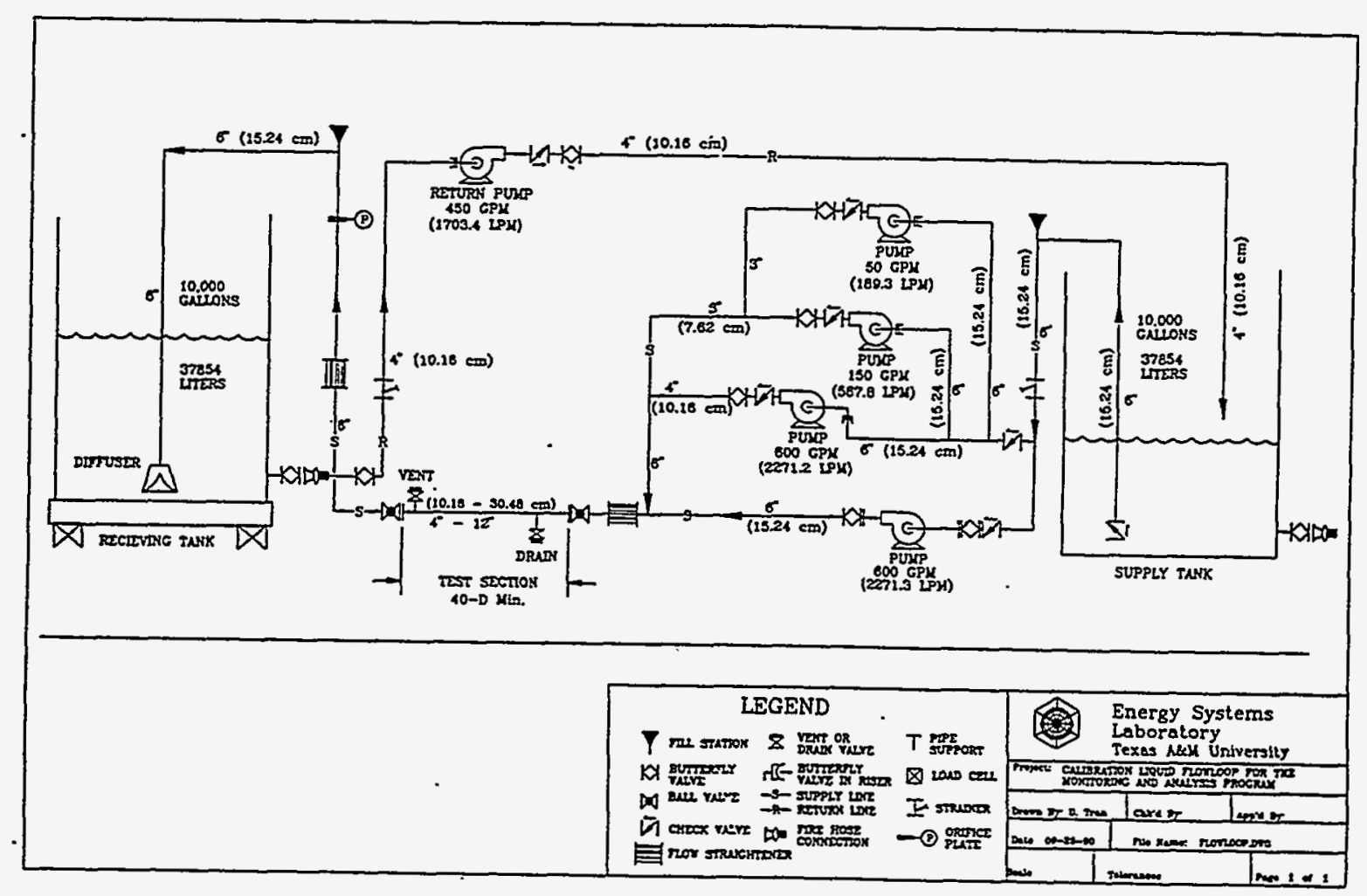


Figure 2. 13: Preliminary Results from Tangential Paddlewheel Flow meters. Results from preliminary tests conducted on three magnetic-type paddlewheel flow meters and one non-magnetic-type paddlewheel flow meter are shown in these figures.

All tests were conducted with the manufacturer's k-factor.

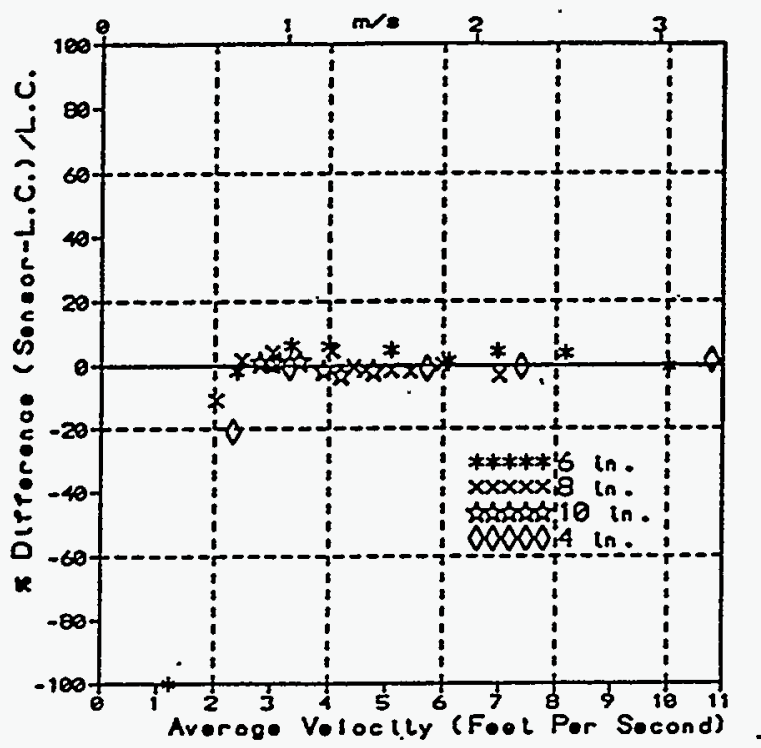

FIGURE 3A: RESULTS OF TESTS OF TANGENTIAL PADDLEWHEEL FLOW METERS. THIS FIGURE SHOWS THE RESULTS OF TESTS THAT WERE PERFORMED ON MAGNETIC-TYPE TANGENTIAL PADDLEWHEEL FLOW METERS USING A DYNAMIC WEIGH FLOW LOOP (ROBINSON ET AL. 1992)

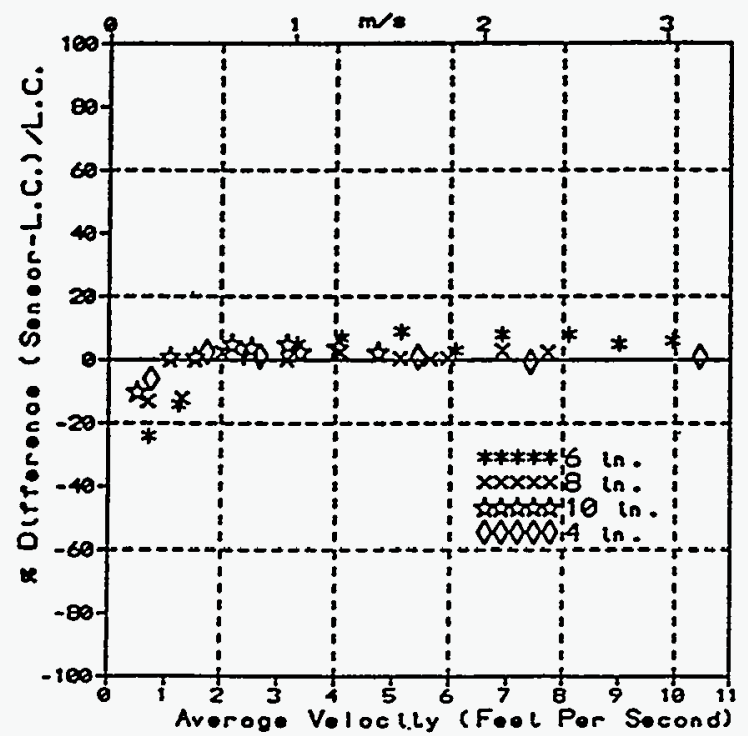

FIGURE 3B: RESULTS OF IESTS OF TANGENTIAL PADDLEWHEEL FLOW METERS. THIS FIGURE SHOWS THE RESULTS OF TESTS THAT WERE PERFORMED ON NON-MAGNETIC-TYPE TANGENITAL PADDLEWHEEI FLOW METERS USING A DYNAMIC WEIGH FLOW LOOP (ROBINSONET AL. 1992) 
Figure 2.14: LoanSTAR Monitoring and Analysis Program Network. This figure shows the LoanSTAR network that has been established for polling, archiving and analyzing building energy data at the Texas A\&M University campus.

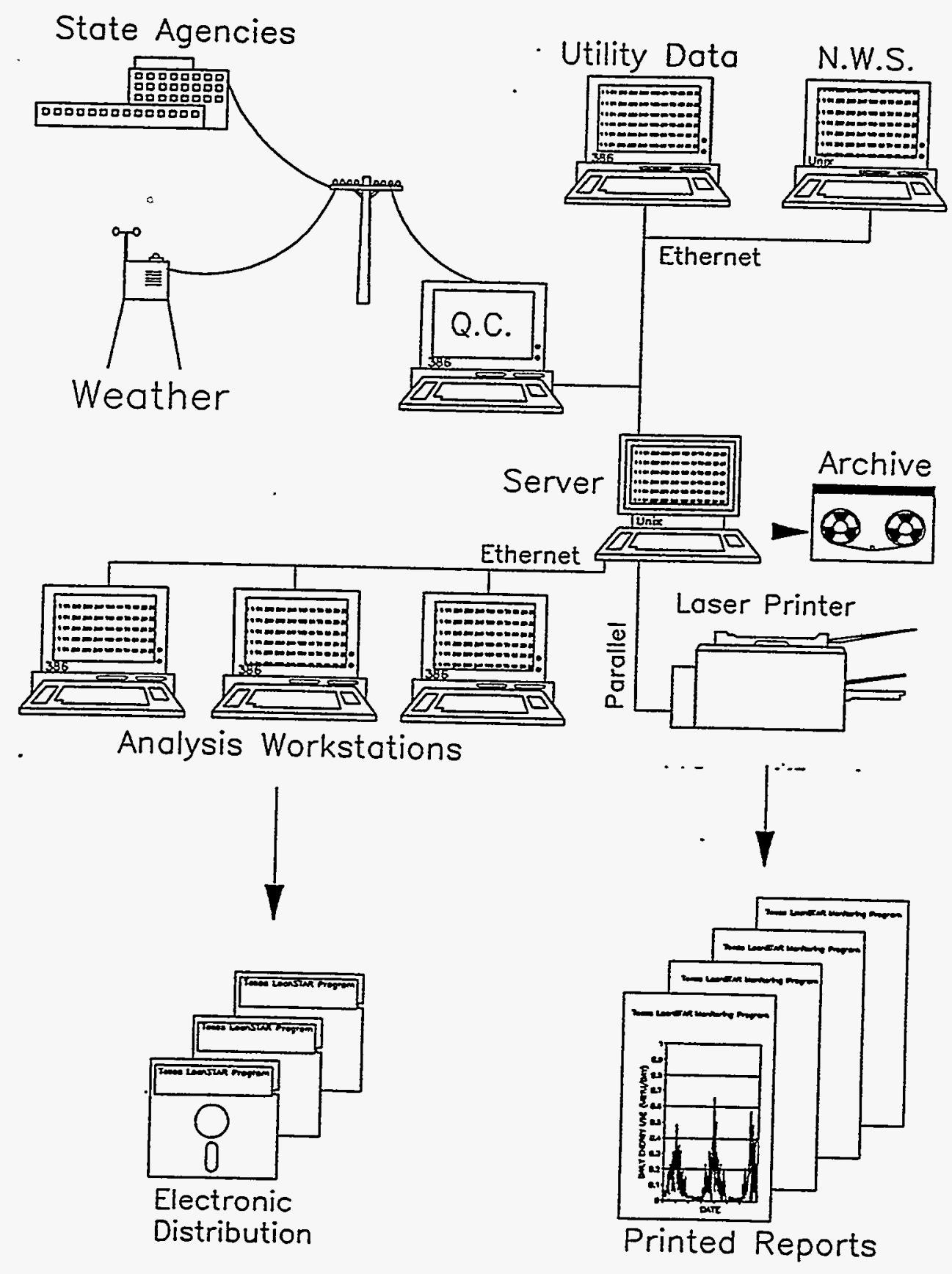


Figure 2.15: DOS-UNIX ASCII Flat File Method for Archiving and Distributing LoanSTAR Data.

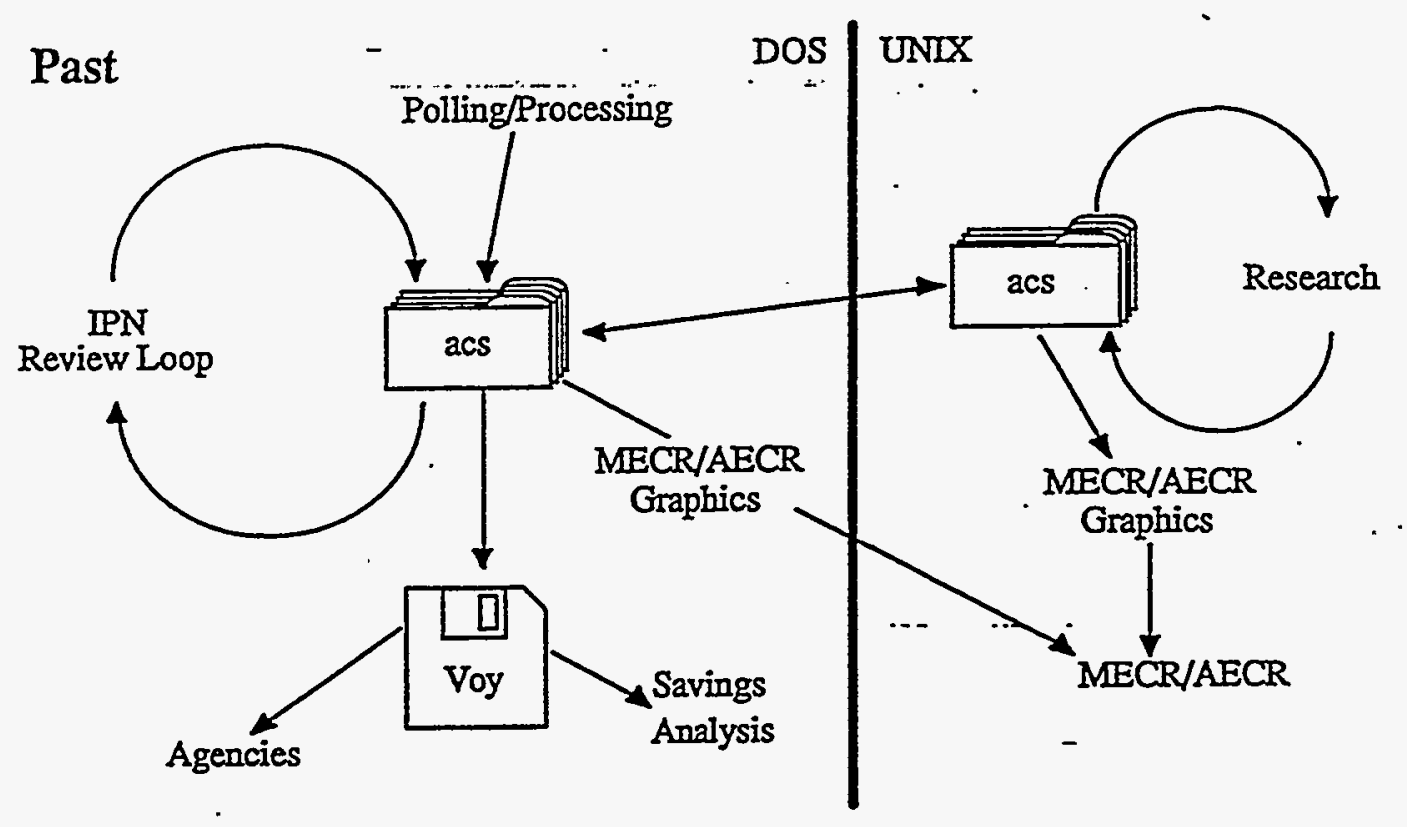


Figure 2.16: DOS-UNIX Relational Method for Archiving and Distributing LoanSTAR Data.

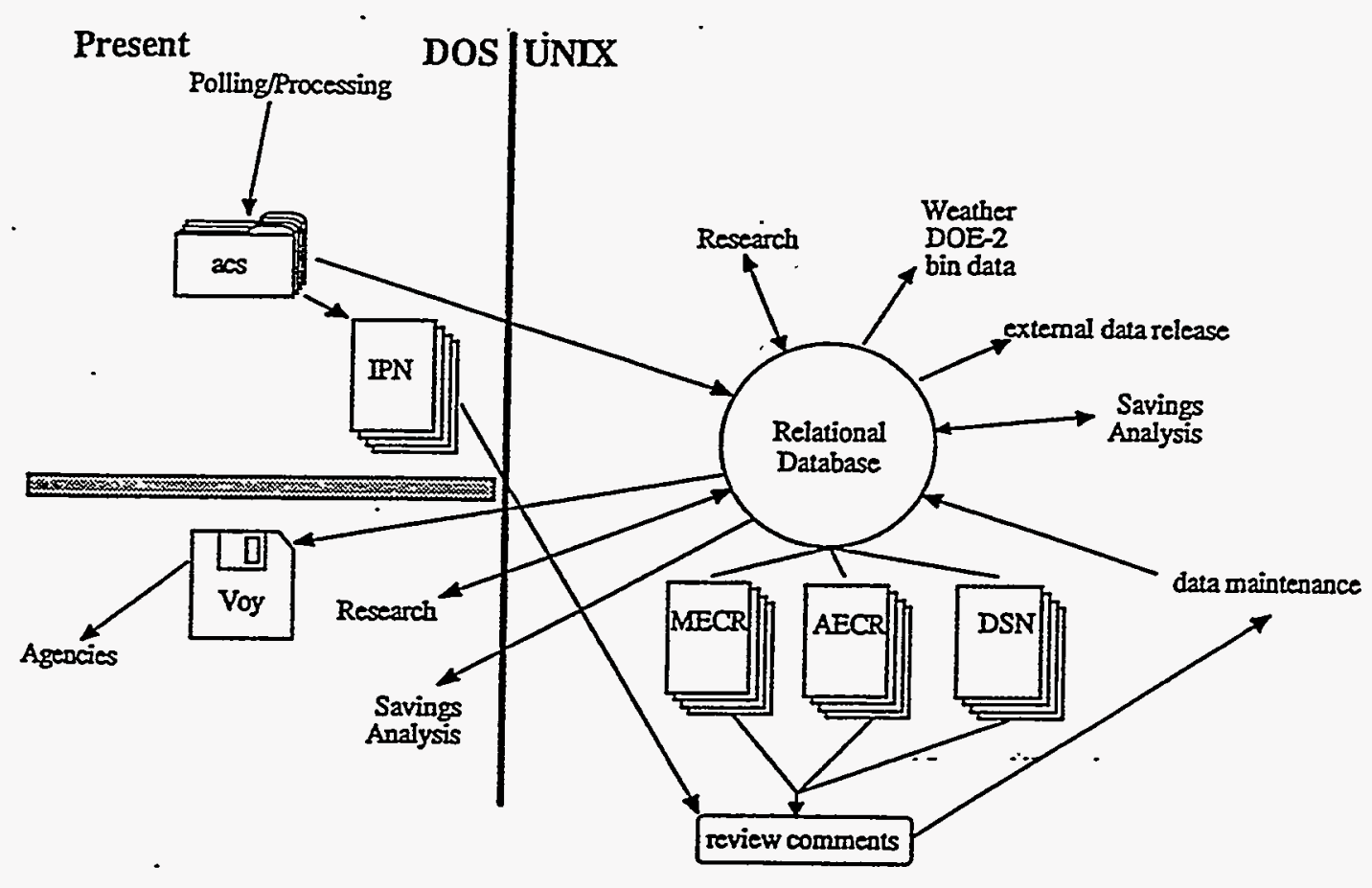


Figure 2.17: LoanSTAR Database Structure.

\section{LoanSTAR Database Structure and Status}

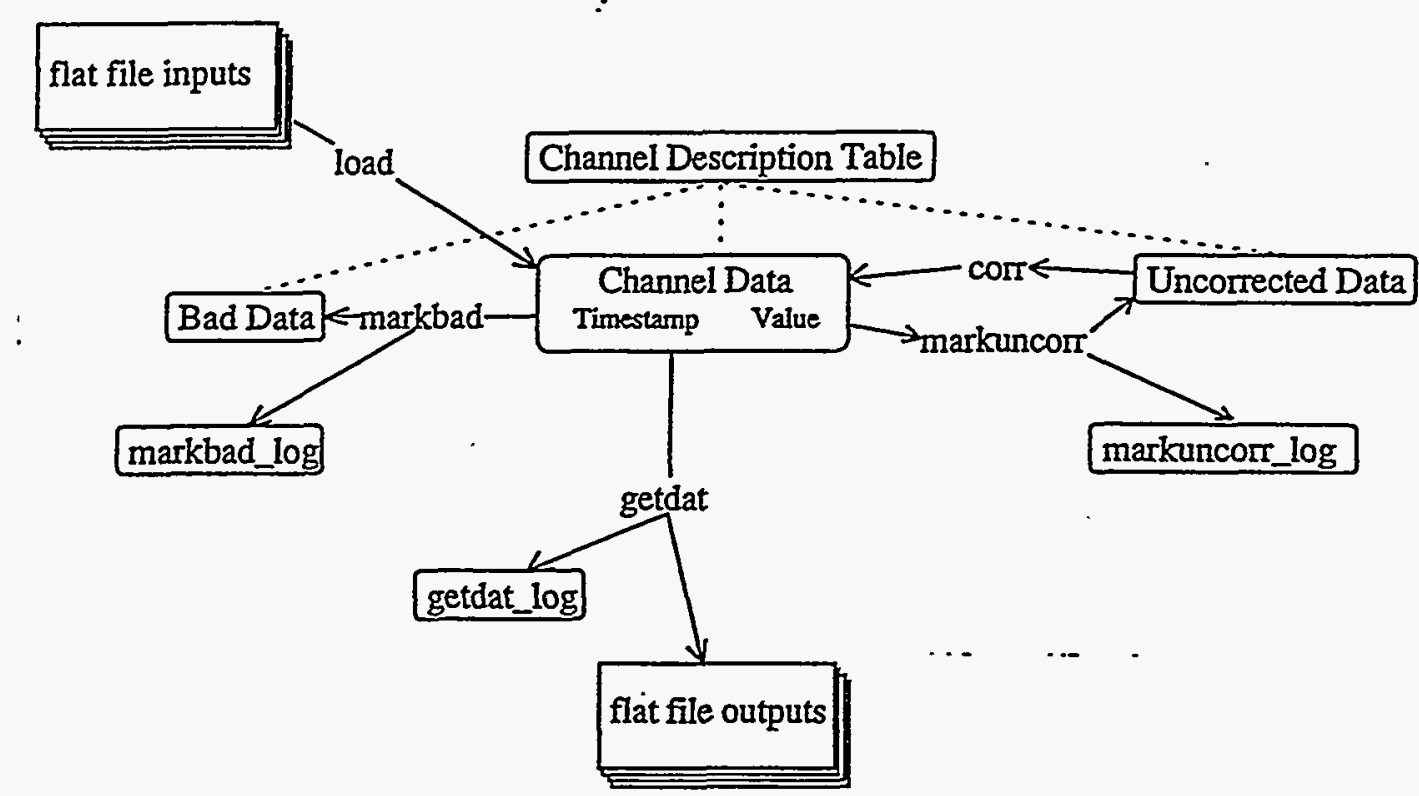


Figure 2.18: LoanSTAR Centralized Commenting and Logging Facility -iComment.

- iComment

Centralized Commenting and Logging

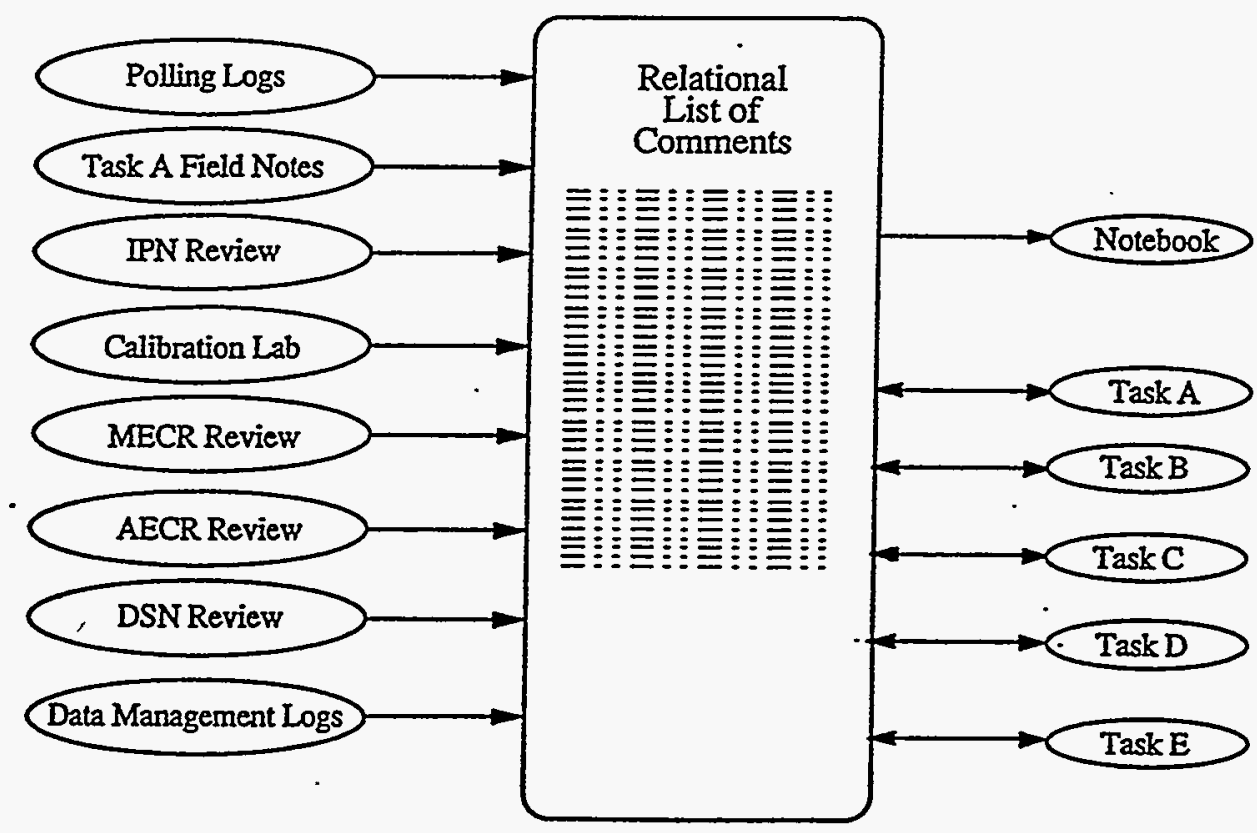


Figure 2.19: Before-After Analysis of Energy Conservation and Savings.

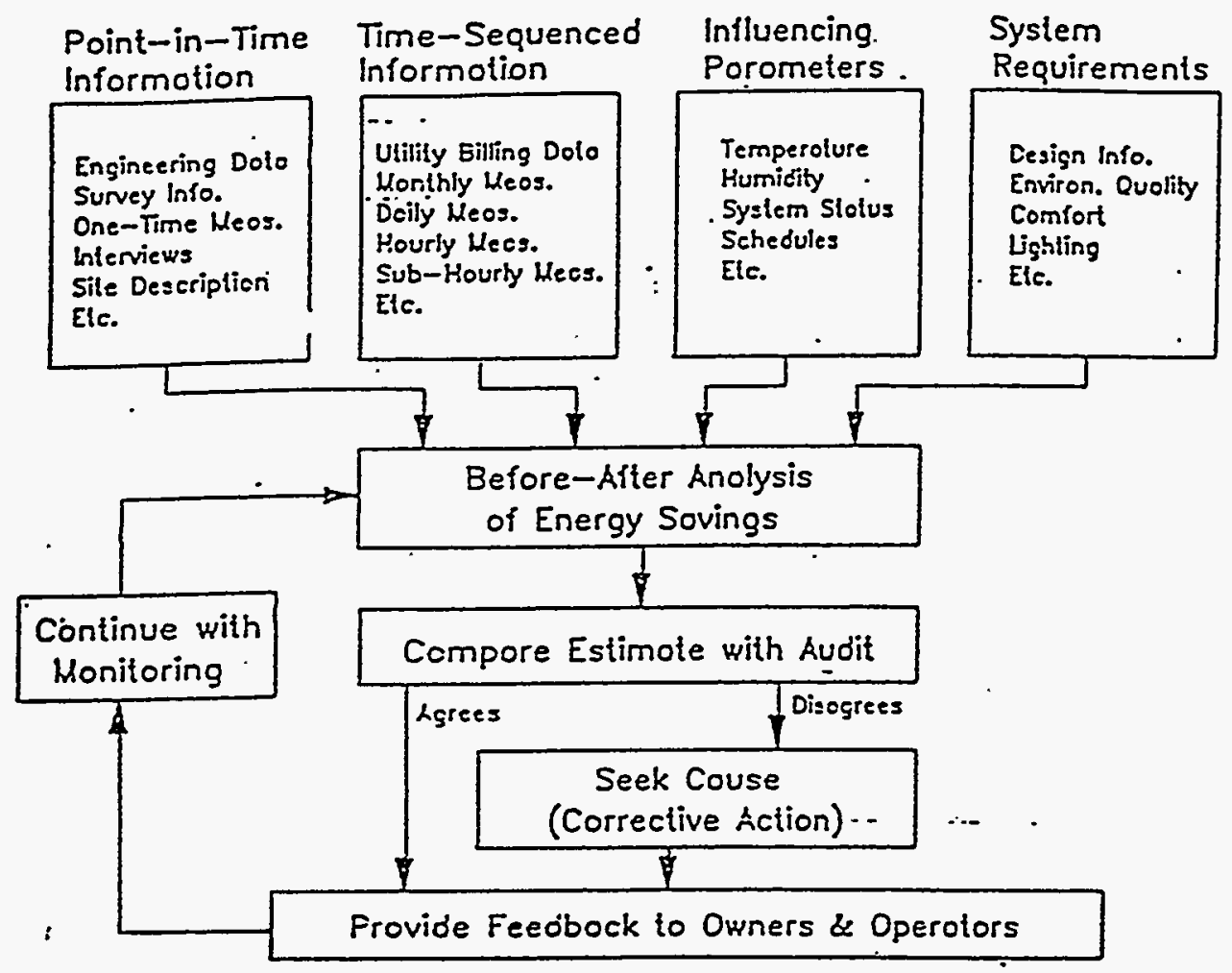




\subsection{ACQUIRING, ARCHIVING, HANDLING, AND REPORTING THE DATA}

\subsection{Measuring the Energy Use}

This section discusses measuring energy use, including general information on acquiring, archiving, handling, and reporting the data, the basics of electricity monitoring, and measuring thermal energy.

\subsection{General Information on Acquiring, Archiving, Handling, and Reporting the Data}

One of the main activities of the LoanSTAR program is the measurement of hourly electricity and thermal energy use for the purpose of determining before/after energy savings. To accomplish this, it was necessary for LoanSTAR staff members to visit each site and determine how the primary energy feeds to the building would be measured. This resulted in a monitoring diagram for each site similar to that shown in Figure 3.1. In this figure, electrical and thermal monitoring for a UT Austin site is shown. The upper diagram is the electrical monitoring diagram, and the lower site is the thermal monitoring diagram. These diagrams serve as one of the primary documents that show where sensors are located and what channels they are assigned.

At each site, loggers needed to be installed and set up to record specific data on each channel. An example logger set-up is provided in Figure 3.2. This diagram illustrates an example logger that is set up to measure one single phase electricity channel (on power channel 0), one digital thermal Btu and flow channel (on digital channels 0 and 1 ), one analog temperature channel (on analog channel 0 ), and one analog humidity channel (analog channel 1). In general LoanSTAR loggers were installed in electrical vaults or mechanical rooms. Figure 3.3 illustrates how three phase electricity is monitored with three current transducer (CT) channels and one 4-wire potential transducer (PT) using the Synergistics logger (Photocopied with permission: Synergistics 1990).

Thermal energy monitoring usually requires physically penetrating the chilled water, hot water and/or steam condensate lines in the building and installing flow meters as shown in Figure 3.4. This figure shows a detail of how thermal energy monitoring of chilled water is achieved with the use of a Btu meter, two temperature probes and a flow meter. Penetration of the "live" chilled water pipes was accomplished without having to drain the entire building's piping network through the use of "hot taps" as shown in Figure 3.5. Hot taps are a standard industry practice for penetrating a live fluid carrying pipe and require a welder and pipe cutting equipment. This figure shows a typical hot-tap flow meter installation used in the LoanSTAR program.

The remainder of this section describes in detail how energy use was recorded from electricity meters, thermal energy meters and other meters of importance and how the data were retrieved, inspected, archived and presented. 


\subsection{Basics of Electricity Monitoring}

The monitoring of electrical energy (a time-varying function) requires a few more steps than the monitoring of electric power (an instantaneous function). In order to measure the energy use of a building or an appliance, it is necessary to have a recording meter that measures and records the amount of power used over a period of time. In the early days of electrical metering this was accomplished with some very ingenious mechanical devices. Beginning in the mid-1980s the direct metering of electrical energy through the use of affordable, easy-to-use microprocessor-based field data acquisition systems became a day-to-day reality. However, in order to get a sense of what is involved, it is helpful to know about the basic components--many of which are still in use today.

From the start, the measurement and recording of electrical energy was accomplished with Watt-hour meters, and pulse-initiating telemetering circuits. Then, in the 1970s, this task was simplified somewhat when Watt/Watt-hour transducers became commercially available, and more recently, with the advent of microprocessor technology, digital Watt/Watt-hour meters. This next section reviews the basics of obtaining digital data from power/energy measurements. The reader is referred to the authoritative Handbook for Electricity Metering by the Edison Electric Institute (EEI 1981), and the paper by Schuster (1985) for additional details. A significant amount of material for the next section of this workbook has come from these texts and from the LoanSTAR Monitoring Handbook (Haberl et al. 1992).

\subsubsection{The Watt-hour Meter}

A Watt-hour/demand meter acts very much like the speedometer and odometer on an automobile. It is composed of a combination of sub-components: a very slow-speed motor whose rotational speed is proportional to the power that passes through it, a magnetic brake to retard the spinning rotor when power is withdrawn from the meter, a series of mechanical registers to record the number of revolutions, and a meter that records the peak electric demand (i.e. - number of revolutions in a specific time interval). Basically, as the power is increased, the rotor spins faster and the Watt-hour meter records more revolutions. A measurement of the energy used during any given period of time can then be obtained by subtracting two consecutive Watt-hour meter readings (revolution counts). Such meters form the basis for almost all of the electrical metering that is performed in this country. The basic principle upon which they work was set forth in 1884 by Ferraris who showed that torque (rotation) can be produced in an electrically conductive rotor when it is exposed to two alternating-current fluxes in such a way that they produce rotational motion in one direction on the rotor.

\subsubsection{Connecting a Computer to a Watt-hour meter}

The basic method that is used to generate an electronic time-series data record of the energy that passes through a Watt-hour meter is to send a series of on/off pulses to a digital recorder. Originally, this was accomplished with pen and ink charts, which gave way to magnetic tapes that were collected and transferred to a mainframe computer periodically. More recently, such information is recorded by microprocessor-based data acquisition systems where it is transferred (sometimes automatically) over phone lines to 
a central facility. In almost all cases, the time-series record consists of a record of pulses where each pulse is equal to some predetermined number of Watt-hour disk revolutions and hence the amount of energy that has passed through the meter during that period of time.

The energy-accounting gear train of the Watt-hour meter is fitted with either a twowire or three-wire pulse initiator (either electronic, optical, or mechanical) to generate these pulses. Most Watt-hour meters that are fitted with pulse initiators use the 3-wire configuration. The difference between 2-wire and 3-wire systems is due to physical problems that arose with the original mechanical pulse receivers. If the pulse initiator was not carefully installed and adjusted, there was a chance that it would chatter and overregister the number of pulses. This egregious characteristic was removed by adding a third wire, which serves as a latching mechanism since the pulse generator must not only switch on/off but also switch between circuits in between each pulse--thus eliminating the chatter. A 2-wire telemetering connection can always be made to a 3-wire pulse initiator by simply using one of the contacts and adjusting the energy/pulse ratio. However, one must ascertain before hand whether or not contact chatter will be a problem.

\subsubsection{Measuring Demand With a Watt-hour Meter}

In most larger commercial buildings both the electricity energy use and peak electric demand are usually recorded for billing purposes. In order to accomplish this, the Watthour meter is equipped with a demand meter, which retains a reading of the peak electric power level that passed through the meter until the demand reading is reset at the end of each billing period. This was originally accomplished through the use of a thermal demand element, which later gave way to a mechanical gear-driven demand meter. In thermal demand meters, a pair of bi-metallic coils are attached to the demand indicator shaft. Movement of the shaft is produced by creating a temperature difference between the coils that is proportional to the power measured. This is accomplished by reversing the currents in one heater when compared to the other. Thermal demand meters are still being used today. However, one should be careful when such meters are exposed to widely varying ambient temperatures because the demand readings can be affected by temperature of the meter.

An indicating-type mechanical Watt-hour demand meter is actually a "Watt-hour meter within a Watt-hour meter". It records the energy used during a pre-specified period, pushing the maximum demand pointer to a new value when the demand for the current period exceeds any previous period, and then resets itself to zero at the end of a predetermined demand period; beginning the cycle over again. Some versions also include a cumulative-type demand meter that displays the current peak demand and adds the demand to another register each time it is reset.

\subsubsection{The Watt/Watt-hour Transducer}

A replacement for the Watt-hour meter became a reality in the 1970 s with the commercial availability of the Watt/Watt-hour transducer. This solid state device produced dramatic improvements in the accuracy and stability of electrical metering and 
paved the way for microprocessor-based electrical power and energy metering. The Watt/Watt-hour meter provides a direct analog or digital output signal that is proportional to the energy being consumed.

Watts are calculated electronically and output as either an analog DC signal or pulsed output that uses a basic time-division-multiplier principle. Conversion of the energy consumption to analog or pulsed output utilizes two different processes. In each process a carefully controlled triangular wave form is compared to a varying sinusoidal wave form to produce a pulse-width and pulse-amplitude modulation. In other words, the width of each pulse is proportional to the input voltage, and the amplitude of each pulse is proportional to the input current. The output from the modulator is a DC current signal that is proportional to the input wattage. The output from the modulator can also be sent to the pulse initiator section to produce a pulse that is proportional to the input wattage.

The basic unit that is inside integrated solid state digital Watt/Watt-hour meters that are used in certain data acquisition systems utilizes a similar principle to the Watt/Watthour transducer. In brief, an input reference voltage from a potential transformer (PT) is supplied that provides a low voltage signal that is proportional to each of the high voltage phases being monitored. This is combined with low voltage input current signals to produce digital wattage output signals that are proportional to the energy used by each circuit being monitored.

The primary advantage with such a multi-channel, integrated, solid state Watt/Watthour meter is that it only requires PTs and CTs to attach it to a building's electrical system, which eliminates the need for a separate Watt/Watt-hour transducer for each load being monitored; and since it is directly combined with the microprocessor that records the data, it can be re-configured in software for different loads, which makes it ideal for portable applications. Continuos power factor measurements can also be taken with such equipment. A more complete description of the circuitry inside the data logger developed for the United States Department of Energy is provided in the paper by Schuster (1985).

\subsection{Measuring Thermal Energy}

Heating and cooling energy use for buildings with hot and chilled water systems can be measured using thermal energy meters. These meters require the input of temperature sensors and flow meters. Some thermal energy meters can report both energy rates and flow rates. This section discusses some of the thermal energy and flow meters used in the LoanSTAR program. Special features and limitations of equipment from several different manufacturers are mentioned.

\subsubsection{Thermal Energy Meters}

A thermal energy meter is typically an electronic device that is used to calculate chilled water or hot water energy used in a building or facility. Each thermal energy meter requires three input signals: a flow meter signal, and one temperature signal each for the supply and return lines. Each thermal energy meter has its own requirements for the type 
of flow meter and temperature sensors needed for proper operation. A schematic of a typical thermal energy meter setup is shown in Figure 3.4.

The calculation procedure performed by the thermal energy meter is based on the following equation:

$$
E_{T}=m \times C_{p} \times \Delta T
$$

where

$$
\mathrm{m}=\rho \times \bar{V} \times \mathrm{D}^{2} / 4
$$

$E_{T}=$ thermal energy usage

$\mathrm{m}=$ mass flow rate of the fluid (usually water)

$C_{P}=$ specific heat of the fluid at a given temperature

$\Delta T=$ difference between entering and leaving fluid temperatures

$\rho=$ density of the fluid

$D=$ inside pipe diameter

$\bar{V}=$ average (bulk) velocity of the fluid stream

Most flow meters don't measure mass flow directly, but measure the velocity of the fluid which allows for the calculation of the volumetric flow rate. The flow rate is then multiplied by a constant, which converts the flow rate into a mass flow rate for the fluid being measured. A modified form of equation (3.1) that includes the volumetric flow rate is given as:

$$
E_{T}=K Q \Delta T
$$

where $K$ is the " $k$-factor" constant containing $\rho$ and $c_{p}$ for the fluid being measured, and some other constants needed for units conversions. The symbol $Q$ is the volumetric flow rate (i.e. $-\bar{V} \pi \mathrm{D}^{2} / 4$ ). For example, the value of $K$ for water is approximately 500 , for $E_{T}$ in units of $\mathrm{Btu} / \mathrm{hr}, Q$ in $\mathrm{gpm}$, and $\Delta T$ in units of degrees $\mathrm{F}$.

The $\Delta T$ value is very straightforward, and is taken as the difference between temperature of the supply and return lines. The volumetric flow rate is a function of pipe size and fluid velocity through the pipe.

\subsubsection{Thermal Energy Meters Used in the LoanSTAR Program}

Three brands of thermal energy meters have been used throughout the LoanSTAR program. They are designated as brands $A, B$, and $C$ for the remainder of this section. The main differences between these meters are the flow meter and temperature sensor requirements, and the ability to specify scaling factors based on pipe size and flow meter calibration. Brand $A$ is field scaleable, while brands $B$ and $C$ are not. 
Brands $B$ and $C$ must be scaled by the manufacturer. The purchaser specifies pipe diameter, flow meter model, type of fluid and estimated maximum volumetric flow rate. The manufacturer then programs the appropriate scale factors into "ROM" chips within the meter electronics. Many times the meters were programmed incorrectly because the diameter was incorrectly estimated beforehand, or the manufacturer mistakenly programmed the wrong size into the meter. Mistakes of this type were usually not discovered until after the thermal energy meters were installed. Excessive time delays resulted from removing and shipping these meters back to the manufacturer for reprogramming.

Brand A meters require no information about the site when ordering except temperature range being measured (either hot or cold) and the fluid being measured. They have DIP switches that allow the scaling factors to be specified in the field. This model also has another DIP switch that lets the user scale the output signals.

The temperature sensors used with these meters are included when the meter is purchased. Brands $A$ and $C$ sensors are interchangeable. This means any one sensor is identical to the next and can be used in either the supply or return line. The brand B thermal energy meters are individually calibrated to the temperature sensors that are labeled "hot" and "cold." Recalibration efforts and repairs are more difficult when the sensors are not interchangeable.

A summary of meter features for the three thermal energy meters used in the LoanSTAR program is listed below.

\begin{tabular}{|l|c|c|c|}
\hline \multicolumn{1}{|c|}{ Features } & Brand A & Brand B & Brand C \\
\hline Cost & $\$ 450$ & $\$ 275$ & $\$ 1,700$ \\
\hline Field Scaleable & yes & no & no \\
\hline Output Signals & Flow, Btus & Flow, Btus & Btus \\
\hline Temp Sensors & Thermistor & Solid State & RTD \\
\hline Interchangeable Temp Sensors & yes & no & yes \\
\hline Flow Meter Signal & Pulse & Pulse & $\begin{array}{c}\text { Pulse or } \\
\text { Analog }\end{array}$ \\
\hline $\begin{array}{l}\text { No. of water lines meter is } \\
\text { capable of monitoring }\end{array}$ & 1 & 1 & 2 \\
\hline
\end{tabular}

The output signal from all three meters is a simple digital pulse (i.e., a contact closure) that is detected by the data logger. The scaling of each pulse is dependent on the pipe size, flow meter characteristics, and thermal energy meter electronics configuration.

Another factor to consider when assessing the validity of the data produced by these thermal energy meters is calibration. The brand A manufacturer produces a test device that simulates input from a flow meter and two temperature sensors. Brands $B$ and $C$ do not offer such a device; however, the temperature sensors can be checked by measuring 
resistance or milliamps produced by the sensor at a given temperature. The brand $\mathrm{C}$ temperatures are easily checked by measuring the resistance of the RTD sensors and using a table to calculate temperature. Brand B temperature sensors produce a 1 milliamp current per degree Kelvin signal, but the manufacturer states that direct measurements are accurate to only \pm 5 degrees $F$.

As always, a reasonableness check should be made with the energy measured by these meters. One easy check is to calculate the energy used per square foot. In the LoanSTAR program, measured building hot water and chilled water use ranges between 3 and 30 $\mathrm{Btu} / \mathrm{ft}^{2}-\mathrm{hr}$.

\subsubsection{Insertion Flow Meters}

The insertion flow meter consists of a sensor with a paddle wheel or turbine that is immersed into the pipe flow. The paddle wheel or turbine spins at a rate proportional to the fluid velocity. This rotation produces an electronic signal that is transmitted to the thermal energy meter or other logging device. These meters can be installed in pipes under pressure through the use of "hot taps," thus avoiding a system shut-down. A schematic of a typical insertion meter installed in a pipe is shown in Figure 3.5.

There are several advantages to using insertion flow meters. They are relatively inexpensive and are easily removed for calibration or repair. A special insertion tool is all that is required to install or remove these meters.

The insertion flow meter is the meter of choice for the LoanSTAR project. Three different brands of meters have been installed in the field and tested in the calibration laboratory. Again, these meters will be referred to as brands A, B, and C.

Brand A contains an axially-mounted stainless steel turbine that is immersed in the fluid flow. This model is capable of withstanding the high temperatures found in hot water distribution systems and boiler feed water and condensate lines. One drawback to this model is its high expense. Another difficulty with this flow meter is that it requires periodic inspection with an oscilloscope to diagnose any problems it may have in the pipe. For instance, if one of the blades has broken, the turbine will continue to rotate and produce a signal, making it appear that nothing is wrong with the turbine. However, the signal would no longer represent the true flow through the meter.

Brand $\mathrm{B}$ is the least expensive model used. It consists of a plastic tangential paddlewheel with embedded magnets. When the paddle wheel rotates, a sinusoidal voltage with a frequency proportional to fluid velocity is generated. Testing at our calibration facility has shown this meter to be accurate to the manufacturer's stated accuracy at flow rates above three feet per second. Extra drag due to the magnetic fields may contribute to the loss of accuracy at low flow rates. These magnets also tend to collect any iron filings that may be circulating through the water system. Removal of several flow meters that had been in use for six months showed significant amounts of iron filings attached to the paddle wheel. These filings can eventually prevent the paddle 
wheel from rotating. Another problem with this brand is that at low flow rates the signal generated is very low, thus making detection with some thermal metering equipment difficult.

Brand $C$ is the flow meter most commonly used on the LoanSTAR project. It is similar to brand $B$, except there are no magnets on the tangential paddle wheel. The meter uses an RF signal that is projected across the path of the paddlewheel. Each tooth contains a non-magnetic metal core that breaks the RF signal as it passes between the antenna and receiver. The sensor produces a square wave frequency that is detected at the thermal energy meter or logger. Calibration tests show this meter to be accurate to the manufacturer's specifications at flow rates as low as $0.5 \mathrm{ft} / \mathrm{s}$. The cost of this meter is about twice that of brand $B$.

A summary of the three meter features is shown below:

\begin{tabular}{|l|c|c|c|}
\hline \multicolumn{1}{|c|}{ Features } & Brand A & Brand B & Brand C \\
\hline Cost & $\$ 1,600$ & $\$ 300$ & $\$ 500$ \\
\hline Sensor & Turbine & $\begin{array}{c}\text { Paddle } \\
\text { Wheel }\end{array}$ & $\begin{array}{c}\text { Paddle } \\
\text { Wheel }\end{array}$ \\
\hline Temperature Range & N/A & $32-220^{\circ} \mathrm{F}$ & $-4-220^{\circ} \mathrm{F}$ \\
\hline Fluid Velocity Range & N/A & $\begin{array}{c}1 \text { to } 30 \\
\text { ft/sec }\end{array}$ & $\begin{array}{c}1 \text { to } 30 \\
\mathrm{ft} / \mathrm{sec}\end{array}$ \\
\hline Output & $4-20 \mathrm{~mA}$ & Frequency & Frequency \\
\hline
\end{tabular}

A variety of thermal energy meters and flow meters is available for use on building energy monitoring projects. New equipment is continually being evaluated to see if it will provide a significant improvement in cost, operation, or reliability over current equipment.

\subsection{Polling and Retrieving Data}

Since 1989, the number of buildings being monitored, and consequently the amount of data collected, has increased dramatically. The first year of the project saw hourly data collection from one building in College Station. Since October 1990, over 200 buildings from around the state have been added at irregular intervals. The first set of buildings added was at the University of Texas at Austin (12 buildings), followed immediately by the State Capitol Complex ( 9 buildings), also in Austin. After this initial rush of LoanSTAR Program buildings, collection of hourly National Weather Service (NWS) data from locations throughout Texas began in November 1990. As of May 1993, the LoanSTAR MAP is collecting data from 77 sites located in various cities throughout Texas as well as weather data from 50 NWS stations.

LoanSTAR MAP data management includes five major functions: polling the data from the data acquisition systems (DAS), processing the data from all the various sites into a reasonably generic format, controlling data quality, generating reports, and retrieving data for analysis. Information regarding polling, processing, and report 
generation can also be found in the following papers and reports: López and Haberl, (1992); Claridge et al., (1992); and Haberl et al. (1990a, b, 1992).

The first step in this data management scheme is the entry of data into the system. This includes both the retrieval of building data from the remote data loggers and the acquisition of NWS data. At LoanSTAR, each building is polled weekly. Using IBM PCbased communication software, the LoanSTAR MAP currently downloads data as basic ASCII columnar text. Each remote DAS collects hourly or fifteen minute consumption information, which is stored in onboard volatile memory. Because these systems have a finite amount of memory, the DAS is polled once per week to avoid older data from being overwritten by newer data and lost. As each site is polled, the data set is saved as one file per site per week. Therefore, every week, one new raw data file per site containing 168 hourly records is created and saved. Prior to processing, these files are stored in a temporary directory on the polling PC. After the data have been processed, the raw files are archived to tape.

The NWS data records were initially collected by the Texas A\&M Meteorology Department using satellite technology. The MAP has been allowed to transfer weather data over the campus internet for internal use in analysis at a minimal cost. The Meteorology Department is actually collecting data from NWS locations nationwide; therefore, some initial filtering is done by the Meteorology Department's computers to extract only Texas sites before the package is transferred. This relieves the strain on the campus network and obviously reduces the disk space required on the LoanSTAR computer system. The NWS data set requires substantial processing to be usable by the LoanSTAR analysis teams. As with the building data, the raw files are archived onto tape. In both cases, if problems are identified somewhere in the processing stream at a later date, all raw data are still readily available for reprocessing. NWS data is also being collected from Accowealth in State College, Pennsylvania.

\subsubsection{Processing/Plotting Synergistics Data}

Included in an appendix at the end of this report are some helpful hints about what to do with the data once they have been collected from a logger. The routines used to process and plot data collected from Synergistics loggers in the Texas LoanSTAR Program over the last three years on a weekly basis are described there. Instructions and sample code are available on disk for developing inspection and summary plots, as are 3$\mathrm{D}$ plots using a combination of public domain data processing tool kits and inexpensive commercially available plotting software. The routines discussed are available in the workbook by Haberl et al. (1992). .

\subsection{Quality Control}

Processing of the weekly data sets and essential quality control are performed through a combination of public domain utilities, commercial software, and routines written inhouse to knit the data streams together. It should be noted that a goal of LoanSTAR MAP has been to use inexpensive existing software wherever possible to decrease potential costs for those who wish to duplicate our methods and also to reduce our development 
time. This methodology has caused an interesting assortment of modules to evolve over the past three years. The routines written by the LoanSTAR staff are generally programmed in either GAWK or C++. GAWK (FSF, 1989) is a public domain version of AWK, a powerful UNIX file processing language. GAWK is available in both DOS and UNIX versions.

The cornerstone of the processing and quality control areas is a public domain DOS program called ARCHIVE, which was developed at Princeton University (Feuermann and Kempton, 1987). ARCHIVE is a general purpose program for manipulating and checking columnar data. With ARCHIVE, a channel table is created to describe the columnar data to be processed. Static lower and upper bounds can be associated with any channel in the channel table. For readings outside the specified range, ARCHIVE will flag the data entry in a diagnostic log file as well as replace the suspect value with some predefined "bad data" marker in the output data. This allows an automated method for assuring that data are reasonable. For example, a dry-bulb temperature channel for a site in most parts of Texas might have a lower bound of -10 and an upper bound of 120 . Obviously, it is quite useful to have a program check the 168 hourly readings each week rather than doing this by hand. ARCHIVE can also perform simple data translations. For example, linear transformations can be used to convert from one unit to another. In fact, a linear translation is used to attach the site number to every record in the output. ARCHIVE produces two files as output: a diagnostic $\log$ file and the actual output data. The log files are inspected every week to inșure data quality.

After passing through ARCHIVE, the data file is scanned for missing hours. It is not terribly uncommon for a data logger to lose power in the field. Usually these loggers have battery backups that perform a minimal amount of work: refreshing the internal memory. This allows the logger to keep any data it has collected up to this point, but the logger does not collect any new data until the power is restored. This in turn creates gaps in the data set. For purposes of merging weather data and certain types of analysis, it was determined early in the project that missing hours should be added back into the data with a "bad data' marker inserted for all data values. Therefore, the data file is filtered through a generalized AWK script to scan for missing hours and put them back in as necessary. While the concept of scanning and replacing missing hours is easy to understand, a generalized program must take into account day boundaries, month boundaries, year boundaries, leap year boundaries, and several other special conditions. As with ARCHIVE, the output of this script consists of two files: a diagnostic log file, which reports the number of hours added back in, and the actual output. This file is the final version in which all LoanSTAR hourly data are kept. These processed files are archived to two tapes and also transferred to the MAP's UNIX file server over the campus Internet. Storing the data on a large file server allows immediate access to all the data across all sites, as well as provides access to powerful tools such as the UNIX version of AWK, C, $\mathrm{C}++$, and commercial statistics packages such as SAS (SAS, 1990).

NWS data are translated into the LoanSTAR format through the use of several UNIX shell scripts and supporting AWK scripts that convert the incoming data into a format 
readable by ARCHIVE. The weekly weather data set is then processed in a fashion similar to LoanSTAR building data with one important difference: the weekly file contains the hourly records from all Texas weather sites. This was done to keep the overall processing scheme as efficient as possible. $\mathrm{C}+$ routines are used to extract particular locations from the weekly data set. As shown in Figure 3.6, this scheme has proven particularly useful for creating verification cross plots between LoanSTAR weather data and the National Weather Service data.

\subsection{Weekly Report Generation}

While simple automated quality control checks have been implemented, a key function of the whole process is the production of weekly verification plots. These plots are circulated between the project's Principal Investigators and research staff in a bundle referred to as the Inspection Plot Notebook (IPN). Figure 3.7 shows several sample verification plots. The plots allow possible problems with the data to be identified by visual checks. Graphical presentation of the data on a weekly basis adds tremendously to the quality control and is much less time consuming than scanning the actual ASCII data columns. Because the data are subjected to a long stream of software filters prior to the production of the plots, any potential problems are usually brought to the attention of the Database Manager, who determines if a processing problem could have corrupted the data. If this is not the case, then a genuine data problem may have occurred (for example, a metering problem), and an appropriate message is forwarded to the field engineers.

These weekly plots are currently produced with a commercial graphics package, along with supporting AWK scripts and a controlling DOS batch file. Three different kinds of pages are created for the notebook: times series readings of all channels; summary pages that include scatter plots of some channels (thermal channels and motor control center electricity consumption) versus temperature and derived time series readings of the primary data types (whole-building electricity consumption and thermal channels); and scatter plots of LoanSTAR weather data versus NWS data (as in Figure 3.7). The batch files and supporting scripts allow these pages to be produced from the processed data on a weekly basis with a simple command. The LoanSTAR MAP currently produces roughly 950 of these small graphs, 80 pages in all, each week. The start-up time was substantial, as is the computing time required each week. Additionally, the logistics of actually printing, copying, filing, and routing the IPN each week should be addressed. All told, the entire process requires $20-30$ person-hours every week. This does not include the time spent by the Principal Investigators and project staff reviewing the plots themselves. It is estimated that the MAP requires an additional 50 person-hours each week for review of the IPN, although this value is hard to quantify because the interested parties have different methodologies and goals.

\subsection{Reporting the Data}

Using consumption data to provide near-term feedback to owners and operators in order to increase operating efficiency has only emerged in the last few years. Methods that provided real-time feedback on energy cost to home-owners were investigated in the 1970s (Seligman et al. 1978), but failed to catch on as concerns about energy cost waned. 
However, the benefits of regular feedback have been shown in several case studies (Haberl and Claridge 1987; Haberl and Vajda 1988; Haberl and Komor 1990; Katzev and Johnson 1987; Kempton and Komor 1990; Kinney and Romano 1990). Different forms of feedback have been found to be useful, including weekly time series plots of consumption, three-dimensional time series plots, three-dimensional residuals of measured minus modeled consumption, and plots of savings resulting from specific operational improvements implemented.

The Texas LoanSTAR MAP staff installs data acquisition equipment to monitor the energy use of each large building at the whole-building level, with consumption often submetered for a short period of time before the retrofits are installed and monitoring continued subsequent to the retrofits.

As noted, the monitoring determines the retrofit savings in the program, but the second major objective of the monitoring program is to use the monitored data to identify additional measures that can be implemented to make the buildings operate even more efficiently. There are questions the program addresses.

- Is the retrofit working properly?

- Are the building systems working properly?

- Can changes in operation or maintenance lower operating costs?

Determining the answers to these questions requires a thorough understanding of the data collected and of the building and systems from which the data are collected. While the audit reports and site description information are very useful in developing an understanding of the building, a crucial part of the process is meetings and discussions with the facility engineer and building operators. Furthermore, if operation and maintenance measures are identified, the cooperation of the facility engineer and building operator is essential before any operational savings can be realized. Part of the communications process is transmittal of the data collected from the building to the operators in a format they can easily understand. Traditional engineering reports and papers are not current enough to be useful, and the format and language would typically obscure key information from most operators. Out of necessity, we have developed several forms of largely graphical reporting that are used with the facility engineers and operators of the buildings being monitored. The three forms described in the next section are 1) monthly energy consumption reports, 2) computer filters of the data with browsing software, and 3) weekly inspection plots. All three of these reporting forms are also used by program staff, building operators, facility engineers, and program managers for a variety of other purposes.

\subsubsection{Monthly Energy Consumption Reports}

A six-page energy consumption report is sent monthly to each facility monitored. This report contains two pages of tables and text and four pages with graphs of consumption data for the previous month. 
The first page of the report provides a concise summary of current energy consumption retrofit savings and a comments section. Figure 3.8 shows the first page of the August 1993 report for a $324,000 \mathrm{ft}^{2}\left(30,100-\mathrm{m}^{2}\right)$ engineering center with a dual-duct VAV retrofit that became operational during March of 1991. The report shows that the building uses electricity, chilled water, and hot water. All three are supplied from a central plant and were not metered at the building until data acquisition equipment was installed to acquire pre-retrofit data. Peak 60-minute electricity demand is reported instead of the standard 15-minute demand, because 60 minutes is the integration period for the data collected. The original report contains the names, addresses, and phone numbers of individuals at the facility who can be contacted regarding unusual data, building schedules, etc., and the name of a person with the monitoring project to whom questions about this report can be directed. The retrofit seems to be working well although the savings are lower than projected by the audit report. The comments section provides individualized feedback to the agency and building operators on items noted by the project staff. For example, savings were also observed during the construction period. Total measured savings of \$411,225 have accrued as of August 1993.

The second page of the report plots daily chilled-water (or other cooling energy) consumption as a function of daily average dry-bulb temperature and hot water (or other heating energy) as a function of average dry-bulb temperature. Figure 3.9 shows an example taken from the August report (shown in Figure 3.8) for the engineering center. Note that the consumption is plotted using $\mathrm{M}, \mathrm{T}, \mathrm{W}, \mathrm{H}, \mathrm{F}, \mathrm{S}, \mathrm{U}$ to indicate days of the week for the current month, with the January-February consumption plotted using dots, and the consumption for August of 1992 plotted as “ + ". This helps identify changes in consumption patterns. The use of letters also helps identify outliers and determine whether specific events occurred on weekdays, weekends, holidays, etc.

The third page of the report gives time series plots of the hourly chilled water and hot water consumption for the month. Figure 3.10 is an example taken from the August report. The right hand axes on page 2,3 and 4 were included to serve as a figure of merit that can be used to compare hourly or daily use across different sites. Data after August 17,1993 are missing due to a hardware problem - one of the reasons why it is important to inspect, identify, and remedy problems as soon as possible.

The top half of the fourth page of the report shows a time series plot of the hourly electricity consumption for the building and also shows submetered electricity consumption (Figure 3.11). The whole-building consumption (top line) shows welldefined weekday/weekend differences. Submetered data are shown for the air handlers, super computer room, and a derived channel for the lights and receptacle loads. The air handler electricity use clearly shows the VAV. The bottom half of page four shows the local ambient dry-bulb temperature and relative humidity. The two-week break between semesters from August $17-28$ is clearly visible in the electricity data on page 4 (Figure 3.11). 
Page five (Figure 3.12) gives two views of a three-dimensional surface plot of the whole-building electricity consumption taken from the August consumption report. This figure provides more detail on daily patterns and day-to-day variation than is readily apparent in the two-dimensional plots given on page 4 of the reports. Obviously, the whole-building electricity data are missing from July $1-15$. The "canyons" show the typical weekend drop in consumption. The view in the top part of this figure tends to make unusually high consumption during any part of the period evident. The last page of the report provides a written summary of the building envelope construction characteristics, HVAC system(s), building use and HVAC schedules, lighting, and planned or installed retrofits and status. This page normally changes only when retrofits or schedules change.

\subsection{Data Exploration Software}

After the first consumption report is sent to the agency and operators, the agency contact person is called and a session is scheduled where personnel from the monitoring program meet with facility engineers and operating personnel to discuss the report format, answer questions, and obtain feedback on the report, including suggestions for improvements, etc. During these meetings there are inevitably requests for different graphs that are not included in the report.

To accommodate these requests a computer loaded with data exploration software (LC 1990) is taken to these meetings. This software was originally developed to help organize and examine meteorological data but is capable of handling most kinds of time series and geographically distributed data. It provides multiple window viewing and zoom-in capabilities by utilizing a cross-indexed, complied data base structure, as shown in Figure 3.13. All data collected from each building monitored at the site are loaded in compiled form for browsing with the software.

The software package cost is comparable to popular word processors, and facilities personnel are encouraged to purchase a copy if they are interested in exploring the data in greater detail than presented in the monthly reports. For these sites, an updated, compiled file of the building data is sent with the consumption report each month for this type of data exploration.

\subsection{Summary of LoanSTAR Data Management}

In summary, the LoanSTAR MAP data management includes five major functions: polling the data from the recorders, processing the data from all the various sites into a standard format, controlling data quality, generating reports, and retrieving data for analysis. Given the large volume of measured data and the critical nature of the analyses performed on those data, the task of controlling data quality is critical. Techniques developed by LoanSTAR to ensure data integrity can be applied directly to any program. 
The principal techniques for providing data verification and validation include:
1) review of polling logs
2) recorder parameter set revision control
3) automated initial verification
4) automated handling of missing records
5) generation and review of inspection plots
6) analytical review of data
7) controlled data release
8) marking, filling and reconditioning in database.

\subsubsection{Review of Polling Logs}

LoanSTAR sites are instrumented with Synergistics C-180 series data recorders. In 1992 the ESL developed specialized software (POLLC180) for automatically polling these recorders. The POLLC180 system calls, connects, and extracts time-series records (TSRs) with minimal human intervention. As it processes a set of recorders, POLLC180 writes an activity log. Each week the data polling administrator examines the log files generated by the polling system for the preceding period. Examination of this log identifies dead loggers and some types of sensor problems. The ESL is also collecting data for several other sites from Campbell Scientific data recorders and is working on an equivalent of POLLC180 for use with them as well as other loggers. Routines have also been developed for converting EMCS data into LoanSTAR format (Claridge, et al 1991)

\subsubsection{Recorder Parameter Set Revision Control}

The key to decoding information stored in each data recorder is the "parameter set" containing information such as channel types and scaling factors. The parameter set is initially defined by the site installation team, but changes over the life of the experiment. When sensors are changed, or other equipment is modified, repaired, or recalibrated, . there is usually a change to the parameter set. One lesson of the LoanSTAR program is that data recovery and analysis requires an iron-clad historical record of every parameter set affecting each data set. For any program, a rigorous policy of retaining each parameter set and pertinent information must be implemented. A software tool such as the Revision Control System (RCS) is an excellent example of an automated procedure for controlling such information.

\subsubsection{Automated Initial Verification}

After the operator has verified reception of raw data by the automated polling system, the raw data are uploaded to the main server for further manipulation. These operations transform the raw data into table entries in the relational database management system (RDBMS). The transformation extracts the data from the raw file and syntactically translates them into a format appropriate for the RDBMS. Site and channel-specific rules from the channel-ID table (CHIDS) in the RDBMS assist in the translation process. These rules include elementary verification procedures, such as "reasonableness" range checks (Ex: Relative humidity of $110 \%$ is "unreasonable") and component-sums (Ex: whole- 
building electric should equal the sum of all the electric subsystems). Suspicious records are flagged in the log for handling by the operator.

\subsubsection{Automated Handling of Missing Records}

It is not uncommon for a data recorder to lose power in the field. Battery backups support the internal memory during an outage but the logger does not collect any new data until the power is restored. This causes gaps to exist in the data set. Gaps cause problems with merging weather data and certain types of analysis, so LoanSTAR implemented a protocol whereby missing records are filled into the data with the -99 flag (Invalid Data) for all data values. Rather than storing "missing" data into the RDBMS (which would waste space), ESL techniques actually fill the missing records on demand during a data extract. While the concepts of scanning and replacing missing data are easy to understand, a general program must account for day boundaries, month boundaries, year boundaries, leap year boundaries, daylight savings, and several other special conditions. Any program will directly benefit from LoanSTAR's development work in this area.

\subsubsection{Generation and Review of Inspection Plots}

The final phase of the raw data translation process is the preparation of inspection plots. After all data has been initially verified through range-checks and other automated procedures and missing data has been filled, inspection plots are prepared according to site-specific procedures stored in the RDBMS. In the LoanSTAR methodology, three different kinds of plots are created: time series readings of all channels, scatter plots of some channels versus temperature, and scatter plots of LoanSTAR weather data versus nearby National Weather Service data. Samples of these plots as used in the LoanSTAR Inspection Plot Notebook (IPN) are shown in Figures 3.6, 3.7, 10.2, 10.3, and 10.7.

The plots allow possible problems with the data to be identified by visual checks. Because of the long stream of filters that the data are subjected to prior to the production of the plots, any potential problems are usually brought to the attention of the Database Manager, who determines if a processing problem could have corrupted the data. If this is not the case, then a genuine data problem may have occurred (for example, a metering problem), and an appropriate message is forwarded to the field engineers. Archives of all comments are also kept in the relational data base.

\subsubsection{Controlled Data Release}

Maintaining the integrity of released data is one of the main goals of the LoanSTAR program. In order to meet this need the ESL developed a procedure for controlling and tracking all data releases. All distributed data are extracted as needed from the RDBMS it is important to note that the powerful database developed by the ESL allows all historical program data to be maintained on-line, ready to meet any analysis or technology-transfer requirement.

Data are extracted into columnar format using the program "GETDATC", which writes a complete log of every request, (including site, channels, time ranges, 
identification of the requester). If any inaccuracy affecting that set of data is later detected and resolved, the log can be used to track down and update the recipients of any updated data.

The importance of this facility is that it resolves the issue of "Well, MY copy of the data clearly shows that ..." Requesters are encouraged to obtain new copies of data as needed for analysis, and not to keep static local copies. Since the ESL's RDBMS is network accessible via the NSF Internet, technology transfer and analysis requests can be filled real-time to almost anywhere in the world.

\subsubsection{Marking, Filling and Reconditioning In Database}

The ESL's database design partitions the data -- "original", as received in the initial load, and "reconditioned", updated to allow for any needed adjustments, such as rescaling due to sensor drift. Unrecoverable data sets (perhaps due to a sensor failure) can be reconditioned as "bad" (-99). Data requests are filled by supplying reconditioned data for site-channel-date ranges that have been reconditioned, and original data for ranges that have not been reconditioned. This partitioning provides a critical validation aid -- the original data, as well as log of all reconditioning steps, is available at all times for further analysis. The ESL's advanced system eliminates much of this difficulty of maintaining accurate records. No system relying on static updates (including most PC-based database implementations) can deliver information so accurately and completely.

The "reconditioning" technique also allows for the inclusion of "synthesized" data. Missing pieces of data are synthesized as necessary by feeding existing data into the appropriate software including the EModel software (Kissock 1993), which then derives a data set representing the building's expected behavior during the period of missing data. Synthesized data can provide for certain types of savings analyses (or graphing) that require contiguous data.

In the next section, the analysis of the retrofit measures is discussed. The focus of the section includes a description of why we monitored what we did and how we intended to analyze it.

In section 10.2 of the appendix additional helpful hints are provided about polling and retrieving data, including special processing required for data obtained from Synergistics loggers. Specific routines are also presented for producing the inspection plots, and special purpose 3-D plots. 
Figure 3.1: Electrical and thermal monitoring diagram for a typical LoanSTAR site. This figure shows the electrical and thermal monitoring diagram for the UT Austin site. The upper diagram is the electrical monitoring diagram, and the lower diagram is the thermal monitoring diagram.

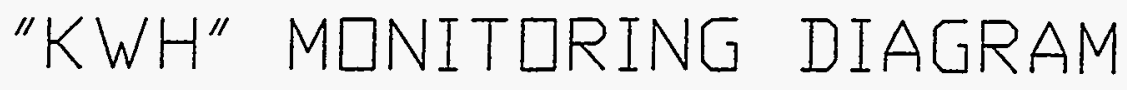

LEGEND

$K=K W H$ CHANNEL

$A=A N A L D G$ CHANNEL

$D=$ DIGITAL CHANNEL

PC=PUMPED CDNDENSATE

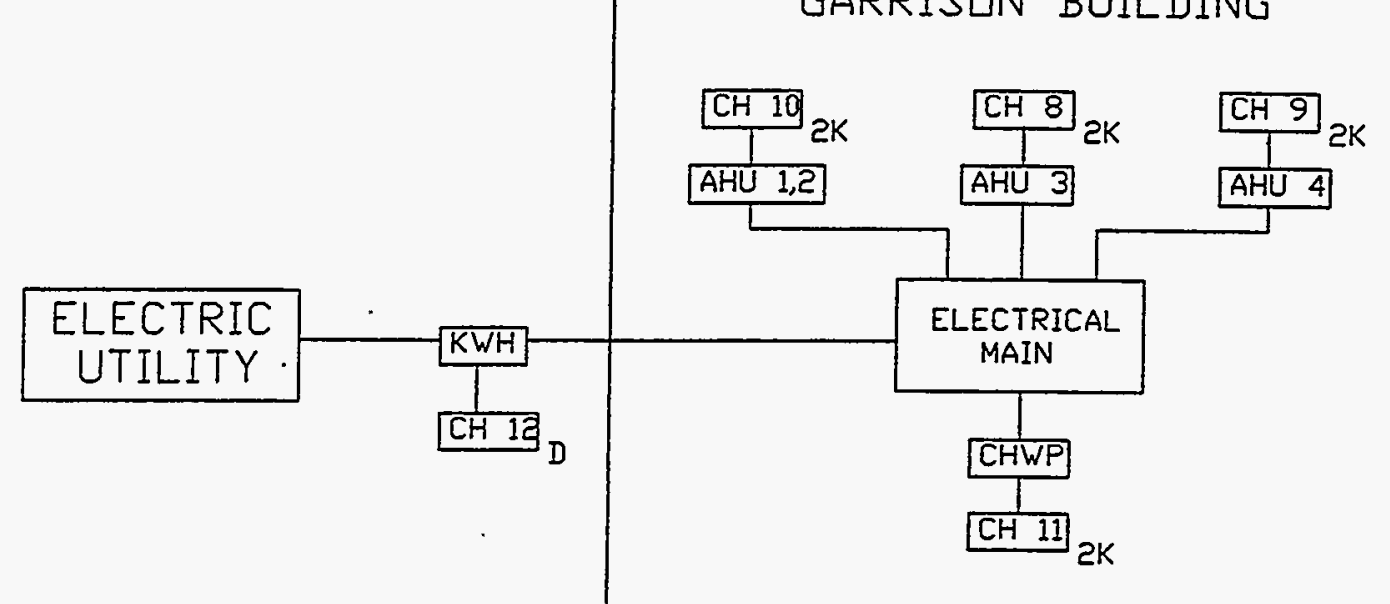

\section{THERMAL MUNITURING DIAGRAM}

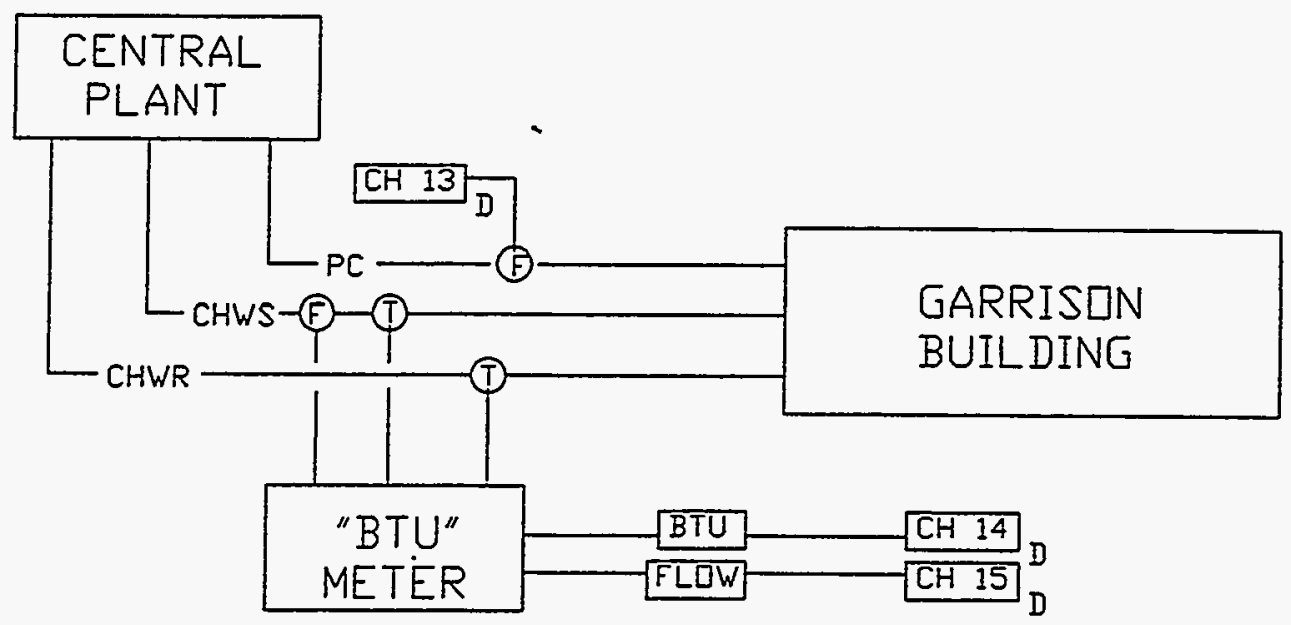

UT AUSTIN-GARRISDN BLDG 
Figure 3.2: Diagram of an example logger set-up. This diagram illustrates an example logger which is set up to measure one electricity channel, one digital thermal Btu channel and one digital flow channel, one analog temperature channel, and one humidity channel.

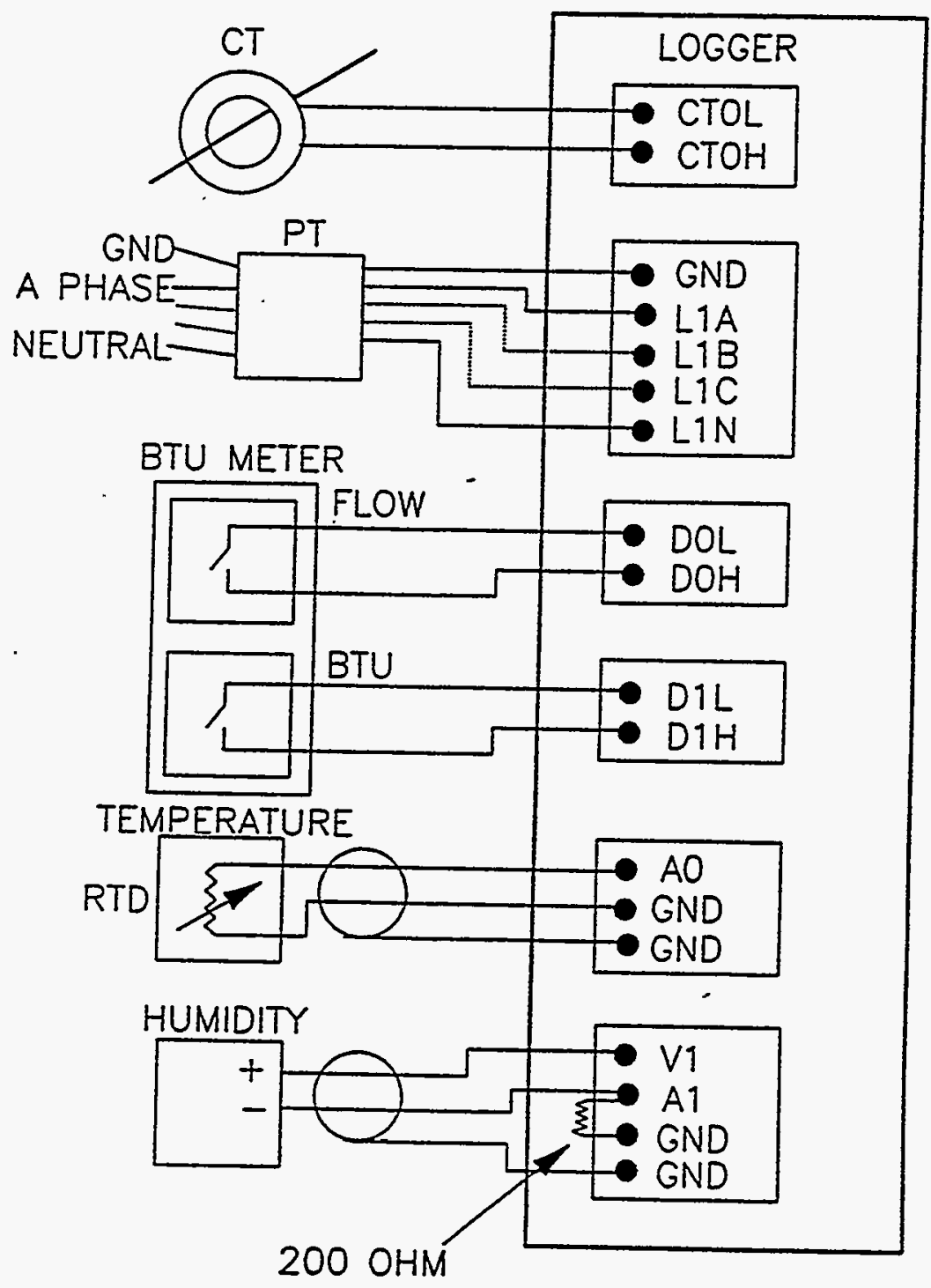


Figure 3.3: Typical logger set-up to measure three phase whole-building electricity. This figure illustrates how three phase electricity is monitored with the Synergistics logger (Photocopied with permission: Synergistics 1990).

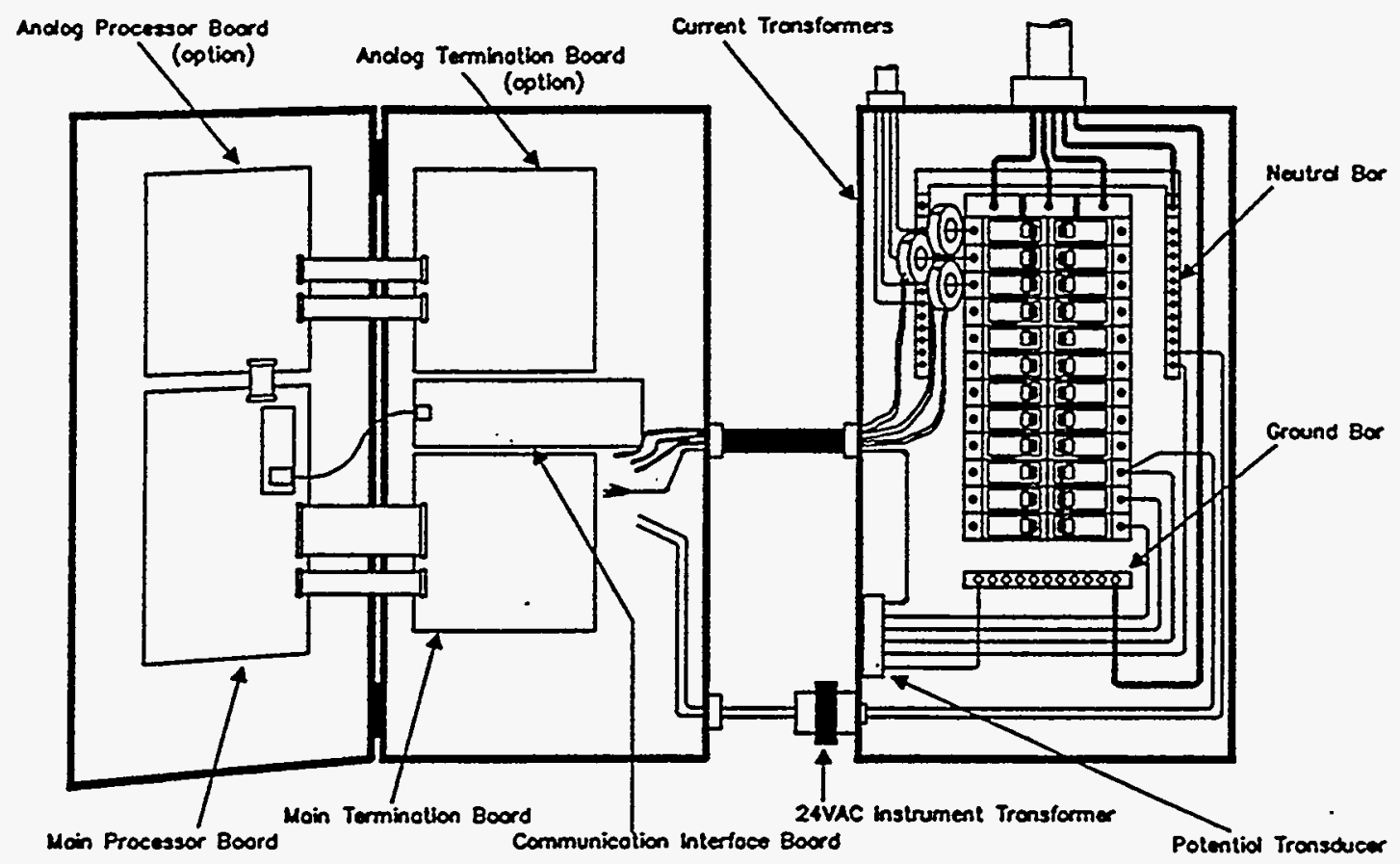


Figure 3.4: Typical thermal energy meter set-up. This figure shows a detail of how thermal energy monitoring of chilled water is achieved with the use of a Btu meter, two temperature probes, and a flow meter.

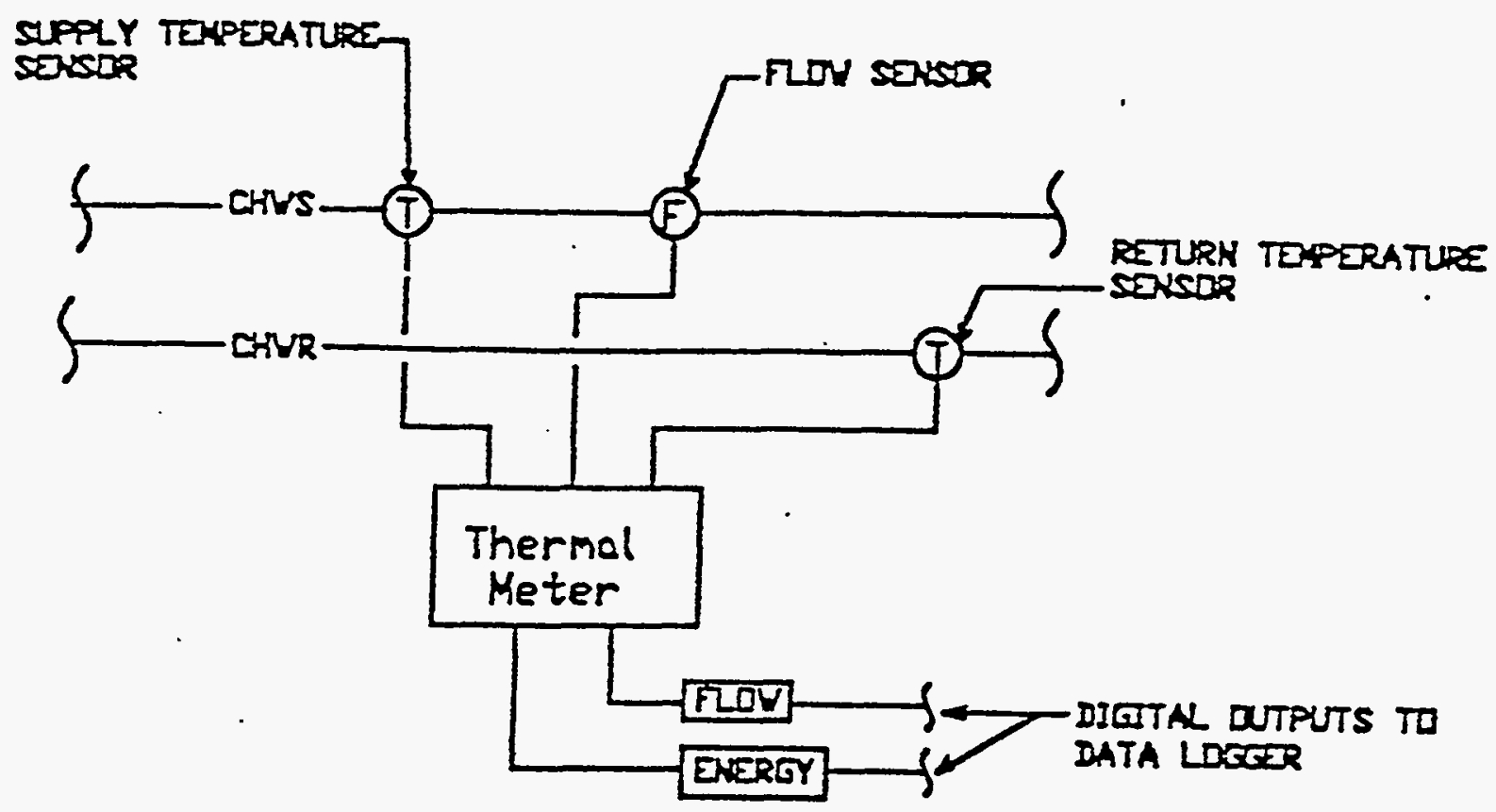


Figure 3.5: Typical hot-tap flow meter installation. This figure shows a typical hottap flow meter installation used in the LoanSTAR program. Hot-tap flow meters were chosen to avoid having to shut down the chilled water or hot water system during installation.

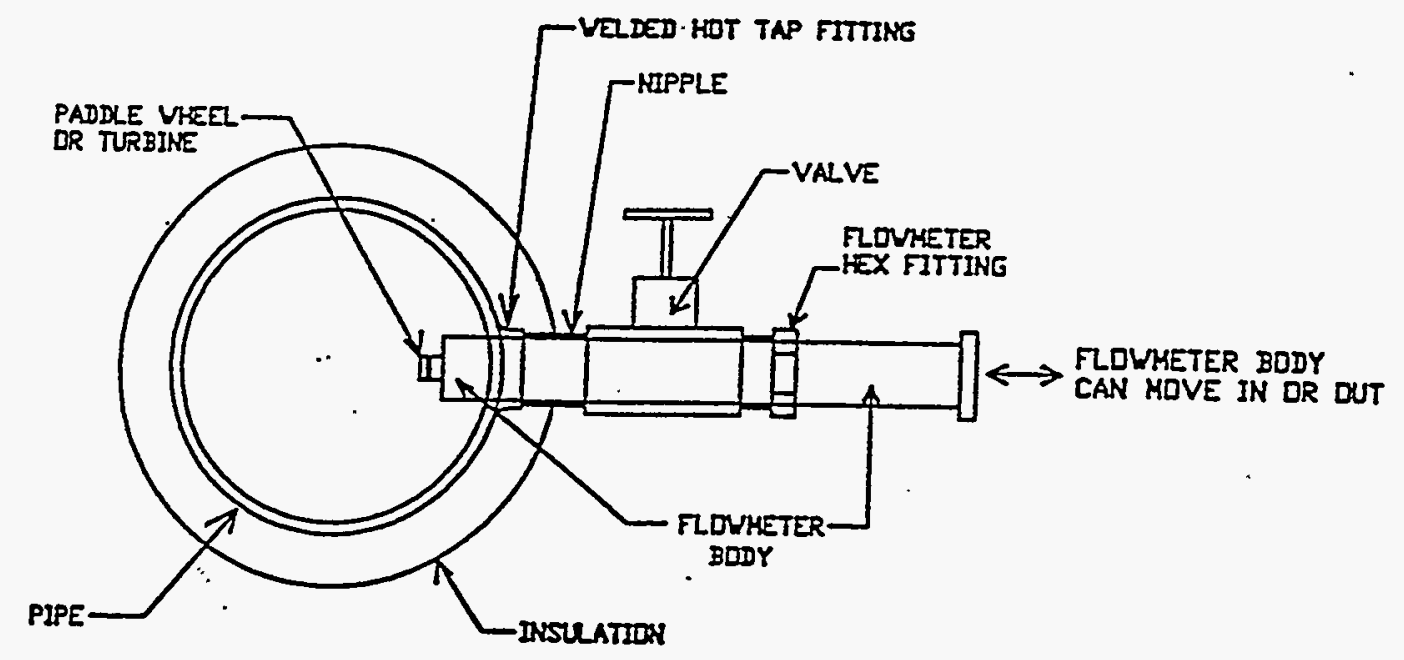


Figure 3.6: Weather cross-plots of LoanSTAR vs. National Weather Service. This figures shows cross-pots of weather data from the LoanSTAR sites (y-axis) vs. the National Weather Service (NWS, $x$-axis) for Dallas/Ft. Worth (DFW), Houston International Airport (IAH), Austin (AUS), College Station (CLL), Galveston (GLS), Harlingen (HRL), and San Antonio (SAT). Cross plots of dry-bulb temperature (DB) occupy the left side of the figure, and cross plots of specific humidity occupy the right side of the figure (Spec. Hum.).
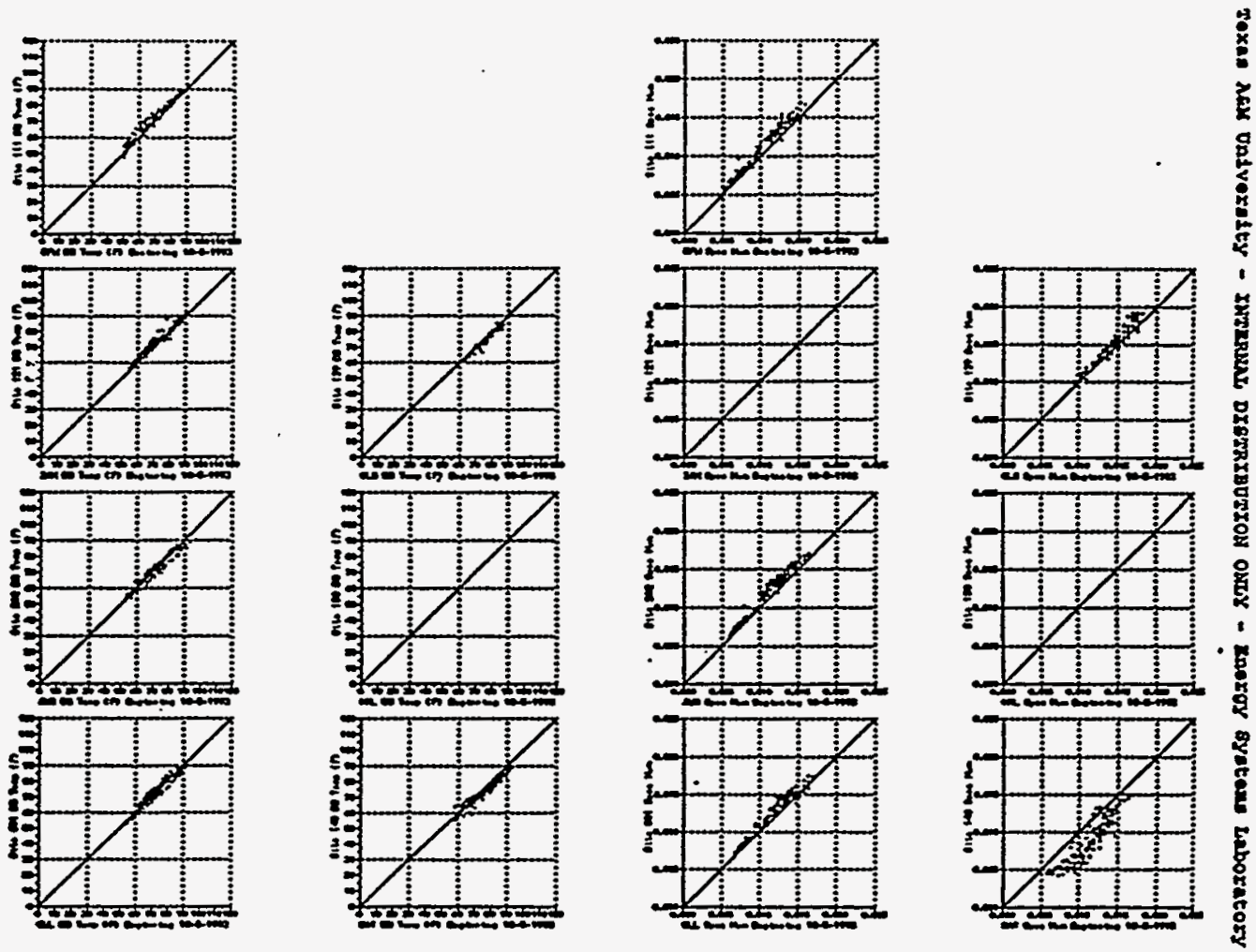
Figure 3.7: Typical weekly inspection plot for a LoanSTAR site. This figure shows the summary page from the weekly inspection plot of the Zachry Engineering Center (Site 001).
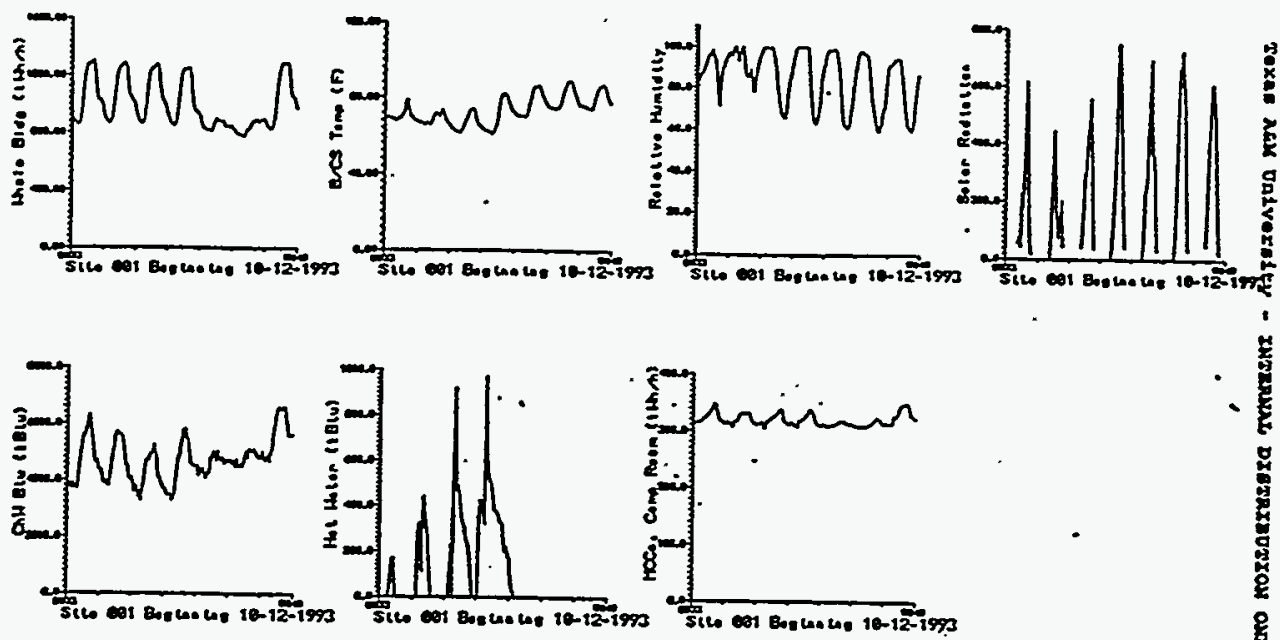

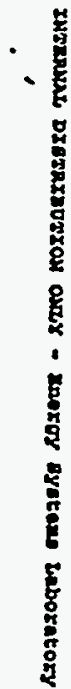
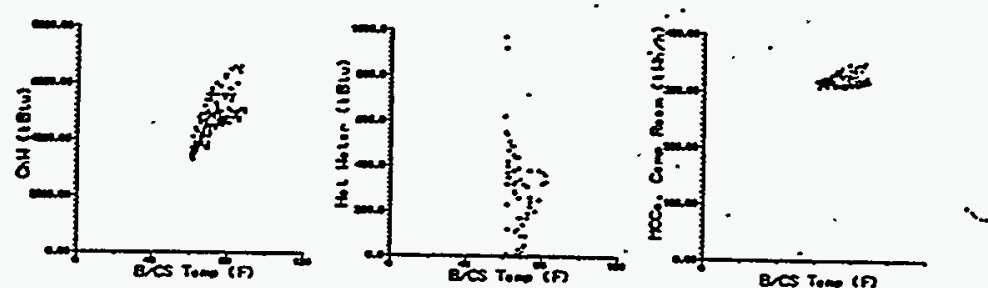
Figure 3.8: Summary page (page 1) from the August 1993 energy consumption report for the Zachry engineering center at Texas A\&M University.

\section{Zachry Engineering Center \\ Texas A\&M University \\ 324,400 square feet}

Site Contact

Mr. Charles Darnell, Jr.

Physical Plant Administration

Texas A\&M University

(409)-845-5318

Gene Stetrart

(409)-845-5511
LoanSTAR Metering Contact

Aamer Athar

053D WERC

Teras AleM University

College Station, TX 77843-3123

(409)-845-9213

\begin{tabular}{|c|c|c|c|c|}
\hline & \multicolumn{3}{|c|}{ Summary of Energy Consumption } & \\
\hline Electrieity & $\begin{array}{l}\text { Measured Use } \\
706194 \mathrm{kWh}\end{array}$ & $\begin{array}{l}\% \text { hours reported } \\
100\end{array}$ & $\begin{array}{l}\text { Unit Cost } \\
\$ 0.02788\end{array}$ & $\begin{array}{l}\text { Estimsted Cost } \\
\$ 19689\end{array}$ \\
\hline Peat 60 Minute Demand & $1301 \mathrm{~kW}$ & 100 & - & 020000 \\
\hline Chilled Water & 4345.9 MMBtu & 100 & $\$ 4.670$ & $\$ 20295$ \\
\hline Hot Water & 87.0 MMBtL & 53 & $\$ 4.750$ & $\$ 413$ \\
\hline
\end{tabular}

\begin{tabular}{|c|c|c|c|c|}
\hline \multicolumn{5}{|c|}{ Monthly Retrofit Savings } \\
\hline & \multicolumn{2}{|c|}{ Measured Savings } & \multicolumn{2}{|c|}{ Audit Estimated Savings } \\
\hline Electricity (kWh) & 118164 & $\$ 3294$ & 162730 & $\$ 4524$ \\
\hline Chilled Water (MMBtr) & 682 & $\$ 3185$ & 2215 & $\$ 10344$ \\
\hline Cond./E.W. (MMBta) & 114 & $\$ 542$ & 956 & $\$ 4541$ \\
\hline $\begin{array}{l}\text { Monthly Total } \\
\text { Total to Date" }\end{array}$ & (34 months) & $\begin{array}{r}\$ 7021 \\
\$ 411225\end{array}$ & (30 months) & $\begin{array}{r}\$ 19409 \\
\$ 582268\end{array}$ \\
\hline
\end{tabular}

-Measured savings inciude construction period. Andit estimated savings do not.

\section{Comments}

Hot water consumption data are missing from 8-17-93 to 8-31-93 due to a hardware problem.

Texas A\&M University - August 1993

\begin{tabular}{|c|c|c|}
\hline 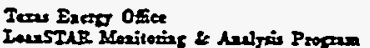 & Monthiy Bnergy Consumption Report(C) & 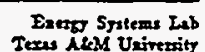 \\
\hline
\end{tabular}


Figure 3.9: Page 2 of the LoanSTAR MECR contains cross plots of daily thermal energy use vs. average daily temperature with the current month annotated as shown.
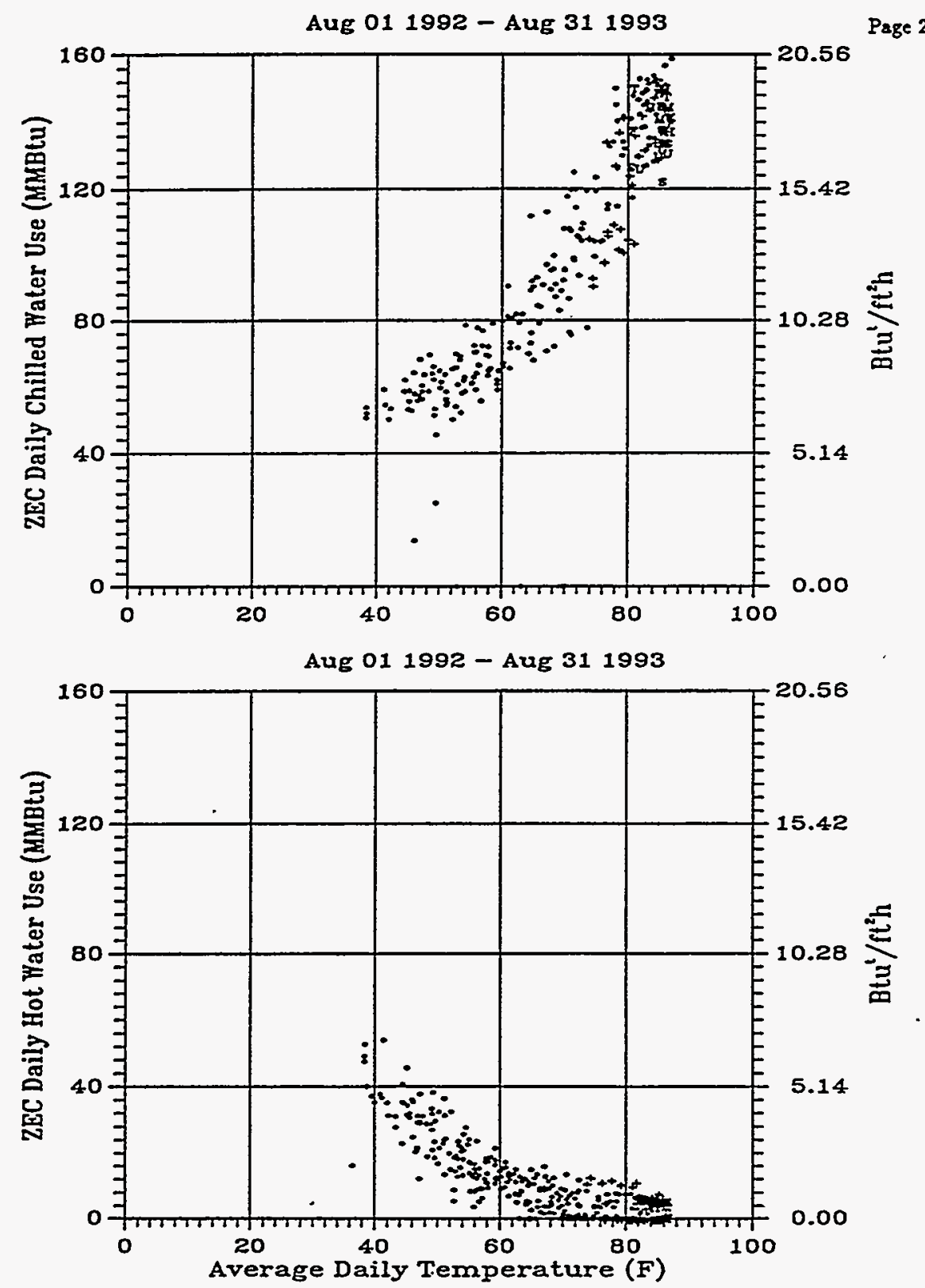

Dats points for the eurrent month are shown as letters. Monday through Sundey are represented as M,T,W,F,F,S, 0 .

$$
\text { Points from this month lest year are shown as }+ \text {. }
$$
All other points are shown as".

Zachry Engineering Center - Texas A\&M University - August 1993

Teas Exerg Ofiee

Tans Exerg Oriee

Monthly Energy Consumption Report (C)

Vertion 2.2

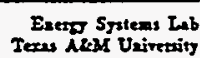


Figure 3.10: Page 3 of the LoanSTAR MECR contains time series traces of thermal energy use, typically chilled water and hot water or steam use.

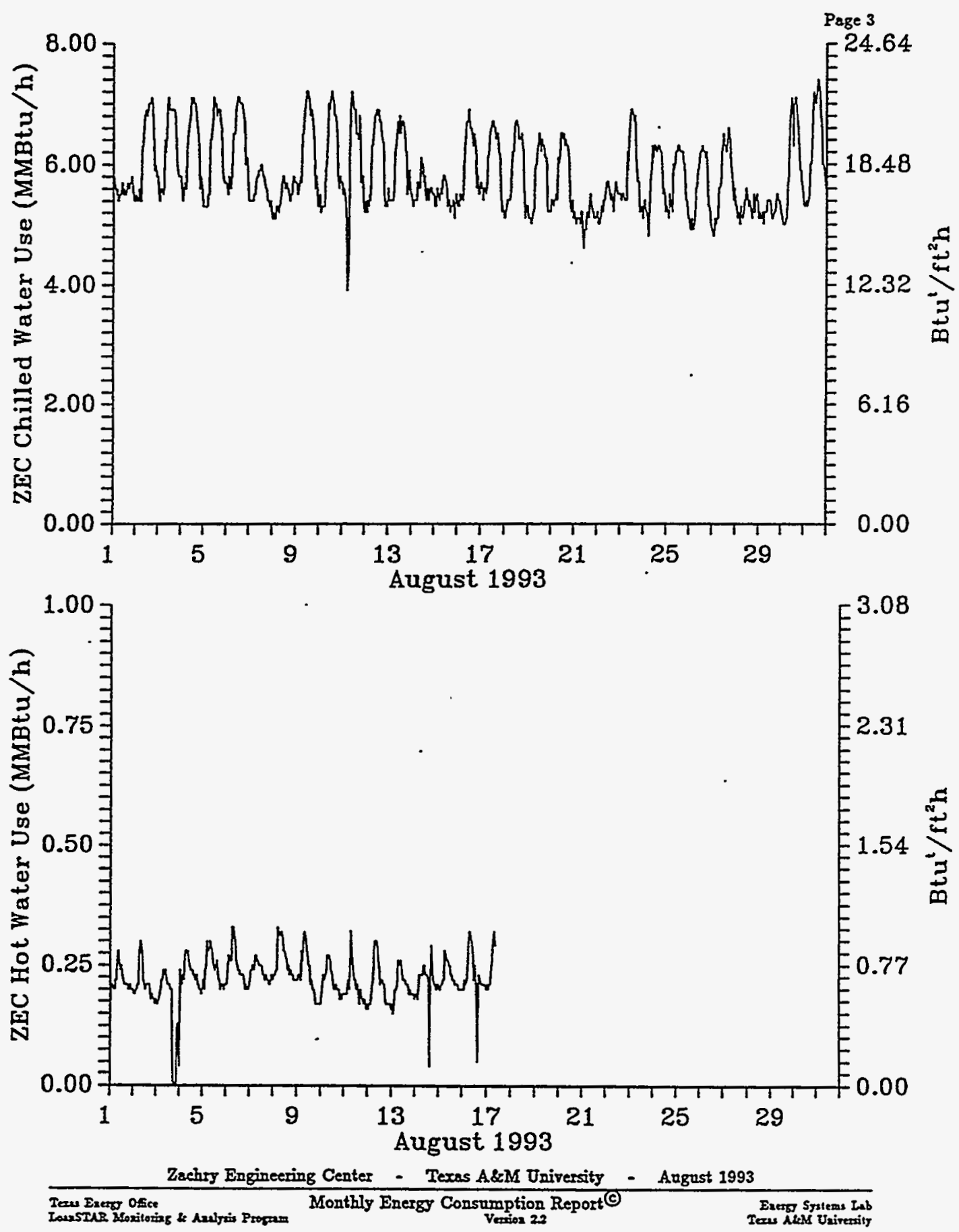


Figure 3.11: Page 4 of the LoanSTAR MECR contains time series traces of electricity use and environmental data. In the upper plot, whole-building electricity is shown along with sub-metered data for lights and equipment, motor control centers, and a central computing facility. The lower plot is a time series trace of hourly dry-bulb temperature and humidity recorded on the roof of the building.

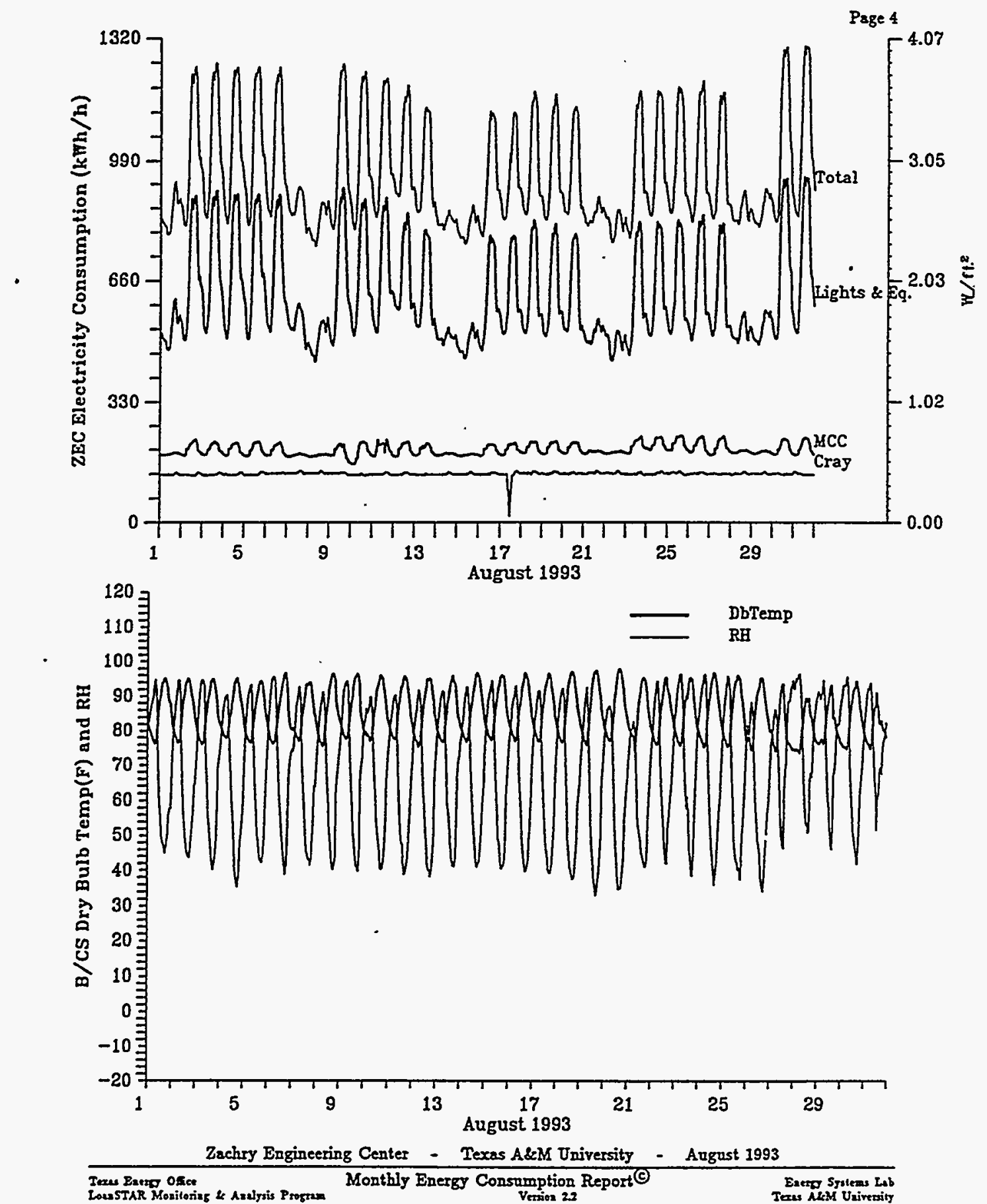


Figure 3.12: Page 5 of the LoanSTAR MECR contains two views of 3-D plots of whole-building electricity.

Page 5
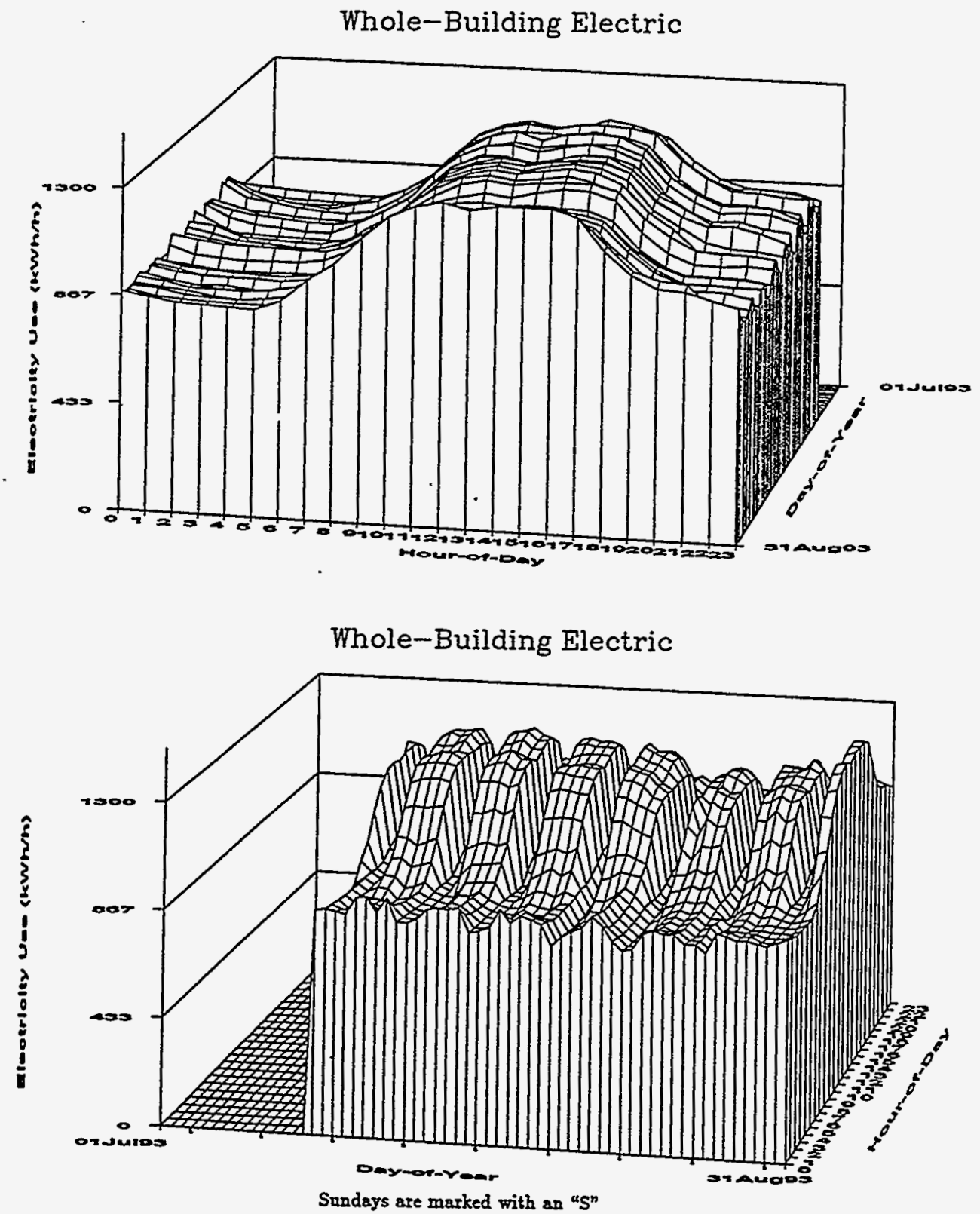

Sundays are marked with an " $\mathrm{S}$ "

Zachry Engineering Center - Texas A\&M University - August 1993

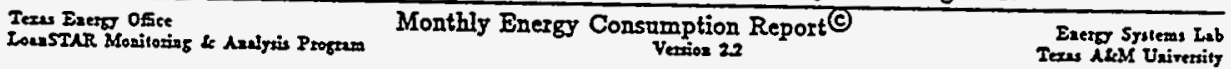


Figure 3.13: LoanSTAR browsing software. This figure shows a multi-window view from the Voyager software package that is used for browsing through LoanSTAR data.

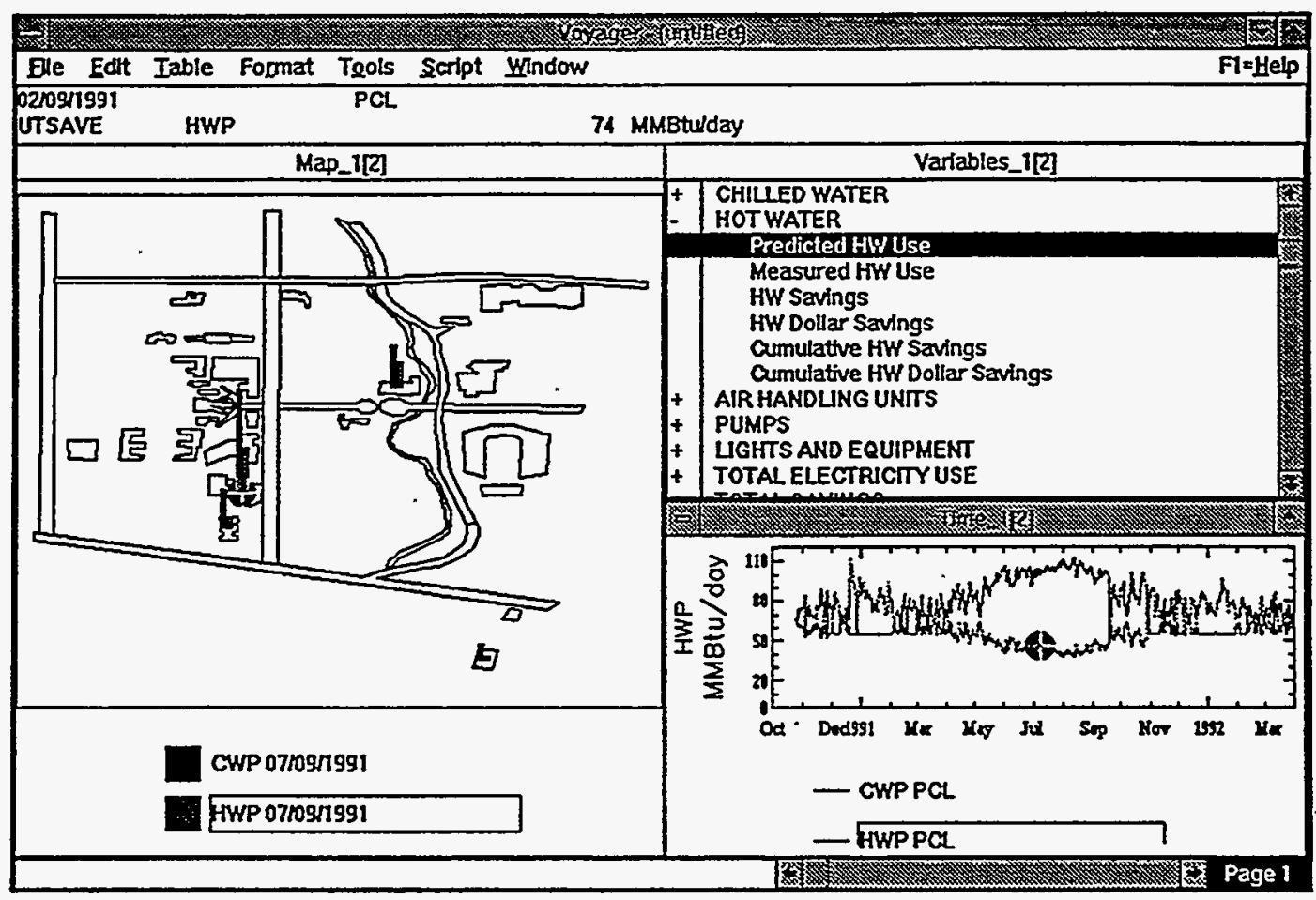




\subsection{CHARACTERIZATION OF THE ANALYSIS OF RETROFIT MEASURES}

\subsection{Background}

Let us start by reiterating the major objectives of the Monitoring and Analysis Program (MAP) of LoanSTAR. These are to:

(a) verify energy and dollar savings of the retrofits,

(b) reduce energy costs by identifying operational and maintenance improvements at monitored facilities,

(c) improve retrofit selection in future rounds of the LoanSTAR program, and

(d) provide a detailed data base of energy use in commercia/institutional buildings

located in Texas.

The scope of this chapter (as well as that of this report) is limited to objective (a) above. Though the loan repayment schedule is based on the energy savings estimated by the energy audits, the purpose of objective (a) is primarily to assure retrofit effectiveness, i.e. to determine whether the actual or measured savings from the retrofits are in effect as large as those estimated during the audit process. This constant verification can avoid expensive oversights and ensure the proper operation of the building after the retrofit stage is complete. Section 4.2 briefly describes the types of energy retrofits performed in the LoanSTAR program and discusses monitoring requirements to properly identify associated energy savings. Section 4.3 presents the methodology by which retrofit energy savings in the framework of the Texas LoanSTAR project are estimated. Other important allied issues are addressed in section 4.4.

\subsection{Monitoring Requirements - Why did we monitor what we did?}

\subsubsection{Types of Retrofits}

Savings monitoring requirements for any site depend upon the type of energy conservation retrofits and the level of audit verification required as described in sections 2 and 3. The projects funded by LoanSTAR primarily include retrofits to lighting, HVAC systems, electric motors, energy management control systems (EMCS), boilers, energy recovery systems, thermal storage and co-generation systems. As of April 1993, energy savings in 24 LoanSTAR sites representing 38 buildings are being reported, while monitoring is underway in 69 sites representing 199 buildings. From Figure 2.2 presented earlier, we note that the majority of monitored buildings are institutional buildings, while a few school districts and thermal energy plants have also come on-line. The buildings located on university campuses vary in size from $49,000 \mathrm{ft}^{2}$ to $484,000 \mathrm{ft}^{2}$ and house classrooms, offices, laboratories, computer facilities, auditoriums, workshops and a major campus library. Such buildings are provided with electricity, chilled water, and steam (or hot water) from centralized campus utility plants that are separate from the buildings. 
The types of retrofits in all monitored buildings, the estimated implementation costs, completion status, and cost savings that can be realized in dollars, in percent of total cost and as simple payback, were previously discussed in Table 2.1. These values are audit estimated values and their comparison with measured savings is discussed in section 5.1. The primary retrofit in all these buildings was the conversion of constant volume air handling units to variable air volume air handling units. The resulting energy savings in whole-building chilled water use, whole-building hot water use, and electricity use of air handlers and chilled water pumps are individually estimated and reported. We note from Table 2.1 that lighting and EMCS retrofits are the second most important types of retrofits.

\subsubsection{Criteria}

The general philosophy of monitoring design in the framework of LoanSTAR is described in this section. Depending on the number of channels being monitored, ensuring the quality of the data may be a formidable task. Meters must be correctly calibrated when installed and recalibrated at frequent intervals to avoid "drift". Detecting bad data can also be difficult. Though certain quality control measures can be automated, proper control requires an inordinate amount of analyst time. Given the financial constraints of the MAP (only 3\% of the retrofit cost can be used for monitoring), the objectives of LoanSTAR are better served by taking fewer channels of good data at the whole-building level rather than at the disaggregated end-use level.

To provide the best measure of energy savings, the energy use of each type of equipment being retrofitted should be separately monitored. For example, if constant air volume (CAV) air handlers are being converted to variable air volume (VAV), the total electricity used by the air-handlers should be metered. This can often be accomplished by metering the electricity used by the main distribution panel (often called a motor-control center) which distributes electricity to all of the air-handlers in the building.

If the energy savings generated by lighting retrofits are to be exactly measured, then all of the electrical feeds to the lighting fixtures must be identified and metered. In practice, this is often difficult and expensive because lighting circuits are usually distributed throughout the building. A less expensive method is to meter the wholebuilding electricity use and the air-handler electricity use separately. The difference between the two channels (provided no large appliances are situated outside the building, something which is easily verified) is the lighting and equipment (LE) use. Comparing LE use immediately before and after the retrofit will yield a good estimate of the electricity saved by the retrofit. Over a long period of time, however, this estimate of savings may be less accurate as other electrical equipment may be added to or removed from the building.

If a retrofit is expected to reduce the heating and cooling energy use, these energy uses should also be metered. In buildings where heating and cooling are generated onsite, metering the energy supplied to the heating (say, in the form of natural gas volume) 
or the cooling (say, electricity in the case of a vapor compression chiller and natural gas in the case of an absorption chiller) equipment is adequate if similar operational strategies are maintained before and after the retrofit. If the building subscribes to district heating and/or cooling (like institutional buildings do) then whole-building heating and/or cooling can be measured separately by individually metering heating and cooling energy as they enter and leave the building. This involves measuring the fluid flow rate AND the temperature difference between both streams. It must be stressed that both these quantities should be monitored and retained as separate channels because this allows for corrections (such as flow rate) to be made at a later time when manufacturer calibration factors are found to have gone astray. This occurred in the LoanSTAR program (Haberl et al., 1992) and hence the absolute need to retain both these channels.

Typically, the following channels are used during retrofit savings calculations: chilled water use, hot water use, whole-building electricity, air handler electricity use, chilled water pump electricity use, and climatic variables hourly averaged (ambient drybulb temperature, relative humidity, wind speed and global horizontal solar radiation).

\subsection{Analysis Approach - How did we intend to calculate savings?}

\subsubsection{Overview}

One way of estimating retrofit savings is to compare directly the unadjusted preretrofit energy use to the post-retrofit energy use. Though this method may yield a firstorder evaluation, it has generally been found to be too simplistic because the effect of the retrofit on energy use may be largely or entirely masked by changes between the pre- and the post-retrofit periods of certain important parameters influencing energy use ( the most important often being the climatic variables and the building operating mode). Consequently, in order to incorporate the effects of such changes into the energy savings calculation, a theoretical model capable of predicting the energy use of the building under pre-retrofit operation needs to be developed. Though pre-retrofit utility bills may be a source for such a model, most of the institutional LoanSTAR buildings do not have such data. Consequently the pre-retrofit monitored data provides both a base-line and a source of developing the model.

Modeling approaches can be grouped according to two generic types:

(A) the regression model approach, sub-divided into two categories:11

(A1) models using billing OR monitored data (Fels, 1986; Claridge et al., 1990;

Kissock et al., 1992), which are by far the most widely used;

(A2) models using a mix of billing AND monitored data (Liu et al., 1992) whose need arose in certain of our smaller LoanSTAR buildings;

(B) the calibrated engineering model approach, which can again be sub-divided into two categories:

${ }^{11}$ Some analysts may prefer classifying regression models according to either time scale (monthly, daily, hourly), model type (simple or multiple) or model functional form (linear, change point, quadratic, spline). 
(B1) detailed simulation codes like DOE-2 (Hsieh et al., 1991; Bronson et al., 1992); and

(B2) simplified HVAC systems models (Katipamula and Claridge, 1993).

Whenever appropriate, model development using the regression approach is used because it is generally the least demanding in effort and user-expertise, yields adequate results and permits uncertainty associated with savings to be quantified using accepted statistical procedures. The calibrated detailed simulation model approach is more tedious and requires knowledge of how the mechanical systems of the building are operated and a certain proficiency in using the particular building energy code. It is typically resorted to during analysis of monitored data for determining retrofit savings only when the quality or length of the data period is not adequate to enable proper regression model identification. The simplified model approach (developed until recently essentially for residential building energy use, Subbarao, 1988) falls between the two approaches both in the level of user-expertise and length of data period. This approach is described in section 4.4.3.

The Texas LoanSTAR program requires that data acquisition equipment to monitor building energy use be installed for a suitable period before the retrofits are carried out (Claridge et al., 1991) and remain in the building possibly throughout the retrofit life. Consequently, estimates of the retrofit energy savings can be based on the regression model approach. There are, however, buildings for which, due to a variety of reasons, the pre-retrofit data are either too short or even entirely spurious. As discussed at more length in section 4.4.1, statistical models for weather related savings calculations based on fewer than about 3 months of data are usually unreliable. Only in such instances is the calibrated simplified systems model approach considered for use in the LoanSTAR program (Katipamula and Claridge, 1993). This approach has yet to reach a stage of maturity in methodology development where it can be used routinely and with confidence by people other than highly skilled analysts. Consequently, unless otherwise specified, the majority of the discussion that follows pertains to regression model approach.

\subsubsection{Savings Methodology}

The methodology currently used to report retrofit savings in LoanSTAR buildings basically involves the following steps (Kissock et al., 1992a, b):

(i) Identification of the pre-retrofit, construction, and post-retrofit periods This is done both from log books and inspection of the hourly time series plots of air handler electricity use. Changes in consumption patterns are very distinct during these three stages and consequently there is little ambiguity, as illustrated by Figure 4.1. In buildings with constant volume AHUs the pre-retrofit period, air-handler electricity use is almost constant, while electricity use behavior during the construction period is many times erratic. Finally, after the VAV retrofit is complete, air-handler use follows a regular but varying pattern depending upon the building heating and cooling loads. 
(ii) Preliminary data handling The entire data set from each building is usually comprised of hourly averaged or hourly summed observations. In most cases these channels are screened and converted into daily averaged data. This is the time scale presumed in all subsequent steps because of the following reasons: 1) it retains the resolution required to observe variation in energy use with climatic conditions and building operating mode; 2) it avoids the complexity introduced by the thermal mass effects of the building shell and the strong diurnal scheduling patterns of lighting and equipment (LE); and 3) it significantly reduces the amount of data to be manipulated and interpreted as compared to hourly data, while remaining large enough for robust statistical analysis. In those special cases where daily data do not provide sufficient detail, hourly data are retained.

(iii) Regression model identification In order to measure savings statistical models of preretrofit energy use of each energy type influenced by the retrofit are developed. Typically, this would include daily cooling energy use, heating energy use, and electricity use. The functional form of each model is determined both by our physical understanding of how a particular type of energy use should vary with time and also by the equipment operating schedules. For example, electricity use of a CAV air handler is independent of weather conditions, but can vary from a weekday to weekend if on/off schedules are implemented. Therefore, this use is normally modeled as the mean electricity use during each type of operational period. LE use can also be reasonably modeled by mean models, one for the weekday and one for weekends. Classical techniques (such as a t-test) are often used to determine whether differences in building use during weekdays and weekends are statistically significant and hence warrant separate models. The same techniques of day-typing, that is, grouping the daily data set into separate subsets and identifying models for each daytype, is also done for other holidays, such as Christmas, Thanksgiving, and for university buildings, spring and summer breaks (Katipamula and Haberl, 1991).

Changes in quantities such as cooling and heating energy are primarily influenced by the local weather conditions, internal loads and mode of building operation or day-type. Because day-types are in effect dictated by internal loads, regression models with weather parameters usually requires a day-type separation prior to modeling. The types of models used in the LoanSTAR program, their deficiencies and how these are currently being improved are discussed in section 4.4 .

(iv) Predicting energy use of non-retrofitted building The set of pre-retrofit regression models (identified using daily data) are then used to predict daily energy consumption of the retrofitted building under pre-retrofit conditions, but with building operation and weather conditions corresponding to each day of the post-retrofit period. Because the building has already undergone retrofits, the use of a model is unavoidable and leads to model prediction uncertainties, which subsequently impact the uncertainty of retrofit savings. 
and improvements in the 4-P model to handle both single variable and multi-variable cases are currently also being studied.

\subsection{Allied Issues Regarding Modeling}

\subsubsection{Effect of Short Pre-retrofit Data Sets}

Ideally, a full year or more of energy use and weather data should be used to construct regression models. The data can then be said to contain the entire range of variation in both climatic conditions and operating modes of the building and HVAC system. However, in many cases, a full year of data is not available and one is constrained to develop models using less than a full year. How temperature-dependent regression models of energy use fare in such cases is discussed by Kissock et al. (1993). The first step was to construct temperature-dependent linear regression models of daily energy use from one-, three-, and five-month data sets. Then the annual energy use predicted by these models was compared to the annual energy use predicted by a model based on an entire year of data.

It was found that annual heating energy use can be more than $400 \%$ greater than the annual energy use predicted by models from short data sets. In addition, in the climate of Central Texas, models of heating energy use have prediction errors 4-5 times greater than those of cooling energy models.

Two characteristics of data sets that influence their ability to predict annual energy use were identified:

(a) As expected, longer data sets provide a better estimate of annual energy use than shorter data sets. In the sample of buildings chosen, the average cooling prediction error of short data sets decreased from $7.3 \%$ to $3.0 \%$ and the average annual heating prediction error decreased from $27.5 \%$ to $12.9 \%$ as the length of data sets increased from one month to five months.

(b) More important than the length of the data set, however, was the range of outdoor temperatures represented by it. Cooling models identified from months with above-average temperatures tend to over-predict annual energy and viceversa. The converse seems to hold for heating models. Either way, limited temperature ranges represented in short data sets can lead to large errors in energy use predictions.

The best predictors of both cooling and heating annual energy use are models from data sets with mean temperatures close to the annual mean temperature. The range of variation of daily temperature values in the data set seems to be of secondary importance. One-month data sets in spring and fall, when the above condition applies, are frequently better predictors of annual energy consumption than five-month data sets from the winter or summer periods.

\subsubsection{Uncertainty in Savings Determination}




$$
E=\alpha_{1}+\alpha_{2} T
$$

(c) Segmented linear regression models, which can be further sub-divided into:

- Three-parameter or PRISM change-point models (Fels, 1986)

$$
\begin{array}{ll}
E=\alpha_{1}+\alpha_{2}\left(T-\alpha_{3}\right)^{+} & \text {(heating) } \\
E=\alpha_{1}+\alpha_{2}\left(\alpha_{3}-T\right) & \text { (cooling) }
\end{array}
$$

- Four parameter or 4-P change-point models (Ruch and Claridge, 1991) expressed as:

$$
E=\alpha_{1}+\alpha_{2}\left(T-\alpha_{4}\right)^{-}+\alpha_{3}\left(T-\alpha_{4}\right)^{+}
$$

where

( )- indicates that the quantity within the parentheses should be set equal to zero when it is positive (i.e., negative only valves are permitted),

()$^{+}$indicates that the quantity within the parentheses should be set equal to zero when it is negative (i.e., positive only valves are permitted),

In the four parameter model when $\alpha_{1}$ is the energy consumption at the change point temperature, $\alpha_{2}$ and $\alpha_{3}$ are the cooling and heating slopes (Figure 4.4). In the four parameter model when $\alpha_{3}$ is constrained to be zero, we get the three-parameter change point model, which is the basis of the heating-only or cooling-only PRISM model (Fels, 1986). In this light, the three-parameter model can be viewed as a special (but important for residential buildings) case of the more general 4-P model.

Identification of model types (a) and (b) is relatively straightforward and can be done in standard packages (for example, we use SAS, 1989 and STATGRAPHICS, 1991). Though linear segmented models are special cases of a much larger set of models, called spline functions (Pindyck and Rubenfeld, 1981), these commercial packages do not allow segmented linear regression modeling to be investigated in a framework convenient enough for building energy analysis. This is because the change point needs to be known and specified in order to use classical spline regression. Because this is not known a priori for buildings (in fact, this is one of the parameters being identified by regression), these commercial packages fall short of the necessary analysis.

Another deficiency in these packages is the lack of proper error diagnostics for spline regression models. Consequently, specially written computer programs, like PRISM (Fels, 1986) or in-house LoanSTAR programs, like 4-P (Ruch and Claridge, 1991) or EModel (Kissock et all., 1993), are used. The computational algorithm of the 4-P model involves a search method where the residual sum of squares over each of the two segments is computed separately for each incremental variation in the change point temperature. These two values of the sum of squares are then added together. The particular value which minimizes this sum is said to correspond to the sought-after change-point temperature (Ruch and Claridge, 1991), as shown in Figure 4.4. Extensions 
(v) Calculation of savings Finally, the savings over a certain number of post-retrofit days are calculated by subtracting the daily measured energy consumption from the daily energy consumption predicted by the pre-retrofit model and summing the daily savings over the time period in question.

The entire procedure for computing total savings of either chilled water, hot water or electricity can be summarized by:

$$
\sum_{j=1}^{m} E_{\text {Save }, j}=\sum_{j=1}^{m} E_{P r e d, j}-\sum_{j=1}^{m} E_{M e a s, j}
$$

or

$$
E_{\text {Save,Tot }}=E_{\text {Pred,Tot }}-E_{\text {Meas,Tot }}
$$

where

$$
\begin{array}{ll}
j & =\text { subscript representing a particular day over the post-retrofit period, } \\
m & =\text { number of post-retrofit days over which savings are estimated, } \\
E_{S a v e, j} & =\text { energy savings over day } \mathrm{j}, \\
E_{P_{\text {red }, j}} & =\text { model predicted daily energy use of non-retrofitted building, } \\
E_{\text {Meas }, j} & =\text { measured post-retrofit daily energy use, and } \\
T o t & =\text { subscript denoting total over the entire retrofit period. }
\end{array}
$$

Figure 4.2 illustrates this methodology by a series of three plots. The upper plot depicts a scatter plot of chilled water use as a function of outdoor dry-bulb temperature (which as discussed in section 4.3.3 as the main regressor variable). A linear regression model is then fit to the pre-retrofit data points. The $95 \%$ uncertainty bounds of the regression line are also shown. In the middle plot, the same linear model is plotted in conjunction with measured post-retrofit data points. The differences between each daily point and the regression line represents the energy savings on that particular day. Summing the daily values over $m$ days yields the net energy savings during a certain time interval as shown in the lower plot.

\subsubsection{Statistical Models Used}

It is clear from the above discussion that the regression model identification phase is crucial in the entire retrofit savings process. Currently, most regression models are linear, and of the first-order. This was based on 1) preliminary findings and previous experience supported by heat transfer and thermodynamic principles that energy flows in buildings could be well represented by linear first order functional forms (Fels, 1986; Rabl, 1988; Subbarao, 1988), and 2) a desire to keep the statistical identification simple (proper nonlinear regression requires a much higher level of expertise). 
The present generation of LoanSTAR models presumes ambient temperature to be the sole regressor variable (Kissock et al., 1992 a \& b). Specifically, T in our daily models is calculated as follows:

$$
\mathrm{T}=\frac{\text { daily } \max . \text { temp }+ \text { daily } \min \text { temp. }}{2}
$$

Though a mean daily $T$ value could be calculated from the 24 hourly monitored values, it was decided to use the above definition because of consistency. In all LoanSTAR sites we rely on the National Weather Service to provide the minimum and maximum daily temperatures. This service is available for most U.S. cities.

In some buildings in the LoanSTAR program, the simple regression model has been found to be adequate. However, studies underway reveal that adding other variables would improve the models in terms of increasing the adjusted $\mathrm{R}^{2}$ and decreasing the coefficient of variation (CV). Implications of such models in terms of 1) multicollinearity between regressor variables which could lead to unstable parameter estimates (Manly, 1986; Draper and Smith, 1981, Ruch et al., 1993; Wu et al., 1992), 2) uncertainty intervals of savings estimates, and 3) the higher measurement uncertainty of monitoring equipment (say, that of specific humidity), which are currently under assessment.

Returning to simple regresșion models with $\mathrm{T}$ as the sole variable, it is well known that energy use in buildings often exhibits a three parameter change-point behavior (Fels, 1986; Ruch and Claridge, 1991; Kissock et al., 1992 a \& b). In residential buildings, where concurrent heating and cooling is typically not required, the presence of a three parameter change point is easily explained by the thermostatically controlled heating or cooling system (Fels, 1986). In commercial buildings, this simple explanation does not always suffice. This is because interior zones may require cooling while the exterior zones may call for heating. This, coupled with the facts that latent loads become substantial during hot, humid days and that HVAC supply air temperatures are often controlled (or reset) non-linearly with ambient temperature, results in four parameter change-point behavior.

Temperature driven regression models adopted for LoanSTAR analysis can be subdivided into three groups (See Figure 4.3):

(a) Mean or one-parameter models, (for example, air handler electricity use for constant volume dual duct systems in buildings is reasonably independent of weather, and a mean daily value has been found to be adequate for most commercial buildings; in the LoanSTAR program);

$$
E=\alpha_{1}
$$

(b) One parameter linear regression models for cooling and heating energy use 
In statistics, ascertaining the uncertainty of a prediction is as important as the prediction itself. Hence determining the uncertainty in our retrofit savings estimate is imperative. Model identification has a direct bearing on determining the uncertainty because the same issues equally affect the nature and magnitude of errors. The uncertainty in savings can be attributed to measurement errors (both in the independent and dependent variables) and to errors in the regression model. The former are usually well known to engineers and the methodology of estimating their effect can be adequately covered using classical engineering textbooks, for example, Bendat and Piersol (1986). Errors in regression models, on the other hand, are more complex and arise from several sources. Reddy et al.(1992) have classified these into three categories which are very briefly mentioned below:

(a) Model prediction errors, which arise due to the fact that a model is never "perfect". Invariably a certain amount of the observed variance in the response variable is unexplained by the model. This variance introduces an uncertainty in prediction even when the range of variation in the regressor variable is within the range over which the model was identified.

(b) Model mis-specification errors which are due to 1) inclusion or non-inclusion of certain regressor variables (neglecting humidity effects, for example); 2) assumption of a linear model when the physical equations suggest non-linear interaction among the regressor variables; and 3) incorrect order of the model, i. e., either a lower order or a higher order than the physical equations suggest.

(c) Model extrapolation errors, which arise when a model is used for prediction outside the region covered by the original data from which the model has been identified.

It is difficult to handle category (c) in a purely statistical manner. Insights gained from studies such as that described in section 4.4.1 are the only way that such effects can be reduced. The net effect of categories (a) and (b) is often improper residual behavior which may partially or even entirely invalidate the major assumptions made during least-squares regression, namely that the residuals have: 1) zero mean; 2) constant variances, i.e., heteroscedasticity is not present; 3) a lack of correlation, i.e., no serial correlation or autocorrelation is present; and 4) a near-normal distribution.

The method of least squares can be used to estimate the parameters in a linear regression model regardless of the form of the distribution of errors, and so the last assumption 4) is not relevant in our current savings calculation methodology. Assumption 1) is also not a serious criterion because it is satisfied in most cases. The normal method for dealing with heteroscedasticity is to perform a weighted regression with the observations inversely weighted with their variance (Draper and Smith, 1981). Data from the individual LoanSTAR buildings do not seem to generally exhibit strong heteroscedasticity, and consequently this issue may also be overlooked. 
Most of the models developed at the daily time scale seem to suffer from autocorrelated residual behavior. The practical implications of neglecting serial correlations in the data are that equations prèsented in elementary statistical textbooks for model prediction uncertainty will underestimate the true model uncertainty. We would then be placing more confidence in our savings estimates than is strictly warranted. A study by Ruch et al.(1993) has addressed this issue and suggested that a hybrid model of ordinary least squares (OLS) and an autoregressive (AR) model be used, which, though akin to OLS in predictive ability, has much more realistic error diagnostics than OLS. The statistical theory of the hybrid model approach developed from fundamental statistical concepts and described in Ruch's paper is validated with measured data from four buildings. In every case, the hybrid model provided far more accurate error estimates of the model prediction than did ordinary OLS. The flow chart summarizing the model fitting procedure is shown in Figure 4.5.

\subsubsection{Simplified Systems Model Approach}

In some buildings, the pre-retrofit monitoring data period was so short that a proper statistical model could not be developed. Even more drastic was the fact that, in a couple of buildings, retrofits were completed before the monitoring instrumentation was even installed. Hence, the simplified calibrated model (Katipamula and Claridge, 1993) was developed which is based on the ASHRAE TC 4.7 Simplified Energy Analysis Procedure (SEAP). This method, as illustrated by Figure 4.6, involves developing one model for the dual-duct variable air volume (VAV) and one model for the dual-duct constant air volume (CAV) system. If no pre-retrofit data are available, the VAV model is first calibrated (i.e., its input parameters tuned so that model-predicted hourly energy use fits the hourly measured energy use as closely as possible) with the post-retrofit monitored data. The calibrated loads from the post-retrofit VAV model are then used with the CAV model to predict the energy use of the building in the pre-retrofit condition. Savings are then calculated by comparing the results of the CAV-predicted energy to the VAV predictable energy use.

Figure 4.7 is a schematic of how the simplified model views the interaction between the HVAC system and the building zones. The building is divided into two zones: an exterior or perimeter zone and an interior or a core zone. The core zone is assumed to be insulated from the envelope heat losses/gains, solar heat gains, and infiltration heat loss/gain; the conduction gains/losses from the roof are lumped with the external zone. Given the internal load schedule, the building description and the climatic parameters, the building loads can be estimated for each hour of the day and for as many days of the year as is needed. Subsequently, using parameters describing HVAC control and operation (hot or cold deck temperatures, economizer cycles, etc.), the heating and cooling energy use of the building are estimated. The simulation process is sketched in Figure 4.8.

\subsubsection{Mixed billing and monitored data}

Another approach, this one statistical rather than engineering model-based, has been developed (Liu et al., 1992) to determine savings under special circumstances, called mixed billing and hourly monitored data. Such circumstances arose in two schools, and 
similar retrofits in many more schools are underway, hence the need to devote time and effort to handle such cases. Here the monitoring began after part of the retrofit was already completed (which is not an uncommon occurrence). Specifically, a gas-based absorption chiller was replaced by a vapor compression chiller which supplemented the cooling provided by already existing roof-top units. Monitoring began after the chiller retrofit was completed. However, after a few months an additional retrofit was made, namely an EMCS was installed. Hence, gas use in the school decreased, but use and demand of electricity increased due to the chiller retrofit which, however, was tempered by the EMCS system. The objective of the analysis is to determine the energy savings due to chiller retrofit and due to the EMCS individually. The methodology involves developing statistical models for each energy type which are then calibrated for the strong seasonal schedules present in schools using gas and electric utility billing data. The methodology is currently being refined but preliminary indications are positive. 
Figure 4.1: Pump and Air-handler Electricity Use at LoanSTAR Building. The preretrofit, construction and post-retrofit periods are clearly identified by changing energy patterns.

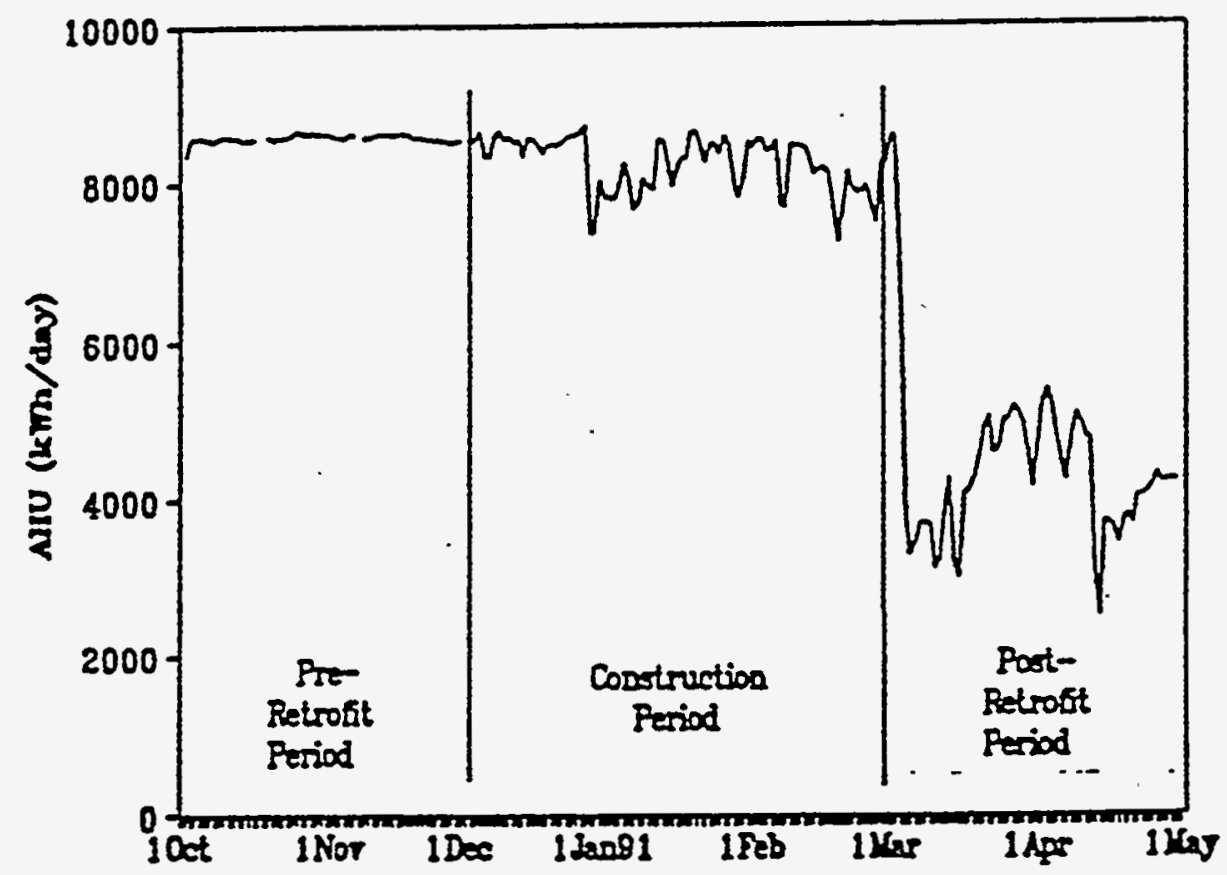


Figure 4.2: Pre-Retrofit Chilled-Water Use with Model and Savings.
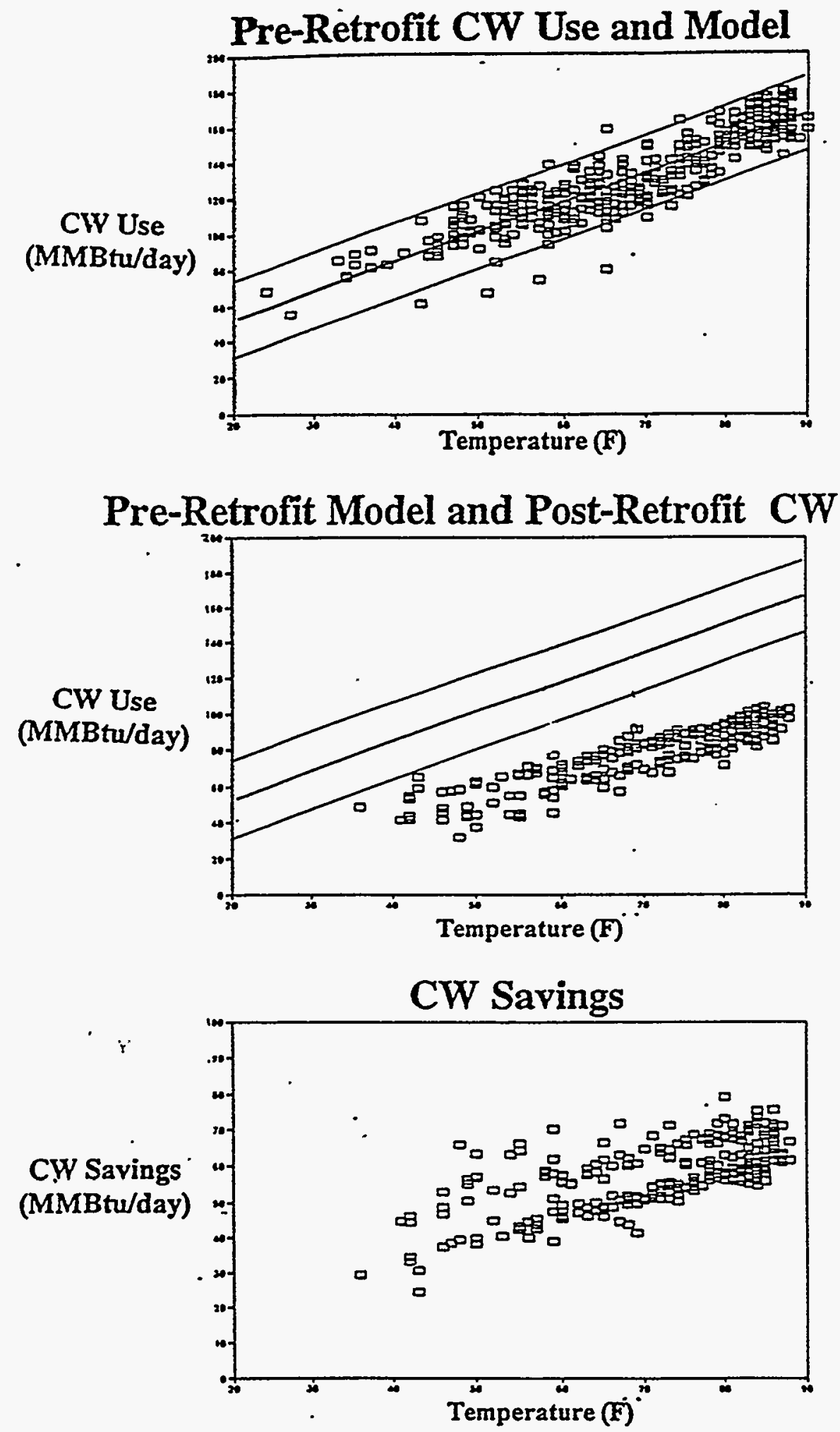
Figure 4.3: One, Two and Four Parameter Baseline Models for Savings

Measurements.
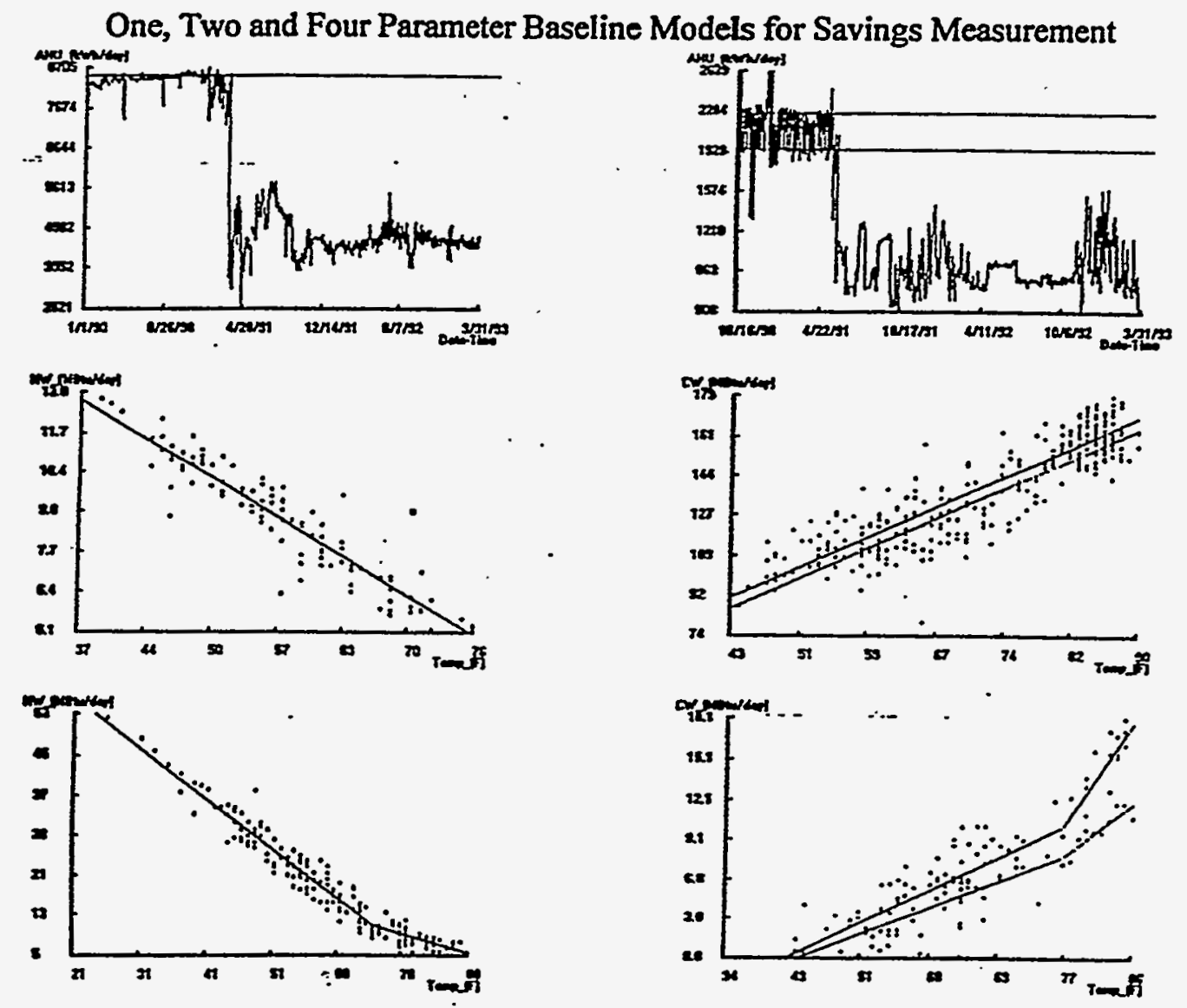
Figure 4.4: Examples of Four-parameter Change-point Models for Hot Water and Chilled Water Energy Use.
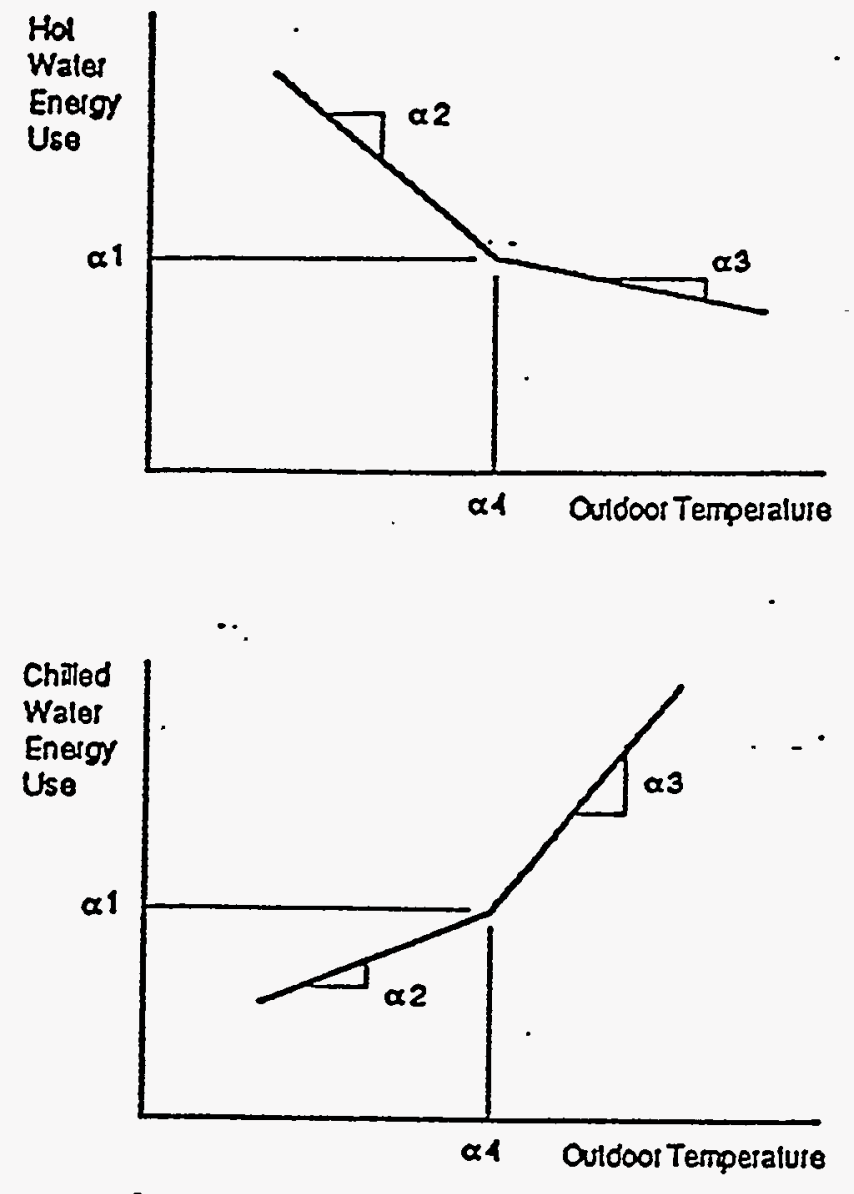
Figure 4.5: Flow Chart Summarizing Model Fitting Procedure.

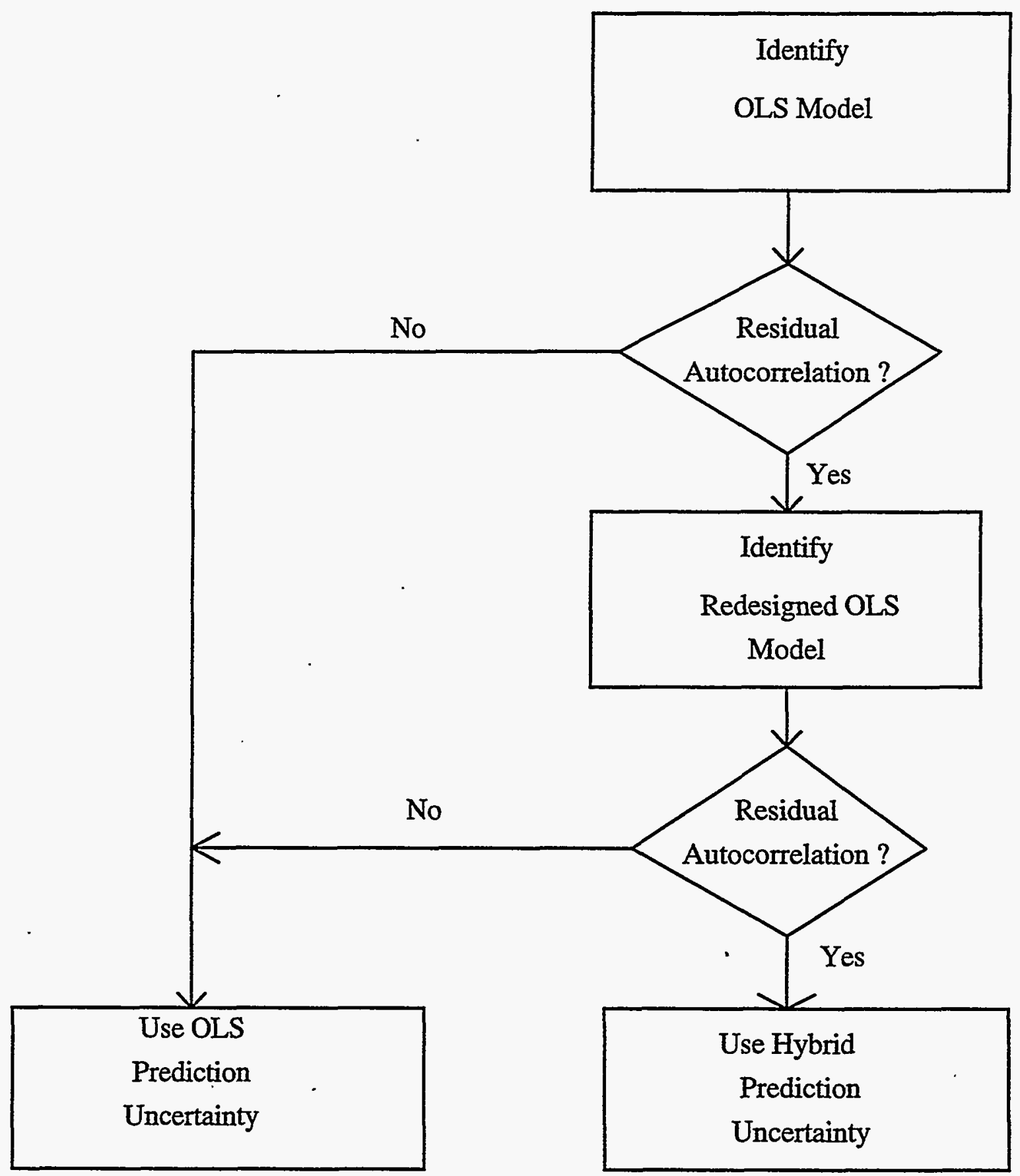




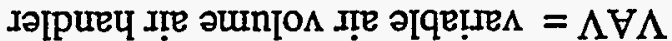

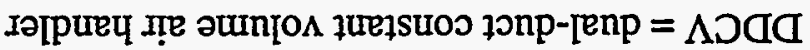

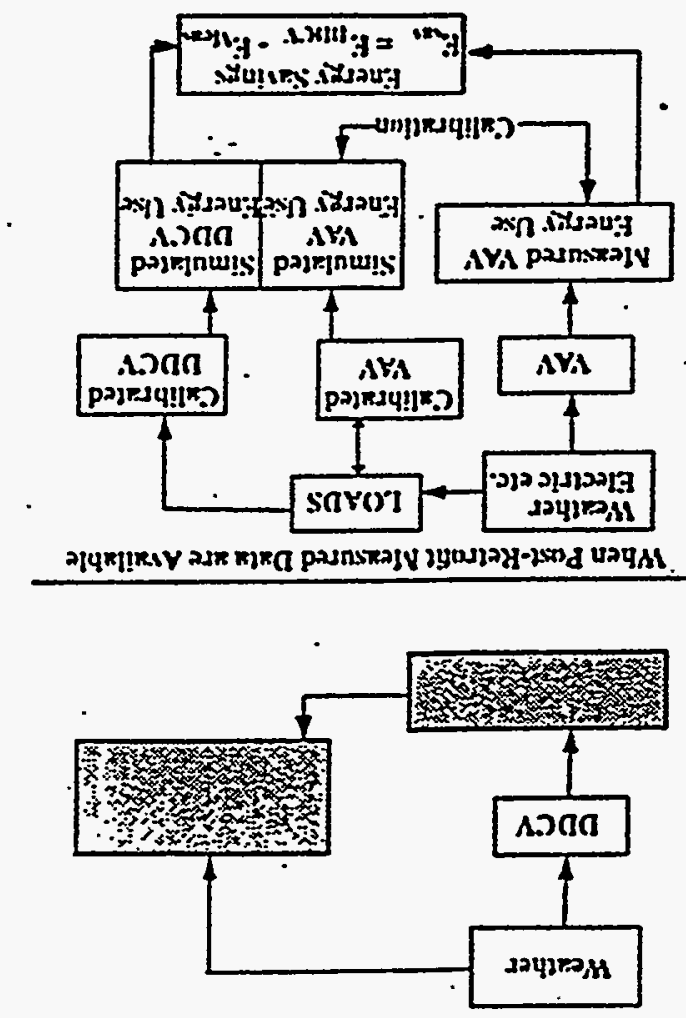

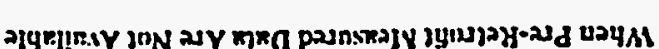

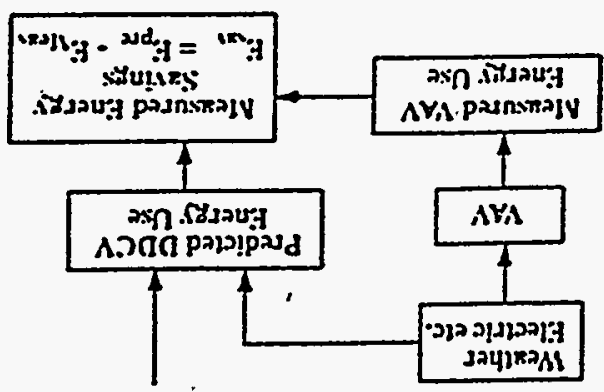

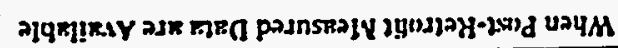

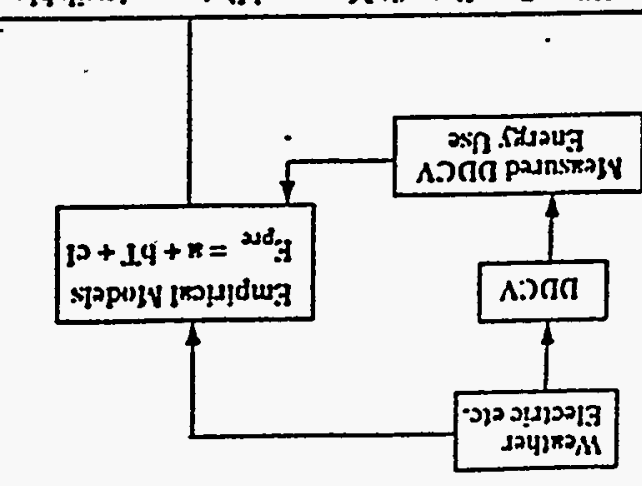

i 
Figure 4.7: Schematic of the HVAC and Building Zone Interaction Assumed in the Simplified Systems Model Approach. Zone E denotes the exterior zone of the two-zone building while zone I is the interior zone.

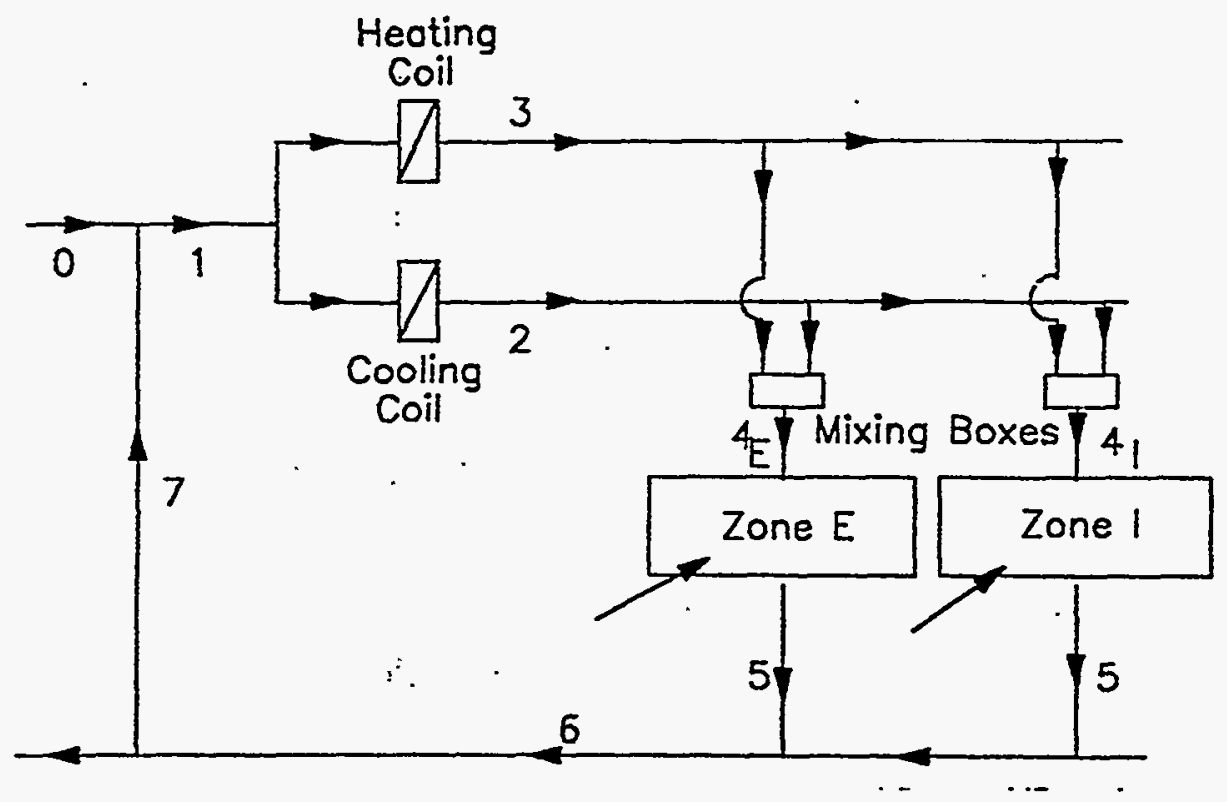


Figure 4.8: Schematic of the Simulation Procedure.

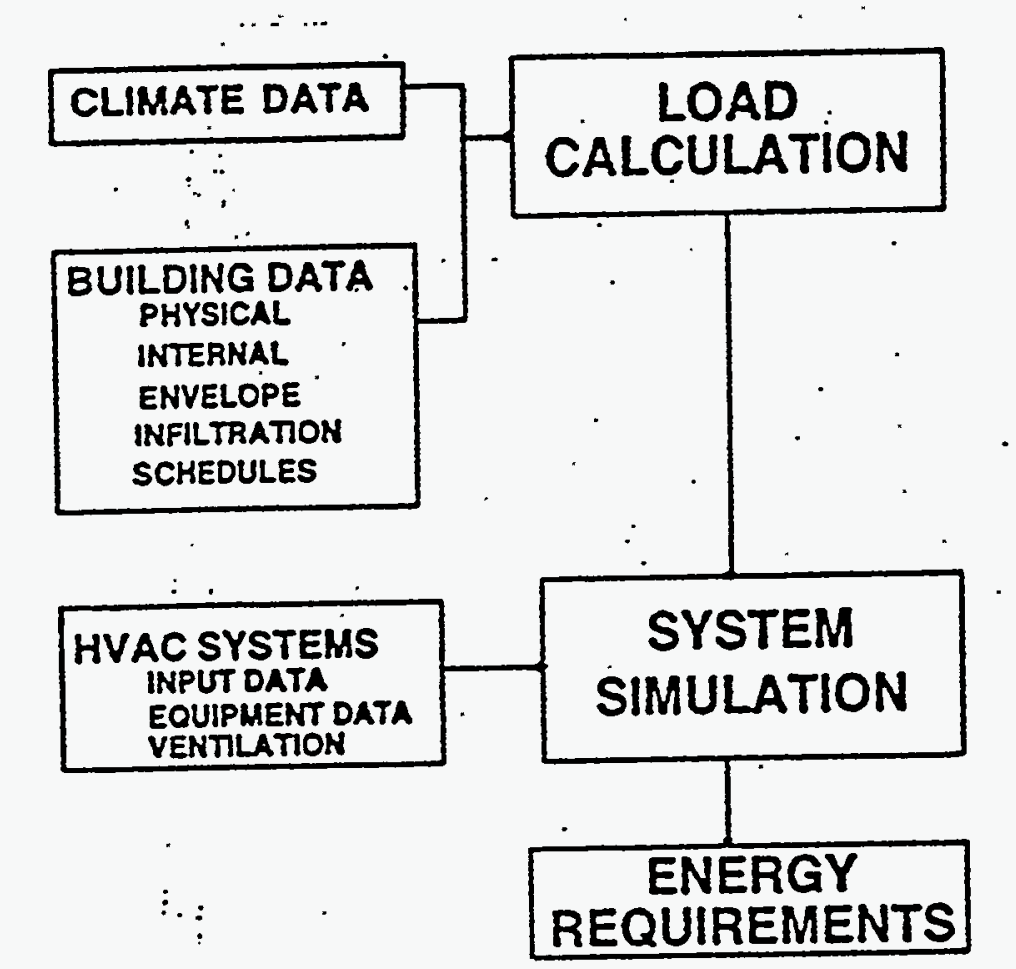




\subsection{RESULTS FROM THE FIRST TWO YEARS OF MONITORING}

\subsection{Verifying Energy and Audit Dollar Savings of Retrofits}

The objective of this section is to describe the savings verification methods used in the LoanSTAR program, to present the retrofit savings currently realized in LoanSTAR, and to compare audited to measured savings.

\subsubsection{Energy Savings}

The cumulative savings in dollars from the 24 LoanSTAR sites reporting savings, as of March 1993, is shown pictorially in Figure 5.1 for each energy type. Additional statistics are given in the table attached to Figure 5.1. The following points are noteworthy:

(a) Until March 1993, measured savings were close to $\$ 4.5$ million, of which $34.4 \%$ were in electricity savings, $43.8 \%$ were in cooling energy, and the rest in heating energy.

(b) The audit estimated savings and the measured savings of electricity and heating energy are very close--within 5\%, with measured savings being surprisingly higher. In fact, measured cooling energy savings are much higher still, close to $100 \%$ more than the estimated value. This unexpected positive difference is difficult to explain satisfactorily, but it is undeniable that part of the cause was the incessant vigilance exhibited by the LoanSTAR analysts in pointing out operation and maintenance (O\&M) problems to concerned building operators as soon as the problems appeared.

Table 5.1 depicts how the measured and audited energy savings for electricity, chilled water, and hot water compare on an individual basis for each of the buildings where savings are currently reported. We note that though audit and measured savings are close for the entire set of 24 buildings, there are large variations on an individual basis, as can be aftested to by the ratio of measured to audit savings columns. More detailed investigation is required in order to ascertain why such differences have occurred.

\subsubsection{Demand Savings}

The audit estimates did not include demand savings benefits while evaluating cost effectiveness of a certain retrofit. We found that the reduction was substantial, close to 2 MW for the 24 LoanSTAR buildings where savings reported as of March 1993. Figure 2.6 presented in Section 2 depicts how this demand reduction was distributed between HVAC, lights and thermal storage retrofits. We note that $60 \%$ of the demand savings came from airside retrofits to the HVAC systems, $37 \%$ from lights, and $3 \%$ from thermal storage.

Figure 5.2 depicts electric demand reductions in 12 of the retrofitted LoanSTAR sites. The demand numbers refer to maximum hourly use during the year (because LoanSTAR 
data are monitored hourly), which is not exactly consistent with the way utilities charge customers. Figure 5.3 shows the extent to which energy use normalized by building floor area, described by the annual energy use index (AEUI) and measured in $\mathrm{kWh} / \mathrm{yr} / \mathrm{sf}$, has been reduced as a result of the retrofits. The two sites having the smallest savings, BUS and UTH, have had a change in operating mode in the post-retrofit period whereby the building is shut down at night. When the HVAC system comes on in the morning, it experiences a momentary spike in energy demand not present in the pre-retrofit period, which negates to some extent the demand benefits due to the retrofit.

Figure 5.2 expresses the same demand reduction as a fraction of post-retrofit airhandler demand to pre-retrofit demand. Other than four sites, namely BUS, UTH, NUR and WAG, the average demand reduction is about $30 \%$. BUS and UTH have had a change in operation mode as described earlier, while problems with the heating coils were identified in NUR and WAG. Thus, we can conclude that if the building and the HVAC system are operated properly, one could expect demand savings of about $30 \%$ due to the air-side retrofits.

\subsection{Reducing Energy Costs by Identifying O\&M Problems}

During the past $1 \frac{1}{2}$ years, the LoanSTAR operations and maintenance (O\&M) group has conducted studies at six agencies participating in the LoanSTAR program to determine the effects of operations and maintenance on energy costs. The six agencies represent a total of 65 buildings with usages that include office buildings, schools, libraries, hospitals, and multi-purpose university buildings. Using the LoanSTAR Monitoring and Analysis Program (MAP) as a starting point, a methodology was developed to determine potential O\&M savings at these sites. This methodology has been applied to six sites in the LoanSTAR program, which include the Texas State Capitol Complex, the University of Texas at Austin, the University of Texas at Arlington, the Fort Worth Independent School District, the Zachry Engineering Building at Texas A\&M University, and the University of Texas Medical Branch at Galveston. A total of over $\$ 1.75$ million in potential O\&M savings has been documented and reported to the above agencies. It should be noted that all sites, with the exception of the Texas State Capitol Complex, have had retrofits fully implemented.

The metering and monitoring aspects of the LoanSTAR program played a key role in helping the O\&M staff recognize potential savings opportunities at each site. The primary form of formal feedback to facility engineers and building operators is the Monthly Energy Consumption Report (MECR). In addition, weekly inspection plots (IPNs) are generated in-house for data quality control but also allow the O\&M engineers to document the positive results of changes in building operations patterns on a very short term basis, thus providing immediate feedback to the building operators.

Based on both the MECR and the IPN reports, the O\&M staff has been able to discern a number of things that lead to potential savings: First, what is the minimum baseline load in the building and can it be lowered without compromising occupant comfort or productivity? Second, how does the actual consumption plot compare with a normalized 
or "ideal" consumption curve? Third, does the plot indicate higher nighttime usage on weekends when compared to weekdays? Finally, have there been any abrupt increases in building energy consumption since the last report? Our case studies found examples of each of the above conditions, which were then reported to the building operators.

Another key indicator of potential O\&M opportunities, as reported in the MECR, is the comparison of pre-retrofit audit predicted savings with post-retrofit measured savings. We have experienced instances of post-retrofit savings not meeting predicted savings. In one case study we found potential O\&M savings far in excess of those originally predicted due to a lighting retrofit. Once a building or site was identified as having O\&M savings potential, a formal procedure was followed. Figure 5.4 displays a flow chart for the O\&M Identification Procedure.

Based on the data provided by the weekly polling and presented in the IPN, a field engineer would telephone the site contact and point out the possibility of O\&M savings. In some instances the site contact would initiate the call to the O\&M field engineer. The O\&M Follow-up Procedure, after a problem is identified, includes:

- Research site from IPN, MECR, AECR, site notebook and audit report

- Telephone site contact and advise of O\&M potential

- Mail or fax supporting data

- Site visit

- Interview operator

- Conduct daytime walk-through

- Conduct nighttime walk-through

- Perform short term test

- Analyze data

- Write report

- Present report

- Follow-up report

Operational and maintenance recommendations (O\&Ms) are actions taken by building operators, as part of their regular duties to reduce energy costs. Typically, they are relatively inexpensive (low cost or no cost) to implement and can save hundreds, even thousands of dollars worth of energy after implementation. During the course of our case studies at the six aforementioned sites, numerous O\&Ms were identified and are reported in Table 5.3.

Table 5.3 breaks down the identified O\&M opportunities into four separate categories: they are lighting, equipment operation, occupant habits and administration. These findings were documented and reported back to the building operators, who have taken steps to implement the O\&M opportunities. In all cases they have been provided 
with graphical feedback to affirm the results of their actions, which includes data documenting their energy cost savings.

Table 5.4 is presented as a summary of the sites studied to date. The number of buildings at each site and the total square footage of the buildings are provided in the table. Potential O\&M savings are also provided for each site. In some instances, annual utility costs were not available due to the fact that individual building metering does not apply because of central campus/complex metering. However, annual energy costs from LoanSTAR measured data are included in the table. Finally, the percentage of annual O\&M savings compared with annual energy costs is presented.

As was mentioned previously, all the sites have had retrofits completed, with the exception of the State Capitol Complex. The potential O\&M savings range from a low of $\$ 20,000$ per year to a high of $\$ 550,000$ per year. In terms of percentage of annual energy costs, the range of O\&M savings is from $5.0 \%$ to $25.9 \%$ of annual energy costs, with an average of $15.2 \%$ for all the sites.

Clearly, the no cost or low cost O\&M opportunities that exist at each site can have a significant impact on energy cost reduction. 
Table 5.I: Comparison of Audit and Measured Savings on an Individual Building Basis for the 24 Buildings Currently Reporting Savings as of March 1993.

\begin{tabular}{|c|c|c|c|c|c|c|c|c|c|}
\hline \multirow[b]{2}{*}{$\begin{array}{l}\text { Site } \\
\text { I.D. }\end{array}$} & \multirow[b]{2}{*}{\begin{tabular}{|l|} 
Months \\
of Post \\
Retro-fits
\end{tabular}} & \multicolumn{2}{|c|}{ Electricity } & \multicolumn{2}{|c|}{ Cooling Energy } & \multicolumn{2}{|c|}{ Heating Energy } & \multicolumn{2}{|c|}{ Total } \\
\hline & & $\begin{array}{c}\text { Measured } \\
\text { Savings } \\
\left(\$ \times 10^{3}\right)\end{array}$ & $\begin{array}{l}\text { Ratio of } \\
\text { Measured } \\
\text { to Audit } \\
\text { savings }\end{array}$ & $\begin{array}{c}\text { Measured } \\
\text { Savings } \\
\left(\$ \times 10^{3}\right)\end{array}$ & $\begin{array}{l}\text { Ratio of } \\
\text { Measured } \\
\text { to Audit } \\
\text { savings }\end{array}$ & $\begin{array}{c}\text { Measured } \\
\text { Savings } \\
\left(\$ \times 10^{3}\right)\end{array}$ & $\begin{array}{l}\text { Ratio of } \\
\text { Measured } \\
\text { to Audit } \\
\text { savings }\end{array}$ & $\begin{array}{c}\text { Total } \\
\text { Measured } \\
\text { Savings } \\
\left(\$ \times 10^{3}\right)\end{array}$ & $\begin{array}{l}\text { Ratio of } \\
\text { Measured } \\
\text { to Audit } \\
\text { savings }\end{array}$ \\
\hline 1 & 29 & 87 & 0.77 & 149 & 0.58 & 124 & 1.09 & 360 & 0.74 \\
\hline 100 & 23 & 236 & 1.1 & 197 & 4.1 & 27 & 0.47 & 460 & 1.44 \\
\hline 101 & 30 & 137 & 1.03 & 114 & 1.52 & 58 & 0.75 & 309 & 1.08 \\
\hline 102 & 30 & 434 & 2.58 & 775 & 2.88 & 500 & 1.21 & 1709 & 2.02 \\
\hline 118 & 27 & 24 & 0.8 & 42 & 2.1 & 14 & 0.93 & 80 & 1.23 \\
\hline 119 & 22 & 34 & 0.62 & 17 & 0.85 & 10 & 1 & 61 & 0.72 \\
\hline 105 & 23 & 18 & 0.49 & 22 & 1.16 & 10 & 0.91 & 50 & 0.75 \\
\hline 106 & 22 & 108 & 2 & 99 & 2.61 & -53 & - & 154 & 1.15 \\
\hline 107 & 23 & 50 & 0.6 & 77 & 2.2 & 11 & 0.61 & 138 & 1.01 \\
\hline 108 & 24 & 54 & 0.73 & 56 & 1.3 & -10 & - & 100 & 0.7 \\
\hline 114 & 21 & 71 & 0.8 & 156 & 5.2 & 81 & 4.5 & 308 & 2.25 \\
\hline 115 & 23 & - & - & 7 & 0.78 & 4 & 0.8 & 11 & 0.79 \\
\hline 116 & 22 & 50 & 1.56 & 24 & 0.45 & 32 & 0.72 & 106 & 0.82 \\
\hline 117 & 26 & 24 & 0.83 & 60 & 4 & 47 & 7.83 & 131 & 2.67 \\
\hline 111 & 22 & 12 & 0.19 & 16 & 0.4 & 0 & 0 & 28 & 0.25 \\
\hline 112 & 20 & 8 & 0.15 & 25 & 0.7 & 11 & 0.37 & 44 & 0.38 \\
\hline 113 & 22 & 37 & 0.46 & 49 & 1.23 & 18 & 0.51 & 104 & 0.67 \\
\hline 124 & 23 & 111 & 0.78 & 0 & 0 & 0 & 0 & 111 & 0.78 \\
\hline 130 & 8 & 19 & 0.48 & 40 & 20 & 5 & - & 64 & 1.52 \\
\hline 126 & 15 & -22 & 0.49 & 0 & N/A & 45 & 0.64 & 23 & 0.92 \\
\hline 127 & 15 & -3 & 0.11 & 0 & N/A & 20 & 0.51 & 17 & 0.81 \\
\hline 128 & 17 & 10 & 0.63 & 0 & N/A & 0 & N/A & 10 & 0.63 \\
\hline 129 & 17 & 8 & 0.89 & 0 & N/A & 0 & N/A & 8 & 0.89 \\
\hline 145 & 10 & 8 & 0.73 & 0 & $\mathrm{~N} / \mathrm{A}$ & 0 & N/A & 8 & 0.89 \\
\hline ALL & - & 1515 & 1.01 & 1925 & 1.84 & 9504 & 0.92 & 4394 & 1.23 \\
\hline
\end{tabular}


Table 5.2: Energy Conservation Identified in Buildings Monitored Under LoanSTAR Program as of May 1993.

\begin{tabular}{|l|l|l|l|l|l|}
\hline $\begin{array}{c}\text { Purchased } \\
\text { Utility } \\
\text { Category }\end{array}$ & Site Energy & $\begin{array}{c}\text { Site Energy** } \\
\text { (million } \\
\text { Btu/yr) }\end{array}$ & $\begin{array}{c}\text { Source Energy * } \\
\text { (million Btu/yr) }\end{array}$ & $\begin{array}{c}\text { Fractional Site } \\
\text { Energy } \\
\text { Savings (\%) }\end{array}$ & $\begin{array}{c}\text { Fractional } \\
\text { Source Energy } \\
\text { Savings (\%) }\end{array}$ \\
\hline Electricity & $\begin{array}{l}113,282,528 \\
(\mathrm{kWh} / \mathrm{yr})\end{array}$ & 386,520 & $1,314,077$ & 26.6 & 52.9 \\
\hline $\begin{array}{l}\text { Natural } \\
\text { Gas }\end{array}$ & $\begin{array}{l}305,274 \\
(\mathrm{MCF} / \mathrm{yr})\end{array}$ & 314,432 & 314,432 & 21.7 & 12.7 \\
\hline $\begin{array}{l}\text { Steam/Hot } \\
\text { Water }\end{array}$ & $\begin{array}{l}318,237 \\
(\mathrm{million} \\
\text { Btu/yr) }\end{array}$ & 318,237 & 424,316 & 21.9 & 17.1 \\
\hline $\begin{array}{l}\text { Chilled } \\
\text { Water }\end{array}$ & $\begin{array}{l}35,986,682 \\
\text { (ton-hr/yr) }\end{array}$ & 431,840 & 431,840 & 29.8 & 17.4 \\
\hline Totals & & $1,451,029$ & $2,484,666$ & 100 & 100 \\
\hline
\end{tabular}

**Btu savings calculated on the basis of site Btus (i.e. $3,412 \mathrm{Btu} / \mathrm{kWh}, 1,030,000$

$\mathrm{Btu} / \mathrm{MCF}$ and $12,000 \mathrm{Btu} /$ ton-hr)

*Btu savings calculated on the basis of source Btus (i.e. 11,600 Btu/kWh, 1,030,000 $\mathrm{Btu} / \mathrm{MCF}$, boiler efficiency of $75 \%$ and $12,000 \mathrm{Btu} / \mathrm{ton}-\mathrm{hr}$ ) 
Table 5.3: O\&M Opportunities identified at six sites.

\section{O\&M Opportunities Identified at Six Sites}

\begin{tabular}{|l|l|}
\hline \multicolumn{1}{|c|}{ O\&M Opportunity Identified } & \multicolumn{1}{c|}{ Location Where Applicable } \\
\hline Lighting & All sites except U.T. Austin \\
\hline Lighting Control & $\begin{array}{l}\text { Capitol Complex, U.T. Arlington and } \\
\text { UTMB Galveston }\end{array}$ \\
\hline $\begin{array}{l}\text { Delamp or reduce lighting levels when } \\
\text { excess of IES standards }\end{array}$ & All sites \\
\hline $\begin{array}{l}\text { Convert incandescent to compact } \\
\text { fluorescent }\end{array}$ & \\
\hline Equipment Operation & Capitol Complex and UTMB Galveston \\
\hline Change zone HVAC set points & Capitol Complex and UTMB Galveston \\
\hline Raise AHU cold deck temperature & Capitol Complex and UTMB Galveston \\
\hline Lower AHU hot deck temperature & $\begin{array}{l}\text { Capitol Complex, Ft Worth ISD and U.T. } \\
\text { Arlington }\end{array}$ \\
\hline Turn off AHUs at night & ZEC and WBT at the Capitol Complex \\
\hline Turn off HW pump in summer & SFA at the Capitol Complex \\
\hline $\begin{array}{l}\text { Repair leaky pipes, valves, and/or } \\
\text { ductwork }\end{array}$ & PCL at U.T. Austin \\
\hline Turn off steam valve during summer & NUR at U.T. Austin \\
\hline Disable economizer cycle & \\
\hline Occupant Habits & All Capitol Complex Buildings \\
\hline Turn off PCs and office machines & All sites except U.T. Austin \\
\hline Turn off lights & \\
\hline Administrative & Ft Worth ISD, GAR,RAS at U.T. Austin \\
\hline $\begin{array}{l}\text { Verify EMS operation, reprogram if } \\
\text { necessary }\end{array}$ & All Capitol Complex and Ft Worth ISD \\
\hline $\begin{array}{l}\text { Optimize custodial operations in the } \\
\text { evenings }\end{array}$ & \\
\hline
\end{tabular}


Table 5.4: Summary of Potential O\&M Savings at Six LoanSTAR Sites.

Summary of Potential O\&M Savings at Six LoanSTAR Sites

\begin{tabular}{|l|c|r|r|r|c|}
\hline \multicolumn{1}{|c|}{ Site } & $\begin{array}{c}\text { No. of } \\
\text { Building } \\
\text { s }\end{array}$ & $\begin{array}{c}\text { Total Sq. } \\
\text { footage }\end{array}$ & $\begin{array}{c}\text { Annual } \\
\text { energy } \\
\text { costs } \$ / \mathbf{y r}\end{array}$ & $\begin{array}{c}\text { Potential } \\
\text { O\&M } \\
\text { savings } \$ / y r\end{array}$ & $\begin{array}{c}\text { O\&M savings } \\
\text { \% of Annual } \\
\text { energy costs }\end{array}$ \\
\hline Capitol Complex & 8 & $2,243,746$ & $4,261,188$ & 486,300 & 11.4 \\
\hline U.T. Austin & 4 & 694,579 & 978,776 & 143,900 & 14.7 \\
\hline U.T. Arlington & 3 & 496,350 & 452,376 & 80,000 & 17.7 \\
\hline Ft Worth ISD & 44 & $2,410,740$ & $2,123,773$ & 550,000 & 25.9 \\
\hline Zachry Eng. Bldg. & 1 & 324,400 & 403,336 & 20,000 & 5.0 \\
\hline UTMB Galveston & 5 & 758,751 & $3,596,348$ & 512,420 & 14.2 \\
\hline TOTAL/AVE & 65 & $6,928,566$ & $11,815,797$ & $1,792,620$ & 15.2 \\
\hline
\end{tabular}




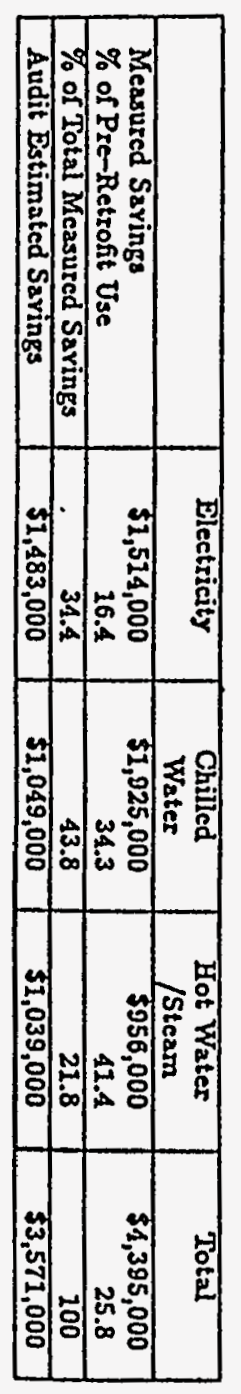

Cumulative Total Savings (Millions of Dollars)
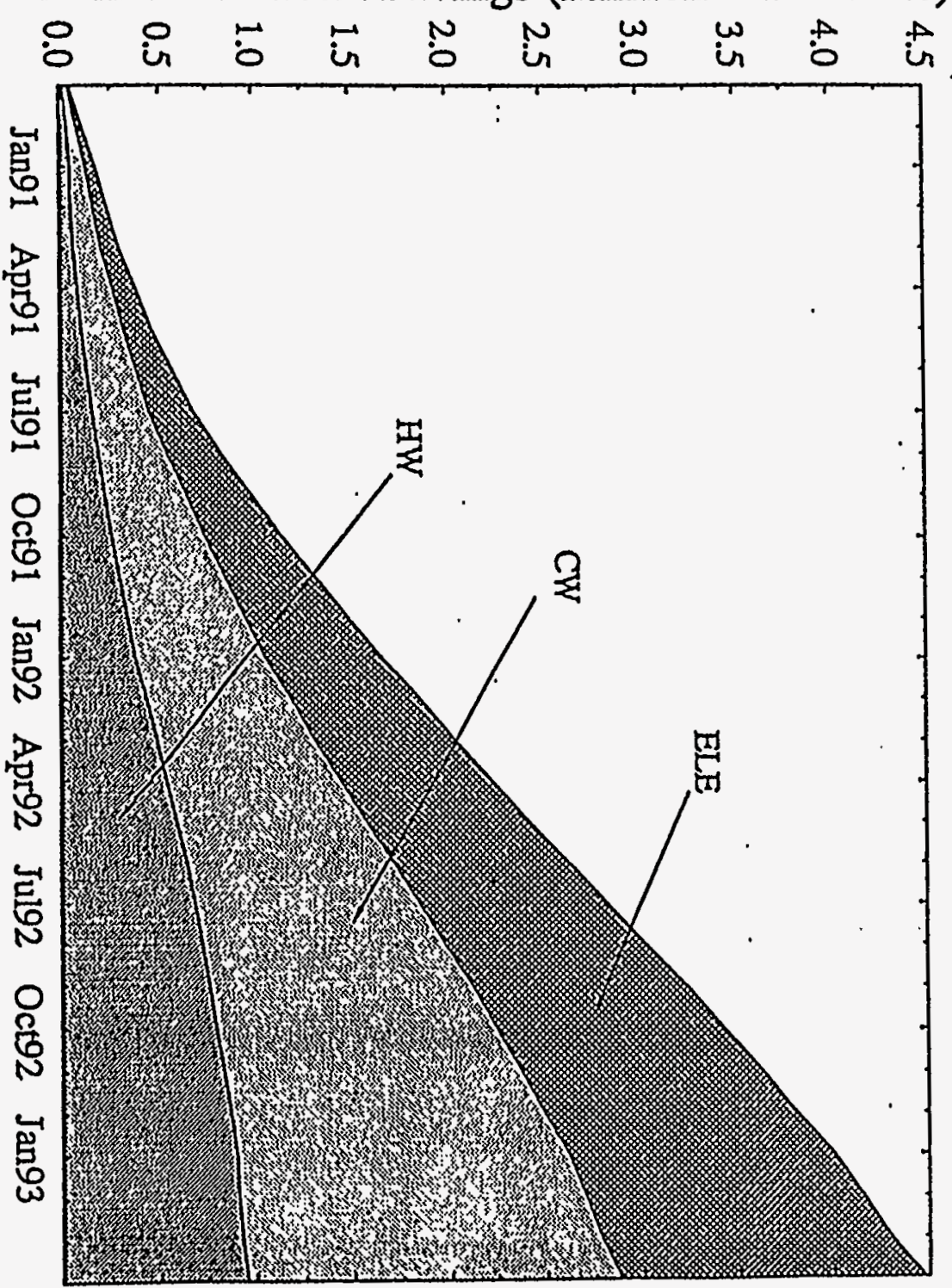

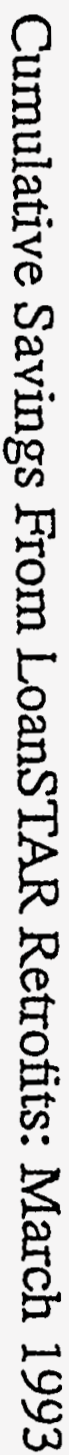

彳亍 
Figure 5.2: AHU Electric Demand Reduction.

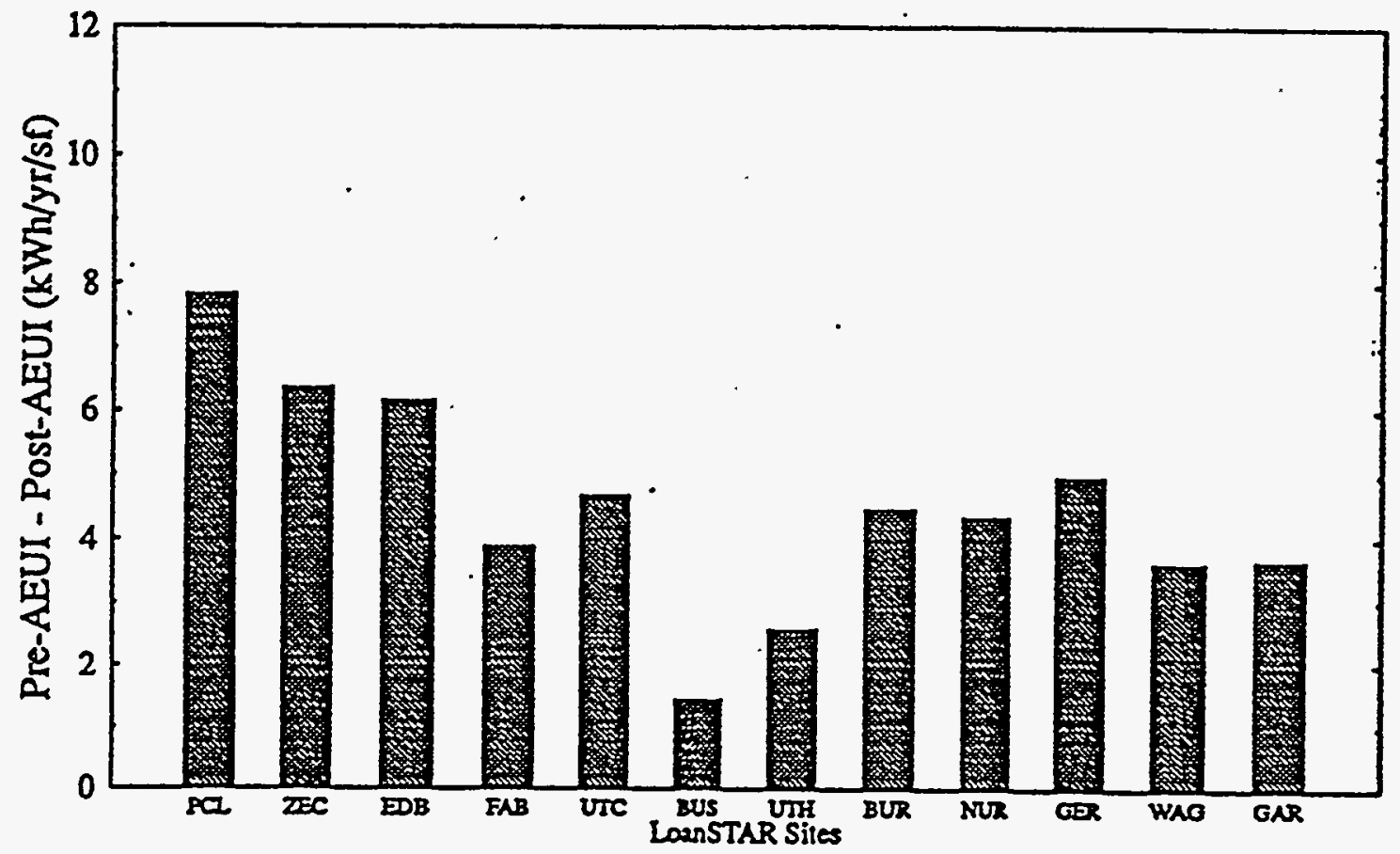


p. 98

Figure 5.3: Electricity Energy Savings from HVAC Retrofits.

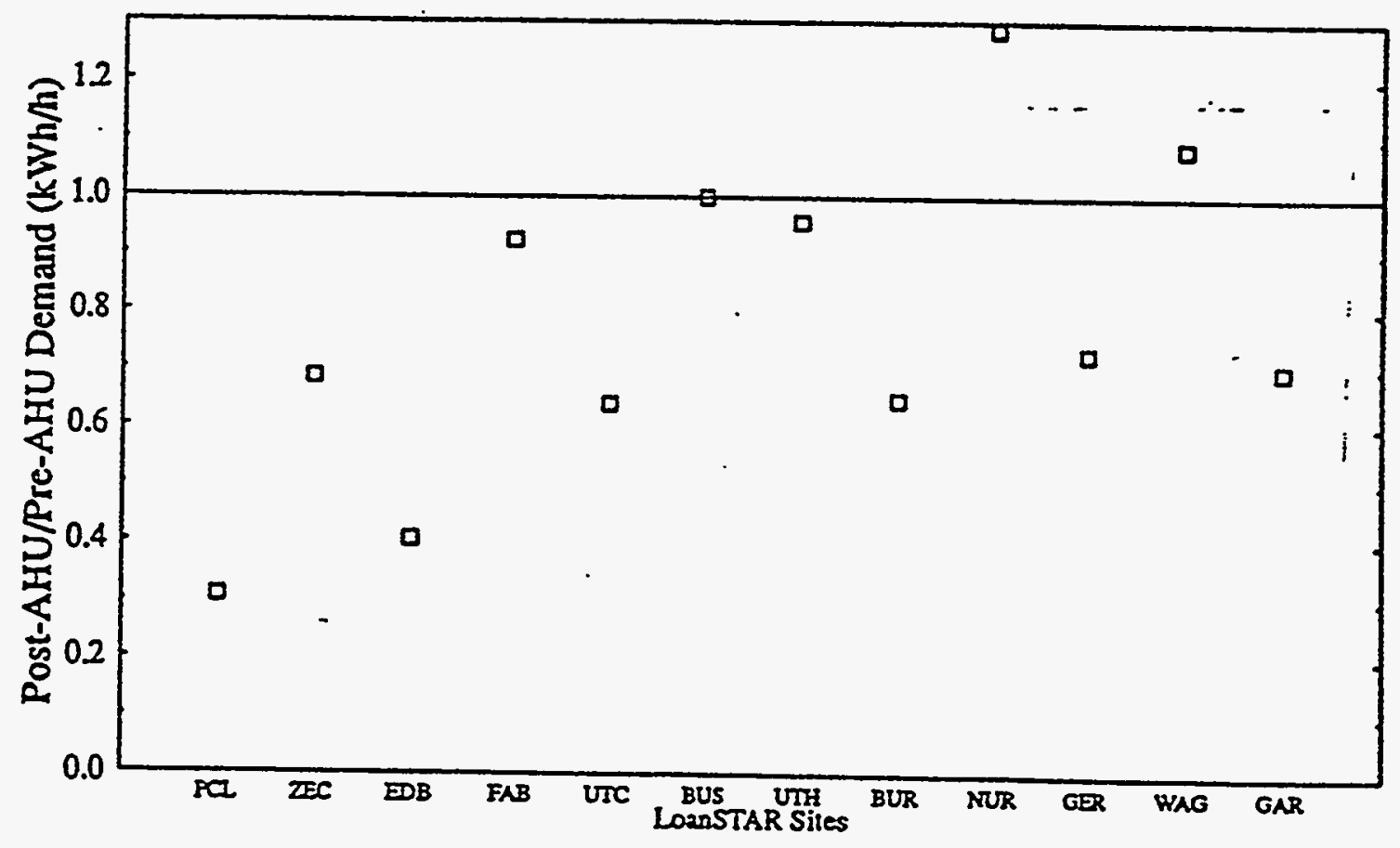



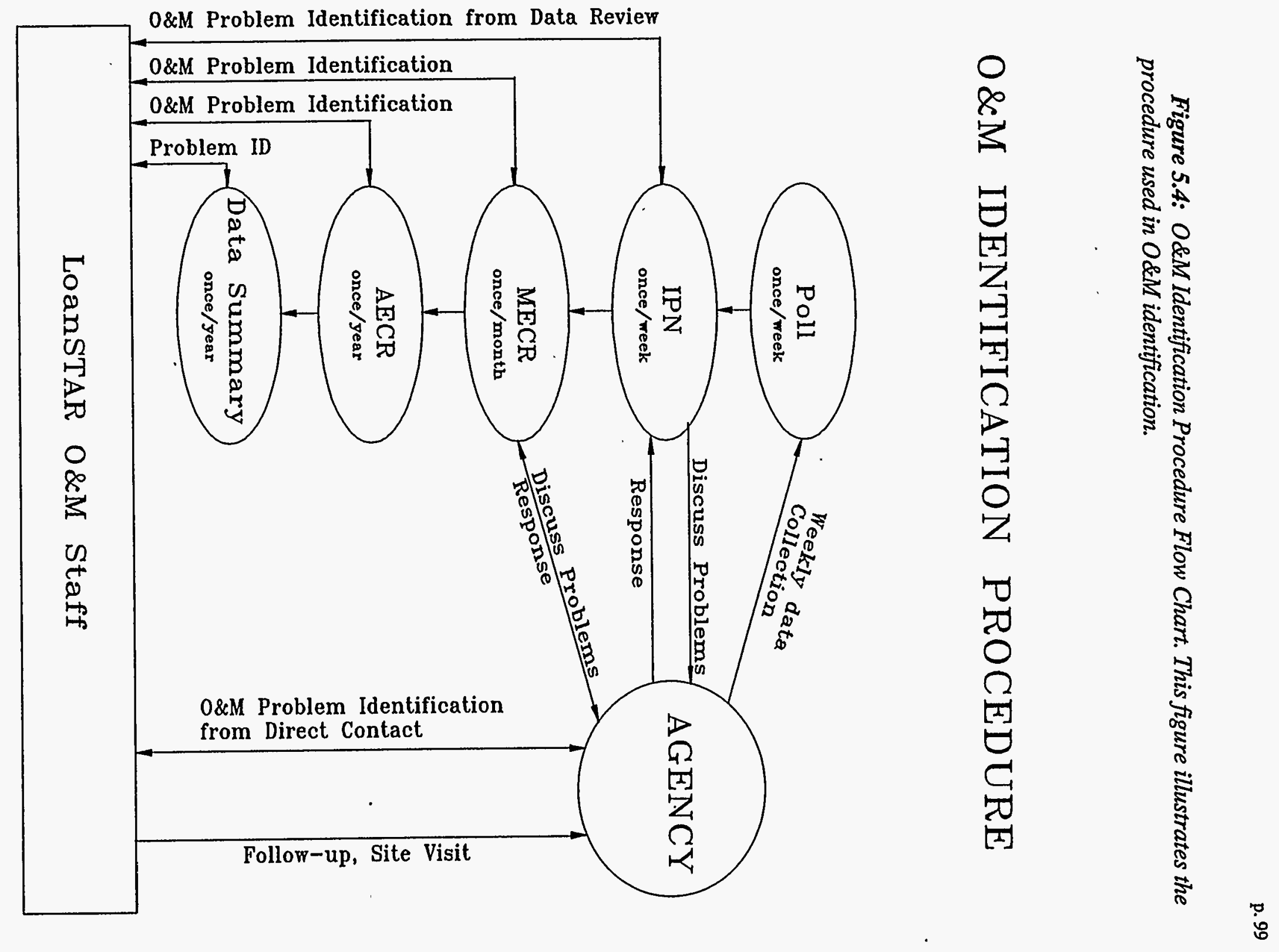


\subsection{RECOMMENDATIONS FROM THE FIRST TWO YEARS OF MONITORING}

\subsection{Recommendations from Task 1}

The LoanSTAR program audit procedure was originally developed from the Institutional Conservation Program (ICP) procedure and format, which generally required an individual report for every building. Therefore, early LoanSTAR reports had individual sections for each building, which could easily be fit into the ICP format, if necessary.

As the program matured, detailed guidelines were written requiring more building and background information, much of which was intended to benefit the subsequent monitoring and analysis of the retrofits. Consultants were at first required to specify metering requirements to monitor retrofits, but this information was not used for a variety of reasons. Actual metering requirements are now determined entirely by the metering and analysis group at Texas A\&M.

As efforts were made to simplify the audit process, the format was changed to an energy conservation reduction measure (ECRM) basis. The goal was to save both on audit cost and on time required to produce and review a report. Instead of repeating an ECRM write-up and calculation for each building, all building data could be compiled and calculated in just one ECRM. This saved effort and often substantially reduced the volume of the report by eliminating repetition. Much of the summary and background information was consolidated to single page table formats and the metering estimate requirements were eliminated.

An effort has been made to simplify the routine procedure even further. Energy saving measures, which are simple to calculate and widely implemented progressed to a fill-inthe-blank type form, referred to as Simplified Calculations (State Energy Conservation Office, 1990). Reference tables with common equipment data (e.g., electric motor efficiencies) and building data (e.g., U-factors) were provided with the forms in order to save consulting time and provide a standard reference base for calculations. The simplified forms have now been computerized into spread sheet programs known as SimpCalc (Apollo Data and Governor's Energy office, 1991) to further speed the process.

Other changes include categorizing ECRMs by degrees of complication. Category I ECRMs (shown in Table 6.1) are those measures whose energy savings are straightforward and paybacks are historically consistent. ECRMs in this category are based on estimated equipment quantities, with the annual cost savings to be determined by dividing the implementation cost by standard paybacks such as those in Table 6.1. Actual equipment numbers are determined for loan purposes by counts of installed or removed equipment made during or after the retrofit. 
Category II ECRMs use the SimpCalc program or other approved simplified calculations. This program includes retrofits such as lighting conversions and controls, building ceiling/attic insulation, and window shading devices. Category III ECRMs require detailed calculations. This category includes complicated projects, which vary widely in either energy savings or implementation costs. These may include variable air volume (VAV) or variable frequency drive (VFD) conversions, chilling system conversions, energy management systems (EMSs), and rate schedule changes.

Accounting for dependencies is accomplished within in each ECRM (i.e., measure interactions). No independent calculations are required as was formerly the case (Governor's Energy Office, 1990). Several consultants informally estimated that this reduces reporting efforts by 10 to $30 \%$.

A review of early program data showed that 19 of 43 reports had no (or negligible) dependencies, while 21 reports revealed dependencies that affected the calculations of cost savings by more than about three percent. In three reports, savings decreased by more than $10 \%$.

O\&Ms have been entirely eliminated from reporting requirements because the program's funding was designated for retrofits and O\&Ms require little or no funding anyway.

Category I-type projects are also known as "direct install” projects. Basically, direct install projects are done with no calculation of energy or cost savings, and Texas A\&M is evaluating LoanSTAR data to see if this approach can be extended to more complex projects than those described here for this Category.

\subsection{Recommendations from Task 2}

Administratively, many lessons have been learned about how to conduct and manage a large monitoring project. The focus of this section, lessons learned, is related specifically to the instrumentation. The presentation of the material is divided into three categories: 1) Equipment, 2) Installation, and 3) Maintenance.

\subsubsection{Administrative Guidelines for Task 2}

There are some administrative guidelines that should be passed on:

1. Installation guidelines should be written for each piece of instrumentation. A prototype monitoring system was installed approximately four months before the project started to allow for evaluation of difficulties of installation, costs, and hardware evaluation. Having a prototype was extremely useful. The feasibility of monitoring a large commercial building at a reasonable cost was demonstrated. Because of the success of the prototype installation and the need to quickly install monitoring hardware in the early phases of the project, it was decided to rely on the contractors' installation guidelines. Unfortunately, the procedures used by the different contractors resulted in non-uniformity in application of instrumentation. 
The only solution was to make sure there was a uniform set of procedures for every installation regardless of contractor.

2. The installation subcontractor must have an engineer on-site during the metering installation. During our first contract year, several data acquisition system contractors were selected through a request for proposal (RFP) process. Only one of the contractors provided an engineer to supervise the installation of their metering projects. The others felt that an initial site visit by the project engineer to get their installing subcontractors (electrical, mechanical, etc.) started and a single follow-up visit to finish the assigned project was adequate. It was quickly determined that the supervision of the installation of this type of instrumentation has to be continuous during the project's duration. Numerous installation errors were made on the sites where no engineer was present. In some cases, these errors were not discovered until every sensor was manually checked and recalibrated. Equally disturbing was that when an electrical or mechanical subcontractor encountered a problem, work was often suspended until the project contractor could be reached, the problem described, and a solution developed. This process at times involved a delay of weeks on the project and incurred extraordinary travel costs.

3. Contractors should be assigned a "test" site to judge their capabilities. Even though contractors selected through the RFP process looked very good on paper, it was decided to assign each contractor a single test site so that an evaluation could be made on the quality of each one's actual installation. It became evident during this process which contractors were capable and which were not. At one of the installations, it became necessary to terminate the contract with the contractor even prior to the completion of the site.

\subsubsection{Equipment Recommendations}

In order to have a meaningful analysis of energy use data on buildings, it is critical that the instrumentation be reliable and provide accurate data on what is being measured. Unfortunately, instrumentation can provide a stream of numbers that may not reflect what is actually being measured. Equipment problems encountered in the first two years of this project have included instrumentation used in thermal metering, electrical measurement, and psychrometric measurements.

\subsubsection{Thermal Metering}

Thermal metering is required for most large commercial building applications where the building is purchasing chilled water, hot water, or steam. In addition, thermal metering may be applied where the user wants to track the efficiency of a chiller or boiler. For the majority of the sites on this project, it has been necessary to install the required transducers (typically thermistors and insertion flow meters) into the piping while the systems are operating. This requirement has made the thermal metering effort difficult and introduces room for more installation errors. These data points typically feed into a 
thermal energy ("Btu") meter, which processes the temperatures and flow rates to calculate the energy use. Some problems with thermal metering have included:

1. A thermal energy meter may pick up $60 \mathrm{~Hz}$ noise from its electrically noisy surroundings. In many building energy applications, a thermal energy meter and the instrumentation associated with it are located in an equipment room, which is an electrically "noisy" environment because of large pump and fan motors. If a turbine flow meter is connected to the thermal energy meter, the thermal energy meter will be expecting a signal from the flow meter, which many have a frequency component. We have seen instances where, with improper shielding, the only signal the thermal energy meter gets from the flow meter is a $60 \mathrm{~Hz}$ noise signal. The analyst may not even realize she or he has a problem because the total thermal energy may show a change from hour-to-hour because of fluctuations in the entering and leaving temperatures of the water. However, the actual thermal energy may be quite different than what is being measured. This problem is being further investigated at the Texas A\&M Energy Systems Laboratory calibration facility (O'Neal, et al., 1990).

2. Two different brands of thermal energy meters most likely will not agree with each other. On one site, one brand of thermal energy meter that was installed according to the manufacturer's recommendations was replaced by a second brand of thermal energy meter installed according to its manufacturer's recommendation. The net result was that the "measured" thermal energy increased by an unexplained factor of two. Currently, both of these brands of thermal meters are being studied in our calibration facility to see if either of them is accurate.

3. A thermal energy meter that is not field scaleable can and will be set improperly at the factory. The initial brands of thermal energy meters utilized had to be set for a specific application at the factory. Information was provided to the factory on the type of flow meter, anticipated temperature difference, pipe size, maximum estimated energy, etc. The factory would then "burn in" a ROM for that particular application or install other hardware for that specific application. Often the estimate provided by the facilities personnel at a given site for the energy rate of the chilled or hot water line was off by factor of two to ten. Likewise, these personnel had only estimates of the pipe sizes and these were often wrong. There were also several meters delivered from the factory that had been incorrectly programmed. The net result was that the meters provided were not appropriate for the particular application. It was not unusual for the manufacturer of the thermal energy meter to tell us that it was going to take an additional four to six weeks to reprogram the meter. Hence, the LoanSTAR program now routinely installs field scaleable Btu meters.

\subsubsection{Electrical Metering}

For many building energy applications, electrical measurements are in many cases the only measurements made. The decision is often based on funds available for the metering installation and on the retrofits being installed in the building. Typically, these 
measurements include whole-building feeds, motor control feed centers, individual motor loads, and lighting loads. Experiences with electrical measurements have included:

1. The marked polarity of current transformers (CTs) may be the opposite of its actual polarity. The polarity of CTs should be checked before installation. On a single phase application, a CT with a reverse polarity may be a nuisance (you'll get a negative power). However, on a three phase application, one CT with reverse polarity will cause major errors in the measured total power of the equipment that are difficult to detect when all three phases are added together.

In a recent application, we had one CT with reversed polarity on a $40 \mathrm{HP}$ three phase variable speed motor. In another instance, a CT with reversed polarity was found on a $30 \mathrm{~kW}$ three phase variable speed motor. The CTs had been installed according to the manufacturer's instructions (i.e., with the arrow pointing toward the line). The indicated power of the motor was $1.5 \mathrm{~kW}$, which did not make sense because of the size of the motor and the fact that it was running at $82 \%$ of its maximum speed. A close check of one of the CTs used to monitor the equipment revealed that the polarity was marked incorrectly. Switching the leads to the CT produced the correct total power of $20 \mathrm{~kW}$.

2. The output of a current transformer may be far different from its rating. Much of the data acquisition equipment used in the monitoring studies utilizes a current transformer that produces a $333 \mathrm{mV}$ output at its rated full load. Voltages of 3 and 10 Volts from some CTs that were clearly marked $333 \mathrm{mV}$ output have been observed. Inputting $10 \mathrm{~V}$ instead of $333 \mathrm{mV}$ into the data logging equipment has produced some very strange readings from the power channels in the data logger. One symptom was that the power signals for a fan load slowly decayed over time. The net result was that the bad CT not only affected the channel to which it was connected, but all power readings from that particular logger including readings from other channels. These problems have mandated to the development of procedures to pre-check the polarity and output of CTs before being installed.

\subsubsection{Other Instrumentation Problems}

In some building applications, it is important to do measurements of the energy transfer into or out of the air stream. These data can be used to better simulate the air-side of the system. Lessons from experience in this area learned thus far include:

1. Some relative humidity instrumentation will be temperature dependent. While relative humidity instrumentation is not supposed to have any dependency on temperature, our experience has shown that specific brands of $\mathrm{RH}$ equipment do show a dependency on temperature. If the RH sensor puts out a 0 to $5 \mathrm{~V}$ signal, and is linear, one would expect it to generate a signal of $2.5 \mathrm{~V}$ for $50 \% \mathrm{RH}$ whether the temperature is $10 \mathrm{C}$ or $30 \mathrm{C}$. Some $\mathrm{RH}$ sensors have indicated that moisture was being added to the air across a heating coil (when, in fact, only sensible heat was being added). While a small error is acceptable, errors that far exceed the stated 
measurement uncertainty of the transducer (typically $\pm 3 \%$ ) are common. Closer inspection of the instrumentation has shown that, as the air temperature increases, deviation from the actual $\mathrm{RH}$ increases.

2. Relative humidity instrumentation may fail to perform adequately after only a few months of operation. Many of the RH sensors use a polymer element. If the humidity instrumentation becomes saturated ( $100 \% \mathrm{RH})$ for any length of time, this type of element does not seem to perform reliably afterwards. Particular applications where this will occur include placement of a RH sensor on the downstream side of a chilled water coil and in weather stations at locations where there are considerable periods (usually at night) when the air is saturated. Measuring relative humidity continues to be a problem. One solution has been to purchase enough $\mathrm{RH}$ sensors that each sensor in the field can be exchanged approximately once every six months (or more often if needed) with a sensor that has been recalibrated.

3. The data logger manufacturer may not volunteer information about an undocumented calibration procedure for their data logger unless asked. In one application, it was noted that none of the analog temperature (1000 Ohm Resistance Temperature Device (RTD)) channels were producing plausible readings; for instance, the entering chilled water temperature reading was $-7 \mathrm{C}$. All instrumentation was checked closely for any possibility of stray voltage being fed into one of the channels. Finally, out of frustration, a call was made to the data logger manufacturer. The applications engineer diagnosed the problem as an analog board that had not been properly calibrated. He provided a step-by-step calibration procedure that was nowhere documented in the technical specification or user manual for the data logger. Not having the board calibrated earlier caused the program to lose four weeks worth of usable data from that data logger. Analog board calibrations are now checked regularly at each logger equipped with the analog option.

\subsubsection{Equipment Installation}

While the above section dealt more with problems with the instrumentation out of the box, many problems associated with instrumentation focus on their application (or misapplication). The problems encountered with the installation of instrumentation are listed below.

\subsubsection{Thermal Metering}

Problems with the installation of thermal metering include the temperature and flow inputs to the thermal energy meter as well as the thermal energy meter itself.

1. The flow velocity may be outside of the useful range of the flow meter. With some buildings, there is already flow instrumentation in place, such as a venturi, orifice, or turbine meter. It can be very cost-effective to utilize this instrumentation. However, for buildings designed before the early 1970s, when dual-duct and reheat systems were predominantly installed in buildings, the flow instrumentation was probably designed for much higher flow rates (and correspondingly higher chilled or 
hot water usage) than is actually occurring in the building. Venturi flow meters operating in flows that were one-third of their minimum rating have been observed. In addition, if no flow meter is in the piping, then a flow meter must be installed. The linear range for several of the insertion turbine meters ranges from 0.6 to $9 \mathrm{~m} / \mathrm{s}$. Chilled water design flow velocities range from 1.2 to $2.4 \mathrm{~m} / \mathrm{s}$. Thus, one would expect the flow velocities to be within this range. However, due to poor design or, perhaps, oversizing in anticipation of future building additions, there have been a number of installations with oversized pipes where the velocities were between 0.15 to $0.6 \mathrm{~m} / \mathrm{s}$. At these lower velocities, insertion turbine flow meters no longer produce a signal at all or produce a signal that is inconsistent with the calibration curve over $0.6 \mathrm{~m} / \mathrm{s}$. One solution has been to develop calibration curves for flow meters in these applications that are only valid at the lower range of the meter. In general, there appear to be no reasonably priced insertion flow meters that can read below $0.15 \mathrm{~m} / \mathrm{s}$. In buildings where this condition occurs a special metering leg will need to be installed that reduces the pipe diameter. This reduced pipe diameter will push the flow velocity back into the range where the meter is useful.

\section{Asbestos insulation may be on the piping where the thermal metering} instrumentation will be installed. Unfortunately, asbestos is one of the hazards encountered in thermal metering in buildings. If the building was constructed before 1970 , one can generally count on asbestos being used in some of the hot water and steam piping insulation. Asbestos abatement can drive the cost of metering so high that it can endanger the installation. "Is there asbestos on the chilled or hot water piping?" should be one of the first questions an engineer asks of the facilities or building manager before even going to the trouble of developing an instrumentation plan. If the answer is "Yes," the next question should be: "Who is going to pay for the abatement of the asbestos?"?

3. The leads from the RTD sensors may follow the longest path and may not be compensated. In many of our installations, the entering and leaving hot or chilled water temperatures are measured. The data logger used for this project can accept a two wire $1000 \mathrm{ohm}$ RTD for direct measurement of temperature. If the lead length to one RTD is $5 \mathrm{~m}$, while to another it is $25 \mathrm{~m}$, then it is possible to have several degrees of temperature difference indicated due to the differences in lead length. Ideally, a three wire RTD should be used, which will allow compensation for the differences in lead length. Otherwise, leads of equal lengths must be used.

4. The diameter of the pipe in which the flow meter is installed may be different from that indicated by the facility manager or shown on the building schematics. With many insertion flow meters, the pipe size is a critical piece of information for both installing the flow meter at the right depth in the flow and setting up the thermal meter correctly. If the pipe diameter is incorrect, then the pipe thickness is also incorrect, which means the depth of the flow meter is also incorrect. While building operators or building schematics (which may not reflect the as-built condition) are useful, the only diameter for the pipe that should be trusted is the one that is measured 
(preferably twice). At one site, the information provided on five different pipes (out of five) was incorrect.

5. If a temperature probe can be reached by a person from the floor, the probe may be used as a chin-up bar, step ladder, or some other aide. On the first major installation on this project, a number of RTD probes were mounted in a near horizontal position within easy reach of maintenance personnel. Within six months, most of these RTDs were at 45 degree angles to the pipe because individuals had used them in ways for which they were not designed.

6. If a temperature probe is no longer functioning, it may be because it no longer exists. On some early installations, the compression fitting used for insertion of RTDs into a pipe allowed the RTD probes to vibrate within the pipe. The vibrations eventually produced a failure of the probe where it protruded from the compression fitting into the flow stream. Eventually, the probes broke off and travelled downstream until they became lodged or were picked up in a stainer. While thermowalls would be one solution to a temperature probe, the cost from "hot tapping" a thermowall is much higher than that for a probe.

\subsubsection{Electrical Metering}

There have been fewer problems with the installation of electrical metering equipment. In many cases, the problems could have been avoided if the installing electrician had been properly supervised.

1. If multiple transformer feeds are available in the building, then the potential transducer (PT) may be connected to the wrong reference voltage. The data logger used for this project has the ability to accept two different PT references, which are used for CT reference and the proper internal calculation of active power. A common field error is referencing CTs to the wrong PT or referencing all CTs in a building to a single PT when there are several transformers (requiring several PTs) in the building. The most extreme case involved a large 12-story office building that had four different transformers. Only one PT was installed and used as a reference for all the CTs in the building. Several costly fixes have been necessary to correct the problem and several months' worth of pre-retrofit data have been lost.

\section{If current transformers are connected to a secondary line, they may not be scaled} correctly. On large electrical loads (i.e. main building feed, centrifugal chiller feed) there often are existing current transformers available. These existing CTs are used by building operations personnel to monitor the electrical loads at these devices. For example, a large centrifugal chiller might have CTs with 1000 to 5 ratios on each of the 3 feeds to the chiller motor. The ratio indicates that the CT will output 5 amps if the motor is loaded at 1000 amps. The monitoring technique consists of installing a second 5 amp CT on the existing CT secondary wire. The CT ratio of the primary and the secondary CT is then necessary to calculate what the final CT ratio actually is. This is the ratio used to properly scale (through the data logger software) the signal 
received at the data logger. In some installations, the primary CT ratio was not determined and the ratio was guessed. Only after the existing CT ratio is properly determined and field verified can the signal be trusted.

3. The standard conventions of three-phase power installation in electrical cabinets may not be followed. Electricians are supposed to use a standard set of rules for installing $A, B$, and $C$ phases of three-phase equipment. These three phases should go (as one faces the electrical connection) left-to-right $(\mathrm{A}, \mathrm{B}, \mathrm{C})$ or up-to-down $(\mathrm{A}, \mathrm{B}, \mathrm{C})$ or front-to-back $(A, B, C)$, depending on the style of the cabinet. One subcontractor installed all the three phase current transformers with the above assumptions without checking to see that the electricians who installed the original equipment in the cabinets were consistent. Another subcontractor had to be brought in to this site and to sort out the problems and resolve the current transformer referencing confusion.

\subsubsection{Other Instrumentation}

1. Data acquisition boards on the data logger can substitute as expensive fuses. With the particular data logger used, it has been found that when a 4 to 20 milliamp transducer is installed into a channel that was expecting a 0 to 5 Volt dc input, the analog board on the logger becomes an expensive fuse that protects the rest of the data logger from any damage. The only problem is that the analog board must be replaced after each mistake.

2. The data logger may be programmed incorrectly when you first start collecting data. The data loggers used vary from 4 to 45 channels connected. While care is taken to program the data loggers correctly when the site is first brought on-line, the loggers on every site have had to be carefully checked channel by channel to ensure that what is given in the documentation is in fact what was programmed into the logger.

\subsubsection{Equipment Maintenance}

Once the instrumentation is in place, it will have to be maintained. The maintenance may be more difficult to handle than the original installation. If an instrument fails, it requires a trip to the site to diagnose the problem and at least one more subsequent trip to the site to fix the problem. The cost of maintenance will probably exceed the initial expectations of personnel on the project. The types of failures seen in the field will depend on the type of instrumentation used. The rule of thumb is to expect every piece of instrumentation to fail at some point in the program. In the two years, the types of maintenance problems and failures seen thus far include:

1. Modem failure. While the number of modem failures in the past two years has been fewer than five, the failure of one modem can potentially disrupt the data collection for two to three buildings when the buildings are tied to the same data logger. One particularly annoying failure of the modem can occur after a short power outage. The modem will not properly reset, and when calls are placed to the data logger, the modem does not answer. Thus, the logger cannot be reached remotely via the phone. The modem and the logger have to be physically turned off and then back on to 
properly reset the modem. Because there are buildings hundreds of kilometers from each other on this project, doing this more than once can be very time consuming and costly. Two methods have been developed to reduce the cost of this type of failure. The first method involves the insertion of a timed power interrupted circuit. The second method involves training personnel at the remote site to reset the loggers.

2. Dewpoint sensor getting dirty. After the temperature dependence and saturation problems were identified with some $\mathrm{RH}$ instrumentation, chilled mirror dewpoint sensors rated for outdoor use were specified for several weather stations at high humidity locations. While more accurate and reliable, these sensors require at least bimonthly maintenance to clean the mirror and they need to be completely recalibrated every six months. Furthermore, it was found that calibrating a chilled mirror is far more difficult than calibrating an $\mathrm{RH}$ sensor.

3. Equipment disconnected or damaged. When energy conservation retrofits were installed under the LoanSTAR program (Nutter, et al., 1990), some of the energy metering equipment was damaged by the retrofit contractor. This damage is not evident until the data logger has been polled. The cause of the problems cannot be diagnosed without a visit to the site. At one site, it was found that an electrical subcontractor had disconnected the wiring for both power and CT inputs to the data logger. At another site, an asbestos abatement contractor ripped the wire out from a steam pressure transducer and caused a short to the data logger. The problem caused the loss of several weeks of building energy data. Measures are being taken to ensure that the building operations people as well as the designers for the energy retrofits are made aware that there is metering equipment installed in their buildings. Contractors are also held liable for damage to the data loggers and sensors (i.e. property of the state of Texas.)

4. Aspirating fan failure on weather station. The weather stations are equipped with aspirating fans, which ensure that an adequate fresh air sample crosses the relative humidity (or dewpoint) sensor and the dry-bulb temperature sensor. When measured air temperatures approached $50^{\circ} \mathrm{C}$ at one site, it became obvious that there was a problem. During a site visit, it was found that the aspirating fan had become "stuck" and after being given a helping twirl, it started again. Subsequent data showed marked improvement and the fan has continued to operate normally.

5. Current transformer failure. There have been several instances of the shunt resistor failing in the CT. This allows the CT to output a voltage far higher than the 0.333 VAC rated load. In one case, the CT was outputting $10 \mathrm{VAC}$, which caused the logger to record false power readings for the affected channel as well as other channels.

6. Flow meters can wear out. In sites where flow velocities are in excess of 5 to 10 $\mathrm{ft} / \mathrm{second}$ the small wheel in the flow meter spins at a very high rate. Over time, this can wear out the shaft. In the worst case the shaft will break in two. In other cases, the wheel wobbles on the shaft which causes inaccurate readings. 
7. Data loggers can lose their identity and become something else. In spite of the fact that the primary data loggers used in the program are extremely reliable a few simply lost their programming for no apparent reason and had too be replaced. Luckily, with some coaxing, the manufacturer overnighted a replacement which saved us travel costs.

\subsection{Recommendations from Task 3}

The recommendations presented here relate to calibration of new equipment, installations of equipment to achieve stated accuracy and re-calibration of equipment to ensure continued accuracy. Accuracy of data depends upon the calibration and stated accuracy of the equipment, proper installation of all equipment, and the maintenance or re-calibration of the equipment.

\subsubsection{Equipment}

Different types of monitoring equipment have different calibration needs. These needs depend upon the harshness of the environment, the sensitivity of the equipment to the environment, the existence of moving parts, and the ability of electronics to maintain stable settings. Additionally, frequency of calibration, ease of calibration, and the need install new parts as part of the calibration process vary for any given piece of equipment. It is reasonable to anticipate that new equipment should arrive fully calibrated with the accuracy as stated in manufacturers specification sheets. At the least, there is a need to field verify the calibration of equipment. However, some equipment does not operate at the stated accuracy and cannot be calibrated other than through software manipulation of data. At the worst, some types of new equipment require calibration in every case.

Recognizing a calibration problem is not always simple once the equipment is installed in the field. Equipment failure, Data Acquisition System (DAS) software problems, data retrieval problems, and data reduction software problems complicate the issue. An effective isolation technique is to view real time data and compare it to time series records (TSRs) data and anticipated load levels. Shared signals from facility energy management and controls system (EMCS) are dependent upon facility calibration schedules if they are calibrated at all. These shared signals are usually difficult to calibrate.

\subsubsection{Electrical Metering}

Electrical metering equipment consisted of current transformers (CTs), potential transducers (PTs), Watt Hour Transducers (WHTs), and the DAS. Additionally, utilities or facilities provided pulse initiators on their meters for whole-building or campus metering in about half of the sites. For the LoanSTAR project, these items were factory calibrated and were accurate. A double check of given scale factors is recommended. Field verification of loads was always completed using hand-held RMS, volt, amp, and watt meters. Early in the project, the CTs, PTs, WHTs, and DASs were checked for accuracy in the Calibration Facility to ensure the specified accuracy of the selected equipment. These types of equipment had to be as accurate as specified because there are 
no physical calibration adjustments available. If errors had existed, software corrections would have been necessary when possible.

\subsubsection{Thermal Metering}

Thermal metering equipment consisted of liquid flow meters, temperature sensors and flow/Btu totalizers. These equipment items were factory calibrated and have no physical calibration capability. The various items selected for use in the LoanSTAR program were tested in the calibration facility. The temperature sensors and Btu/flow totalizers were as accurate as specified. Spot checks on those items of new equipment are completed on an ongoing basis. The insertion type paddle wheel flow meters are not as accurate as specified by the manufacturers in flows less than $3 \mathrm{ft} /$ second depending on the manufacturer. The calibration facility tests every new insertion flow meter prior to installation, so that corrections may be made to data. In-line type turbine flow meters, target meters and shedding vortex meters were tested and found to be accurate.

\subsubsection{Other Equipment}

Other equipment requiring calibration attention or review included Analog Data Acquisition Systems, weather stations, and gas pulse initiating meters. The gas meters were calibrated by the utility and in effect are identical to the meters used for their billing purposes. The Analog DASs have a calibration capability and are checked and adjusted if necessary upon completion of installation. The modular weather stations complete with solar radiation, wind speed, dry-bulb temperature, and relative humidity $(\mathrm{RH})$, or dew point temperature sensors, were calibrated by the supplier. Replacement sensors and newly constructed weather stations are tested and calibrated at the calibration facility. The solar and temperature sensors with associated transmitters calibrate easily and are normally accurate. The wind and $\mathrm{RH}$ sensors are difficult to calibrate and are typically not within the manufacturer's stated accuracy.

\subsubsection{Installation}

Proper handling and installation of equipment is a necessity in order to ensure the calibration and proper function of the equipment.

\subsubsection{Thermal Metering}

In order to achieve maximum accuracy there are several considerations. Study of the physical piping is usually necessary to be sure which pipes are right for supply and return. This may seem simple, but in a maze of piping, it is easy to neglect to notice a supply or return line, which feeds from or into the line being metered. This can reduce the metered load and could be difficult or impossible to detect. Placement of the flow meter in a straight section of piping without obstructions for 10 pipe diameters on the up stream side and five pipe diameters on the downstream side is normally recommended. Although this is rarely possible, the installer should study the piping to find the best possible alternative. Extra care should be taken to insert the meters to the specified insertion depth. Field verifications of flow rate and temperatures is necessary to be certain that the flow/Btu totalizers are functioning properly.

\subsubsection{Electrical Metering}

Texas LoanSTAR Program

Texas Engineering Experiment Station

Energy Systems Laboratory

Texas A\&M University 
The main consideration for installation of electrical metering equipment to achieve accurate readings is phasing. The $C T, \mathrm{PT}$ and DAS programs must all be in phase agreement for accurate power measurements. Also, in the confined areas of electrical panels, it is easy to place the CT on the wrong phase or the wrong load. Care must be taken to trace each wire prior to installing the CTs. Field verification of every CT and PT output and DAS power calculations is desired using hand-held amp, volt and watt meters. In some cases watt verifications may be impossible, but volt and amp readings can be adequate for a calculated watt verification.

\subsubsection{Other Equipment}

The physical placement of weather stations and DASs is important for maintaining accuracy of calibration and accuracy of data. The DAS should be located in an environment that is not too harsh, such as one that is or could become wet, too hot, or too dusty. The weather station must be placed where it is free from interference from ambient conditions. The main considerations are shading of the solar sensor and building exhaust, which would affect RH and temperature data. Extra care should be taken with sensors as they are very sensitive. Field verification of $\mathrm{RH}$ and temperature using a hand-held instrument is recommended.

\subsubsection{Maintenance}

Maintaining calibration of equipment throughout the life of a monitoring project is essential. Naturally, when equipment fails it is anticipated that replacement items will be calibrated. It is simple to recognize failed equipment, but a different matter to recognize equipment that has lost its calibration. Weekly review of data records is needed to spot equipment problems. When a potential problem is spotted, it is suggested that current data be compared to old data and that real time data be reviewed and compared to the most current time series record. Additionally, a discussion with facilities operators will help recognize operational changes of equipment being monitored.

Rather than wait for equipment to lose its calibration, it is more desirable to change it out just prior to the need for re-calibration. In order to accomplish that, a maintenance schedule for calibration must be established. Naturally, this will depend upon the quality of the equipment used, as well as the quality of the installation.

\subsubsection{Thermal Metering}

In-line flow meters have proven to be accurate and dependable if they are measuring flow velocities between 3 and $10 \mathrm{ft} / \mathrm{second}$. The life of the calibration has not been determined. Failure of these items has been limited to excessive temperature and most often, mistreatment by facilities personnel. Flow rates have been fairly stable where this type of meter has been used, making it relatively easy to recognize equipment problems.

Insertion type paddle wheel flow meters are removed for calibration after 12 to 18 months of service. It appears that calibrations have been maintained over the period in most cases. The main problem has been paddle wheel shaft wear, which eventually leads to failure. The meters with excessive wear were repaired and recalibrated. A post-removal 
re-calibration was completed in every case except one, where the paddle wheel shaft was broken. Upon completion of a flow meter change out, a field verification of flow and temperatures must be completed and compared to flow/Btu totalizers data.

\subsubsection{Electrical}

There has been no need of a maintenance schedule for electrical metering equipment. The life of the factory calibration has not been determined. A very limited number of current transformers have failed. Failure was easily noted in the weekly data review. Replacement and field verification of new equipment was completed.

\subsubsection{Other Equipment}

Analog Input Data Acquisition Systems should be checked for calibration annually. The Analog DAS used in this project has a calibration check channel, which can be stored into time series records or viewed in real time each week when data are down-loaded. Drift is normally less than $1 \%$ of scale and adjustments made were completed during visits to the facility for other purposes.

Weather stations require the most calibration maintenance. It is recommended that all sensors be recalibrated every 6 to 12 months. Depending upon the quality of the instruments, replacement of the wind sensor and RH sensor may be necessary every 1 to 2 years. The LoanSTAR project maintains seven weather stations with an eighth station now used as a complete calibration change out. After nearly three years of service, it became necessary to rebuild the entire weather station with a new wind sensor, $\mathrm{RH}$ sensor, and temperature sensor. A recalibrated solar sensor was used and a new aspiration fan was installed. Each removed sensor undergoes a post-removal calibration check and is then recalibrated if possible. During the 3 years of service there have been many individual sensor failures. Weather stations require the most in calibration needs and first in maintenance needs when compared to all other equipment used.

\subsection{Recommendations From Task 4}

In this section recommendations are presented based on experiences from Task 4-the Communications Test Bench and Computer Support group. In a large project such as the LoanSTAR program, the first step in the data management involves acquiring the data by polling the remote loggers over existing phone lines, followed by some sort of quality control and cross checking, and finally visual inspection of the incoming data, including cross-checking of weather data against NWS weather data, etc. The sections that follow discuss the recommendations for each of these issues. A list of the public domain software used in the LoanSTAR program is included at the end of this section.

As of June 1993, each week the LoanSTAR program was retrieving and analyzing over 3 MBytes of data (1,000 + channels) from 82 loggers, which covers 200 + buildings, and 50 weather stations from the NWS. This includes hourly and 15 -minute data from remote Synergistic and Campbell loggers via phone lines and data from weather stations accessed through the NWS Aviation Weather Observations. Special purpose software was developed for the polling, including the POLLC180 program, to call the loggers 
automatically and download exactly 168 hourly records or 67215 -minute records from each logger beginning and ending on midnight on Monday each week.

For any project involving this many data channels, the following recommendations are made:

\subsubsection{Acquiring the data}

1. First, make sure to check the manufacturer's polling software to be sure how the loggers are called, how records are retrieved, and how data are captured on the disk. In general these programs allow the user to connect to the Data Acquisition system either through a modem or RS232 and perform rudimentary functions on the system from remote locations. The programs also allow data to be downloaded into predetermined formats, such as columnar ASCII, spreadsheet formats, or complicated proprietary formats that might include headers and footers for each page of information, which need to be removed prior to integration into a continuous data base.

2. DASs must be polled periodically to remove data before the local memory is overwritten with new data. The maximum time between pollings depends on the amount of data collected and the frequency with which data are stored in memory.

3. A PC-based flat file type of data structure is appropriate for a limited number of sites, say 10 to 20 . Beyond that number, at 52 files per site per year and one directory per site, the data handling limits of the PC can soon become a problem. Each hour of data should have a site number attached (i.e. - each row of data) in case file names become corrupted and one needs to double check the individual records.

4. Raw files should be captured and archived without any tampering. In this way data can be restored to the data base in case of a disk crash. Any adjustments, and/or editing required for a given channel can then be recreated exactly.

5. A flawless permanent record should be made of any "adjustments" made to the data.

6. The processing of data should be as automated as soon as possible to avoid human error. Access to the data, especially the ability to write permanently to the data base, should be tightly controlled and monitored. Multiple generations of tape backups are required.

7. The use of modular routines, or filters, and a standard format is the most efficient means of handling data from different sites. Modular routines are very helpful for processing data, such as the ones that form the foundation of the LoanSTAR data processing. The use of a standard format ensures that one routine will work across multiple sites. A decimal date stamp is important for calculating the day of the week and is helpful in plotting. 
8. Most of the polling in the LoanSTAR program is performed at 1200 baud. At 1200 baud a significant amount of time is spent "on the phone" each week pulling data down from the loggers. Certain "quiet" sites can use 2400 baud, which cuts the connect time; however, 1200 baud will probably be required in most large mechanical rooms where $60 \mathrm{hz}$ electrical noise is significant. Budgets should be prepared for significant long distance phone bills. For example, the polling of 82 loggers in the LoanSTAR program requires almost 13 hours on the phone each week. Obviously, with the advent of fiber optics, digital-FM communications, the internet and satellitebased communications, this should improve substantially.

9. In general, experience with the LoanSTAR program has indicated that 9 out of 10 (i.e., 90\%) sites will be error-free each week during the polling process. With due diligence, this can be cut to 19 out of 20 (i.e., 95\%) sites. This reinforces the need for rapid response to problems and easy access to loggers and sensors, etc. For a given logger, $5+$ weeks of data could be lost each year yet still maintain $90 \%$ data quality (assuming all the retrieved data were perfect).

\subsubsection{Data quality control}

1. Control of logger parameter sets and channel tables is as important as the data itself since the data are $100 \%$ dependent on any processing that takes place at the logger or on the way toward the data base. Therefore a complete history of channel tables and logger parameter sets, as well as backup copies, is mandatory.

2. All data should pass through static high-low filters, such as those provided by the public domain ARCHIVE program (Feuerman and Kempton 1987).

3. Data should be checked for continuous records. Loggers often lose power and certain loggers do not record data until power is restored, leaving a gap in the data records. These gaps must be sought out and tagged with a missing label such as "-99" or filled by the appropriate means.

4. Each week a logger should be checked for power outages, and have its clock inspected to ensure that the time is synchronized. Sumchecks and analog ANCHECKs (this is a special feature that one manufacturer provides to check the integrity of their analog to digital conversions) should be applied where appropriate. Some thought should be given ahead of time how to handle daylight savings. All of these features are incorporated into the public domain LoanSTAR software, such as the POLLC180 and ARCHIVE programs.

5. Weather data are also critical if weather-dependent analysis is being performed on a building. Cross-checking weather station data with the NWS data are helpful and can be useful for quickly spotting "dead" aspiration fans or sensor drift. With some diligence, dry-bulb temperature, humidity, and solar can be cross-checked with the NWS. Only the wind speed is problematic since the NWS records peak wind gusts 
each hour, which typically do not correlate with the average hourly wind readings that a data logger records.

\subsubsection{Hardware issues}

1. DOS-based PC's are probably useful up to the 50-site level with no more than one year's worth of data. Beyond that a networked, UNIX-based system or mainframe computer becomes a necessity. This is driven mostly by efficient access to the data. Also, having more than one PC means that a user will need to go from one computer to the next to retrieve data. This can be a problem when one wants to access channel five from site 40 on the first PC and merge it with channel 1 from site 10 on another PC. Networked PCs do provide some advantage but are still limited in their data storage capability and processing speed, especially when a large relational data base is used.

2. In the LoanSTAR program we found the following to be barely adequate for 50+ users: One UNIX-based server, 64 MB RAM, 3.5 GB disk space; one PC NetWare server, 386-33 MHz, 16 MB, 1.5 GB disk, one floating license server, 386SX-20, 4 MB RAM, 40 MB disk; 64 PC workstations, 3 UNIX workstations, 3 X-terminals, one high speed printer and 26 desk top printers.

3. Staffing needs are critical. LoanSTAR has a programming manager, a data base administrator, a hardware manager, and a small group of staff, students, and faculty.

4. If inspection plots are to be plotted for more than a few hundred channels there is a need for a high speed laser printer, preferably one that is very durable and can be fixed fast when it breaks.

\subsection{Recommendations from Task 5}

In this section, we list and briefly discuss recommendations relating to our experience from Task 5-Analysis and Reporting. Specifically, we shall address issues involving 1) agency contact and site description, 2) pre-screening of data, 3) modeling and analysis , 4) savings calculation, and 5) reporting of savings.

\subsubsection{Agency Contact and Site Description}

- 1. There is a definite need for an agency contact to provide a two-way communication channel for determining status of retrofits, verification of monitored data, setting up meetings and scheduling visits, following up on monthly reports and O\&M identification and verification. It is recommended that one person from the monitoring group and one person from the site being monitored be selected to carry out all communication. We have found this system to be the least intrusive while maintaining good communication.

2. It is also recommended that a Site Description Notebook (SDN) be maintained for each building. The SDN should include the following specifics: photographs of the site, site summary form, site description form, data channel list, monitoring diagrams, 
ECRM list, O\&M opportunities, estimated savings from the audit report, modeling characteristics, Monthly Energy Consumption Reports (MECRs), Annual Energy Consumption Reports (AECRs), Data Summary Notebooks (DSNs), Weekly Inspection Plots (IPNs)and all communication to and from the site.

\subsubsection{Pre-screening of Data}

1. Weekly Inspection Plots (IPN) in the form of time series plots of hourly data for all monitored channels have been found to be useful in providing the analyst a means of detecting data abnormalities in either the building operation or in the monitoring. These abnormalities can then be either rectified or the bad data eliminated before further data manipulation and analysis is done. This data quality control and diagnosis of operating changes and problems is crucial for proper retrofit savings analysis.

2. Data exploration software (we are currently using Voyager software) is routinely used to examine system performance and analyze consumption data at an hourly level. A program such as this is a very useful tool to have.

3. A software program that automatically deletes missing hourly data and aggregates hourly data into daily data eliminates hours of tedious manual data manipulation.

4. A program that merges the monitored energy data with concurrent climatic data, either from specially installed weather stations or from National Weather Stations, is also a useful tool that reduces analyst time.

\subsubsection{Modeling and Analysis}

1. Normally, six months or more of hourly or daily pre-retrofit data are required to develop accurate regression models. It was found (Kissock et al., 1992) that regression models based on fewer than three months of data may seriously misrepresent annual energy use. However, if the mean outdoor dry-bulb temperature during the period of data availability is close to the annual mean temperature, three months of data may be adequate to yield accurate regression models. If fewer than three months of data are available, the simplified calibrated systems modeling approach (Katipamula and Claridge, 1993) is recommended.

2. Though there are numerous computer packages available to view data and perform statistical analysis, we have found none that is user-friendly, relatively cheap and enables data viewing and statistical analysis to be performed interactively. In an attempt to resolve this problem an in-house program called EModel (Kissock et al., 1993) has been developed for the analysis of building energy use data. It integrates the previously laborious tasks of processing, graphing and modeling in a user-friendly Microsoft Windows environment. Its built-in features allow for quick determination of baseline energy use models. Copies of EModel can be obtained by contacting the authors at the Energy Systems Laboratory. 
3. Regression models based on daily time scales with outdoor dry-bulb temperature as the only regressor variable are most frequently used in the LoanSTAR program to model weather dependent energy use. Models may involve two parameters, three parameters or four parameters. On the other hand, weather independent energy use is modeled using mean or one-parameter models. In any case, we have found that the accuracy of our savings estimates is increased if proper day-typing is done. This involves separating days into groups with more or less similar building operating schedules. The common data groups for buildings on a university campus or in school districts are: weekdays, weekends, holidays, Christmas-New Year's Day holidays and semester breaks. The extent to which the models improve when other regressor variables are added is an issue currently being investigated. Finally, for those buildings where neither hourly or daily pre-retrofit nor post-retrofit data are available, utility bill analysis is the only recourse. Analysis methodologies for such cases have been studied, and though preliminary recommendations are available (Yue, 1993), these are rather specific to the building, the type of retrofits performed, and the type of post-retrofit monitoring installed.

There are specific instances where hourly models are more appropriate, for example, in buildings where HVAC systems are scheduled on/off according to a predetermined time-of-day. As of May 1993, we have 17 sites with daily regression models, 3 sites with hourly regression models, 3 sites with zero level models, and 2 sites with calibrated simplified systems models. An example of a site that needs an hourly model would be one where HVAC systems are turned on/off according to a EMCS schedule that varies with semester and non-semester use.

4. Increased automation in the modeling phase would be valuable for monitoring programs. Our current approach to modeling, which involves a more or less well defined methodology, is not automated, partly because several judgment decisions are required at several points. Though the analyst cannot be entirely eliminated, her or his involvement can be reduced by resorting to methodologies that are amenable to automation.

\subsubsection{Savings Calculation}

Once the models have been developed, it is recommended that a special program be written for routine (i.e., monthly) calculations of energy savings. As of May 1993, LoanSTAR uses an in-house program called ESAVE, which contains all the dates (retrofit dates, day grouping information, etc.) and model data (regression coefficients, etc.) specific to each individual building. The user has merely to supply the program with climatic data and energy use of each day of the month for the program to calculate savings for all buildings. This procedure is currently being further automated by imbedding the model data specific to each building into the Informix Database, which contains all the monitored hourly data as well.

\subsubsection{Savings Reporting and Follow-up}


1. Monthly Energy Consumption Reports (MECRs) are mailed each month to the site contact of each building. These MECRs are about 6 pages per building and provide hard copy tabular and graphical feedback on monthly, daily and hourly performance of building systems. Plots such as time series plots (both 2-D and 3-D) and scatter plots are used. We have found this type of reporting to be useful to building operators and administrators, facility and design engineers, and project managers.

2. Another form of reporting, which is strongly recommended, is an Annual Energy Consumption Report (AECR) for each building. This is similar to the MECR but performance over the entire year is summarized. In the LoanSTAR program the $\mathrm{AECR}$ (and the accompanying monthly analysis) is the only report for sites where the retrofit cost is to small to justify installing a logger.

3. We also recommend telephoning each of the site contacts a few days after the MECRs have been received to discuss the problems highlighted in the MECR by the LoanSTAR staff. This follow-up call is a means of maintaining continued involvement and fostering good will. All comments about a site need to be entered into the permanent database for that site.

4. Finally, we recommend that a minimum of information be sent routinely to the site contact; sending too much information can overwhelm them and is often distracting. For example, it is not wise to send weekly Inspection Plots (IPNs) or a detailed description of the particular models used to determine savings to sites where it has not been requested. Our current practice is to send Weekly Plots and Voyager data files only to those sites, which have specifically requested them. 
Table 6.1: Category I ECRMs.

\begin{tabular}{|l|l|l|}
\hline \multicolumn{1}{|c|}{ ECRM } & $\begin{array}{c}\text { Payback } \\
\text { (years) }\end{array}$ & \multicolumn{1}{|c|}{$\begin{array}{c}\text { Minimum Annual } \\
\text { Operation (Hours) }\end{array}$} \\
\hline Delamping & 1 & N/A \\
\hline Repair Steam Traps & 2 & N/A \\
\hline Incandescent to 18-W Screw-in & 2 & 6500 (replacing 60-W inc.) \\
or Fluorescent PL (cost less than \$20/unit) & 2 & 3400 (replacing 75-W inc.) \\
\hline Incandescent to H.P. Sodium & 4 & N/A \\
\hline Incandescent Exit Lamps to 9-W (or less) & 3 & N/A \\
Fluorescent (install cost less than \$35 per & & \\
unit) & & 4400 \\
\hline Energy-Efficient Fluorescent Lamps & 2 & N/A \\
\hline Photocells on Exterior Lights & 3 & N/A \\
\hline Time Clock Shutdown of Equipment & 3 & \\
\hline
\end{tabular}




\section{ENERGY SYSTEMS LABORATORY \\ Dept. of Mechanical Engineering/Texas A\&M University/College Station, TX 77843-3123 \\ AVAILABLE SOFTWARE \\ These packages are available for distribution now. Others will be added as they are ready. Send inquiries to the attention of Mr. Robert Sparks, ph. 409-847-8779.}

\begin{tabular}{|c|c|}
\hline $\begin{array}{l}\text { 1. 023-124 } \vee 1.1 \\
\text { Adjusts time stamps in columnar data to convert from the 0-23 } \\
\text { representation of hours to 1-24 representation. } \\
\text { D Bronson, R. Sparks, J. Haberl }\end{array}$ & $\begin{array}{l}\text { 14. MK3DSurf v.9 10/92 } \\
\text { Creates a 3D surface animation from time series data using Golden } \\
\text { Software's SURFER and Lantern Corporation's MOVIE. } \\
\text { R. Belur, J. Haberl, R. Sparks }\end{array}$ \\
\hline $\begin{array}{l}\text { 2. 3DMac }>1.010 / 91 \\
\text { A Lotus } 1-2-3 \text { macro that facilitates graphing 3D surfaces using } \\
\text { Intex Solutions' 3D-Graphics. } \\
\text { Matson, J. Haberl }\end{array}$ & $\begin{array}{l}\text { 15. MKVoy-DOS } \quad \mathbf{9} 7 / 92 \\
\text { Prepares time series data for compilation into Lantem } \\
\text { Corporation's Voyager. } \\
\text { Kissock, J. Haberl }\end{array}$ \\
\hline $\begin{array}{l}\text { 3. 3DMacXC } 72.09 / 92 \\
\text { A Microsoft Excel v4.0 macro for producing 3D surface plots. } \\
\text { R. Belur, R. Sparks, J. Haberl }\end{array}$ & $\begin{array}{l}\text { 16. Min_Conv v } 1.34 / 92 \\
\text { Converts an } \mathrm{n} \text {-minute data stream to an m-minute data stream } \\
\text { where } \mathrm{n} \text { divides m. (e.g. } 15 \text { min. to hourly or houriy to daily) } \\
\text { R.Sparks, R. Belur, J. Haberl }\end{array}$ \\
\hline $\begin{array}{l}\text { 4. Air } \quad \text { v } 1.31 / 92 \\
\text { Performs psychrometric calculations on columnar data. } \\
\text { R. Sparks. S. Katipamula, J. Spadaro, J. Haberl }\end{array}$ & $\begin{array}{l}\text { 17. Min_Shift } \quad 1.14 / 92 \\
\text { Moves timestamps in a file by an arbitrary number of minutes } \\
\text { (useful for correcting for DST) R. Sparks, R. Belur, J. Haberl }\end{array}$ \\
\hline $\begin{array}{l}\text { 5. Multiwindow Animate } \quad 1.13 / 93 \\
\text { A flexible MS Windows compatible program for producing X-Y } \\
\text { animation of columnar data. } \\
\text { R. Sparks, G Bailey, J. Haberl }\end{array}$ & $\begin{array}{l}\text { 18. Missing } \quad \nabla 1.42 / 93 \\
\text { Replaces missing records (rows) in columnar data. } \\
\text { R.. Sparks, K. Weber, J. Haberl }\end{array}$ \\
\hline $\begin{array}{l}\text { 6. Archive A\&M } \quad \mathbf{1 . 1 1 / 9 2} \\
\text { Princeton Archive with A\&M patches. }\end{array}$ & $\begin{array}{l}\text { 19. PollC180 v1.1 WFA* } \\
\text { Unattended polling of Synergistics C180. } \\
\text { R. Sparks, K. Weber, J. Haberl }\end{array}$ \\
\hline $\begin{array}{l}\text { 7. ColRow3D } \quad \text { 4.0 10/91 } \\
\text { Converts columnar data to a matrix suitable for input to Intex } \\
\text { Solution's 3D-Graphics add-in for Lotus } 123 \text {. } \\
\text { J. Matson, R. Sparks, J. Spadaro, J. Haberl }\end{array}$ & $\begin{array}{l}\text { 20. PowerFactor v 1.0 WFA* } \\
\text { Calculates power factors from kW \& kVA on an arbitrary number } \\
\text { of phases. } \\
\text { R. Cox, R. Sparks, R. Belur, N Ahmed, J. Haberl }\end{array}$ \\
\hline $\begin{array}{l}\text { 8. Datcon } \quad \mathbf{1 . 6 6 / 9 3} \\
\text { Converts dates and times between Gregorian, Julian and } \\
\text { Decimal formats. } \\
\text { R. Sparks, N. Ahmad, J. Haberl }\end{array}$ & $\begin{array}{l}\text { 21. PRMWatch } \vee 1.010 / 91 \\
\text { Graphs the output of the Esterline Angus Power Reporter Module } \\
\text { in real time. } \\
\text { R. Sparks, J. Haber }\end{array}$ \\
\hline $\begin{array}{l}\text { 9. EModel v 1.2 WFA* } \\
\text { An MS-Windows program for browsing, manipulating, and } \\
\text { modeling columnar data (with special features for time series } \\
\text { data). It is copyrighted by TEES and Kelly Kissock for } \\
\text { distribution in the public domain. } \\
\text { K. Kissock }\end{array}$ & $\begin{array}{l}\text { 22. Psychrometric plotting with Grapher v1.0 1/92 } \\
\text { A .plt template of a psychometric chart for use with Golden } \\
\text { Software's Grapher. M. Palani, J. Haberi }\end{array}$ \\
\hline $\begin{array}{l}\text { 10. KWC } 1.010 / 91 \\
\text { A PC-based interface to the Acurex Autocalc, which includes } \\
\text { program editing and real time graphics. } \\
\text { R. Sparks, J. Haberl }\end{array}$ & $\begin{array}{l}\text { 23. TimeMerge } \nabla 1.53 / 92 \\
\text { Combines two timestamped data streams, merging on the } \\
\text { timestamp fields. } \\
\text { R. Sparks, J. Haberl }\end{array}$ \\
\hline $\begin{array}{l}\text { 11. LoanSTAR Monitoring Workbook } 7 / 92 \\
\text { This workbook is intended to be a stand-alone survival guide to } \\
\text { acquiring energy use and environmental data in buildings. It } \\
\text { includes monitoring procedures and data analysis routines } \\
\text { developed for the Texas LoanSTAR program and is copyrighted } \\
\text { for distribution in the public domain. } \\
\text { R. Lopez, R. Sparks, J. Haberl }\end{array}$ & $\begin{array}{l}\text { 24. Xair } \quad \nabla .1 \text { WFA* } \\
\text { X windows utility psychometric calculator. } \\
\text { K. Weber, S. Katipamula, J. Haberl }\end{array}$ \\
\hline $\begin{array}{l}\text { 12. MKMov } \quad \mathbf{9 1 1 0 / 9 2} \\
\text { Produces contour animation from time series data using Golden } \\
\text { Software 's SURFER and Lantem Corporation's MOVIE. } \\
\text { R. Belur, J. Haberl, R. Sparks }\end{array}$ & $\begin{array}{l}\text { 25. Solrpath } \quad \text { v.1.0 } 2 / 93 \\
\text { A graphical preprocessing program that plots Olgyay's sunpath - } \\
\text { diagram and shading protractor for any location. Requires Golden } \\
\text { Software's Grapher. } \\
\text { K. McWatters, J. Haberl }\end{array}$ \\
\hline $\begin{array}{l}\text { 13. MRMov3D } \quad \nabla .97 / 92 \\
\text { Creates a 3D animation from time series data using Lotus 123, } \\
\text { Intex Solution's 3D Graphics and Lantern Corporation's MOVIE. } \\
\text { R. Belur, T. Bou Saada, D. Bronson. J. Haberl, R. Sparks }\end{array}$ & *WFA = Write for Availability \\
\hline
\end{tabular}

Texas LoanSTAR Program

Texas Engineering Experiment Station
Energy Systems Laboratory

Texas A\&M University 


\subsection{REFERENCES}

Akbari, H., Heinemeier, K., LeConiac, P., and Flora, D. 1988. "An Algorithm to Disaggregate Commercial Whole-Building Hourly Electricity Load into End Uses," Proceedings of the 1988 ACEEE Summer Study on Energy Efficiency in Buildings, Volume 10.

Anderson, D., Lincoln, G., Reinert, W., Kreider, J., and Dow, J. 1989. “A Quasi-RealTime Expert System for Commercial Building HVAC Diagnostics," ASHRAE Transactions, Vol. 95, Part 2.

Apollo Data and State Energy Conservation Office, 1991, "SimpCalc, Simplified ECRM Calculation System, LoanSTAR version 1.0". Software developed by Apollo Data, Austin, Texas in conjunction with and for the use of the State Energy Conservation Office, Austin, Texas.

ASME MFC 9M. 1988. "Measurement of Liquid Flow in Closed Conduits by Weighing Method," American Society of Mechanical Engineers, New York, N. Y.

Baker, D. W., and Hurley, C. W. 1984. "On-site Calibration of Flow Metering Systems Installed in Buildings," NBS Building Science Series 159, (January).

Bronson, D., Hinchey, S., Haberl, J., O'Neal, D., and Claridge, D., 1992. “A Procedure for Calibrating the DOE-2 Simulation Program to Non-Weather Dependent Measured Loads," ASHRAE Transactions, v. 98, pt. 1, AN-92-1-5.

Claridge, D., Haberl, J., Bryant, J., Poyner, B., and McBride, J. 1991. "Use Of Energy Management \& Control Systems for Performance Monitoring of Retrofit Projects: Final Summary Report, Summary Report, U.S.D.O.E. Grant \#DE-FG-01-90CE21003. U.S.D.O.E. Office of Conservation \& Energy

Claridge, D., Haberl, J., O'Neal, D., Heffington, W., Turner, D., Tombari, C., Roberts, M., Jaeger, S. 1991. "Improving Energy Conservation Retrofits with Measured Results." ASHRAE Journal, October, 1991.

Claridge, D. E., Haberl, J., S., Katipamula, S., Ruch, D., Chen, L., Heneghan, T., Hinchey, S., Kissock, K., and Wang, J. 1990. "Analysis of Texas LoanSTAR Data," Proceedings of the Seventh Symposium on Improving Building Systems in Hot and Humid Climates, Ft. Worth, Texas, October 9-10, pp. 53-60.

COLROW3D 1991. COLROW3D: Software for creating 3-D plots, J. Matson, R. Sparks, J. Spadaro, J. Haberl, Energy Systems Laboratory, Texas A\&M University, (October). 
Diamond, R. J., Harris, J., de Buen, O., Nordman, B., 1990. "Evaluating Actual Performance of New Commercial Buildings: The Energy Edge Demonstration Program," American Council for an Energy Efficient Economy, Proceedings of the ACEEE 1990 Summer Study on Energy Efficiency in Buildings, Washington D.C., pp. 3.77 - 3.90.

Doebelin, E., 1990. Measurement Systems Application and Design, McGraw Hill Publishing Company, New York, N. Y.

Draper, N., and Smith, H., 1981. Applied Regression Analysis, 2nd Edition, John Wiley \& Sons, New York.

Energy Systems Laboratory, 1991, "Report to the Monitoring Advisory and Review Committee," vol. 1, Texas A\&M University, College Station, TX.

Fels, M. (Ed.), 1986. "Special Issue Devoted to Measuring Energy Savings, The Princeton Scorekeeping Method (PRISM)," Energy and Buildings, Vol. 9, Nos. 1 and 2.

Feuermann, D., Kempton, W. 1987, “ARCHIVE: Software for the Management of Field Data," Center for Energy and Environmental Studies Report No. 216, (This also includes Tony's Tools, and Art's Tools, which are useful columnar data processing tools), Princeton University.

FSF 1989. GAWK, Free Software Foundation (PC version of the UNIX-based AWK toolkit), 675 Massachusetts Ave., Cambridge, Massachusetts 02139.

Golden 1990. GRAPHER and Surfer, Golden Software, 809 14th Street, P. O. Box 281, Golden, Colorado, 80402-0281.

State Energy Conservation Office, October, 1990, Texas LoanSTAR Program Audit Guidelines and Training Manual, Austin, Texas.

Greenspan, L. 1977. "Humidity Fixed Points of Binary Saturated Aqueous Solutions," Journal of Research of the National Bureau of Standards, Physics and Chemistry, Vol. 81A, No. 1., p. 89-96.

Haberl, J., and Claridge, D. 1987. "An Expert System for Building Energy Consumption Analysis: Prototype Results," ASHRAE Transactions, V. 93.

Haberl, J., and Komor, P. 1989. "Investigating an Analytical Basis for Improving Commercial Building Energy Audits: Early Results from a New Jersey Mall," Proceedings of the Thermal Performance of the Exterior Envelopes of Buildings IV, Sponsored by ASHRAE, DOE, BTECC and CIBSE, December. 
Haberl, J., Lopez, R., Sparks, R. 1992. LoanSTAR Monitoring and Analysis Program Building Energy Monitoring Workbook, Energy Systems Laboratory Report No. ESLTR-92/06-02, (August).

Hàberl, J., and Vajda, J. 1988. "Use of Metered Data Analysis to Improve Building Operation and Maintenance: Early Results From Two Federal Complexes," Proceedings of the ACEEE 1988 Summer Study on Energy Efficiency in Buildings, Vol. 3.

Haberl, J., Turner, D., Glass, M., Finstad, C., Scott, F. 1992. "Calibration of Flow meters Used in HVAC Systems Monitoring," Proceedings of the 1992 ASME/JSES/KSES International International Solar Energy Conference, ASME, New York, N. Y., pp. 1277-1283, (April).

Hadley, D. and Tomich, S. 1990. "Multivariate Statistical Assessment of Meteorological Influences on Residential Space Heating," American Council for an Energy Efficient Economy, Proceedings of the ACEEE 1986 Summer Study on Energy Efficiency in Buildings 9, Washington, D.C.

Heffington, W., Athar, A., Britton, A., Nutter, D. "LoanSTAR Energy Audits: Update and Changes," Proceedings of the Eighth Symposium on Improving Building Systems in Hot and Humid Climates, Texas A\&M University, (May).

Heffington, W., Britton, A., Athar, A., Nutter, D. 1992. "Auditing for Energy Retrofits: Results and Lessons from a Major State Program," Proceedings of the ASMEJJSES/KSES International Solar Energy Conference, (March).

Heffington, W. M., Lum, S. K., and Bauer, V. A. "Audit Costs for the 1986 Texas Energy Cost Containment Program," Proceedings of the Fourth Symposium on Improving Building Systems in Hot and Humid Climates, Houston, TX, September 15-16, 1987, pp. 146-153.

Heffington, W. M., Britton, A. J., Athar, A., and Nutter, D. W. "Auditing for Energy Retrofits: Results and Lessons from a Major State Program," Proceedings of the 1992 ASME/JSES/KSES International Solar Energy Conference, Vol. 1, Maui, HA, April 1992, pp. 291-298.

Heffington, W. M., Athar, A., Britton, A. J., Nutter, D. W., and Stuewe, C., Proceedings of the Eighth Symposium on Improving Building Systems in Hot and Humid Climates, Dallas, TX, May, 1992, pp. 174-177.

Holman, J. P., 1984. Experimental Methods for Engineers, McGraw Hill Publishing Company, New York, N. Y. 
Hsieh, E. 1988. "Calibrated Computer Models of Communication Buildings and Their Role in Building Design and Operation," Center for Energy and Environmental Studies, Report No. 230, Princeton University, Princeton, NJ, August.

Huang, P. 1991. "Humidity Measurements and Calibration Standards," ASHRAE Transactions, Vol. 97, Pt. 2, (June), p. 3521.

Hyland, R. W., and Hurley, C. W. 1983. "General Guidelines for the On-Site Calibration of Humidity and Moisture Control Systems in Buildings," N. B. S. Building Science Series 157, (September).

Katipamula, S., and Claridge, D. 1993. "Use of Simplified Systems Model to Measure Retrofit Energy Savings," Transactions of the ASME Journal of Solar Energy Engineering, Vol. 115, pp. 57-68, May.

Katzev, R. and T. Johnson, 1987. Promoting Energy Conservation: An Analysis of Behavioral Research, Boulder, CO: Westview Press.

Kempton, W., and Komor, P. 1990. "Maybe Somebody Forgot to Turn the Chiller On: Graphical Feedback for Small Businesses," Proceedings of the ACEEE 1990 Summer Study on Energy Efficiency in Buildings, Washington D.C., American Council for an Energy Efficient Economy, pp. 2.75 - 2.76.

Kinney, L. F., and Romano, J. P. 1990. "Feedback Mechanism to Promote Weatherization Client Conservation," American Council for an Energy Efficient Economy, Proceedings of the ACEEE 1990 Summer Study on Energy Efficiency in Buildings, Washington D.C., pp. 2.77 - 2.79.

Kissock,. J. K., Reddy, T. A. , and Claridge, D. E. 1992(a). "Measuring Retrofit Savings for the Texas LoanSTAR Program: Preliminary Methodology and Results," Proceedings of the ASME/JSES/KSES International Solar Energy Conference, Hawaii, March.

Kissock,. J. K., T. A. Reddy, and Claridge, D. E. 1992(b). "A Methodology for Identifying Retrofit Energy Savings in Commercial Buildings," Proceedings of the Eighth Symposium on Improving Building Systems in Hot and Humid Climates, Dallas, May 1314, 1992.

L.C. 1990. Voyager: Data Exploration. Clayton, MO. Lantern Corporation.

Liu, Y., Reddy, T. A., Katipamula, S. and Claridge D. E., 1992. “Calculating Energy and Demand Retrofit Savings for Stroman High School," Interim Report ESL-TR92/12/02, Energy Systems Laboratory, Texas A\&M University, December. 
Lopez, R. E. and Haberl, J. S., 1992. "Data Processing Routines for Monitored Building Energy Data," Proceedings of the ASME/JSES/KSES International Solar Energy Conference, Hawaii, March.

Lutz, K. 1990. "Information Transfer of Conservation Research Results: Writing for a Broad Audience," Proceedings of the ACEEE 1990 Summer Study on Energy Efficiency in Buildings, Washington D.C., American Council for an Energy Efficient Economy, pp. $7.101-7.102$.

MacDonald, M., and Wasserman, D. 1989. "Investigation of Metered Data Analysis Methods for Commercial and Related Buildings," Oak Ridge National Laboratory Report ORNL/CON-279.

Manly, B. F. J., 1986. Multivariate Statistical Methods: A Primer, Chapman Hall, London.

Miller, R. 1989. Flow Measurement Handbook, McGraw Hill Publishing Company, New York, N. Y.

Neter, J., Wasserman, W., and Kutner, M. H., 1989, Applied Linear Regression Models, 2nd Ed., Irwin, Homewood.

Nutter, D. W., Britton, A. J., Muraya, N. K., and Heffington, W. M. "LoanSTAR Energy Conservation Audits: January 1989-August 1990," Proceedings of the Seventh Symposium on Improving Building Systems in Hot and Humid Climates, Ft. Worth, TX, October 9-10, 1990, pp. 35-40.

Olsen, L. 1974. "Introduction to Liquid Flow Metering and Calibration of Liquid Flow meters," NBS Technical Note 831.

Pindyck, R. S., and Rubenfeld, D. L., 1981. Economic Models and Economic Forecasts, 2nd Edition, McGraw-Hill, New York.

Pratt, R. G., Conner C. C., Richman, E. E., Ritland, K. G., Sandusky, W. F. and Taylor, M. E. 1989. "Description of Electric Energy Use in Single-Family Residences in the Pacific Northwest--End-use Load and Consumer Assessment Program (ELCAP)." DOE/BP-13795-2 1, prepared by Pacific Northwest Laboratory for the U.S. Department of Energy.

Rabl, A., 1988. "Parameter Estimation in Buildings: Methods for Dynamic Analysis of Measured Energy Use," ASME Journal of Solar Energy Engineering, Vol. 110, p. 52.

Reiter, P. 1986. "Early Results From Commercial ELCAP Buildings: Schedules as a Primary Determinant of Load Shapes in the Commercial Sector," ASHRAE Transactions, V.91. Pt. 2. 
Ruch, D., and Claridge, D. 1991. "A Four Parameter Change-Point Model for Predicting Energy Consumption in Commercial Buildings," Solar Engineering 1991: Proceedings of the ASME-JSES -JSME International Solar Energy Conference, Reno, Nevada, March 17-22, pp. 433-440.

Ruch, D., Chen, L., Haberl, J., and Claridge, D. 1991. “A Change-Point Principal Component Analysis (CP/PCA) Method for Predicting Energy Usage in Commercial Buildings: The PCA Model," Solar Engineering 1991: Proceedings of the ASME-JSES JSME International Solar Energy Conference, Reno, Nevada, March 17-22, pp. 441-448.

SAS 1989, SAS Language and Procedures: Usage, Version G, 1st Ed., Cary, North Carolina, SAS Institute, Inc.

Schrock, D., and Claridge, D. 1989. "Predicting Energy Usage in a Supermarket," Proceedings of the Sixth Symposium on Improving Building Energy Efficiency in Hot and Humid Climates, Texas A\&M University.

STATGRAPHICS, 1991. Statistical Graphics System: User's Guide, version 5. Statistical Graphics Corporation, STSC Inc., Rockville, Maryland.

Subbarao, K., 1988. "PSTAR-Primary and Secondary Terms Analysis and Renormalization: A Unified Approach to Building Energy Simulations and Short-term Monitoring," SERI/TR-254-3175, Solar Energy Research Institute, Golden, Colorado.

Theil, H., 1971. Principles of Econometrics, John Wiley, New York.

Turner, W., D., Haberl, J., Bryant, J., Finstad, C., Robinson, J. 1992. “Calibration Facility for the LoanSTAR Program," Proceedings of the 1992 ASME/JSES/KSES International Solar Energy Conference. 


\subsection{BIBLIOGRAPHY}

ACEC 1987. ASEAM 2.1: A Simplified Energy Analysis Method, Version 2.1, American Consulting Engineering Council Research and Management Foundation, Washington, D.C.

Belur, R., Kissock, K., Haberl, J. 1992. "Exploring an Enhanced Data Viewing Facility for Building Operators," Proceedings of the 1992 ACEEE Summer Study on Energy Efficiency in Buildings, (August).

Bendat, J. S., and Piersol, A. G. 1986. Random Data Analysis and Measurement Procedures, John Wiley and Sons, New York, ISBN-0-471-04000-2.

Benedict, R. 1984. Fundamentals of Temperature, Pressure, and Flow Measurement. John Wiley and Sons, New York, N. Y., ISBN 0-471-89383-8.

Bevington, P. R., Robinson, D. K., 1992. Data Reduction and Error Analysis for the Physical Sciences, 2nd Edition, McGraw-Hill, New York, ISBN-0-07-911243-9.

Boecker, C., Boles, K., O'Neal, D., Bryant, J. 1992. "Building Energy Instrumentation for Determining Retrofit Savings: Thermal and Flow Meter Equipment Selection," Proceedings of the Eighth Symposium on Improving Building Energy Efficiency in Hot and Humid Climates: Conference Notes, Texas A\&M University, (May).

Bronson, D., Hinchey, S., Haberl, J., O'Neal, D., Claridge, D. 1991. “A Toolkit to Help Calibrate the DOE-2 Simulation Program to Non-weather Dependent Measured Loads," IBPSA Newsletter.

Bryant, J., O'Neal, D. 1992. "Calibration of Relative Humidity Transducers for use in the Texas LoanSTAR Program," Proceedings of the Eighth Symposium on Improving . Building Energy Efficiency in Hot and Humid Climates, Texas A\&M University, May.

Claridge, D., Haberl, J., Kissock, K., Wu, J. 1991. "The Texas LoanSTAR Program: Early Measured Results," Proceedings of the 1991 International HVAC Symposium, Beijing, China, September.

Clark, D. R. 1985. "HVACSIM+ Building Systems and Equipment Simulation Program," User's Guide and Reference Manual, National Bureau of Standards - Reports No. NBSIR-84-2996 and NBSIR-85-3243.

Cortina, V. (ed.) 1988. "Precision Humidity Analysis," EG\&G Environmental Equipment, 151 Bear Hill Road, Waltham, MA, 02154, (IR sensors).

Date, C. 1989. A Guide to SQL/DS, Addison Wesley Publishing Co., Reading Massachusetts. 
DeCicco, J. M., and Kempton, W. 1987. "Behavioral Determinants of Energy Consumption in a Centrally-Heated Apartment Building," Energy Systems and Policy, Vol. 11.

EEI 1981. Handbook for Electricity Metering, Edison Electric Institute, Washington, D.C., ISBN-0-931032-11-3.

EIA 1989. Consumer Electronics Bus (CEBus) - Home Automation Standard, Electronic Industries Association, 2001 Eye Street, N. W., Washington, D.C., 20006.

Englander, S., Reynolds, C., Haberl, J. 1990. "The Princeton Boiler Plant Electronic Logbook Project," Proceedings of the ACEEE 1990 Summer Study on Energy Efficiency in Buildings, ACEEE, Washington, D.C., August.

Fracastoro, G. V., and Lyberg, M. D. 1983. Guiding Principles Concerning Design of Experiments, Instrumentation and Measuring Techniques, International Energy Agency and the Swedish Council for Building Research, Stockholm, Sweden.

Gilmore, V. E. 1988. "Smart House," Popular Science, August, (an article that describes the Smart House project being developed by the Smart House Limited Partnership, Washington, D.C.).

Haberl, J., Bronson, D., O'Neal, D. 1992. "An Evaluation of the Impact of Using Measured Weather Data Versus TMY Weather Data in a DOE-2 Simulation of an Existing Building in Central Texas," ESL-TR-91/08-10, to be published in the ASHRAE Transactions, July.

Haberl, J., Claridge, D., Harrje, D. 1990. "The Design of Field Experiments and Demonstrations," Proceedings of the 1990 IEA Field Monitoring Workshop, Gothenburg, Sweden, (April).

Haberl, J., Claridge, D., O'Neal, D., Heffington, W., Turner, W. D., Verdict, M. 1990. "The Texas LoanSTAR Program: A Brief Introduction," ipbsaNEWS, Vol. 3, No. 2, (May).

Haberl, J., Englander, S., Reynolds, C., Nyquist, T., McKay, M. 1989. "Whole Campus Performance Analysis Methods," Proceedings of the Sixth Symposium on Improving Building Systems in Hot and Humid Climates, Texas A\&M University, College Station, Texas, October. 
Haberl, J., Katipamula, S., Willis, D., Weber, K., Matson, J., Rayaprolu, M., Subramanian, U. 1990a. "The Texas LoanSTAR Program: Acquiring and Archiving LoanSTAR Data," Proceedings of the Seventh Symposium on Improving Building Systems in Hot and Humid Climates, Texas A\&M University, College Station, Texas, October.

Haberl, J., Komor, P. 1990. "Improving Commercial Building Energy Audits: How Annual and Monthly Consumption Data Can Help," ASHRAE Journal, August, 1990.

Haberl, J., Komor, P. 1990. "Improving Commercial Building Energy Audits: How Daily and Hourly Data Can Help," ASHRAE Journal, September 1990.

Haberl, J., Norford, L., Spadaro, J. 1989. “Diagnosing Building Operational Problems: Intelligent Systems for Diagnosing Operational Problems in HVAC Systems," ASHRAE Journal, June.

Harding, J. (ed.). 1982. "Recent Advances in Chilled Mirror Hygrometry," General Eastern Corporation Technical Bulletin, 50 Hunt St., Watertown, MA, 02172.

Harrje, D. T. 1982. "Monitoring Energy Use - What is Needed?," Proceedings of the ACEEE Summer Study on Energy Efficiency in Buildings, August.

Harrje, D. T. 1982. "Monitoring Energy Use - What is Needed?," Proceedings of the ACEEE Summer Study on Energy Efficiency in Buildings, August.

Harrje, D. T. 1986. "Obtaining Building Energy Data, Problems and Solutions," Proceedings of the Field Data Acquisition for Building and Equipment Energy-Use Monitoring Workshop, ORNL Publication No. CONF-8510218, pp. 205-209.

Harrje, D. T., Kirkpatrick, D. L., Norford, L. K., and Seroussi, R. E. 1984. "Data Collection and Analysis Hardware for Measuring Building Energy Use," Doing Better Setting an Agenda for the Second Decade, ACEEE, Vol. C, pp. 177-192, August.

Harrje, D. T. 1986. "Obtaining Building Energy Data, Problems and Solutions," Proceedings of the Field Data Acquisition for Building and Equipment Energy-Use Monitoring Workshop, ORNL Publication No. CONF-8510218, pp. 205-209.

Hart, G. 1985. "Non-Intrusive Appliance Load Data Acquisition," Proceedings of the International Load Management Conference, Section 40 , Sponsored by the Electric Power Research Institute - Report No. EPRI-EM4643, Palo Alto, Calif.

Haves, P., and Trewhella, D. 1988. "Towards an Environment for HVAC Control System Evaluation," Proceedings of the USER-1 Building Simulation Conference, Society for Computer Simulation, September. 
Howell, R., and Sauer, H. 1985. Environmental Control Principles: A Textbook Supplement to the ASHRAE 1985 Handbook of Fundamentals, ASHRAE, Atlanta, GA, ISBN-0-910110-43-3.

Hsieh, E. H., Norford, L. K., Socolow, R. H. 1989. “Calibrated Computer Models to Track Building Energy Use: The Role of the Tenant and Operator Decisions.," Energy and Buildings, in preparation.

Hurley, W. 1985. "Measurement of Temperature, Humidity, and Fluid Flow," Field Data Acquisition for Building and Equipment Energy-use Monitoring, ORNL Report No. CONF-8510218, (March).

Hurley, C. W., and Schooley, J. F. 1984. "Calibration of Temperature Measurement Systems Installed in Buildings, " N. B. S. Building Science Series 153, January.

Hyland, R. W., and Hurley, C. W. 1983. "General Guidelines for the On-Site Calibration of Humidity and Moisture Control Systems in Buildings," N. B. S. Building Science Series 157, September.

Intex 1990. 3-D Graphics, Intex Solutions, 161 Highland Ave., Needham, Massachusetts 02194 (requires Lotus 123).

ISA 1976. Recommended Environments for Standards Laboratories, Instrument Society of America - Recommended Practice, Research Triangle Park, North Carolina.

Jilar, T. 1990. Proceedings of the Field Monitoring for a Purpose Workshop, Gothenburg, Sweden, Sponsored by the Swedish Council for Building Research, Stockholm Sweden, and prepared by the Building Services Engineering Department, Chalmers University of Technology.

Katipamula, S., K., and Haberl, J. 1991. "A Methodology to Identify Diurnal Load Shapes for Non-Weather Dependent Electric End-Uses," Solar Engineering, 1991: Proceedings of the ASME-JSES -JSME International Solar Energy Conference, pp. 457467, Reno, NV, March.

Klein, S. A., Beckman, W. A., and Duffie, J. A. 1976. "TRNSYS - A Transient Simulation Program," ASHRAE Transactions, Vol. 82, Pt. 2.

Komor, P., Kempton, W., and Haberl, J. 1989. "Energy Use, Information, and Behavior in Small Commercial Buildings," Center for Energy and Environmental Analysis - Report No. 240, Princeton University, July.

Kulwicki, B. 1991. "Humidity Sensors," Journal of the American Ceramic Society, Vol. 74, pp. 697-707. 
Lee, I. (ed.) 1988. Review of Humidity Sensors, Texas Instruments Incorporated, Attleboro, MA, 02703 (general reference).

Leider, M. et al. 1990. "A Solid State Amperometric Humidity Sensor," Journal of Applied Electrochemistry, Chapman and Hill: Vol. 20, pp. 964-8.

Lotus 1985, Lotus 1-2-3 Spreadsheet, Lotus Development Corp., 55 Cambridge Parkway, Cambridge, Massachusetts 02142.

Lyberg, M. D. (ed.) 1987. Source Book For Energy Auditors, Volume 1 and 2, International Energy Agency and the Swedish Council for Building Research, Stockholm, Sweden.

MacDonald, J. M., Sharp, T. R., and Gettings, M. B. 1989. “A Protocol for Monitoring Energy Efficiency Improvements in Commercial and Related Buildings," Oak Ridge National Laboratory Report ORNL/CON-291, September.

McQuiston, F., C., and Parker, J. D. 1988. Heating, Ventilating, and Air Conditioning. John Wiley and Sons, New York, ISBN 0-471-63757-2.

Miller, R. C. 1989. "Identification of Acoustic Signals Using Artificial Neural Networks," Master's Thesis, Marquette University, Milwaukee, Wisconsin, December.

Morrissey, C. J. 1990. “Acoustic Humidity Sensor," NASA Tech Brief. Vol. 14, \#19, April, (acoustic).

Norford, L., Mabey, N. 1992. "Non-intrusive Electric Load Monitoring in Commercial Buildings," Proceedings of the Eighth Symposium on Improving Building Systems in Hot and Humid Climates, Energy Systems Laboratory, Texas A\&M University.

Norford, L., Tabors, R., Byrd, G. 1992. "Non-Intrusive Electrical Load Monitoring, a Technique for Reduced-Cost Load Research and Energy Management: Results of Field Tests and Recent Developments," Proceedings of the 1992 ACEEE Summer Study on Energy Efficiency in Buildings, Asilomar, CA.

O'Neal, D., Bryant, J., Turner, W., Glass, M. 1990. "Metering and Calibration in LoanSTAR Buildings," Proceedings of the Seventh Symposium on Improving Building Systems in Hot and Humid Climates, Texas A\&M University, College Station, Texas, October.

Olsen, K., Komor, P., and Fels, M. 1988. "Development of a Data Base to Characterize the Small Commercial Sector: A New Jersey Example," Proceedings of the ACEEE 1988 Summer Study on Energy Efficiency in Buildings, Volume 10. 
Press, W., Flannery, B., Teukolsky, S., and Vetterling, W. 1986. Numerical Recipes: the Art of Scientific Computing, Cambridge, MA, Cambridge University Press.

Ramboz, J. D. and McAuliff, R. C. 1983. A Calibration Service for Wattmeters and Watt-hour Meters, N. B. S. Technical Note 1179.

Reddy, T. A. 1989. “Application of Dynamic Building Inverse Models to Three Occupied Residences Monitored Non-Intrusively," Proceedings of the Thermal Performance of the Exterior Envelopes of Buildings IV, ASHRAE/DOE/BTECC/CIBSE, Orlando, Florida, December.

Robinson, J., Bryant, J., Haberl, J, Turner, D. 1992. "Calibration of Tangential Paddlewheel Insertion Flow meters," Proceedings of the Eighth Symposium on Improving Building Systems in Hot and Humid Climates, Texas A\&M University, Energy Systems Laboratory Report No. ESL-PA-92/02-09.

Ross, I., J., and White, G. M. 1990. "Humidity," Instrumentation and Measurement. for Environmental Sciences: Transactions of the ASAE, 2nd ed., p. 8-01.

Schuster, G. 1985. "Field Data Acquisition Hardware," Field Data Acquisition for Building and Equipment Energy-use Monitoring, ORNL Report No. CONF-8510218, (March).

Seligman, C., Darley, J. M., and Becker, L. J. 1978. "Behavioral Approaches to Residential Energy Conservation," Saving Energy in the Home, R. H. Socolow, ed., Cambridge, MA, Balinger Publishing Co., pp. 231-254.

Sonderegger, R. C., 1978a. "Movers and Stayers: The Resident's Contribution to Variation Across Houses in Energy Consumption for Space Heating," Saving Energy in the Home, Robert Socolow (ed.), Ballinger Publishing Co.

Sonderegger, R. C. 1978b. "Diagnostic Tests Determining the Thermal Response of a House." ASHRAE Transactions, Vol. 84, Part 1, pp. 691-702.

Sparks, R., Haberl, J., Bhattacharrya, S., Rayaprolu, M., Wang, G., Vadlamani, S. 1992. "Testing for Data Acquisition Systems for Use in HVAC System Monitoring," Proceedings of the ASME/JSES/KSES International Solar Energy Conference, (March).

Sparks, R., Haberl, J., Bhattacharrya, S., Rayaprolu, M., Wang, G., Vadlamani, S. 1992. "Testing for Data Acquisition Systems for Use in Monitoring Building Energy Conservation," Proceedings of the Eighth Symposium on Improving Building Systems in Hot and Humid Climates, Texas A\&M University, (May).

Synergistic. 1990. Software, Installation, and Technical Specifications for the Model C180 Survey Meter/Recorder, 5725 Bundy Rd., New Orleans, LA 70127. 
Taylor, J. 1981. An Introduction to Error Analysis, University Science Books, Oxford University Press, Mill Valley, CA, ISBN 0-935702-07-5.

Ternes, M. P. 1987. "Single-Family Building Retrofit Performance Monitoring Protocol: Data Specification Guideline," Oak Ridge National Laboratory report No. ORNL/CON-196.

TeX 1986. The TEXbook, Donald Knuth, The American Mathematical Society and the Addison Wesley Publishing Company, Reading, Massachusetts.

Threlkeld, J. 1970. Thermal Environmental Engineering, Prentice-Hall, Englewood Cliffs, N. J., (general reference).

Treado, S. J., and Bean, J. W. 1988. The Interaction of Lighting, Heating and Cooling Systems in Buildings - Interim Report, National Institute of Standards and Technology, NISTIR 88-3860, December.

Treado, S. J., 1988. Experimental Plan for Investigation of Lighting and HVAC Interactions, National Institute of Standards and Technology, NISTIR 87-3656, February.

Turner, W. D. 1990. "Overview of the Texas LoanSTAR Monitoring Program," Proceedings of the Seventh Symposium on Improving Building Systems in Hot and Humid Climates, Texas A\&M University, College Station, Texas, October 9-10.

Tufte, E. R. 1983. The Visual Display of Quantitative Information, Graphics Press, Cheshire, Connecticut.

Ullman, J. 1988. Principles of Database and Knowledge-base systems, Computer Science Press, Rockville, Maryland.

Verdict, M., Haberl, J., Claridge, D., O'Neal, D., Heffington, W., Turner, D. 1990. "Monitoring \$98 Million in Energy Efficiency Retrofits: The Texas LoanSTAR Program," Proceedings of the ACEEE 1990 Summer Study on Energy Efficiency in Buildings, ACEEE, Washington, D.C., pp. 7.261-7.271.

Wiesman, S. (ed.) 1989. "Measuring Humidity in Test Chambers," General Eastern Corporation, 50 Hunt Street, Watertown, MA 02172. (chilled mirror dewpoint sensors).

Wise, J. A., Soulen, R. J. 1986. Thermometer Calibration: A Model for State Calibration Laboratories, N. B. S. Monograph 174, January.

Wise, J. A. 1976. Liquid-In-Glass Thermometry, N. B. S. Monograph 150, January.

Zuboff, S. 1988. In the Age of the Smart Machine: The Future of Work and Power, Basic Books, New York, N. Y. 


\subsection{ACKNOWLEDGMENTS}

Contributions to this report by the following people are acknowledged: Aamer Athar, Curtis Boecker, Chuck Bohmer, Keith Boles, Doug Bronson, John Bryant, Ron Chambers, Clint Finstad, John Houcek, Srinivas Katipamula, Kelly Kissock, Mingsheng Liu, Wang Jinrong, Rob Lopez, David Ruch, Namir Saman, Robert Sparks, Dean Willis, and an energetic cadre of graduate and undergraduate students. Special thanks to Daralyn Wallace, Susan Swanson, Jean Mahoney, and Cindi Vargas for their time and effort spent editing this report.

This project was conducted by the Energy Systems Laboratory, Department of Mechanical Engineering, Texas A\&M University, under subcontract with Oak Ridge National Laboratory as part of the U.S. Department of Energy's Existing Building Research Program.

Portions of this work would not have been possible without support from the Texas LoanSTAR program through the State Energy Conservation Office, and funding through the Texas ERAP project \#227.

Special thanks are also due to Mike MacDonald, the Oak Ridge project manager, and Mr. Ernest Freeman at the USDOE. 


\subsection{APPENDIX}

\subsection{Compendium of Analysis Papers}

This section provides a compendium of the associated LoanSTAR documentation that has been published in ACEEE, ASME, ASHRAE, and other publications. These papers can be found in the proceedings and journals indicated. Copies of the papers can also be obtained by contracting the authors at the Energy Systems Laboratory.

1. Abbas, M., Athar, A., Challa, V., Haberl, J., Claridge, D. 1992. "Texas LoanSTAR Monitoring and Analysis Program: Characterizing LoanSTAR Building and Energy Consumption," Proceedings of the Eighth Symposium on Improving Building Systems in Hot and Humid Climates, Texas A\&M University (May).

2. Athar, A., Abbas, M., Challa, V., Haberl, J., Claridge, D. 1992. “Texas LoanSTAR Monitoring and Analysis Program: Improving the Performance of Retrofits by Providing Operator Feedback from Measured Data," Proceedings of the Eighth Symposium on Improving Building Systems in Hot and Humid Climates, Texas A\&M University (May).

3. Belur, R., Kissock, K., Haberl, J. 1992. "Exploring an Enhanced Data Viewing Facility for Building Operators," Proceedings of the 1992 ACEEE Summer Study on Energy Efficiency in Buildings (August).

4. Boecker, C., Boles, K., O'Neal, D., Bryant, J. 1992. "Building Energy Instrumentation for Determining Retrofit.Savings: Thermal and Flow Meter Equipment Selection," Proceedings of the Eighth Symposium on Improving Building Systems in Hot and Humid Climates: Conference Notes, Texas A\&M University (May).

5. Bronson, D., Hinchey, S., Haberl, J., ONeal, D. 1992. "A Procedure for Calibrating , the DOE-2 Simulation Program to Non-Weather-Dependent Measured Loads," ASHRAE Transactions, Vol. 98, pt. 1.

6. Bronson, D., Hinchey, S., Haberl, J., O'Neal, D., Claridge, D. 1991. “A Toolkit to Help Calibrate the DOE-2 Simulation Program to Non-weather Dependent Measured Loads," ibpsaNEWS, Vol. 4, No. 3 (December).

7. Bryant, J., O'Neal, D. 1992. "Calibration of Relative Humidity Transducers for use in the Texas LoanSTAR Program," Proceedings of the Eighth Symposium on Improving Building Systems in Hot and Humid Climates, Texas A\&M University (May).

8. Claridge, D., Haberl, J., Katipamula, S., O'Neal, D., Ruch, D., Chen, L., Heneghan, T., Hinchey, S., Kissock, K., Wang, J. 1990. "Analysis of LoanSTAR Data," 
Proceedings of the Seventh Symposium on Improving Building Systems in Hot and Humid Climates, Texas A\&M University, Ft. Worth, TX (October).

9. Claridge, D., Haberl, J., Kissock, K., Wu, J. 1991. "The Texas LoanSTAR Program: Early Measured Savings," Proceedings of the International Symposium on HVAC, Beijing, China (September).

10. Claridge, D., Haberl, J., Sparks, R., Lopez, R., Kissock, K. 1992. "Monitored Commercial Building Energy Data: Reporting the Results," ASHRAE Transactions, Vol. 98, pt. 1.

11. Claridge, D., Haberl, J., Turner, W. D., O'Neal, D., Heffington, W., Tombari, C., Roberts, M., Jaeger, S. 1991. "Improving Energy Conservation Retrofits with Measured Savings," ASHRAE Journal, October.

12. Cox, R., Haberl, J., Claridge, D. 1993. "A Study of Energy Use in Grocery Stores," ASHRAE Transactions, Vol. 99, pt. 1 (January).

13. Haberl, J. 1992. "The Use of a Monthly Whole-campus Energy Analysis for Evaluating a Third Party Energy Service Agreement," Proceedings of the 1992 ACEEE Summer Study on Energy Efficiency in Buildings (August).

14. Haberl, J., Athar, A., Abbas, M., Claridge, D. 1992. "Comparing Monitoring Protocols for Energy Retrofits Using Data from the Texas LoanSTAR Program," ASHRAE Transactions, Vol. 98, pt. 1.

15. Haberl, J., Beasley, R., Claridge, D. 1992. "Characterizing Steam and Chilled Water use for a 40,000 Student Campus in Central Texas," ASHRAE Transactions. Vol. 99, pt.2 (December).

16. Haberl, J., Bronson, D., ONeal, D. 1991. "An Evaluation of the Impact of Using Measured Weather Data Versus TMY Weather Data in a DOE-2 Simulation of an Existing Building in Central Texas," ESL-TR-91/08-10, to be published in the 1992 ASHRAE Transactions, August.

17. Haberl, J., Bronson, D., Hinchey, S., O'Neal, D., Claridge, D. 1992. "Graphical Tools to Help Calibrate the DOE-2 Simulation Program to Measured Loads," DOE-2 Users News, Vol. 13, No. 1, (Spring).

18. Haberl, J., Claridge, D., Harrje, D. 1990. "The Design of Field Experiments and Demonstrations," Proceedings of the 1990 IEA Field Monitoring Workshop, Gothenburg, Sweden, (April). 
19. Haberl, J., Claridge, D., O'Neal, D., Heffington, W., Turner, W. D., Verdict, M. 1990. "The Texas LoanSTAR Program: A Brief Introduction," ipbsaNEWS, Vol. 3, No. 2, (May).

20. Haberl, J., Doruk, B., Heffington, W. 1990. "An Evaluation of Institutional Energy Audits Performed for the Texas LoanSTAR Program," Proceedings of the 1990 ACEEE Summer Study on Energy Efficiency in Buildings, Vol. 6 (August).

21. Haberl, J., Jagannathan, V., Lopez, R., Sparks, R., Kissock, K., Willis, D., Claridge, D. 1991. "Exploring an Integrated Database Structure for Building Energy Monitoring Data," Proceedings of the 1991 IBPSA Building Simulation Conference, Nice, France, (August).

22. Haberl, J., Katipamula, S., Willis, D., Weber, K., Matson, J., Rayaprolu, M., Subramanian, U. 1990. "The Texas LoanSTAR Program: Acquiring and Archiving LoanSTAR Data," Proceedings of the Seventh Symposium on Improving Building Systems in Hot and Humid Climates, Texas A\&M University, Ft. Worth, TX (October).

23. Haberl, J., Kissock, K., Belur, R. 1993. "Improving the Paradigm for Displaying Complex Building Energy Consumption Data," Proceedings of the 1993 ASME/ASES/SED International Solar Conference, Washington, D.C. (January).

24. Haberl, J., Turner, W. D., Finstad, C., Scott, F., Bryant, J., Coonrod, D. 1992. "Calibration of Flow Meters for Use in HVAC Systems Monitoring," Proceedings of the ASME/JSES/KSES International Solar Energy Conference, (April).

25. Heffington, W., Athar, A., Britton, A., Nutter, D. "LoanSTAR Energy Audits: Update and Changes," Proceedings of the Eighth Symposium on Improving Building Systems in Hot and Humid Climates, Texas A\&M University, (May).

26. Heffington, W., Britton, A., Athar, A., Nutter, D. 1992. "Auditing for Energy Retrofits: Results and Lessons from a Major State Program," Proceedings of the ASME/JSES/KSES International Solar Energy Conference, Vol. 1 (March).

27. Katipamula, S., Claridge, D. 1992. "Use of Simplified System Models to Measure Retrofit Savings," Proceedings of the ASME/JSES/KSES International Solar Energy Conference, Vol. 1 (March).

28. Katipamula, S., Claridge, D. 1992. "Importance of Monitoring Air Handler Performance," Proceedings of the 1992 Summer Study on Energy Efficiency in Buildings, Vol. 3 (August). 
29. Katipamula, S., Haberl, J. 1992. "A Methodology to Identify Diurnal Load Shapes for Non-Weather Dependent Electric End-Uses," Proceedings of the ASME/JSES/KSES International Solar Energy Conference, (March).

30. Katipamula, S., Reddy, A., Claridge, D. 1992. 'Disaggregating Cooling Energy Use of Commercial Buildings into Sensible and Latent Fractions from Wholes-building Monitored Data: Methodology and Advantages," Proceedings of the Eighth Symposium on Improving Building Systems in Hot and Humid Climates, Texas A\&M University, (May).

31. Kissock, K., Claridge, D., Haberl, J., Reddy. A. 1992. "Measuring Retrofit Savings for the Texas LoanSTAR Program: Preliminary Methodology and Results," Proceedings of the ASME/JSES/KSES International Solar Energy Conference, Vol. 1 (March).

32. Kissock, K., Reddy, A., Claridge, D. 1992. "A Methodology for Identifying Retrofit Energy Savings in Commercial Buildings," Proceedings of the Eighth Symposium on Improving Building Systems in Hot and Humid Climates, Texas A\&M University, (May).

33. Kissock, K., Reddy, A., Fletcher, D., Claridge, D. 1993. "The Effect of Short Data Periods on the Annual Prediction Accuracy of Temperature Dependent Regression Models of Commercial Building Energy Use," Proceedings of the 1993 ASME/ASES/SED International Solar Conference, Washington, D.C. (January).

34. Lopez, R., Haberl, J. 1992. "Data Processing for Monitoring Building Energy Data," Proceedings of the ASME/JSES/KSES International Solar Energy Conference, Vol. 1 (March).

35. Lopez, R., Haberl, J. 1992. "Data Management in the LoanSTAR Program," Proceedings of the Eighth Symposium on Improving Building Systems in Hot and Humid Climates, Texas A\&M University, (May).

36. Nutter, D., Britton, A., Muraya, N., Heffington, W. 1990. 'LoanSTAR Energy Conservation Audits: January 1989 - August 1990," Proceedings of the Seventh Symposium on Improving Building Systems in Hot and Humid Climates, Texas A\&M University, Ft. Worth, TX (October).

37. O'Neal, D., Bryant, J., Boles, K. 1992. "Building Energy Instrumentation for Determining Retrofit Savings: Lessons Learned," Proceedings of the ASME/JSES/KSES International Solar Energy Conference, Vol. 2 (March).

38. O'Neal, D., Bryant, J., Turner, W., D., Glass, M. 1990. "Metering and Calibration in LoanSTAR Buildings," Proceedings of the Seventh Symposium on Improving 
Building Systems in Hot and Humid Climates, Texas A\&M University, Ft. Worth, TX (October).

39. Palani, M., O'Neal, D., Haberl, J. 1992. "The Effect of Reduced Evaporator Air Flow on the Performance of a Residential Central Air Conditioner," Proceedings of the Eighth Symposium on Improving Building Systems in Hot and Humid Climates, Texas A\&M University, (May).

40. Reddy, A., Kissock, K., Claridge, D. 1991. "Uncertainty Analysis in Estimating Building Energy Retrofit Savings in the LoanSTAR Program," Proceedings of the 1992 ACEEE Summer Study on Energy Efficiency in Buildings, Vol. 3 (August).

41. Robinson, J., Bryant, J., Turner, D., Haberl, J. 1992. “Calibration of Tangential Paddlewheel Flow Meters," Proceedings of the Eighth Symposium on Improving Building Systems in Hot and Humid Climates, Texas A\&M University, (May).

42. Ruch, D., Chen, L., Haberl, J., Claridge, D. 1991. “A Change-Point Principal Component Analysis (CP/PCA) Method for Predicting Energy Usage in Commercial Buildings: The PCA Model," ASME Solar Engineering, (March).

43. Ruch, D., Claridge, D. 1992. "A Four Parameter Change-Point Model for Predicting Energy Consumption in Commercial Buildings," ASME Solar Engineering, (March).

44. Ruch, D., Claridge, D. 1992. "NAC for Linear Change-Point Energy Models," Proceedings of the 1992 ACEEE Summer Study on Energy Efficiency in Buildings, (August).

45. Ruch, D., Kissock, K., Reddy, A. 1993. "Model Identification and Prediction Uncertainty of Linear Building Energy Use Models with Autocorrelation," Proceedings of the 1993 ASME/ASES/SED International Solar Conference, Washington, D.C. (January).

46. Selkowitz, S., Haberl, J., Claridge, D. 1992. "Future Directions: Building Technologies and Design Tools," Proceedings of the 1992 ACEEE Summer Study on Energy Efficiency in Buildings, Asilomar, CA, (August).

47. Sparks, R., Haberl, J., Bhattacharrya, S., Rayaprolu, M., Wang, G., Vadlamani, S. 1992. "Testing Data Acquisition Systems for Use in HVAC System Monitoring," Proceedings of the ASME/JSES/KSES International Solar Energy Conference, Vol. 1 (March).

48. Sparks, R., Haberl, J., Bhattacharrya, S., Rayaprolu, M., Wang, G., Vadlamani, S. 1992. "Testing Data Acquisition Systems for Use in Monitoring Building Energy Conservation," Proceedings of the Eighth Symposium on Improving Building Systems in Hot and Humid Climates, Texas A\&M University, (May). 
49. Turner, D., Haberl, J., Bryant, J., Finstad, C., Robinson, J. 1992. "Calibration Facility for the LoanSTAR Program," Proceedings of the ASME/JSES/KSES International Solar Energy Conference, Vol. 2 (March).

50. Verdict, M., Haberl, J., Claridge, D., O'Neal, D., Heffington, W., Turner, D. 1990. "Monitoring \$98 Million in Energy Efficiency Retrofits: The Texas LoanSTAR Program," Proceedings of the ACEEE Summer Study on Energy Efficiency in Buildings, (August).

51. Willis, D., Haberl, J. 1992. "A Collaborative Support System for the Review of Building Energy Data in the LoanSTAR Monitoring and Analysis Program," Proceedings of the Eighth Symposium on Improving Building Systems in Hot and Humid Climates, Texas A\&M University, (May).

52. Wu, J., Reddy, A., Claridge, D. 1992. "Statistical Modeling of Daily Energy Consumption in Commercial Buildings Using Multiple Regression and Principal Component Analysis," Proceedings of the Eighth Symposium on Improving Building Systems in Hot and Humid Climates, Texas A\&M University, (May). 


\subsection{Helpful Hints about Polling and Retrieving Data}

\subsubsection{Processing/Plotting Synergistics Data}

The following are some helpful hints about what to do with the data once they have been collected from a logger. A collection of routines used to process and plot data collected from Synergistics loggers used by the Texas LoanSTAR Program over the last three years on a weekly basis is described here. Instructions and sample code are available on disk for developing inspection and summary plots, and 3-D plots using a combination of public domain data processing tool kits and inexpensive commercially available plotting software. The routines discussed are available in the workbook by Haberl et al. (1992).

This section describes a collection of routines that are used to process and plot data collected from data loggers. These routines have been used by the Texas LoanSTAR Program over the last three years on a weekly basis to create a set of inspection plots, which can be used as a primary quality control measure. One of the major goals of LoanSTAR has been to provide a fully functional system for presenting measured building energy data at a minimum of both cost and effort. To these ends, the system utilizes a collection of inexpensive commercially available products and public domain packages, as well as a set of public domain software filters written in-house to knit the streams together.

Controlling batch files are used to call the routines in sequence; once a production mode is established for creating the plots for a particular building, only a few keystrokes are required to actually create the graphic report. As each building being measured possesses some unique properties, an inherent amount of tailoring of these routines is required. Most of the effort required to run and maintain this system is in the initial setup.

Software available with the Monitoring Workbook (Haberl et al. 1992) contains a sample set of data for a typical university building, an associated weather file, and the routines used to process the data. This processing includes:

1) Automated quality control checks of all data channels against static lower and upper bounds.

2) Insertion of missing records with bad data markers (-99).

3) Creation of time series graphs of all channels, grouped twelve graphs per page.

4) Creation of summary plots.

The processing stream makes these assumptions:

1) Data are being collected on an hourly basis.

2) Each data file to be processed contains exactly one week worth of hourly records.

3) Each site (data logger) has an associated three-digit code. The example used herein is site 101 - The University Teaching Center at the University of Texas in Austin. 
4) The raw data recorded from the Synergistics logger has been stored into a file using real numbers and no headers from the Synergistics software (10192168.RAW).

5) The file name used to record the raw data follows the strict format of $\mathrm{XXXYYDDD.RAW}$, where XXX is the three-digit site code, $\mathrm{YY}$ is the year, and DDD is the number of the day during which the data were collected. Collectively, YYDDD is known as the Julian date. As an example, the raw data file available on the distribution diskette is 10192168.RAW (Table 10.1). This is data for site 101. Because it was collected on 92168 (the 168th day of 1992 or June 15, 1992), this file contains data for the period beginning 92161 (June 8, 1992 at midnight) and ending 92167 (June 15, 1992 at 11:00 p.m.).

6) To print summary plots, a weekly weather file containing hourly data for the region is present (20292168.WEA).

7) The commercially available graphing program GRAPHER (Golden 1990) is used to create the plots.

8) The public domain programs ARCHIVE and COLS (Feuermann and Kempton 1987), and GAWK(FSF 1989) (available on a distribution diskette) are used for quality control and data manipulation.

9) The subdirectory ITEMP has been created prior to running the routines. Additional information about the routines is contained in the LoanSTAR Monitoring Workbook.

The following sections discuss the methodology of these routines as well as possible modifications for plotting other metered data.

\subsubsection{Preparing Data from Time Series Channels from Raw Synergistics Data with R2A.BAT}

Given this set of filters and programs, a rudimentary quality control range check can be performed and a full set of time series plots can be created with a simple command line operation. To perform the quality control and produce plots the following simple commands are issued:

\section{R2A $1019216890001<C R>$}

This command calls the controlling batch file R2A.BAT to begin the process as shown in Figure 10.1. The parameters passed to R2A.BAT include the three-digit logger code (101), a Julian polling date (92168), and a channel table descriptor (90001). R2A.BAT uses the logger code and Julian date to understand which file to process.

R2A includes an ARCHIVE channel table, which is a data dictionary that attaches static high/low bounds, English language descriptions, and scaling factors to each data column. In a long term monitoring project, this channel table might change significantly during the course of the project; therefore, new channel tables can be written or changes added to the same channel table. The channel table descriptor tells R2A.BAT which channel table is current for the data being processed. 
The output of this scheme includes the flat file 10192168.ACS, which is incorporated into the LoanSTAR database, and two pages of Postscript output, 101ONE.OUT and 101TWO.OUT. These pages contain time series plots of all the channels being monitored at site 101. Examples of these pages are given as Figures 10.2 and 10.3.

Briefly, these steps are performed by R2A.BAT:

1) The GAWK script RAW2DAT.AWK is called to preprocess the raw data 10192168.RAW for quality control checks. The quality control is performed by the public domain program ARCHIVE (Feuermann \& Kempton, 1989); which is unable to understand some of the characters that the Synergistics software leaves in the 10192168.RAW file. An example of Synergistics data is given as Table 10.1. The output of RAW2DAT is given as Table 10.2. Notice date/time columns have been adjusted, and certain characters have been stripped out of the file (e.g., " $/$, " ":," etc.).

2) The output of RAW2DAT and the site's ARCHIVE channel table are fed into ARCHIVE for static high/low range checking. The ARCHIVE channel table 10190001.CHT for site 101 is given as Table 10.3. Example output from ARCHIVE is given as Table 10.7. ARCHIVE will report any offending data readings in a log file and will replace such readings in the data with a "bad data" marker (Table 10.4). For the LoanSTAR program, this marker is -99 . ARCHIVE automatically appends the DOS file extension .ACH to the filename. For the example dates as provided, this step will have created the file 10192168.ACH.

An ARCHIVE channel table is created for each site that contains the instructions that ARCHIVE uses to process the data from each site. In Table 10.3, the ARCHIVE channel table 10190001.CHT that processes the data from site 101 is shown. The first four lines of the channel table are labels for the columns below. The "-._._._" column alignment guide indicates to the user how many characters to include in each parameter, and uses a blank as a separating delimiter. The line beginning with “\#” contains special characters that tell ARCHIVE what kind of data it is processing, and what to use as a missing variable (the default is -99 ).

- The first eight characters are the date to which the parameters are to be applied. Excluding the last line, this is "04/23/92" for site 101, which is the most recent date for this parameter set.

- The next variable is the time, in this case "00:00". This is instructing ARCHIVE to begin processing on April 23, 1992 at midnight.

- Next are the line number and column number of the input channel. These are followed by the ARCHIVE output column number. A " 0 " value is essentially a comment line and does not appear in the $\mathrm{ACH}$ file. 
- Following the ARCHIVE column position indicator is an eight character descriptor of the channel. This is followed by another twelve character descriptor of the ARCHIVE units and a six character code word for the ARCHIVE output format.

- The next two variables contain the conversion code word and conversion constants. The conversion code word is an integer from 1 to 31 and instructs ARCHIVE whether or not to perform conversions on the incoming data. Conversion code "0" will place a missing variable into this column, code " 1 " is an identity code that allows the value to pass through ARCHIVE untouched, code "2" is a linear transformation that requires two constants (i.e., slope and intercept), and so forth.

- The last three columns contain the error code, error constants, and channel description. The error checking code, $1=$ on, $0=$ off, initiates the high/low limit checking, which makes use of the high/low limit values that immediately follow.

In the 10190001.CHT channel table in Table 10.3, there are 24 lines of input. The first line

\section{4/23/92 00:00 100 Begin UTC Beginning Date}

is basically a comment line that does not appear in the output. The next line

04/23/92 00:00 11 i Bldg. \# XX I3 2010100 *Good starting 92.19*

places the site number "101" in the first column of the ARCHIVE output. This is done by using a linear transformation of slope $=0$ and intercept $=101$.

The next six lines

$$
\begin{array}{ll}
04 / 23 / 92 & 2 \\
B \ldots & B \ldots \\
04 / 23 / 92 & 6
\end{array}
$$

create the second through seventh columns in the output file. The second, third, and fourth columns in 10192168.ACH are the month, day and year that are simply passed through ARCHIVE without change.

- The fifth column is the Julian date (92161), that is calculated by ARCHIVE using the first, second, and third input columns.

- The sixth column is the decimal date (4543.000) that is calculated by ARCHIVE. The decimal date is a combined date and time stamp that is an offset number of days and hours from January 1, 1980. It is similar to the @DATE(YR,MO,DAY) function that is used in many spreadsheets. 
- The seventh column is the hour of the day using military notation (i.e., 0 to 23 hours).

- Columns eight through eighteen in 10192168.ACH all contain monitored data from the UTC building.

As can be seen in Table 10.7, many additional columns have been appended to the data. These columns are:

Site number Because these files are stored as ASCII text, it is very easy for records from other sites to be mistakenly inserted into a data set. This simple site number at the beginning of each line is a first step to ensure that the data recorded in this file really belong here.

Month, Day, Year This is recorded in the file so that people can understand the dates.

Julian date This has been discussed previously.

Decimal date Although this looks bizarre at first, the decimal date is a very handy way for a computer to understand time and graph data points as a time series. The integer part of the decimal date is merely an offset number of days from January 1,1980 . The decimal part is the hour of the reading divided by 24 . This date format guarantees different timestamps for all data points including leap years. A time series graph based on hourly indices is difficult to handle and plot because of the cyclic nature of the clock (20, $21,22,23,0,1,2,3$, etc.).

Time This is recorded in military units to differentiate between a.m. and p.m.

3) The .ACH file is fed to the program MISSING. This program scans the timestamps and inserts records and appropriate bad data markers for any missing records. When a Synergetics logger loses power in the field, it stops recording TSRs, and begins recording TSRs when the power is restored. However, a hole will exist in the data for those periods when the power was off. This hole is filled to aid in file merging and in graph readability. The output of MISSING uses the file extension.ACS. This is the ASCII flat file from which most of the work at LoanSTAR gets done. When there are no missing data there is no difference between an .ACH and .ACS file except the extension.

4) The final task of R2A is to call the graphing routines found in the batch file 101GRAPH.BAT. This program is sufficiently complicated and merits discussion on its own.

\subsubsection{Using GRAPHER to Create an Individual Graph}

GRAPHER is one of many commercially available general purpose graphics software programs. GRAPHER is very useful for rapidly plotting data because of its flexibility, overlay, and programmable batch mode operation. GRAPHER is actually composed of several subprograms, as shown in Figure 10.4. The most important of these (once 
configured) are the VIEW and PLOT programs. VIEW allows one to quickly preview a graph that has been created. PLOT translates GRAPHER 's .PLT file into device-specific plot instructions.

In general, to produce a plot with GRAPHER , one needs data (.DAT) and plotting instructions (.GRF). GRAPHER also allows for additional customization with axis (.AXS), grid (.GRD), dividing line (.DT) and text (.TXT) files.

Figure 10.5 shows the result of processing the T1017.GRF GRAPHER instruction file. 12 Table 10.5 contains a summary of the graphics instructions provided in the T1017.GRF file. Table 10.6 is the T1017.GRF file that GRAPHER produces. From Table 10.5 , one can see that input file T101.DAT is being used and that a linear X-Y plot is being produced using the sixth column $(F)$ for the $X$ variable and the fourteenth column (N) for the $\mathrm{Y}$ variable. GRAPHER produces a time series graph because the $\mathrm{X}$ variable is actually the decimal date. A solid line without symbols is being used to plot the data. Each graph that is to be plotted requires a .GRF file. The use of GRAPHER to produce weekly inspection plots is reasonably efficient because the same .GRF file (modified slightly) can be used with each week's data.

\subsubsection{Creating Graphs Using 101GRAPH.BAT}

101GRAPH.BAT is another controlling batch file. Its function is to automatically produce a set of time series plots (Figures 10.2 and 10.3), one per channel being reported by the logger. A flowchart for 101GRAPH.BAT is given as Figure 10.6.

Briefly, these steps are performed by 101GRAPH.BAT:

1) Copy a temporary version of the 10192168.ACS file into the ITEMP directory and rename the file to T101.DAT. This is required because GRAPHER only takes files with the .DAT extension as input.

2) Call the GAWK script 101DATE.AWK to determine the beginning dates. This script automatically writes the batch file 101CHGRF.BAT.

3) Call 101CHGRF.BAT. This uses the GAWK script 101CHGRF.AWK and the dates found in 101DATE.AWK to change the .GRF files for each plot. These files need to be changed to start the time line (the $\mathrm{X}$ axis) at the correct spot for each week. As each GRAPHER file is modified, it is written into ITEMP.

4) For each .GRF file in ITEMP, call GRAPHER. The output is an intermediate GRAPHER .PLT format.

12 This .GRF file and sample input data are provided with the distribution diskette that comes with the LoanSTAR Workbook by Haberl et al. (1992). 
5) Format each page. To print twelve graphs per page, the .PLT files need to be shrunk and pasted together. This is accomplished with a simple set of scale/translate files and the DOS copy command. The scale/translate files work as follows:

- A.PLT: Shrink. Move to the lower left corner (only one shrink command is needed).

- B.PLT: Move up one row.

- C.PLT: Move to the right one column and down two rows (back to the bottom of the page).

Therefore, a full page of twelve plots (i.e., $\# 1, \# 2, \ldots \# 12$ ) is created by appending all of these together:

A.PLT + \#1 + B.PLT +\#2 + B.PLT + \#3 + C.PLT +\#4 + B.PLT + \#5 + B.PLT +\#6 + C.PLT + \#7 + B.PLT + \#8 + B.PLT + \#9 + C.PLT + \#10 + B.PLT + \#11 + B.PLT + $\# 12$.

6) For each page of twelve graphs, use the GRAPHER PLOT program to create a Postscript.OUT file.

7) Clean out all the temporary files.

\subsubsection{Modification of Routines}

In order to modify the example routines to produce plots of channels from another logger, the following steps must be taken:

1) Assign a three digit code to the logger. For the purposes of these instructions, we'll use the generic designation $\mathrm{XXX}$.

2) Using the Synergistic PARSET program, make a printout of the logger's parameter set for this site. This is accomplished with the EDIT PRINT command after a logger has been selected. The last page produced by this report is a list of the channels that the PARSET software is using, as well as the left-to-right ordering of the columns in which they will appear in each TSR.

3) Using the last page of the parameter set report, modify the example ARCHIVE channel table (Table 10.3) to reflect the new site. This can be accomplished with any ASCII editor. These modifications include:

- the site number (line 2 after the header);

- the start date (first column of all lines after the header);

- the name of each channel;

- the error constants for each channel;

- the description of each channel;

- scaling of any channel that has not been previously scaled by PARSET. 
Save this file as XXX90001.CHT.

4) Modify 101DATE.AWK to utilize site XXX instead of 101. Save this file as XXXDATE.AWK:

5) Modify 101CHGRF.AWK to utilize site XXX instead of 101. Save this file as XXXCHGRF.AWK.

6) 101CHGRF.BAT does not need to be changed. This routine will be written automatically at runtime.

7) For each channel in the parameter set, a template GRAPHER .GRF file needs to be written. The easiest way to do this is to modify the T1011.GRF through T10116.GRF files. This can be accomplished by either using GRAPHER interactively or by handediting the .GRF files. The following items must be changed:

- Data file name from T101 to TXXX (in line 3).

- The site/date designation from "Site 101 Beginning" to "Site XXX Beginning" (line 16).

- The actual description of the channel being plotted (line 24).

8) Modify and rename 101GRAPH.BAT to utilize site XXX. This includes changing the user diagnostics that appear on the screen both at the beginning of the script and the termination, but it mainly consists of tailoring the middle section to knit together the page sections that print all the graphs cleanly. As has been stated previously, the given scaling and translation factors in A.PLT, B.PLT, and C.PLT can yield up to twelve graphs per page. Additional pages that might be required can be pasted into the routines by copying the lines, which create page XXXONE.PLT and using a different destination filename.

\subsubsection{Creation of Summary Pages From Raw Synergistics Data and Area Weather Data}

Because each building usually has a unique parameter set, summary plot pages have been created to produce a generalized scheme for quickly inspecting data collected from multiple buildings. A summary plot page contains whole-building information presented in a standard orientation.

The motivation for creating such a page is twofold: first, in many buildings, wholebuilding readings are often recorded on multiple channels (e.g. A, B, and C phases); second, unless a very rigid channel selection is followed each time, it is very difficult to get the same graph appearing in the same location on the standard time series pages over several buildings. This makes it difficult to review data from multiple sites because a fair amount of time is spent finding relevant channels in different places for each site. Summary plot pages decrease the time required during plot inspection to find the information that might be crucial to them. It was found early on in the LoanSTAR Program that pages such as these are tremendously helpful for visual quality control. 
An example summary plot page is shown in Figure 10.7. The first row of the summary plot page always contains a time series plot of whole-building electric for the site, as well as weather time series data (outdoor dry-bulb temperature, relative humidity, and solar radiation) for the region. In the LoanSTAR program, one or more loggers may share the same weather station. In the case where a logger does not have its own weather station, weather data from a nearby site must be merged in from an outside file.

The second row contains time series graphs of building chilled water consumption, hot water consumption or steam condensate, submetered electrical points, and lighting where applicable. The third and final row contains scatter plots of the same data points in the second row plotted against outdoor dry-bulb temperature for the region.

To create a summary plot page for the example dates as provided, the following command would be typed:

\section{UTSUMM $10192168<$ CR $>$}

This invokes the controlling batch file UTSUMM.BAT, and tells it to print a summary of site 101, using the Julian date of 92168 as its target. The output is the file 101SUMM.OUT, which contains the summary page in Postscript form. The flowchart of UTSUMM.BAT is given in Figure 10.8 .

The methodology behind the creation of summary pages is almost identical to that of the standard time series plots, preceded by two steps:

1) A step to create summary pseudo-channels. This is needed in buildings with multiple electric or chilled water feeds to create a temporary channel, which totals all the subfeeds. This is accomplished for site 101 with a call to the GAWK script 101SUMM.AWK.

For example 10192168.ACS is passed to 101SUMM.AWK and produces TS101.DAT in the current directory. Within 101SUMM.AWK channels \#8, 9, 10, 11 , $12,13,19,20,21$, and 22 are added together to form a Motor Control Center Channel (MCC), excluding any values that are missing (-99). The TS101.DAT output file then contains values for the Motor Control Center (MCC), whole-building electricity (ELEC), whole-building steam use (HW), and whole-building chilled-water use (CW). The whole-building steam is multiplied by 9.075 to allow for units of Btus.

The output file TS101.DAT is then merged together with local weather data with the command:

$$
\text { COLS ^TS\%1.DAT ^202\%2.WEA A1:5 B8:11 > ITEMPITS\%1.DAT <CR> }
$$


This calls COLS with the input files TS101.DAT and 20292168.DAT. Columns 1 through 5 from TS101.DAT and 8 through 11 from 20292168.DAT are merged together to form TS101.DAT in the subdirectory ITEMP, which is immediately followed by a deletion of TS101.DAT in the current directory because it is no longer needed.

2) A step to merge in regional weather data for the same week. Assuming both the building data and the weather data have been filtered through the MISSING program, this step can be accomplished with a simple call to COLS. COLS is one of the helpful tool kits that comes with ARCHIVE.

The remaining steps that are performed in UTSUMM.BAT are as follows:

3) Call the GAWK script 101DATE.AWK to determine the beginning dates. In a similar fashion to 101GRAPH.BAT, this creates the batch file 101CHGRF.BAT.

4) Call 101CHRGF.BAT, which uses 101CHGRF.AWK to change the TS*.GRF files for each plot. Modified graphs are then written to ITEMP.

5) Change directory to ITEMP. Then for each .GRF file in ITEMP, call GRAPHER.

6) Format the summary page using a combination of shrink and paste commands as shown.

7) Plot the Postscript file and clean-up.

\subsubsection{Modification of Summary Plot Routines}

Prior to modification of summary plot routines, it is assumed that the process for creating the standard time series plot pages is in order and functional. To modify the example routines to produce summary plots of channels from an arbitrary logger, the following steps would need to be taken:

1) Modify each template GRAPHER file, TS1011.GRF through TS10112.GRF, to reflect site XXX. This is identical to changing the original files when creating the standard pages.

2) Modify UTSUMM.BAT to do the following:

a) Report the correct site number in the user diagnostics upon entrance and exit.

b) Merge the weather data from the correct region/file.

3) Create a GAWK summary script similar to 101SUMM.AWK. The contents of this script will be completely site specific.

10.2.4 Creating a 3-D Graph Using Lotus 123 and Intex Solutions 3D Graph 
Three dimensional (3-D) graphs have been shown to be useful in displaying schedulerelated whole-building and end-use energy profiles. However, it is not always easy to create useful 3-D plots on a PC because certain software packages require that data be placed in a special format prior to processing. One such combination of processing schemes is shown in Figure 10.9. Columnar data are plotted with the Intex Solutions 3-D plot package that can be attached to Lotus 123 on a PC.

To facilitate the creation of 3-D plots, a special routine was created to convert COLumnar data into ROW format to produce a 3-D plot -- COLROW3D (1991). With this routine two columns of ASCII data are fed to COLROW3D where they are reformatted into a row-wise matrix to allow for importing into 123 for plotting with the 3$D$ graphics add-on package. ${ }^{13}$ To facilitate this easily in a batch mode previously compiled 3-D plot instructions can be used in a 123 macro file. Output from 123 consists of .PIC files that can be plotted or passed on to additional programs for further processing. This next section describes how to use the software to produce 3-D surface plots with the Lotus 123 add-on package that is available from Intex Solutions. The reader is referred to the Lotus 123 manual or the Intex Solutions 3D graphics manual for further information about plotting the 3-D graphs.

\subsubsection{Using the COLROW3D Columnar to Row Data Processing Routine}

COLROW3D is a columnar data manipulation program that processes hourly energy consumption data to produce a "new" file containing a spread sheet-compatible data matrix. COLROW3D compresses each day's worth of data into one row in the matrix. For example, a leap year's worth of hourly data (8784 lines) will be compressed down to just 367 lines!

The output file generated by COLROW3D can be used in conjunction with Lotus 123 and Intex Solution's 3D-Graphics add-on package to produce a 3-D picture of energy consumption versus day of year and time of day. COLROW3D also creates a .LOG file containing information about the run and any erroneous data found. The COLROW3D program is written in ANSI Standard C.

\section{Keywords:}

Source: $\quad$ COLROW3D's input filename.

Dest or Destination: COLRंOW3D's output filename.

LOG: COLROW3D's log file.

Method or Option: Code used to process input data.

3D extension: Output filename extension.

$3 D$ Graph:

Decimal date: $k W h / h$ : Three dimensional graph. Data string used to express date and time of data together. Hourly energy consumption data.

13 This matrix file can also be passed to Microsoft Excel, which results in a similar looking 3-D graph. The ESL has a similar routine for Excel called 3DMACXI. 


\section{Requirements:}

For COLROW3D: IBM PC compatible computer with at least $128 \mathrm{~K}$ memory MS-DOS 2.11 or greater

\section{Input file(s):}

The original energy consumption file contains two columns of data: Date (day of year and time of day expressed as a single decimal date string), and consumption (expressed in units between -999.9 and +9999.9 ). The data should be separated by a space from the decimal date and can be of real or integer type. The input file may contain up to 366 days of hourly data with each day containing 24 hours. All dates must be in chronological order.

COLROW3D requires one input file. Table 10.8 is a sample input file. The input file contains two columns of data separated by at least one space. The first column is the date and time of the data expressed in decimal format, while the second column is the energy consumption data. When preparing the input file, keep in mind the following "Rules":

- The input file may only contain numeric data of the integer and real type. No characters other than the numerals 0 through 9 , decimal points, minus signs, and spaces are allowed.

- Each line row or record should contain only two data fields. If more than two values are included, data beyond the second value are ignored. If only one datum is given on a line, the program will assume a missing value for the second field. A value of 0 is used as the missing code.

- The maximum data that will be read are 366 days worth of hourly data. Each day may contain from 1 to 24 hours of data--one record per hour. Only hourly data should be used as input to COLROW3D. Data in sub-hourly format must be converted to hourly format prior to processing.

- The first column of data in the input file is the decimal date stamp. The decimal date is a contrived method of representing the date and time using a single data string. Before you run COLROW3D, you must first convert your date and time to the decimal date format. The Princeton ARCHIVE program by Feuermann and Kempton (1987) is recommended for this purpose. A copy of ARCHIVE is included with the LoanSTAR workbook.

Arbitrarily, January 1, $198000: 00: 00$ hours is considered to be day 0 and has the decimal date representation 0000.0000 . The number on the left hand side of the decimal point represents the number of days since January 1, 1980. The number on the right hand side of the decimal point represents the hour as a fraction of the day. Hours range from 0 
through 23 and are calculated using the formula Hour = Decimal portion multiplied by 24 and rounded to the nearest integer. Hour 24 becomes Hour 0 of the following day. Note: while the days of the year must be in chronological order, no such requirement is imposed on the hour of the day.

Valid dates are from January 1, 1980 (day 0) through December 31, 2009 (day 10957). Leap years and century leap years are taken into consideration. The program will need to be updated for decimal dates beyond the year 2009. Table 10.11 gives decimal dates for January 1 from 1980 through 2009. The following are examples of decimal date conversion:

\begin{tabular}{|c|c|c|}
\hline Date & Time & Decimal date \\
\hline $\begin{array}{c}\text { January 21, } \\
1988\end{array}$ & 11 p.m. & 2942.9583 \\
\hline May 1, 1990 & 1 a.m. & 3773.0417 \\
\hline $\begin{array}{c}\text { December 31, } \\
1991\end{array}$ & 5 p.m. & 4382.7083 \\
\hline
\end{tabular}

The second data column in the input file can be either consumption or environmental data. Acceptable values are between -999.9 and 9999.9. A value of 0 will be used for missing data. If the value lies outside the acceptable range, the program records an error message to the .LOG file, and sets the hourly consumption to 0 for missing data. Data are recorded to the output file by rounding off to the first decimal place.

\section{Examples of Energy use data}

2901.0417100 record indicates that on December 11, 1987 at 1:00 am the building used $100 \mathrm{~kW}$ of energy.

$4020.000099999 \quad$ ERROR! data value is out of bounds. A message will be written to the .LOG file, and the consumption will be set to 0 .

\section{Output file(s):}

The output data file contains the original energy use data, which have been rearranged in a matrix format for use with Lotus 123 . This file must have a .3D extension. The .LOG file contains information written by COLROW3D while the program is executed. Information regarding date and time of run, and any errors encountered during processing are included. The date of the first and last string of processed data are shown.

\section{Output File.}


The output file is an $\mathrm{N}$ by 24 matrix containing only the valid input data. Here $\mathrm{N}$ stands for number of days between the first and last valid date stamp read from the input data file. For example, for one year's worth of data $\mathrm{N}$ is 366 .

Both sample output files are shown in Table 10.9. The first row is a header that contains the hour of the day (ranging from 0 to 23); the first column is the day of the year (for example, day 121 is May 1st); and the remaining fields are hourly consumption data (in units of $\mathrm{kWh} / \mathrm{h}$ ). Missing data are represented by the value 0 . The very first value in the first row shows the day of year for the last date read. This makes it convenient to use the output file in a spreadsheet because it can be used to compute the number of rows in the table.

\section{.LOG File.}

COLROW3D keeps a record of what happened during each run of the program. This information is written to disk in a .LOG file. The .LOG file has the same name as the input data file, but with a.LOG extension. Existing .LOG files with the same name will be overwritten. Any errors encountered during execution are written to the .LOG file. An example of a .LOG file is shown in Table 10.10 .

The header specifies the name of the program and the date and time the run was made. The next line gives the name of the input file, the output file, the .LOG file, and the option selected. The following line gives the time the first record was read and the beginning date associated with that record.

The error table follows, and lists the location of the erroneous record, the data in the record, and the invalid datum. Because COLROW3D can deal with very large data files, a maximum of 50 date stamp errors and 20 data errors will be recorded in the .LOG file. This is to prevent a single bad datum from causing the entire data file to be written to the .LOG file. At the end of the error table is the time the last record was read and the ending date associated with that record.

The last part of the .LOG file consists of statistics about the input records. The .LOG file ends with a note, which states that the time portion of the date stamp is not checked for chronological order, and a message that the .LOG file is complete.

\section{Execution:}

\section{COLROW3D Input Output Option $<\mathrm{CR}>$}

Input is the input file name (with complete path and extension specified.)

Output is the processed data file (with .3D extension). 
Option is the integer 0 or 1 . Choose 0 to create a file beginning with days $=1$ and ending with day $=366$, each day containing 24 hours of data. If the original file has fewer than 366 days of data, missing data are set to 0 . Select a value of 1 to output fewer than one year's worth of data in contiguous order. Option 1 preserves the chronological order of input file. Figure 10.10 illustrates the difference in $3-D$ graphs between a " 0 " and " 1 " option. Table 10.9 shows the difference in the output files.

\section{Example:}

\section{COLROW3D SAMPLE.DAT SAMPLE.3D $1<C R>$}

Action: COLROW3D will read data from the input file called SAMPLE.DAT, output data to SAMPLE.3D, and create the .LOG file SAMPLE.LOG. Because the SAMPLE.DAT input file contains less than one year's worth of data, missing data are given the value of 0 .

\section{Example:}

\section{COLROW3D SAMPLE.DAT SAMPLE.3D $0<$ CR $>$}

Action: COLROW3D will read the file SAMPLE.DAT, output to the file SAMPLE.3D, and create the .LOG file SAMPLE.LOG. The output file is a 366 by 24 matrix with missing data set to 0 .

\section{Example:}

\section{COLROW3D ? $<$ CR $>$}

Action: COLROW3D displays the on-line help screen. For additional help, check the manual.

\section{Notes:}

1) An additional program is available from the Energy Systems Lab that automatically creates the Lotus .PIC graphing instructions called 3DMAC.WK1. Feel free to contact the Energy Systems Laboratory about availability. ${ }^{14}$ This program is useful for automatically creating 3-D spreadsheet graphics in the batch mode.

Table 10.12 above contains the 3DGRAPH plotting instructions that were used to produce the lower half of Figure 10.10 above. The plot instructions are also included in electronic form in the SAMPLEM1.3DP file that is included with the workbook diskette. After installing, configuring, and initiating the Intex 3DGRAPH Lotus add-

14 Ask for a copy of the ESL publications list which contains a list of the public domain software that is available. 
on, the SAMPLE.3D data matrix can be loaded with a FILE IMPORT command (with the pointer in cell A1). The SAMPLEM1.3DP graphing instructions can then be loaded after the 3D Graph has been initiated with a GRAPH NAME USE command.

2) COLROW3D will accept only numeric data of the real and integer type separated by at least one space. This program cannot handle any other data types. Two primary kinds of errors can occur:

(i) Decimal date errors. An error with the date stamp will occur if the day is not in chronological order. The hours of the day do not need to be in order. Example, if the input file reads:

$\begin{array}{ll}3840.0000 & 24.2 \\ 3840.0417 & 25.3 \\ 3880.0000 & 28.0 \\ 3840.1250 & 25.9 \\ 3840.0833 & 25.5 \\ \ldots \ldots . . . & \ldots\end{array}$

The last two records will be skipped and reported as an error in the .LOG file because the decimal dates 3840.1250 and 3840.0833 are out of sequence with the record 3880.0000 .

Another date error will occur if the decimal date value is less than 0 (January 1, 1980) or larger than 10957 (December 31, 2009). Refer to the COLROW3D manual for further details.

(ii) Energy use errors. A data out-of-bounds error will occur if the consumption value lies outside the acceptable range [-999.9, 9999.9]. If this should happen, the data record is skipped and an error message is written to the .LOG file. These limits are established by the maximum file import size in Lotus 123. 
Table 10.1: Example Synergistics Raw Data Format 10192168.RAW.

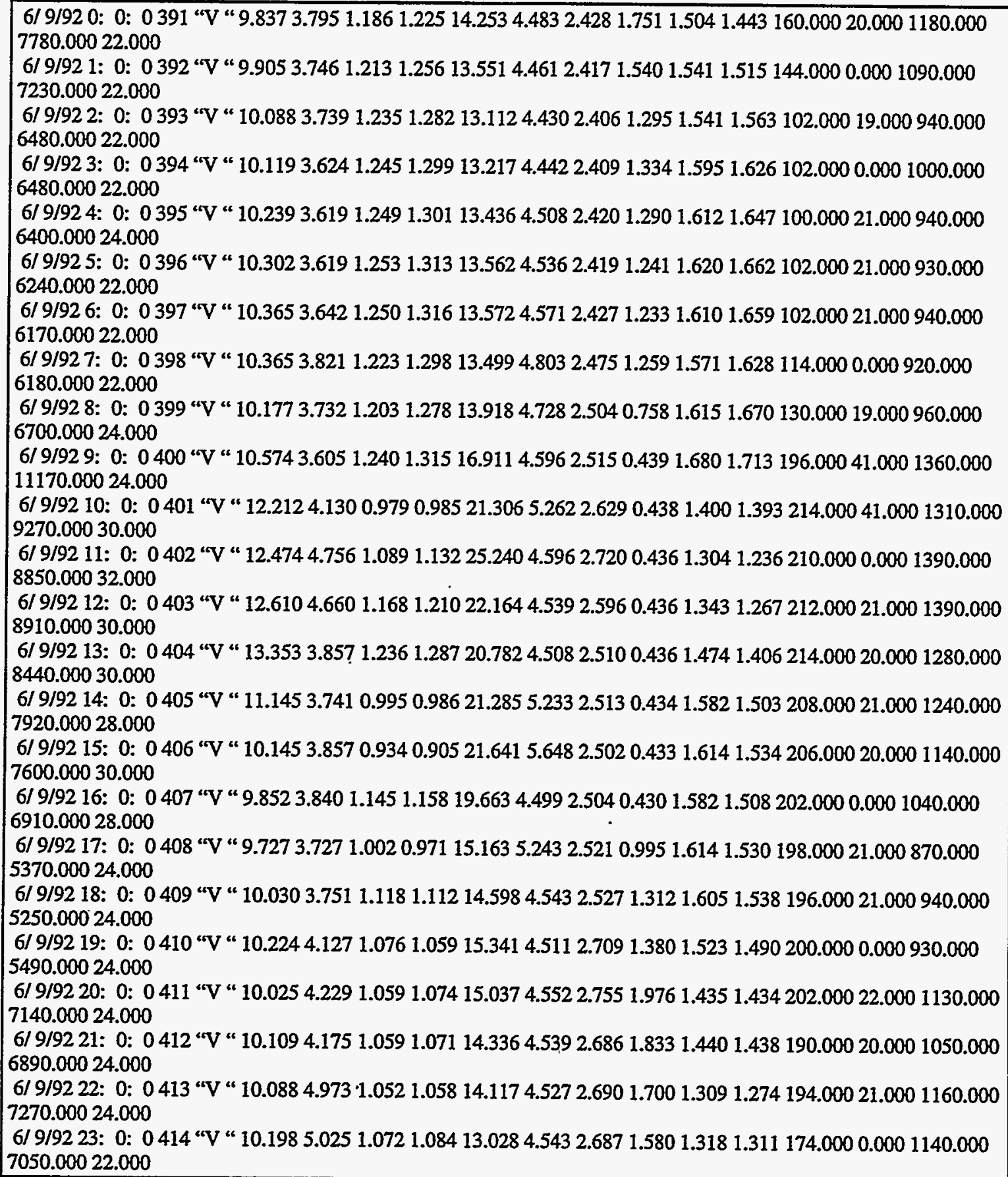

Texas LoanSTAR Program

Texas Engineering Experiment Station
Energy Systems Laboratory Texas A\&M University 
Table 10.2: Example Output 10192168.DAT From RAW2DAT Program.

6992009.8373 .7951 .1861 .22514 .2534 .4832 .4281 .7511 .5041 .443160 .00020 .0001180 .0007780 .00022 .000 6992109.9053 .7461 .2131 .25613 .5514 .4612 .4171 .5401 .5411 .515144 .0000 .0001090 .0007230 .00022 .000 69922010.0883 .7391 .2351 .28213 .1124 .4302 .4061 .2951 .5411 .563102 .00019 .000940 .0006480 .00022 .000 69923010.1193 .6241 .2451 .29913 .2174 .4422 .4091 .3341 .5951 .626102 .0000 .0001000 .0006480 .00022 .000 69924010.2393 .6191 .2491 .30113 .4364 .5082 .4201 .2901 .6121 .647100 .00021 .000940 .0006400 .00024 .000 69925010.3023 .6191 .2531 .31313 .5624 .5362 .4191 .2411 .6201 .662102 .00021 .000930 .0006240 .00022 .000 69926010.3653 .6421 .2501 .31613 .5724 .5712 .4271 .2331 .6101 .659102 .00021 .000940 .0006170 .00022 .000 69927010.3653 .8211 .2231 .29813 .4994 .8032 .4751 .2591 .5711 .628114 .0000 .000920 .0006180 .00022 .000 69928010.1773 .7321 .2031 .27813 .9184 .7282 .5040 .7581 .6151 .670130 .00019 .000960 .0006700 .00024 .000 69929010.5743 .6051 .2401 .31516 .9114 .5962 .5150 .4391 .6801 .713196 .00041 .0001360 .00011170 .000 24.000 699210012.2124 .1300 .9790 .98521 .3065 .2622 .6290 .4381 .4001 .393214 .00041 .0001310 .0009270 .000 30.000 699211012.4744 .7561 .0891 .13225 .2404 .5962 .7200 .4361 .3041 .236210 .0000 .0001390 .0008850 .000 32.000 699212012.6104 .6601 .1681 .21022 .1644 .5392 .5960 .4361 .3431 .267212 .00021 .0001390 .0008910 .000 30.000 699213013.3533 .8571 .2361 .28720 .7824 .5082 .5100 .4361 .4741 .406214 .00020 .0001280 .0008440 .000 30.000 699214011.1453 .7410 .9950 .98621 .2855 .2332 .5130 .4341 .5821 .503208 .00021 .0001240 .0007920 .000 28.000 699215010.1453 .8570 .9340 .90521 .6415 .6482 .5020 .4331 .6141 .534206 .00020 .0001140 .0007600 .000 30.000 69921609.8523 .8401 .1451 .15819 .6634 .4992 .5040 .4301 .5821 .508202 .0000 .0001040 .0006910 .00028 .000 69921709.7273 .7271 .0020 .97115 .1635 .2432 .5210 .9951 .6141 .530198 .00021 .000870 .0005370 .00024 .000 699218010.0303 .7511 .1181 .11214 .5984 .5432 .5271 .3121 .6051 .538196 .00021 .000940 .0005250 .000 24.000 699219010.2244 .1271 .0761 .05915 .3414 .5112 .7091 .3801 .5231 .490200 .0000 .000930 .0005490 .00024 .000 699220010.0254 .2291 .0591 .07415 .0374 .5522 .7551 .9761 .4351 .434202 .00022 .0001130 .0007140 .000 24.000 699221010.1094 .1751 .0591 .07114 .3364 .5392 .6861 .8331 .4401 .438190 .00020 .0001050 .0006890 .000 24.000 699222010.0884 .9731 .0521 .05814 .1174 .5272 .6901 .7001 .3091 .274194 .00021 .0001160 .0007270 .000 24.000 699223010.1985 .0251 .0721 .08413 .0284 .5432 .6871 .5801 .3181 .311174 .0000 .0001140 .0007050 .000 22.000 
Table 10.3: Example Channel Table For the 10190001.CHT ARCHIVE Program.

\begin{tabular}{|c|c|c|c|c|c|c|c|c|c|c|c|c|}
\hline $\begin{array}{c}\text { Date } \\
\text { MM/DD/YY } \\
\text { (YY DDD) }\end{array}$ & $\begin{array}{l}\text { Time } \\
\text { HH: } \mathrm{mm}\end{array}$ & $\begin{array}{l}\text { Raw- } \\
\text { lin } \\
\text { pos }\end{array}$ & $\begin{array}{l}\text { Data } \\
\text { coln } \\
\text { pos }\end{array}$ & $\begin{array}{l}\text { Arch } \\
\text { coln } \\
\text { pos }\end{array}$ & $\begin{array}{l}\text { Name of } \\
\text { Channel }\end{array}$ & $\begin{array}{l}\text { Archive } \\
\text { Units }\end{array}$ & $\begin{array}{l}\text { Arch } \\
\text { Format }\end{array}$ & $\begin{array}{l}\text { Conv'n } \\
\text { Code }\end{array}$ & $\begin{array}{c}\text { Conv'n } \\
\text { Constants }\end{array}$ & $\begin{array}{l}\text { Error } \\
\text { Code }\end{array}$ & $\begin{array}{l}\text { Error } \\
\text { Constants }\end{array}$ & $\begin{array}{c}\text { Channel } \\
\text { Description }\end{array}$ \\
\hline $04 / 23 / 92$ & $00: 00$ & 1 & 0 & 0 & Begin & UTC & & & & & . & \\
\hline $04 / 23 / 92$ & $00: 00$ & 1 & 1 & 1 & Bldg.\# & $\mathbf{x x}$ & $I 3$ & 2 & 0101 & 0 & & Beginning Date \\
\hline $.04 / 23 / 92$ & $00: 00^{\circ}$ & 1 & 1 & 2 & Mon-Raw & $M M$ & I3 & 1 & & 0 & & ${ }^{\star}$ Good starting \\
\hline $04 / 23 / 92$ & $00: 00$ & 1 & 2 & 3 & Mon-Raw & $\mathrm{DD}$ & I3 & 1 & & 0 & & Month \\
\hline $04 / 23 / 92$ & $00: 00$ & 1 & 3 & 4 & Mon-Raw & YY & I3 & 1 & & 0 & & Day \\
\hline $04 / 23 / 92$ & $00: 00$ & 1 & 3 & 5 & Greg-Jul & MMDDYY & I5 & 24 & 12 & 0 & & Year \\
\hline $04 / 23 / 92$ & $00: 00$ & 1 & 4 & 7 & Time & FH $m$ & I5 & 16 & 5 & 0 & & Time \\
\hline $04 / 23 / 92$ & $00: 00$ & 1 & 3 & 6 & Greg-DeC & DDD.frac & $=F 10.4$ & 28 & & 0 & & Gregorian Date \\
\hline $04 / 23 / 92$ & $00: 00$ & 1 & 6 & 8 & S/RMCC1 & F9.3 & F9.3 & 1 & & 1 & -5500 & $S / R$ MCC $1(\mathrm{kWh})$ \\
\hline $04 / 23 / 92$ & $00: 00$ & 1 & 7 & 9 & S/RMCC1 & F9.3 & F9.3 & 1 & & 1 & -5500 & S/R AHUS 15,2 \\
\hline $04 / 23 / 92$ & $00: 00$ & 1 & 8 & 19 & $\mathrm{HDF} 1-2 \mathrm{NI}$ & F9.3 & F9.3 & 1 & & 1 & -5500 & Hot Deck Fans \\
\hline $04 / 23 / 92$ & $00: 00$ & 1 & 9 & 20 & HDFI-2N2 & F9.3 & F9.3 & 1 & & 1 & -5500 & Hot Deck Fans \\
\hline $04 / 23 / 92$ & $00: 00$ & 1 & 10 & 10 & S/RMCC2 & F9.3 & F9.3 & 1 & & 1 & -5500 & $S / R \operatorname{MCC} 2(k W h)$ \\
\hline $04 / 23 / 92$ & $00: 00$ & 1 & 11 & 11 & $S / R M C 2 / 1$ & F9.3 & F9.3 & 1 & & 1 & -5500 & $S / R$ AHU $2 n, R$ \\
\hline $04 / 23 / 92$ & $00: 00$ & 1 & 12 & 12 & $S / R M C 2 / 1$ & F9.3 & F9.3 & 1 & & 1 & -5500 & $S / R$ AHO $1 n, R$ \\
\hline $04 / 23 / 92$ & $00: 00$ & 1 & 13 & 13 & ChwPunp & F9.3 & F9.3 & 1 & & 1 & 0500 & ChW Pump (kWh) \\
\hline $04 / 23 / 92$ & $00: 00$ & 1 & 14 & 21 & HDF1-2S1 & F9.3 & F9.3 & 1 & & 1 & -5500 & Hot Deck Fans \\
\hline $04 / 23 / 92$ & $00: 00$ & 1 & 15 & 22 & HDF1-2S2 & F9.3 & F9.3 & 1 & & 1 & -5500 & Hot Deck Fans \\
\hline $04 / 23 / 92$ & $00: 00$ & 1 & 16 & 14 & $\mathrm{kWh} M$ & F9.3 & F9.3 & 1 & & 1 & 0500 & Bldg kWh Meter \\
\hline $04 / 23 / 92$ & $00: 00$ & 1 & 17 & 15 & CondRet & F9.3 & F9.3 & 1 & & 1 & 099999 & 9 Cond Ret Meter \\
\hline $04 / 23 / 92$ & $00: 00$ & 1 & 18 & 16 & ChWBtuT & F9.3 & F9.3 & 1 & & 1 & 099999 & 9ChW Btu (kBtu) \\
\hline $04 / 23 / 92$ & $00: 00$ & 1 & 19 & 17 & ChWGalT & F9.3 & F9.3 & 1 & & 1 & 099999 & 9chw Gal (gal) \\
\hline $04 / 23 / 92$ & $00: 00$ & 1 & 20 & 18 & kWh M B & F9.3 & F9.3 & 1 & & 1 & 0500 & Bldg kWh Meter \\
\hline $04 / 11 / 99$ & $23: 00$ & 1 & 0 & 0 & End & UTC & & & & & & \\
\hline
\end{tabular}


Table 10.4: Example .LOG File From the ARCHIVE Program.

Log of Archive, version: 1.41 of 15 June 1987, processed on 24 June 1992

Files:

RAW DATA 10192168.dat

CHANNEL TABLE 10190001.cht

ARCHIVE 10192168.ach

LOG 10192168.log

Archive delimiter is " ".

Missing or bad data values are replaced by the value -99.000 .

Line errors: are identified by their line number in the raw data file.

Data errors: are identified by the channels name, line and position within the case: "name "(line in case/position in line).

Line numbers in raw data file are shown as Inumberl or as *number* Inumbersl indicates a line of data, *numbers* is a comment line.

First case on raw data: 92161 00:00

BeginDate: 92114 00:00 First output case: 92161 00:00

EndDate: 99101 23:00 Last output case: 92167 23:00

\section{STATISTICS:}

168 lines read from beginning of raw data file.

168 lines processed between Begin and End dates.

(including 0 comments and 0 all-blank lines)

0 line errors detected.

0 data errors, and 0 missing data detected 
TABLE 10.5: Summary of GRAPHER Instructions for Graph T1017.GRF.

AXIS DATA COLUMNS CENTERED BEST

$X Y$ FILENMS X Y LINE SYM. FIT

TYPE: LINEAR LINEAR 1 T101 F N SOLID NO NO

TITLE: Site 101 Building Meter 2

START: $1.5,1.01 .5,1.03$

LENGTH: 6.06 .04

START: 4543.00 .05

END: 4550.00 .06

TICS: YES YES 7

TIC LAB: YES YES 8

AXIS FILE: X-AXIS Y-AXIS

GRID FILE:

TEXT FILE:

DIV.FILE: 
Table 10.6: T1017.GRF GRAPHER File.

1243

12000

$\mathrm{t} 101$

70784819 "NO " 48

"YES" "SOLID" 1.500e-001 1

"NO" $411.000 \mathrm{e}-00111$

$489.900 \mathrm{e}+0289.900 \mathrm{e}+0280.000 \mathrm{e}+000$ "DEFAULT" 1.000e-001 1

"SOLID" 0 1.500e-001 9.9000000e+029 9.9000000e+029 200 2.000e+000 1

$9.9000000 e+0289.9000000 e+0299.9000000 e+0289.9000000 e+0291.500 e-001$

$\mathrm{X}$-AXIS

$1.5000000 \mathrm{e}+0001.0000000 \mathrm{e}+0006.0000000 \mathrm{e}+00088$

$3.9200000 e+0033.9270000 e+0039.9000000 e+02811$

$0.0000000 \mathrm{e}+0001.0000000 \mathrm{e}+0001.5000000 \mathrm{e}-00111$

701

$19.9000000 \mathrm{e}+0280.0000000 \mathrm{e}+0009.9000000 \mathrm{e}+0282.5000000 \mathrm{e}-001$

"DEFAULT" "DEFAULT" "Site 101 Beginning"

4.0000000e-002

Y-AXIS

$1.5000000 e+0001.0000000 e+0006.0000000 e+00089$

$0.0000000 e+0009.9000000 e+0289.9000000 e+02811$

$2.7000000 \mathrm{e}+0029.9000000 \mathrm{e}+0281.5000000 \mathrm{e}-00111$

1011

$19.9000000 e+0280.0000000 e+0009.9000000 e+0282.5000000 e-001$

"DEFAULT" "DEFAULT" "Bldg Meter A (kWh/h)"

4.0000000e-002 
TABLE 10.7: Example Output from the ARCHIVE Program, File 10192168.ACH.

1016992921614543.000009 .8373 .79514 .2534 .4832 .4281 .751160 .00020 .0001180 .0007780 .00022 .000 1.1861 .2251 .5041 .443

1016992921614543.04171009 .9053 .74613 .5514 .4612 .4171 .540144 .0000 .0001090 .0007230 .000 22.0001 .2131 .2561 .5411 .515

1016992921614543.083320010 .0883 .73913 .1124 .4302 .4061 .295102 .00019 .000940 .0006480 .000

22.0001 .2351 .2821 .5411 .563

1016992921614543.125030010 .1193 .62413 .2174 .4422 .4091 .334102 .0000 .0001000 .0006480 .000

22.0001 .2451 .2991 .5951 .626

1016992921614543.166740010 .2393 .61913 .4364 .5082 .4201 .290100 .00021 .000940 .0006400 .000 24.0001 .2491 .3011 .6121 .647

1016992921614543.208350010 .3023 .61913 .5624 .5362 .4191 .241102 .00021 .000930 .0006240 .000

22.0001 .2531 .3131 .6201 .662

1016992921614543.250060010 .3653 .64213 .5724 .5712 .4271 .233102 .00021 .000940 .0006170 .000

22.0001 .2501 .3161 .6101 .659

1016992921614543.291770010 .3653 .82113 .4994 .8032 .4751 .259114 .0000 .000920 .0006180 .000

22.0001 .2231 .2981 .5711 .628 1016992921614543.333380010 .1773 .73213 .9184 .7282 .5040 .758130 .00019 .000960 .0006700 .000

24.0001 .2031 .2781 .6151 .670

1016992921614543.375090010 .5743 .60516 .9114 .5962 .5150 .439196 .00041 .0001360 .00011170 .000

24.0001 .2401 .3151 .6801 .713

1016992921614543.4167100012 .2124 .13021 .3065 .2622 .6290 .438214 .00041 .0001310 .0009270 .000

30.0000 .9790 .9851 .4001 .393

1016992921614543.4583110012 .4744 .75625 .2404 .5962 .7200 .436210 .0000 .0001390 .0008850 .000

32.0001 .0891 .1321 .3041 .236

1016992921614543.5000120012 .6104 .66022 .1644 .5392 .5960 .436212 .00021 .0001390 .0008910 .000

30.0001 .1681 .2101 .3431 .267

1016992921614543.5417130013 .3533 .85720 .7824 .5082 .5100 .436214 .00020 .0001280 .0008440 .000

30.0001 .2361 .2871 .4741 .406

1016992921614543.5833140011 .1453 .74121 .2855 .2332 .5130 .434208 .00021 .0001240 .0007920 .000

28.0000 .9950 .9861 .5821 .503

1016992921614543.6250150010 .1453 .85721 .6415 .6482 .5020 .433206 .00020 .0001140 .0007600 .000

30.0000 .9340 .9051 .6141 .534

1016992921614543.666716009 .8523 .84019 .6634 .4992 .5040 .430202 .0000 .0001040 .0006910 .000

28.0001 .1451 .1581 .5821 .508

1016992921614543.708317009 .7273 .72715 .1635 .2432 .5210 .995198 .00021 .000870 .0005370 .000

24.0001 .0020 .9711 .6141 .530

1016992921614543.7500180010 .0303 .75114 .5984 .5432 .5271 .312196 .00021 .000940 .0005250 .000

24.0001 .1181 .1121 .6051 .538

1016992921614543.7917190010 .2244 .12715 .3414 .5112 .7091 .380200 .0000 .000930 .0005490 .000

24.0001 .0761 .0591 .5231 .490

1016992921614543.8333200010 .0254 .22915 .0374 .5522 .7551 .976202 .00022 .0001130 .0007140 .000

24.0001 .0591 .0741 .4351 .434

1016992921614543.8750210010 .1094 .17514 .3364 .5392 .6861 .833190 .00020 .0001050 .0006890 .000

24.0001 .0591 .0711 .4401 .438

1016992921614543.9167220010 .0884 .97314 .1174 .5272 .6901 .700194 .00021 .0001160 .0007270 .000

24.0001 .0521 .0581 .3091 .274

1016992921614543.9583230010 .1985 .02513 .0284 .5432 .6871 .580174 .0000 .0001140 .0007050 .000

22.0001 .0721 .0841 .3181 .311

Texas LoanSTAR Program

Texas Engineering Experiment Station
Energy Systems Laboratory

Texas A\&M University 
Table 10.8: Example Input Data File for COLROW3D.

\begin{tabular}{|c|}
\hline An Example of An Input Data File \\
\\
4138.0000928 .74 \\
4138.0417915 .18 \\
4138.0833903 .13 \\
4138.1250876 .25 \\
4138.1667864 .20 \\
4138.2083857 .17 \\
4138.2500861 .44 \\
4138.2917883 .79 \\
4138.3333982 .74 \\
4138.37501094 .50 \\
4138.41671178 .63 \\
4138.45831215 .80 \\
4138.50001218 .32 \\
4138.54171196 .97 \\
\hline
\end{tabular}


Table 10.9: Example Output Data File for COLROW3D.

\begin{tabular}{|c|}
\hline Method "0" \\
\hline $\begin{array}{c}3660123420212223 \\
1929915903876864 \ldots 980982984957 \\
2910883869855840 \ldots 969974988968\end{array}$ \\
\hline $366918887863850837 \ldots 877889895892$ \\
\hline Method "1" \\
\hline $\begin{array}{c}12001234 \ldots 20212223 \\
359831828822816809 \ldots 839853850851 \\
360839822813811809 \ldots 835846853844\end{array}$ \\
\hline $\begin{array}{c}366877873864874879 \ldots 874889877883 \\
1875851811807807 \ldots 859863867864 \\
2351839831827818 \ldots 821832839841 \\
3841831827825825 \ldots 857866855852\end{array}$ \\
\hline $120894883881878872 \ldots 926921922920$ \\
\hline
\end{tabular}


Table 10.10: An Example.LOG File for COLROW3D.

\begin{tabular}{c} 
Sample.LOG file. \\
.LOG of COLROW3D run Fri Aug 16 01:59:30 1991 \\
Raw data file : njb0691.DAT \\
COLROW3D matrix file : NJB0691.3D \\
.LOG file : NJB0691..LOG \\
Method used : 1 \\
First record read at 01:59:31 Begin Date : 4138.0000 \\
The following records were skipped \\
Record Decimal Date kWh/h data Incorrect Value \\
\hline 94138.3335 99982.7422 kWh \\
494139.9165 987.5110 date \\
\hline Statistics : \\
\hline Last record read at 01:59:55 End Date : 4198.9585 \\
Total number of records read: \\
Total number of records processed: \\
Total number of records skipped: \\
Total number of bad Decimal Dates: 1 \\
Total number of bad data values: \\
Time values within a day are NOT checked for \\
chrono.LOGical order. \\
*** Error report completed. $* * *$
\end{tabular}


Table 10.11: Decimal Date Reference Table for COLROW3D. The following is a table of decimal dates for January 1 for the years from 1980 through 2009.

\begin{tabular}{|c|c|}
\hline & Year Dec.Date \# Days \\
\hline January 1 & 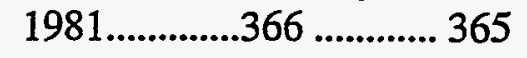 \\
\hline January 1 & $1982 \ldots \ldots . . . . . .731$........... 365 \\
\hline January 1 & 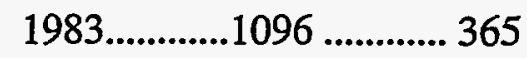 \\
\hline January 1 & 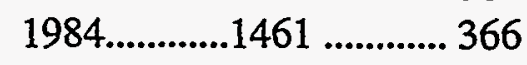 \\
\hline January 1 & 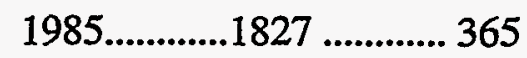 \\
\hline January 1 & 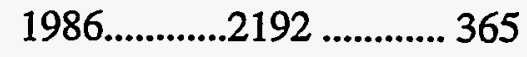 \\
\hline January 1 & 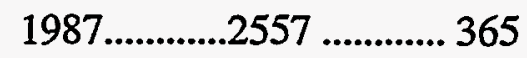 \\
\hline January 1 & 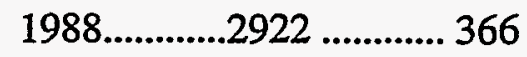 \\
\hline January 1 & 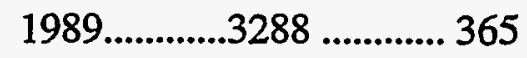 \\
\hline January 1 & $1990 \ldots \ldots . . . . . .3653 \ldots \ldots . . . \ldots . . . . .365$ \\
\hline January 1 & $1991 \ldots . . . \ldots . . . .4018 \ldots . . . . . . . . .365$ \\
\hline January 1 & $1992 \ldots \ldots . . . . . .4383 \ldots . . . . \ldots . . . .366$ \\
\hline January 1 & 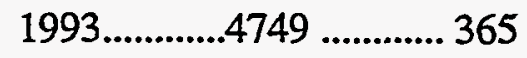 \\
\hline January 1 & $1994 \ldots . . . \ldots \ldots . . .5114 \ldots . . . . . . . . . .365$ \\
\hline January 1 & 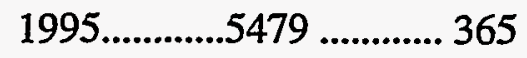 \\
\hline January 1 & 1996.............5844 ............ 366 \\
\hline January 1 & 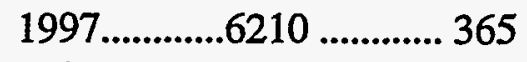 \\
\hline January 1 & 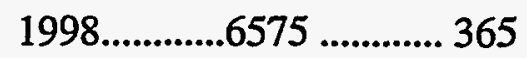 \\
\hline January 1 & 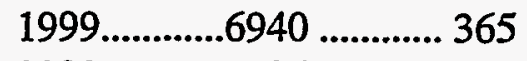 \\
\hline January 1 & 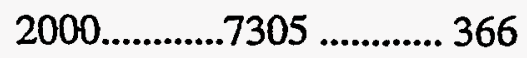 \\
\hline January 1 & $2001 \ldots \ldots . . . . . . .7671 \ldots . . . . . . . .365$ \\
\hline January 1 & $2002 \ldots \ldots . . . . . . .8036 \ldots . . . . . . . .365$ \\
\hline January 1 & $2003 \ldots . . . . . . . .8401 \ldots . . . . . . . . .365$ \\
\hline January 1 & 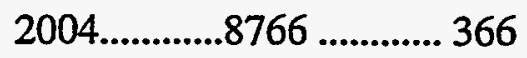 \\
\hline January 1 & $2005 \ldots \ldots . . . . . . . . . . . . . .36132$ \\
\hline January 1 & 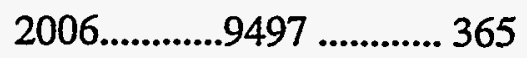 \\
\hline January 1 & $2007 \ldots \ldots . . . . . .9862 \ldots \ldots . . . . . . . .365$ \\
\hline January 1 & $2008 \ldots \ldots . . . . .10227 \ldots \ldots \ldots . . . . . .366$ \\
\hline January 1 & 2009..........10593............365 \\
\hline
\end{tabular}


Table 10.12: Intex Solutions 3DGRAPH Plotting Instructions for 3D Surface Plot SAMPLEM1.3DP.

TYPE SURFACE HIDDEN

$\mathrm{XB1..Y1}$

Y A2..A127

A B2..Y127

OPTIONS TITLE FIRST "EXAMPLE PLOT FOR COLROW3D" SECOND "INPUT=SAMPLE.DAT, OPTION=1"

$X$ AXIS "HOUR OF DAY"

Y AXIS "DAY OF YEAR"

Z AXIS "ELECTRICITY USE (KWH/H)"

OPTIONS SCALE Z-SCALE AUTOMATIC

X-SKIP 2

Y-SKIP 15

OPTIONS B\&W

DISPLAY ROTATION 270

VIEWPOINT MEDIUM

AXIS YES 
Figure 10.1: Flow Chart for R2A.BAT Plotting Procedure.

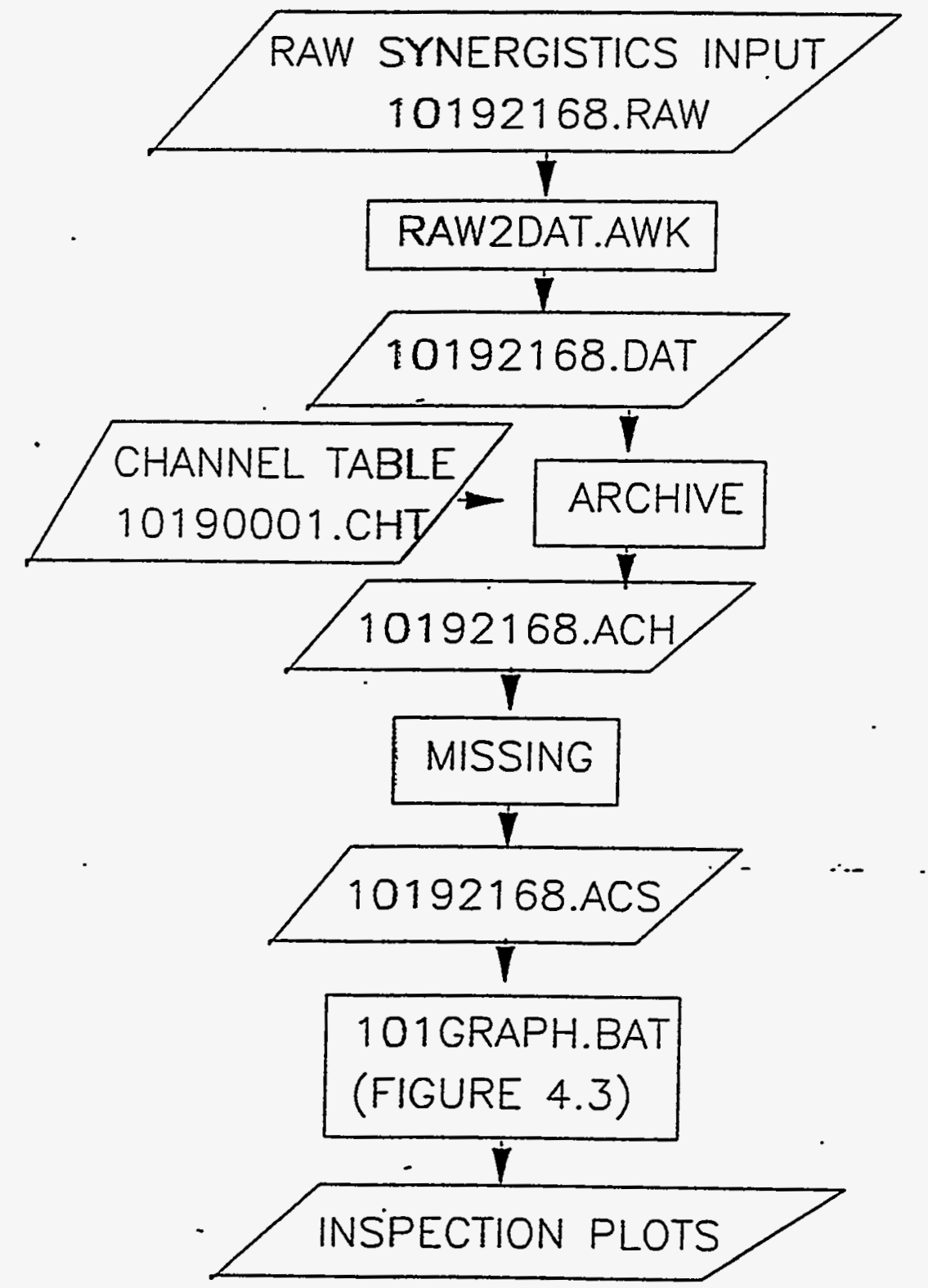


Figure 10.2: Example plot of the first 12 channels from Site 101.
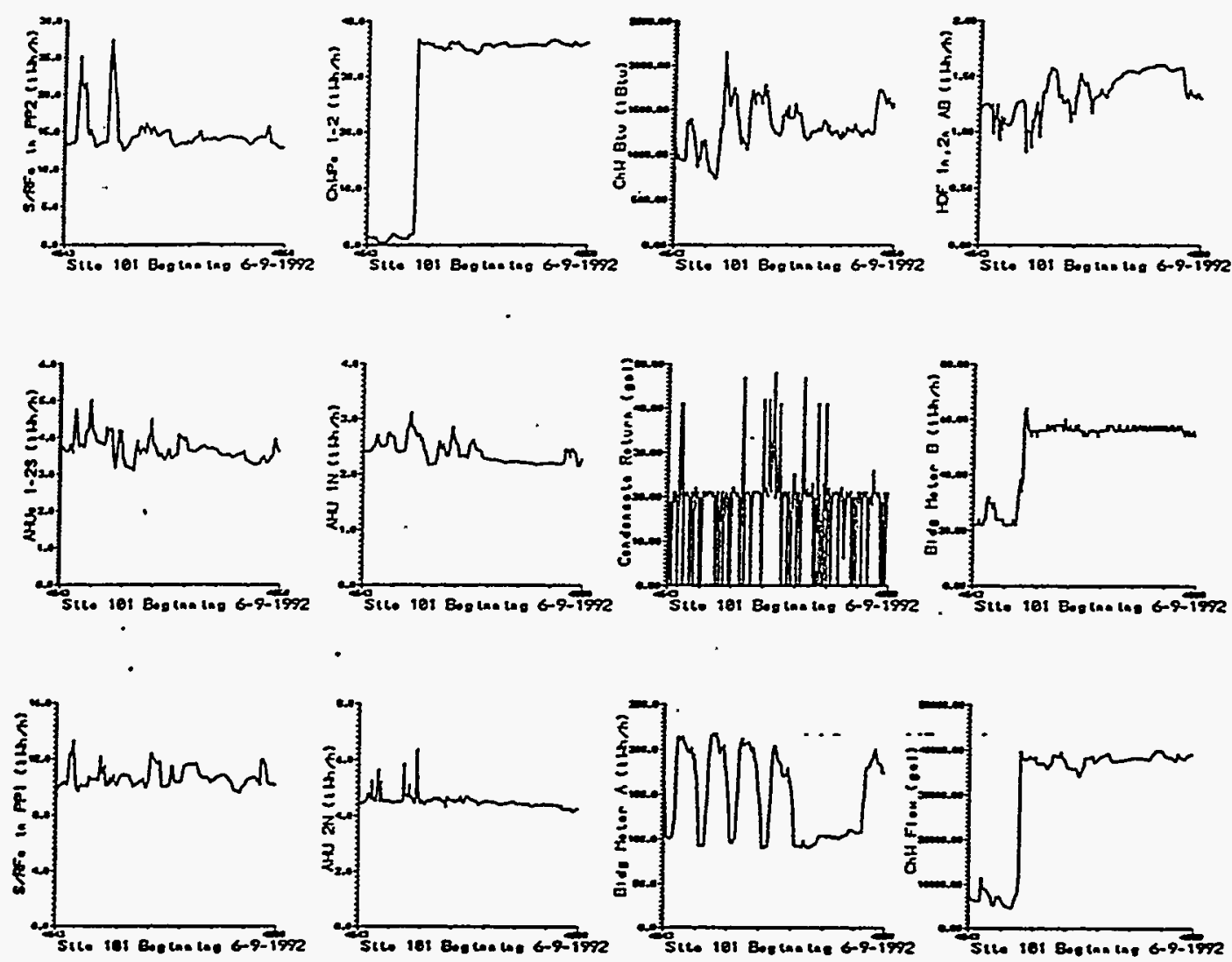
Figure 10.3: Example plot of the remaining channels from Site 101.
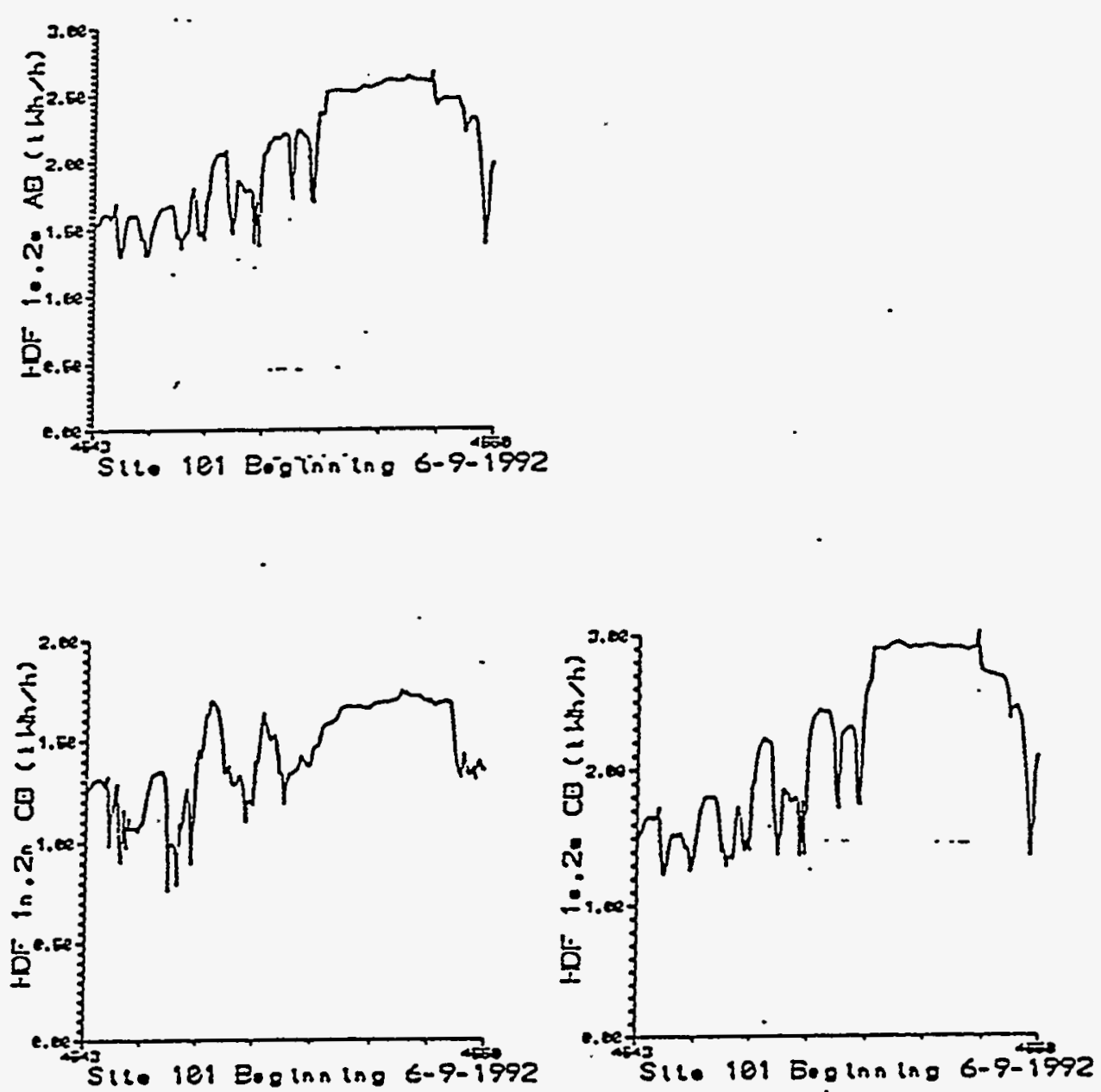
Figure 10.4: Flow Chart for the GRAPHER Program. This figure illustrates the basic command flow chart for the GRAPHER software

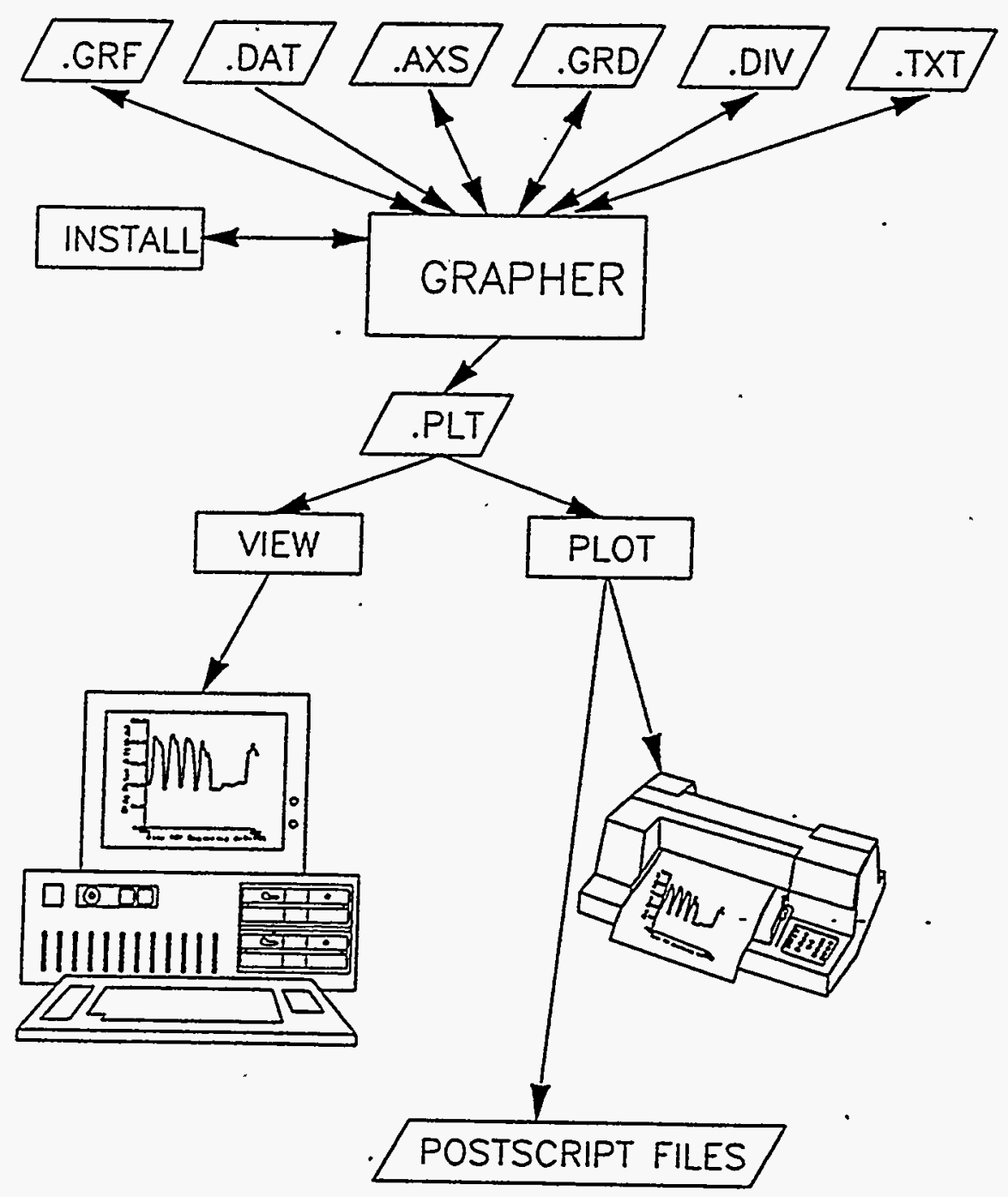


Figure 10.5: Graph created with T1017.GRF and T101.DAT Data File.

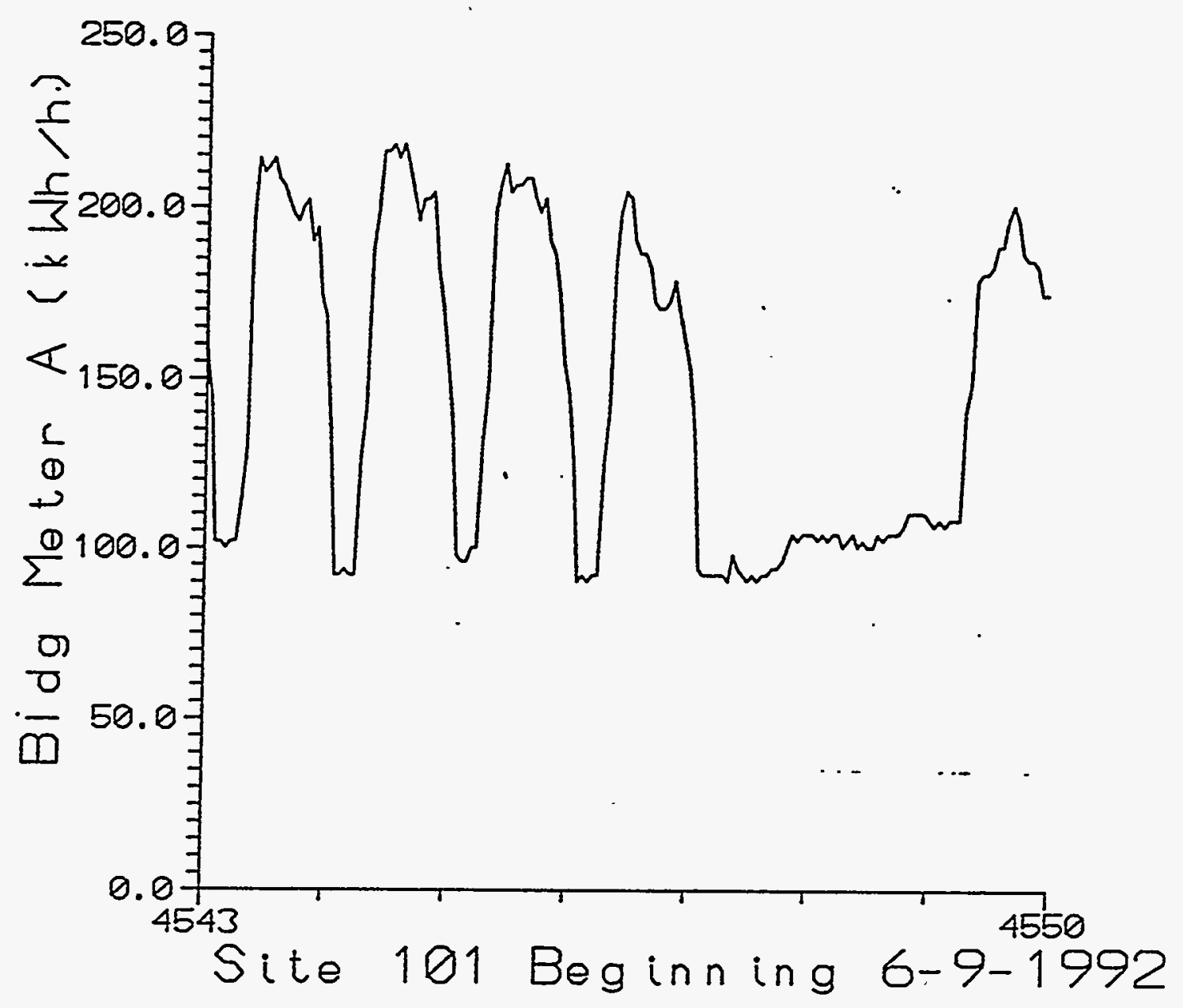


Figure 10.6: Flow chart for 101GRAPH.BAT.

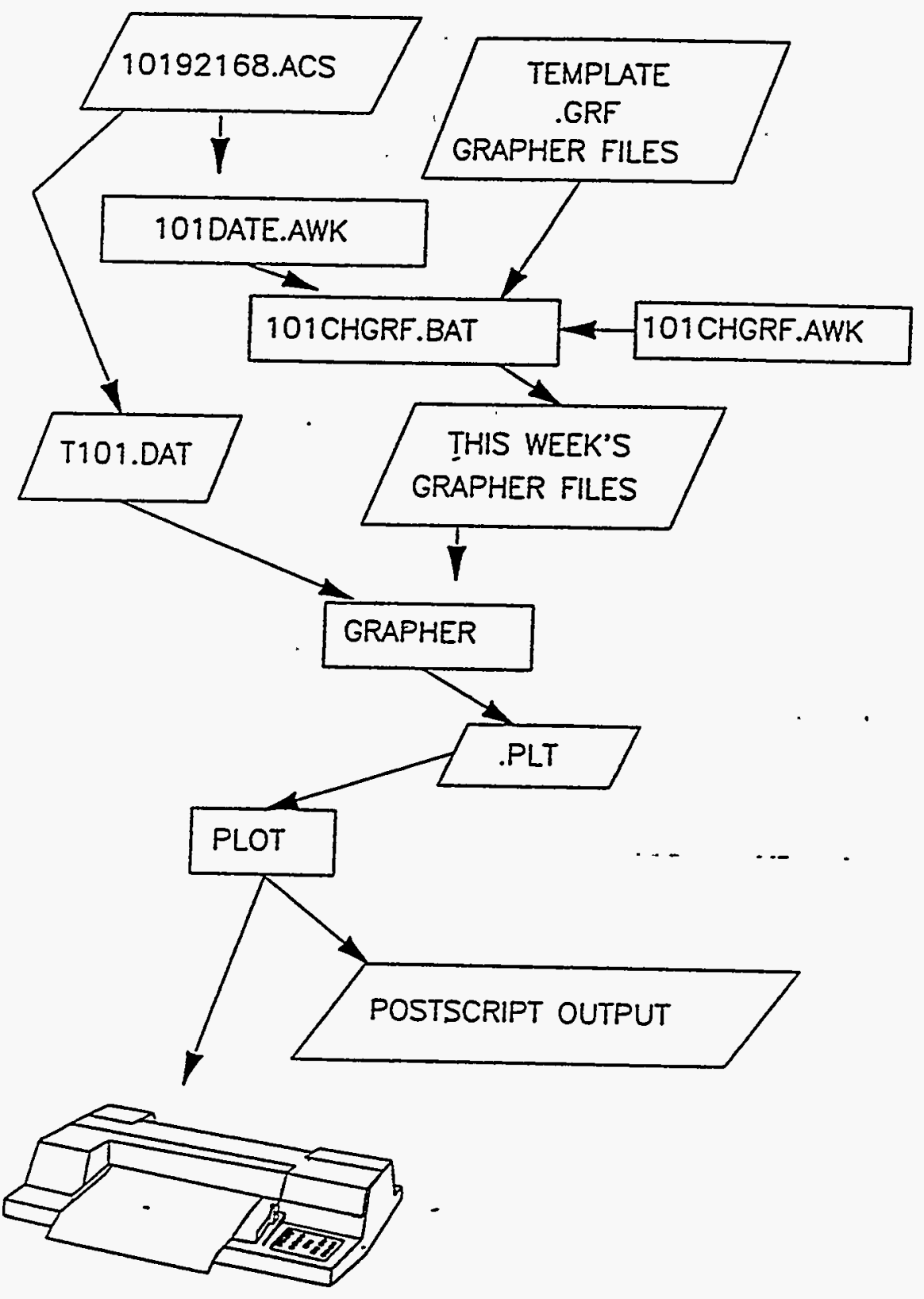


Figure 10.7: Example summary plot for Site 101.
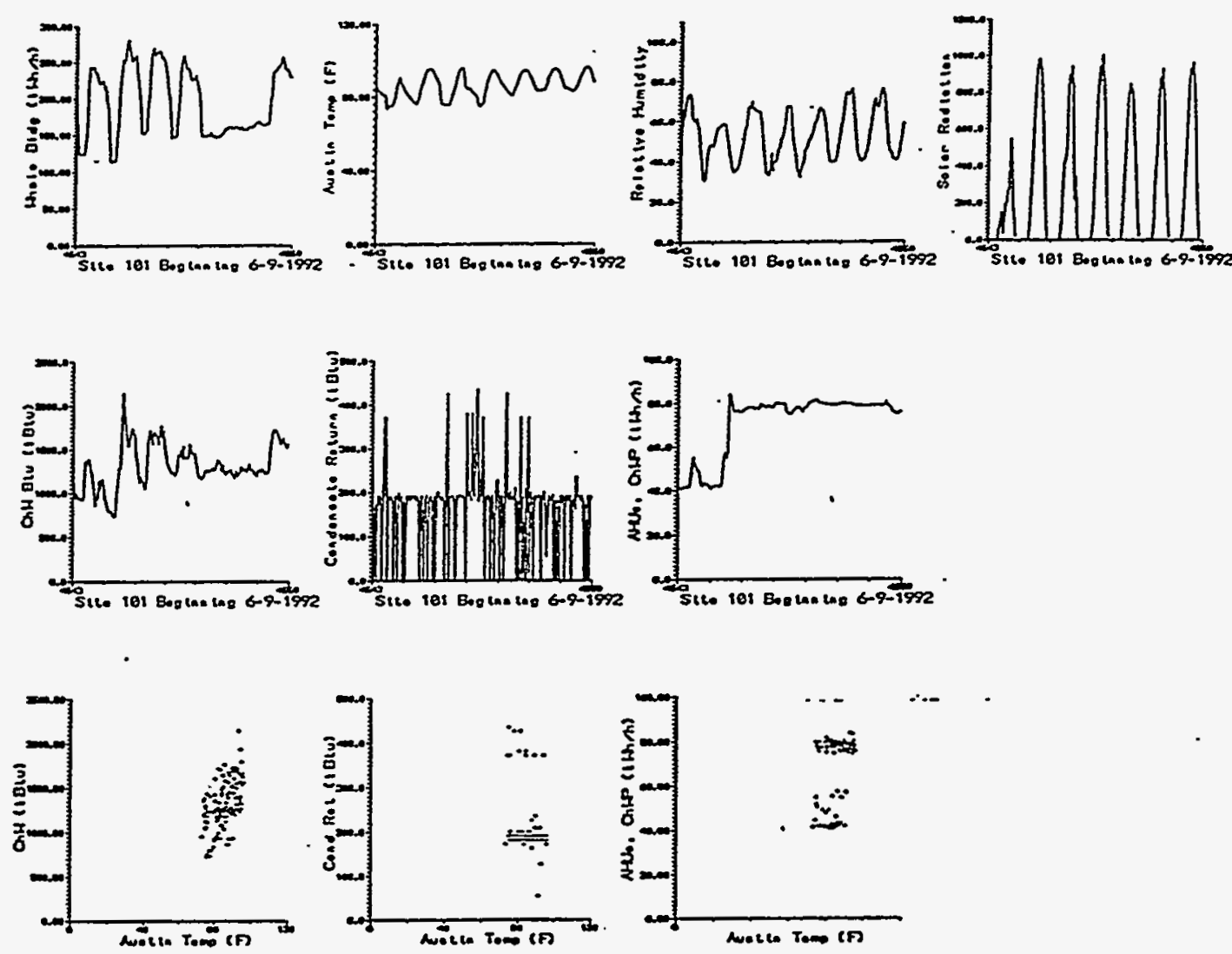
Figure 10.8: Flow chart for summary page UTSUMM.BAT.

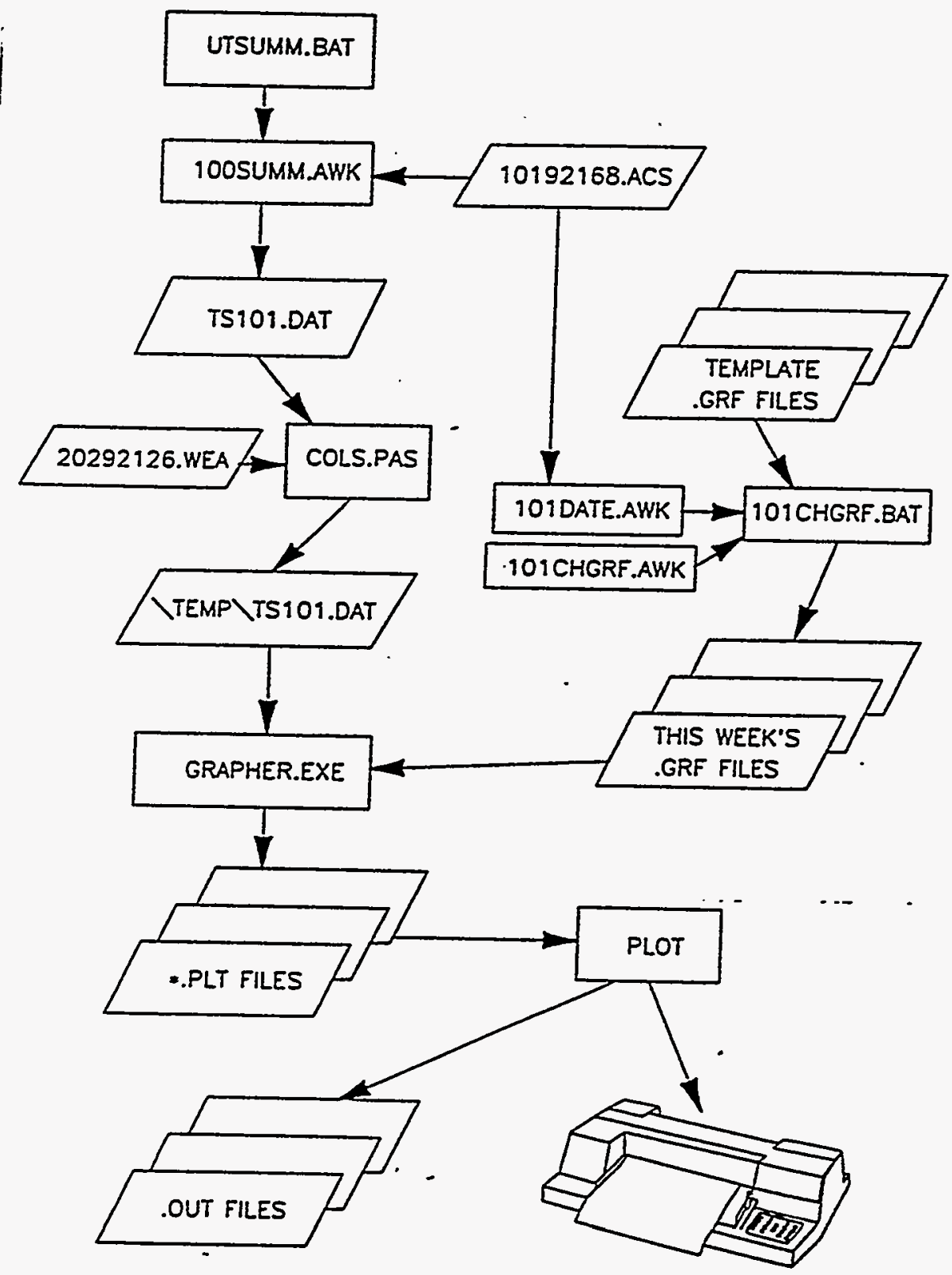


Figure 10.9: Basic flow chart for producing 3-D plots. This figure shows a basic flow chart for producing 3-D plots using several commercially available software packages and data processing routines from the LoanSTAR program.

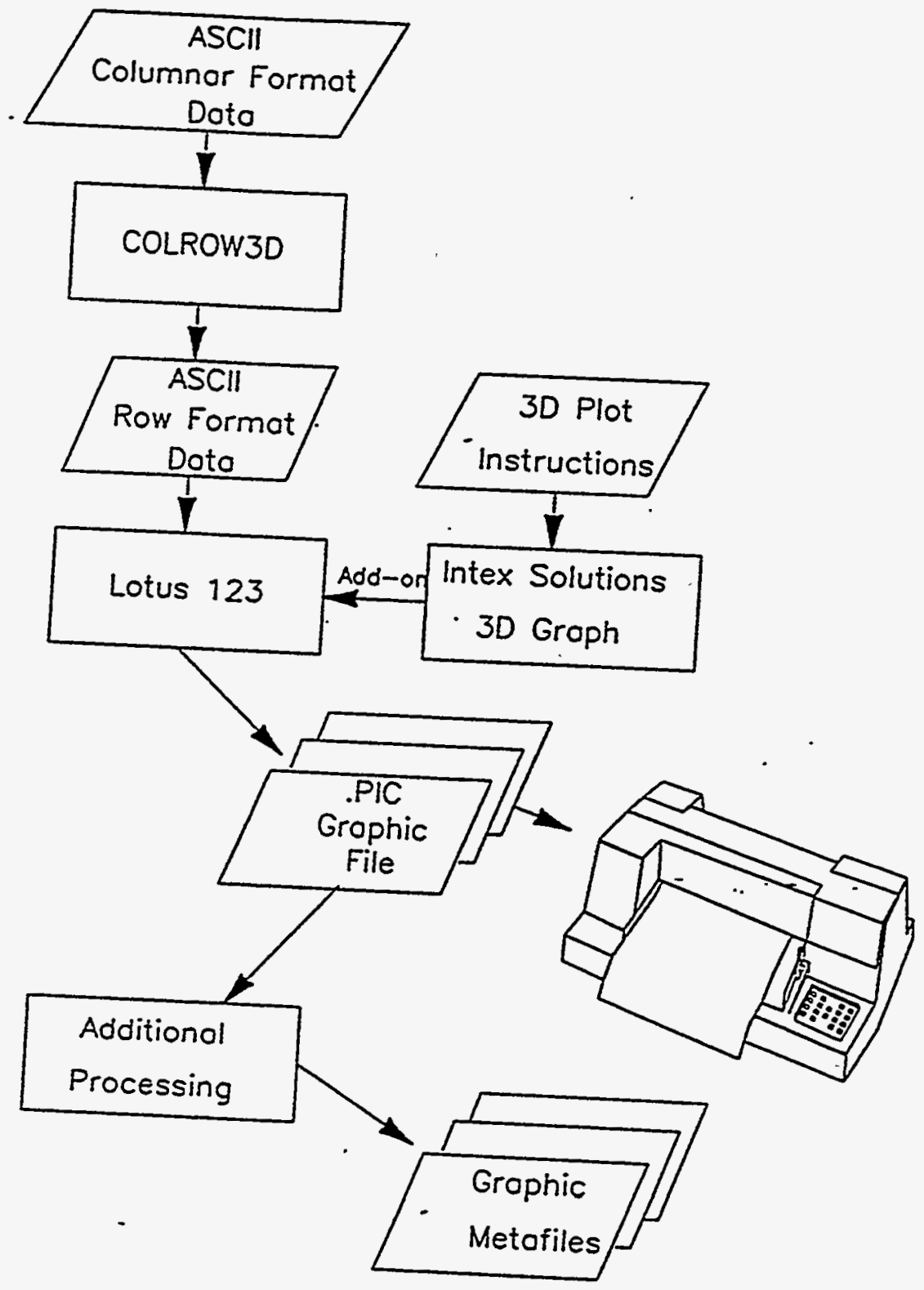


Figure 10.10: Example.PIC plots using the COLROW3D software packages.

\section{Example plot for COLROW3D}

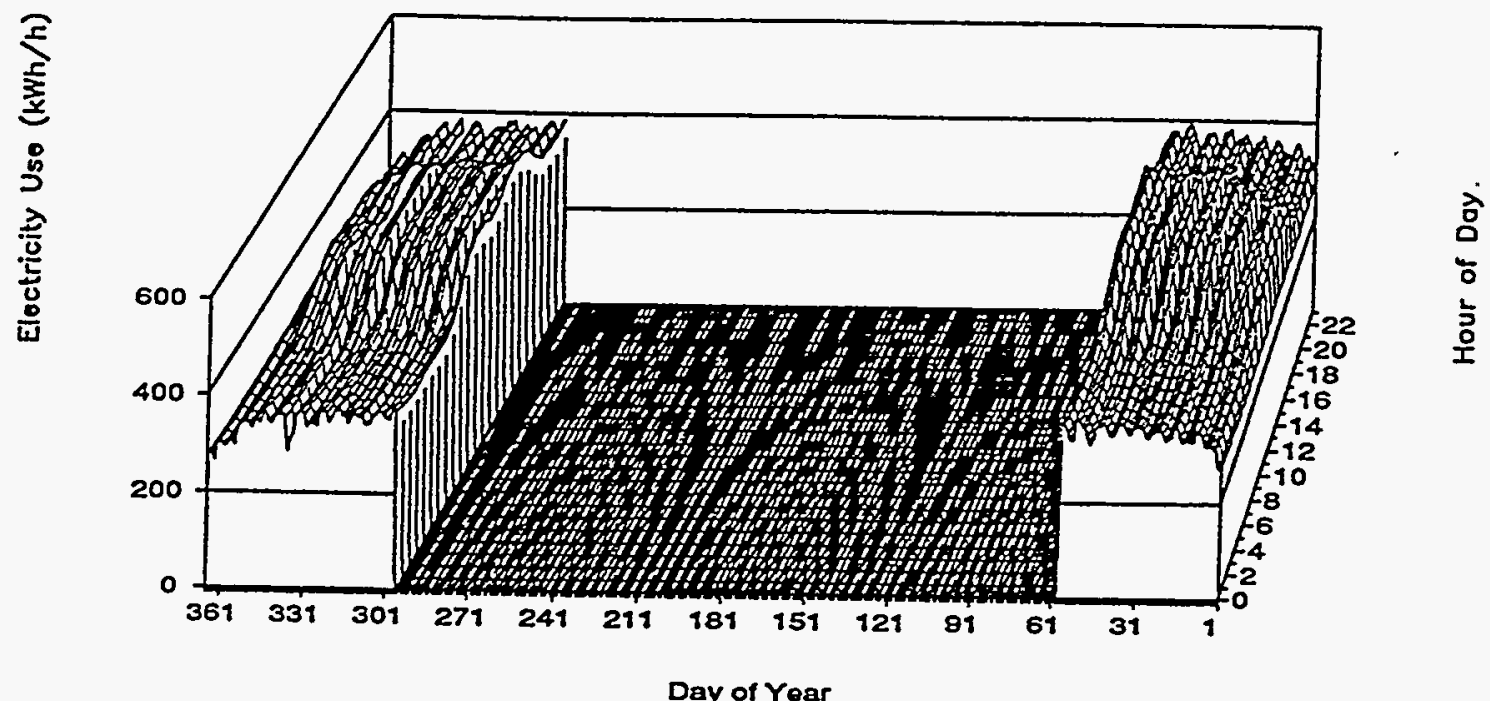

\section{Example plot for COLROW3D \\ input $=$ sample.dat, option $=1$}

.

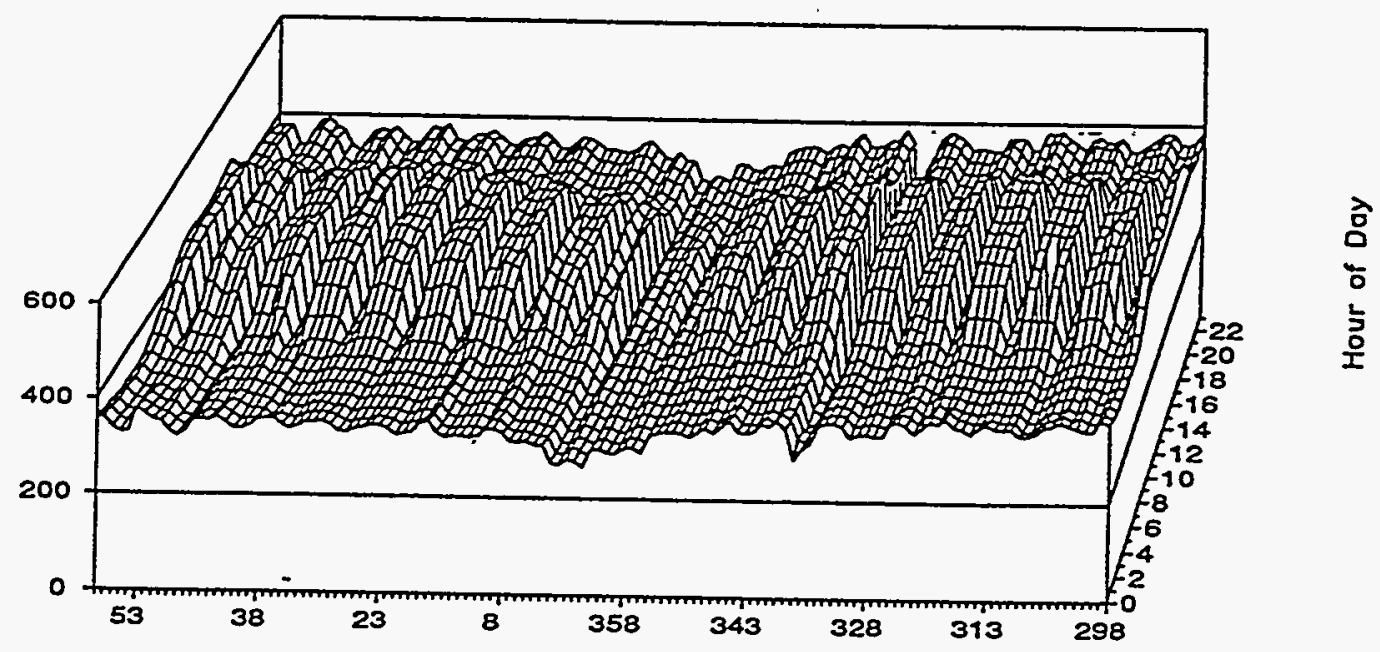

Day of Yoar 



\section{INTERNAL DISTRIBUTION}

$\begin{array}{llll}1 & \text { M. M. Abraham } & 15 & \text { R. L. Shelton } \\ 2 & \text { M. A. Brown } & 16 & \text { J. A. Shonder } \\ 3 & \text { J. E. Christian } & 17 & \text { J. N. Stone } \\ 4 & \text { G. E. Courville } & 18 & \text { M. P. Ternes } \\ 5 & \text { A. O. Desjarlais } & 19 & \text { J. J. Tomlinson } \\ 6 & \text { M. B. Gettings } & 20 & \text { R. L. Wendt } \\ 7 & \text { S. G. Hildebrand } & 21-70 & \text { Energy Conservation Dist., } \\ 8 & \text { P. J. Hughes } & & \text { Building 3147, MS-6070 } \\ 9 & \text { W. P. Levins } & 71-72 & \text { Central Research Library } \\ 10 & \text { J. M. MacDonald } & 73 & \text { Document Reference Section } \\ 11 & \text { H. A. McLain } & 74 & \text { Laboratory Records-RC } \\ 12 & \text { A. C. Schaffhauser } & 75 & \text { Laboratory Records } \\ 13 & \text { T. R. Sharp } & 76 & \text { ORNL Patent Office } \\ 14 & \text { R. B. Shelton } & & \end{array}$

\section{EXTERNAL DISTRIBUTION}

Association of ES Professionals, 7040 W. Palmetto Park Rd., ste. \#2315, Boca Raton, FL 33433

Barry Abramson, Servidyne Systems, Inc., P.O. Box 93846, Atlanta, GA 30377

Antonio Actis, Consiglio Nazionale delle Ricerche, Instituto di Metrologia "G. Colonnetti", Strada delle Cacce, 73-10135 Torino, Italy

John D. Acherman--Specialist, Corporate Planning Department, Wisconsin Electric Power Company, 231 W. Michigan, P.O. Box 2046, Milwaukee, WI 53201

Marlin S. Addison, Senior Energy Specialist, Energy Simulation Specialists, Inc., 64 E. Broadway Road, Ste 230, Tempe, AZ 85282

Dr. Bernard Aebischer, Dip. Phys. ETH, ETH Zentrum, ETL G 24, Physikstrasse 3, CH_8092 Zurich, Switzerland

James Afarin, NASA Lewis Research Center, 21000 Brookpark Rd, Cleveland, OH 44135-3127

Alan C. Ahrens-Supervisor, Load Management, Houston Lighting \& Power, P.O. Box 1700, Houston, TX 77251

Maurice Aizlewood, Lighting and Applied Vision, Environmental Systems Division, Building Research Establishment, Garston, Watford, WD2 7JR, United Kingdom

Hashem Akbari, Ph. D., Lawrence Berkeley Laboratory, Bldg. 90, Rm 4000, University of California, Berkeley, CA 94720

James Akridge, College of Architecture, Georgia Institute of Technology, Atlanta, GA 30332

Mike Albanes, 8000 Spandera Cove, Austin, TX 78759

Mr. Taghi Alereza, ADM \& Associates, 3299 Ramos Cir.; Sacramento, CA 95827

Henry Amistadi, Scinetific Computing, RR2 Box 2191C, Brunswick, ME 04011

Dr. Ren Anderson, Staff Engineer-Building Research Branch, Solar Heat Research Division, NREL, 1617 Cole Blvd., Golden, CO 80401

Peter R. Armstrong, Energy Sci Dept, MSIN K5-20, Battelle PNL, Battelle Boulevard, PO Box 999, Richland, WA 99352-0999

Jose Miguel Aroztegui, Arquitecto, Profesor de Acond. Natural, Jefe de Seccion del SCAA, Universidad de la Republica Oriental del Uruguay, BV. Artigas 1031, C.P. 11200

Jay D. Atkins, Manager, Energy Management and Operations, Physical Plant Dept.-517, The University of Texas: MD Anderson Cancer Center, 1515 Holcombe Blvd., Houston, TX 77030

B. Michal Aucoin, D. Engr., P.E., Lecturer, Dept. of Electrical Engineering, Texas A\&M University, College Station, TX 77843-3128

H.R. (Bob) Bach, P. Eng., Senior Consultant, Engineering Interface Limited, 2 Sheppard Ave. E., Ste. 200, Toronto, Ontario M2N 5Y7, Canada 
Leonard R. Bachman, AIA, President, Building Climate Interface, Inc., 945 Rutland, Houston, TX 77008 Mark Bailey, Office of Building Technologies, U. S. Department of Energy, EE-421, FORS, 1000 Independence Ave., SW, Washington, DC 20585-0121

Asst. Prof. Ciprian Bacotiu, M.Sc. (Eng.), Univeritatea Technica din Cluj-Napoca, Str. C Dalcoviciu 15, 3400 Cluj-Napoca, Romania

Gheorghe Badea, dipl. eng. dr., Chairman of the Board, IntelEnerg, 54 Siretului St., Alba Iulia 2500, Alba, Romania

Patrick J. Bailey, RLW Analytics, Inc., 17389 Gehricke Road, Sonoma, CA 95476

Michael Baker, Principal, SBW Consulting, Inc., 2820 Northup Way, ste. 230, Bellevue, WA 98004

Erv Bales, Ph.D., Research Professor, Architecture and Mechanical Engineering, New Jersey Institute of Technology, University Heights, Newark, NJ 07101-1982

Joel A. Banks, Center for Energy Studies, The University of Texas at Austin, Balcones Research Center, 10100 Burnet Road, Austin, TX 78758

Sherif A. Barakat, Ph.D., Head, Building Performance Laboratory, National Research Council, Ottawa, Canada K1A OR6

Charles E. Baus, Energy Policy Directorate, Office of the Deputy Assistant Secretary of Defense, Dept of Defense, Pentagon, Room 1D760, Washington, DC 20301-8000

Dave Baylon, Ecotope Inc., 2812 E. Madison, Seattle, WA 98112

Rodney Beasley, Marketing Consultant, Technical Services, Houston Lighing \& Power Company, P.O. Box 1700 , Houston, TX 77251

William A. Beckman, Ouweneel-Bascom Professor, Mechanical Engineering, University of Wisconsin at Madison, 1303 Engineering Research, 1500 Johnson Dr., Madison, WI 53706

Adrian Bejan, J.A. Jones Professor of Mechanical Engineering, Duke Univeristy, Durham, NC 27706

Michael Bekker, Executive Assistant Manager, Asilomar Conference Center, Asilomar Blvd., P.O. Box 537, Pacific Grove, CA 93950

Ned (Chuck) W. Belt, P.E., C.E.M., President, Systems/Corp, Cherokee Place, Ste 306, 2200

Sutherland Avenue, Knoxville, TN 37919

Pierre A. Bernard, Cabinet Bernard, 13 rue Jean-Philippe Rameau, 94440 Santeny, France

Scott Bernstein, President, Center for Neighborhood Technology, 2125 West North Ave., Chicago, II 60647

David Birr, Syncronous Energy Solutions, Inc., 2017 Allen Drive, Geneva, II 60134

Al Black, McClure Engineering, 7616 Big Bend Blvd., St Louis, MO 63119

Steven L. Blanc, P.E., Research and Development, Pacific Gas \& Electric Company, 2303 Camino

Ramon, Suite 200, San Ramon, CA 94583

Dave Bohac, CEE, 540 First Avenue North Suite 400, Minneapolis, MN 55403-1609

Kirk Bond, U.S. Department of Energy, Kansas City Support Office, 911 Wanut St., 14th Floor, Kansas

City, Missouri 64106

Don Boysen, 201 E. 68th Terrace, Kansas City, MO 64113

Michael R. Brambley, Battelle PNL MSIN K5-12, P.O. Box 999, 2400 Stevens Dr., Richland, WA 99352

David J. Branson, P.E., Vice President, Compliance Services Group, Inc., 7619 University, Ste. 2A, Lubbock, TX 79423-2126

Larry Bravo, Citizens Conservation Services, 75 Broadway, San Francisco, CA 94111

Barry B. Bridges, P.E., Minnesota Building Research Center, Rm. 220, 1425 University Ave. S.E., Minneapolis, MN 55455

Robert S. Briggs, K5-19, Sr. Research Scientist, Energy Sciences Dept., Battelle PNL, Battelle

Boulevard, Richland, WA 99352

Marianne M. Brodatch, 11 Parkovaya 42-2, Apt 4, Moscow 105215, Russia

Thomas M. Brotherton, P.E., Assistant Director, State of Colorado, Office of Energy Conservation, 112 E. 14th Ave., Denver, CO 80203

Peter W. Brothers, Manager, Knowledge-Based Systems Research, Johnson Controls, Inc., P.O. Box 423, Milwaukee, WI 53201

Karl Brown, Lawerence Berkeley Lab, Building 90, Rm 3026, One Cyclotron Road, Berkeley, California 94720

John Browning, Marketing Supervisor, Gulf States Utilities Company, P.O. Box 158, Conroe, TX 77305 Cary Bullock, Kenetech Management Services, 15 New England Executive Park, Burlington, MA 01803 Jay Burch, National Renewable Energy Lab, Joyce Street Facility, 1617 Cole Blvd., Bldg. 27, Golden, CO 80401

Jeff Burch, Measurement Systems Dept., Hewlett-Packard Laboratories, 3500 Deer Creek Road, M/S

26U, Palo Alto, CA 94304-1392 
134 Scott A. Campbell, P.E., P.O. Box 655303, MS 8319, Dallas, TX 75265

135 James A. Carison, P.E., Leo A. Daly \& Co., 8600 Indian Hills Drive, Omaha, NB 68114

136 Anders Carlsson, Assistant to the Counselor for Science Technology, Sveriges Tekniska Attacheer, Swedish Embassy, 600 New Hampshire Ave. N.W., Washington, DC 20037

137 Laurence A. Carmichael, Senior Project Manager, Controls Technology, EPRI, 34112 Hillview Ave., P.O. Box 10412, Palo Alto, CA 94303

138 James Cavallo, Argonne National Laboratory, Building 900, 9700 South Cass Avenue, Argonne, IL 60439

139 Center for Energy and Environmental Technologies, University of Ljubljana, Slovenia, Faculty of Mechanical Engineering, Askerceva 6, Ljubljana 61000, Slovenia

140 Gary Chadwick, Recreation Department, University of Colorado at Boulder, Campus Box 355, Boulder, CO 80309-0355

141 Alan Chalifoux, USA CERL, P.O. Box 9005, Champaign, II 61826

142 Matt Chwalowski, Edison Electric Institute, 701 Pennsylvania Ave NW, Washington, DC 20004-2608

143 Jim Chace, Director, Pacific Energy Center, 851 Howard Street, San Francisco, CA 94103

144 Robert E. Chase, Army Research Laboratory, Arsenal St Amskl Op in RT, Watertown, MA $02172-0001$

145 Andrew Chiang, Software Programer/Sales, Supersymmetry, Block 73 Ayer Rajah Crescent \# 07-06/09, Singapore 0513

146 Mario Chiarelli, P. Eng., Manager, Energy Monitoring \& Analysis, Tescor Energy Services Inc., 2 Sheppard Ave. E, ste. 200, North York, Ontario M2N 5 Y7

147 Ishtiaq A. Chisti, Southern California Edison, 2244 Walnut Grove Ave., Room 460, Rosemead, CA 91770-3714

148 Charles N. Claar, P.E., Director of Research, International Facility Management Association, 1 E. Greenway Plaza, Ste. 1100, Houston, TX 77046-0194 Johan Claesson, Dr. Sc., University of Lund, Dept. of Building Physics, Box 118, S-221 00, Lund, Sweden

150 Dr David Claridge, Mechanical Engineering, Texas A\&M University, College Station TX 77843-3123

151 Prof. Joe Clarke, Energy Systems Research Unit, James Weir Building, University or Strathclyde, Glasgow 911XJ Scotland

152 Sherry A. Coker, Electrical Engineer, Bosek, Gibson \& Associates, Inc., 508 W. Fletcher Ave., Ste. 102, Tampa, FL 33612 John Brady Coleman Jr., Entex, 1600 Smith St., Houston, TX $77002-7315$

David R. Conover, 11100 Streamview Ct., Great Falls, VA 22066-3319

Howard Coogler, State Energy Office, 1201 Main St., Ste 820, Columbia, SC 29201

Patrick G. Coon, CEM, Manager, Commercial/Industrial Marketing Ser., West Texas Utilities Company, P.O. Box 841, Abilene, TX 79604

157 Kevin P. Cooney, Manager-Resource Use, RCG/Hagler Bailly, Inc., P.O. Drawer O, Boulder, CO 80306-1906 Richard H. Counihan, U.S. House of Representatives, Room H2-331, 2nd and D Streets, S.W., Washington, DC 20515

160 John Cowan, Cowan Quality Buildings, 74 Willowbank Blvd., Toronto, Ontario, Canada M5N 1 G6

161 Jim Cox, ASHRAE Government Affairs, 1825 K Street, N.W. \#215, Washington, DC 20006

166 Paul R. Cunningham, P.E., President, 100 Brookside Office Park, 1161 Corporate Dr. West, Arlington, TX 76006

167 Keith Curtis, Emory University, 638 Asbury Circle, Atlanta, GA 30322

168 Iolanda Daduianu-Vasilescu, Sr. Scientific Researcher, Institute of World Economy, Romanian Academy, B-dui Republicii 12, Sector 3, Bucuresti, Romania, CP 70384 CP 1158 
178-182 Rick Diamond

\section{CA 94720} OR 97701 20585-0121 3PJ, England 94720 32920 94105 2021 20036 77843-3137

Christopher L. Dent, P.E., Principal, 64 N.W. Franklin Ave., Pacific Science \& Technology Co., Bend,

Joseph J. Deringer, AIA, The Deringer Group, 1349 Addison Street, Berkeley, CA 94702

Keith A. Derrington, Systems Corp., 2200 Sutherland Ave., Suite 306, Knoxville, TN 37919

K. Dean DeVine, FEMP $\quad$ EE, Department of Energy, 1000 Independence Ave., Washington, DC

Arthur L. Dexter, Department of Engineering Science, University of Oxford, Parks Road, Oxford OX1

Ralph A. Dickinson, Consultant Tecnhical Services, Electric Mrkting, Northern States Power Company, 414 Nicollet Mall, (RS-5), Minneapolis, MN 55401

Judith Dimitriu, P.Eng., Director, School of Mechanical Engineering, Ryerson Polytechnic University, 350 Victoria St, Toronto, Ontario M5B 2K3, Canada

T. E. Drabek, Professor, Department of Sociology, University of Denver, Denver, Colorado 80208-0209 Joseph A. Driscoll III, Envirocon Assocs., 16937 York Rd., Monkton, MD 21111-1023

Joseph H. Eto, Bldg 90-4000, Lawrence Berkeley Laboratory, University of California, Berkeley, CA

Philip Fairey, State of Florida, Florida Solar Energy Center, 300 State Road 401, Cape Canaveral, FL

Charles H. Fafard, Resource Management Associates, 5837 Woods Edge Rd., Madison, WI 53711-5135

Heinrich C. Feistner, Sr. Energy Consultant, Energy Efficiency Office, Public Works and the

Environment, City Hall, 12th Floor, East Tower, Toronto, Ontario M5H 2N2, Canada

Edward D. Fitts, Avanti Technologies, 9200 Watson Rd., Ste G100, St. Louis, MO 63126-1528, (314) 842-8334 FAX (314) 842-7338

Joseph S. Fitzpatrick, President, EUA Cogenex Corporation, Boott Mills South, Lowell, MA 01852 Tom Fitzpatrick, Director, Office of Facility Planning, General Services Commission, P.O. Box 13047, Austin, TX 78711-3047

William S. Fleming, SAIC / Fleming , 6310 Fly Road, East Syracuse, NY 13057

Ellen M. Franconi, Building Energy Data Group, Mail stop: 90-4000, Lawrence Berkeley Laboratory, University of California, Berkeley, CA 94720

C.W. Frazell, P.E., Sr Engineer, Technical Services, TU Electric, Energy Plaza, 1601 Bryan St, ste. 22134, Dallas, TX 75201-3411

Donald J. Frey, P.E., Executive Vice President, Architecture Energy Corporation, 2540 Frontier Ave, Ste. 201, Boulder, CO 80301

Robert H. Fuller, Robert H. Fuller \& Associates, 2901 N. High Street, Columbus, Ohio 43202-1101 Peter Gadde, US General Services Administration, 525 Market Street - 30th Floor, San Francisco, CA

Michael W. Gallagher, Western Allied Corporation, 11230 Little Dipper St., Mira Loma, CA $91752-$

James Garrick, Principal, Garrick \& Associates, 6188 Willow Springs Drive, Morrison, CO 80465

Carol Gardner, P.E., Gardner Energy Management Services, 821 S. W. Green Ave., Portland, OR 97205

Donald Gatley, Gatley \& Associates, 489 Westover Drive, NW, Atlanta, GA 30305

Howard Geller, Executive Director, ACEEE, 1001 Connecticut Ave., NW Ste 801, Washington, DC

Ken Gillespie, Technical and Ecological Svcs, Pacific Gas and Electric Co, 3400 Crow Canyon Road, San Ramon, CA 94583

Richard Gillmann, Bonneville, P.O. Box 3621 RPEE, 905 NE 11th Ave., Portland, OR 97208

Dan J. Goldberger, ICLEI, City Hall, East Tower, 8th Floor, Toronto, Ontario M5H 2N2 , Canada

Raj Gopal, Neil Associates, 6267 W. Silver Brook Ln., Brown Deer, WI 53223

Frederick M.Gordon, Pacific Energy Associates, 333 N.E. 18th Avenue, Portland, OR 97212

Dr. Jeff Gordon, Applied Solar Calculations Unit, Institute for Desert Research, Sede Boker, Israel

Julius M. Gribou, AIA, Head, Department of Architecture, Texas A\&M University, College Station, TX

David T. Grimsrud, Director, Minnesota Building Research Center, Room 220, 1425 University Ave

S.E., Minneapolis, MN 55455

Waiter Grodzik, P.E., 2998 Foxcoft Drive, Tallahassee, FL 32308

David L. Grumman, Grumman/Butkus Associates, 500 Davis Street, Evanston, II 60201

Ron Gumina, Synergistic Control Systems, Inc., 2700 Lake Villa Dr, \#180, Metairie, LA 70002

Anne Gummerlock Lee, PG\&E, Mail Code T-16A, PO Box 770000, San Francisco, CA 94177 
217-300 Jeff Haberl, Department of Architecture, Texas A\&M University, College Station TX 77843-3581

301 Jay Hall, ICI Inc., 409 12th Street SW, Ste. 700, Washington, DC 20024

302 Arthur D. Hallstrom, Manager Engineered Solutions, Air Handling Systems, The Trane Company, 1500 Mercer Road, Lexington, KY 40511

303 Jim Halpern, Measuring and Monitoring, 620 Shrewsbury Ave., Tinton Falls, NJ 07701

304 Jeffrey R. Harris, 732 Lawton St., McLean, VA 22101-1510

305 Mark Hegberg, Commonwealth Edison Co., 1919 Swift Drive, Oak Brook, IL 60521

306 Kristin E. Heinemeier, Lawerence Berkeley Lab, Building 90, Rm 4000, One Cyclotron Road, Berkeley, California 94720

307 Harold W. Heiss, Ohio Power, Columbus Southern Power, 215 N. Front Street, Columbus, Ohio 432152291

308 Tia Heneghan, Energy Manager, Texas Department of Criminal Justice, P.O. Box 99, Huntsville, TX 77342-0099

309 Magnus Herrlin, Bell Comunications, Research, Rm 3x-291, 331 Newman Springs Rd., Red Bank, NJ 07701

310 Martha J. Hewett, CEE, 540 First Avenue North Suite 400, Minneapolis, MN 55403-1609

311 Peter R. Hill Bsc, ACGI, Ceng, MICE, Project Officer, Energy Management Section, Buildings Energy Efficiency Group, BREOSU, Garston, Watford, WD2 7JR, United Kingdom

312 Adam W. Hinge, P.E., Energy Utilization Manager, Niagara Mohawk Power Corp., 1125 Broadway, Albany, NY 12201

313 James J. Hirsch, Building Performance Simulation, Research and Consulting, 2138 Morongo Drive, Camarillo, CA 93010

314 Douglas C. Hittle, Ph.D., Director, Solar Energy Applications Laboratory, Colorado State University, Ft. Collins, CO 80523

315 Rusty T. Hodapp, P.E., Assistant Director, Dallas/Ft. Worth International Airport, P.O. Draw DFW, Dallas/Ft. Worth Airport, TX 75261

316 Michael J. Holtz, A.I.A., President, Architecture Energy Corporation, 2540 Frontier Ave, Ste. 201, Boulder, CO 80301

317 Patricia J. House, Energy Specialist, O'Connell Robertson and Associates, 801 Barton Springs Rd., Ste. 900, Austin, TX 78704

318 Bion D. Howard, 14513 Jent Dr., Upper Mariboro, MD 20772-7772

319 Yu Joe Huang, Lawerence Berkeley Lab, University of California, Mail Stop: 90-4000, One Cyclotron Road, Berkeley, California 94720

320 Bruce D. Hunn, Ph.D., Head, Conservation and Solar Energy Program, Center for Energy Studies, The University of Texas at Austin, Balcones Research Center, 10100 Bumet Road, Austin, TX 78758 Dr. Rudolf Husar, Center for Air Polution Impact and Trend Analysis, Mechanical Engineering, Washington University, 1 Brookings Dr., St. Louis, MO 63130 Mark Hydeman, P.E., HVAC Programs Coordinator, Consultants to PG\&E Energy Center, Pacific Gas and Electric Company, 851 Howard Street, San Francisco, CA 94103 Gheorge Indre, Senior Engineer, Romanian Electricity Authority, Bd. Magheru 33, 70164-Bucharest, Romania Dan Inthout, Titus, 990 Security Row, Richardson, Texas 75081

Donald G. Iselin, Rear Admiral, CEC, ESN (Ret.), Engineering and Management Consultant, 2695 Sycamore Canyon Rd., Santa Barbara, CA 93108 Frank Jablonski, Attorney at Law, 7 North Pickney St., Madison, WI 53703

Steve Jaeger, P.E., Assistant Director, Research, Alternative Fuels Research and , Education Division, Railroad Commission of Texas, P.O. Box 12967, Austin, Texas 787Martin L. Jensen, Civilingenir, DEFU-energiteknologi, Postboks 259, 2800 Lyngby, Denmark R.E. (Bob) Jensen, Retired Consulting Engineer, 435 Carol Canyon Dr., Sedona, AZ 86336 Yi Jiang, Dr. Eng., Professor, Dept. of Thermal Energy, Head of HVAC Division, Tsinghua University, Beijing 100084, P.R. China Bruce Jones, Project Engineer, Portland Energy Conservation Inc., 921 SW Washington, Ste. 840, Portland, OR 97205 Prof. Jerold Jones, Dept. of Mech. Engr., ETL5160, University of Texas at Austin, Austin, TX 78712 Robert Jones, Nordyne Inc., 10820 Sunset Office Dr., St Louis, MO 63127 Register, 1 Centre Street, Room 2403, New York, NY 10007 
Prasanna V. Kadaba, Georgia Institute of Technology, School of Mechanical Engineering, Atlanta, GA 30332-0405

Piotr Kaleta, Ph.D., Assistant Professor, Polish Academy of Sciences, Institute of Environmental Engineering, Ambient Air Quality Dept., U1. Sklodowskiewj-Curie 34, 41-819 Zabrze, Poland Brian K. Kammers, P.E., Energy Engineered, Marketing Manager, Automation technologies, MagneTek, 16555 West Ryerson Road, New Berlin, WI 53151 Ronald Kammerud, Ph.D., Paradigm Consulting, 4032 Waterhouse Rd., Oakland, California 94602 Srinivas Katipamula, P.E., Ph.D., Energy Sciences Dept, MSIN: K5-08, Battelle PNL, Richland, WA 99353 John T. Katrakis, P.E., Center for Neighborhood Technology, 2125 W. North Ave., Chicago, IL 60647 Washington, DC 20585

Minoru Kawashima, Sr. Research Engineer, Institute of Technology, Shimizu Corporation, 4-17, Etchujima 3-chrome, Koto-ku, Tokyo 135, Japan

346 Henry Kelly, Office of Science \& Technology Policy, White House, OEOB Room 423, 1600 Pennsylvania Avenue, Washington, D.C. 20500

347 Robert A. Kennedy, P.E., C.E.M., Account Manager, NATKIN Energy Management, 2775 S. Vallejo St., P.O. Box 1598, Englewood, CO 80150

348 Rob Kerr, ICLEI, City Hall, East Tower, 8th Floor, Toronto, Ontario MSH 2N2, Canada Helen Kessler, Sieben Energy Associates, 2154 North Halsted, Chicago, II 60614 Ken-Ichi Kimura, Professor, Dept. of Architecture, Waseda University, Okubo-3, Shinjuko, Tokyo 169, Japan

351 Larry Kinney, Synertech Systems Corporation, 472 South Salina Street, Suite 800, Syracuse NY 13202

352 Dr. Michael Kintner-Meyer, Sr. Energy Analyst, Science Applications International Corporation, 1710 Goodridge Drive, M/S E-8-2, McLean, VA 22102

353 Kelly Kissock, University of Dayton, Dept of Mechanical Engineering, 300 College Park, Dayton, OH 45419-0210

354 Paul Knight, Domus Plus, 408 North Grove, Oak Park, IL 60302

355 Tim Koehn, Assistant Director, U.T. Health Science Center at Houston, 1851 Cross Point, Ste 2.100, P.O. Box 20036, Houston, TX 77054

356 William L. Kopko, Program Manager for Refrigeration, Global Change Division, U.S. Environmental Protection Agency, 401 M Street, S.W. 6202J, Washington, DC 20460

357 Moncef Krarti, Ph.D., Assistant Professor, Dept of Civil, Environmental and Architectural Engineering, University of Colorado, Campus Box 428, Boulder, CO 80309-0428

358 Dr. Jan F. Kreider, P.E., Dept of Civil, Environmental and Architectural Engineering, University of Colorado, Campus Box 428, Boulder, CO 80309-0428

359 Bob Grizman, Trend Group, Trend Energy, 208 West 4th St., Plainfield, NJ 07061

360 Steve Kromer, Lawrence Berkeley Laboratory, One Cyclotron Road, Building 90G, Berkeley, CA 94720

361 James Kummer, P.E., C.E.M., Johnson Controls, Inc., 507 East Michigan Street, P. O. Box 423, Milwaukee, WI 53201-0423

362 Henry Kurth, Mlinois Office of Energy Conservation, 325 W. Adams, Rm 300, Springfield, II 62704

363 William A. Kyle, Program Advisor, Commerical Marketing, Central Power and Light Company, P.O. Box 2121, Corpus Christi, TX 78403

364 Ing. Jorge Lavarreda Grotewold, Director, Universidad Rafael Landivar, Campus Vista Hermosa III, Zona 16, Guatemala, C.A.

365 Andrew S. Lau, Penn State Harrisburg, W-262 Olmsted Building, Middletown, PA 17057

366 Michael D. Leach, P.E., President, Way Engineering Company, Inc., P.O. Box 36530, Houston, TX 77236

367 Professeur Jean LeBrun, Universite de Liege, Laboratoire de Thermodynamique, Campus du Sart-Tilman, Batiment B 49, B-4000 Liege, Belgium

368 Dr Alan Letton, Dean of Engineering \& Architecture, Tuskegee University, Engineering Building, Room 202, Tuskegee, AL 36088

369 Tom Livers, Energy Division, Dept. of Environmental Quality, 1520 E. 6th Ave., Helena, MT 59620

370 Anthony Lo, B.A. Sc., Load Market Research, BC Hydro, 970 Burrard Street, 18th Floor, Vancouver, B.C. V6Z $1 Y 3$

371 Lee Eng Lock, Technical Director, SUPERSYMMETY-Services Pte Ltd., Block 73 Ayer Rajag Crescent \#07-06/09, Singapore 0513 
Bruce Long, Vice President, Engineering, The Prudential Realty Gropu, Three Gateway Center, Newark, NJ 07102-4082

Mr. Nance Lovvorn, Alabama Power, P.O. Box 2641, Birmingham, AL 35291

David M. Lush, Ove Arup Partnership, 2 Snaresbrook Dr., Stanmore, Middlesex, HA7 4QW, England Managing Editor, Home Energy, 2124 Kittredge, Ste. 95, Berkeley, CA 94704

Mats Douglas Lyberg, Ph.D., Energy Conservation, Swedish Institute for Building Research, Box 785, S80129 Gavle, Sweden

Roman S. Lysiak, Ontario Ministry of Housing, TSSB, P.O. Box 136, Toronto, Ontario M6A 3B4, Canada

378 David J.C. MacKay BA Ph.D., Cavendish Laboratory; Madingley Road, Cambridge CB3 OHE, United Kingdom

R. Michael Martin, California Energy Commission, 1516 9th Street, Sacramento, CA 95814-5504

Mark S. Martinez, Energy Managment Engineer, Southern California Edison, Room 391, P.O. Box 800, Rosemead, CA 91770

381 Takashi Matsumoto, Professor of Electrical Engineering, Waseda University, 3-41 Okubo, Shinjuko, Tokyo 169, Japan

382 Robert D. Mayo, Administrator-Commercial Marketing, Gulf States Utilities Corp., P.O. Box 2951, Beaumont, TX 77704

Richard Mazzucchi, SBW Consulting, Inc., 2820 Northup Way, Suite 230, Bellevue, WA 98004

John R. McBride, President, NCAT Development Corporation, P.O. 5000, Butte, MT 59702

James D. McClure, Estes, McClure \& Associates, Inc., 3608 West Way, Tyler, TX 75703

Michael McDiarmid, M.S., P.E., Energy Engineer, State of New Mexico, Energy, Minerals and Natural Resources Dept., 2040 South Pacheco Street, Santa Fe, New Mexico 87505

Edward E. McGee, Assistant Superintendent of Building Operations, Bramalea Texas, 6510 NCNB Plaza, 901 Main Street, Dallas, TX 75202

388 K. Michael McGrath, Director, Customer Programs, Edison Electric Institute, 701 Pennsylvania Ave. N.W.

389 Dave McGowen, PSCRC, 9 Campus Dr., Parsippany, NJ 07054

390 Dr. Mario A. Medina, Assistant Professor, Mechanical and Industrial Engineering, Texas A\&I University, Campus Box 191, Kingsville, TX 79363

391 Alan Meier, Room 90-4000, Lawrence Berkeley Laboratory, University of California, Berkeley, CA 94720

392 Tom Merka, Administrator, Purchased Utilities, Texas Department of Criminal Justice, P.O. Box 99 Purchasing, Huntsville, TX 77342-0099

393 Jerzy Michna, Prof. dr hab. eng., General Manager in Institute of Environmental Engineering, PL-41-700 Ruda Slaqska, ul. , Wolnosci 6, Poland

Paul L. Miller, Ph.D., P.E., NREL, 1617 Cole Blvd., Golden, CO 80401-3393

396 Harry Misuriello, Energy Conservation and Demand-Side Management, 23 Millbrook Court, Danville, CA 94526

397 William R. Mixon, Tech Support Services, 1018 West Outer Dr., Oak Ridge, TN 37830

398 Mark P. Modera, Lawrence Berkeley Laboratory, Bldg. 90, Rm 3074, University of California, Berkeley, CA 94720

399 Robert Mowris, P.E., Energy Consultant, 1084 Sterling Ave., Berkeley, CA 94708

400-409 Michael Myers, US Department of Energy , FORS EE-421, 1000 Independence Avenue SW, Washington DC

410 Guy Nelson, Energy Services Manager, Western Area Power Administration, 1825 Bell St., \#105, Sacramento, CA 95825

411 Ron M. Nelson, Ph.D., P.E., Professor, Department of Mechanical Engineering, Iowa State University, 2024 H.M. Black Engineering Building, Ames, IA 50011-2160

412 Glen G. Neuburger, Ph.D., Director, Environmental Science \& Technology, Bellcore, 331 Newman Springs Rd., Red Bank, NJ 07701

413 Prof. Les Norford, M.I.T., Dept. of Arch. , Room 7-403, 77 Mass Ave., Cambridge, MA 02139

414 Darin W. Nutter, Ph.D., P.E., Assistant Professor, Department of Mechanical Engineering, Mechanical Engineering Building, University of Arkansas, Fayetteville, AR 72701

415 Thomas Nyquist, P.E., Manager, Mechanical Systems, Department of Engineering, Princeton University, P.O. Box 2158, Princeton, NJ 08543-2158

416 Richard Oberg, P.E., NEOS Corporation, 8950 Cal Center Drive, Ste. 255, Sacramento, CA 95826

417 Christopher O'Brien, Program Manager, Global Change Division, U.S. E.P.A. - 6202J, Washington, DC 20460 
418 Julia Dell Oliver, U.S. Dept. of Energy, 23 Millbrook Court, Danville, CA 94526

419 Patrick J. O'Niell, Ph.D., Home and Building Control Systems, Honeywell Technology Center, 3660 Technology Dr., Minneapolis, MN 55418

420 Jeffrey B. Otto, 411 Ivy Ln, Glen Mills, PA 19342-1327

421 Fred A. Ouellette, Shuttle Subsystem Manager, NASA, Lyndon B. Johnson Space Center, Houston, TX 77058

422 Dave Baylon, Ecotope Inc., 2812 E. Madison, Seattle, WA 98112

423 Danny S. Parker, Senior Research Scientist, Florida Solar Energy Center, 300 State Road 401, Cape Canaveral, FL 32920

424 Richard J. Pearson, Pearson Engineering, 437 S. Yellowstone Dr., Ste. 212, Madison, WI 53719-1096

425 Ellen Ku, Assistant Vice President, Research, Building Owners and Managers Association Intl., 1201 New York Ave, NW Ste 300, Washington, DC 20005

426 John Petze, President, Teletrol Systems, Inc., 324 Commercial Street, Manchester, NH 03101

427 Tom Philben, HEC Energy and Design Services, 24 Prime Parkway, Natick, MA 01760

428 James N. Phillips, P.E., CEM, Technical Sales and Services, Lone Star Gas, 1133 S. Madison, Dallas, TX 75208

429 Robert A. Potter, Jr., Ph.D., P.E., Department of Civil and Mechanical Engineering, United States Military Academy, West Point, NY 10996, (914) 938-4093

430 John T. Powers, Quantum Consulting, Inc., 2030 Addison St., Berkeley, CA 94704

431 John Proctor, Proctor Engineering Group, 5725 Paradise Drive, \#820, Corte Madera, CA 94925

432 Jane Pulaski, Sustainable Energy Development Council, 1700 N. Congress, Rm. 850, Austin, TX 787011455

433 Richard W. Quadrel, Ph.D., Energy Sciences Dept., MSIN: K5-16, Battelle PNL, PO Box 999, Richland, WA 99352

434 Dr. Ari Rabl, Centre D'Energetique, Ecole Des Mines, 60 Boulevard St. Michel 75272, Paris, France 06

435 Kathleen M Radke, Sensors Dept., Honeywell Technology Center, MN14-4B65, 12001 State Hwy. 55, Plymouth, MN 55441

436 Leo Ranier, Davis Energy Group, Inc., 123 C Street, Davis, CA 95616

437 James B. Redden, P.E., Vice President of Operations, HEC Energy and Design Services, 24 Prime Parkway, Natick, MA 01760

438 Vijay E. Reddy, P.E., Technical Evaluation and Planning, Houston Lighting \& Power Company, P.O. Box 1700, Houston, TX 77251

439 James Etta E. Reed, Chief Weatherization Unit, Commonwealth of Pennsylvania, Bureau of Human Resources, 362 Forum Building, Harrisburg, PA 17120

440 George Reeves, George Reeves Associates, 136 Chincopee Rd., Lake Hopatcong, NJ 07849-1550

441 Susan Reilly, M.S., P.E., Enermodal Engineering, Inc., 1221 Preservation Park Way, Oakland, CA 94612

442 Gordon M. Reistad, Ph.D., P.E., Oregon State University, Dept. of Mechanical Engineering, Rogers Hall 204, Corvallis, OR 97331

443 Randy J. Richgruber, P.E., Marketing Program Manager, Minnesota Power, 30 W. Superior St., Duluth, MN 55802

444 David Rinebolt, NASEO, 1615 M St., Washington, DC 20036

445 Lawrence J. Ringel, P.E., President, Synergistic Control Systems, Inc., 2700 Lake Villa Dr., Ste. 180, Metairie, LA 70002

446 Joseph E. Rizzuto, New York State Energy Research, 30 Carriage Rd., Delmar, NY 12054-3704

447 Wayne K. Robertson, Heery International, Inc., 999 Peachtree St NE, Atlanta GA 30367-5401

448 Patricia H. Rose, U.S. Department of Energy, 1000 Independence Ave SW, Mail Stop EE-522, Washington, DC 20585-0121

449 William B. Rose, Building Research Council, University of Illinois, One East St. Mary's Road, Champaign, II 61820

450 Arthur Rosenfeld, U. S. Department of Energy, EE-1, Washington, DC 20585-0121

451 Halvor Rostad, Forlagsleder/Redaktor KULDE, Sorkedalsvn. 10A, P.O. Box 5042, Majorstua, 0301 , Oslo, Norway

452 Jacques Roturier, Centre d'Etudes Nucleaires de Bordeaux Gradignam, Universite Bordeaux, Domaine du Haut Vigneau - BP 120, 33175 GRADIGNAN Cedex, France

453 Andrew C. Rudin, Energy Management Consultant, 7217 Oak Ave., Melrose Park, PA $19027-3222$

454 William H. Ruppert, C.E.M., EG\&G Florida, Inc., P. O. Box 21267, M/S BOC-126, Kennedy Space Center, FL 32815

455 Dennis R. Rydzewski, P.E., Director of Engineering, Wisconsin Public Power, Inc. System, 1425 Corporate Center Drive, Sun Prairie, WI 53590 
John D. Roach, Property Manager, Corporetum Management Company, 550 Warrenville Road, Ste 280, Lisle, II 60532 TX 79423

Harry Romine, P.E., Energy Manager, Construction, John Peter Smith Hospital, 1500 South Main Street, Fort Worth, TX 76104 Energy, 1000 Independence Ave., SW, Washington, DC 20585 Dr. Robin Roy, O.T.A. , U.S. Congress, Washington, DC 20510

Kalev Ruberg, Institute for Research \& Construction, Bldg. M24, National Research Council of Canada, Montreal Road, Ottawa, Ontario K1A OR6, Canada W. Sample, C.E.A. Program Director, Energy Conservation Assistance Program, Energy Conservation Office, 1678 Paul Direc Dr., Innovation Park, Ste. D, Tallahassee, FL 32310 Bill Sandusky, Battelle PNL, PO Box 999 / MS K5-08, Richland, WA 99352 Dale Sartor, P.E., Lawrence Berkeley Laboratory, University of California, Mail Stop : 90-3058, Berkeley, CA 94720 Gary W. Schanche, Energy Systems Division, U.S. Army Corps of Engineers, P.O. Box 4005, Champaign, IL 61820-1305

467 Larry L. Schedin, P.E., Schedin \& Associates Inc., 920 Plymouth Building, 12 South Sixth Street, Minneapolis, MN 55402 Steve Schiller, Schiller Associates, 1800 Harrison St., 18th Floor, Oakland, CA 94612 Marc Schuldt, Principal, SBW Consulting, Inc., 2820 Northup Way, Ste. 230, Bellevue, WA 98004 Mike Schwedler, P.E., Applications Engineer, the Trane Company, 3600 Pammel Creek Road, La Crosse, WI 54601-7599

William W. Seaton, ASHRAE, 1791 Tullie Circle NE, Atlanta, GA 30329-2305 Anthony V. Sebald, Associate Professor, Dept. of Electrical \& Computer Engineering, University of California, San Diego, La Jolla, CA California 92093-0407 Stephen E. Selkowitz, Lawrence Berkeley Laboratory, University of California, Mail Stop : 90-3111, Berkeley, CA 94720 ServiceMaster Energy Management, 9000 E. Nichols Avenue, Ste. 150, Englewood, CO $80222-3407$ Ottawa K1A-0M2, Canada Dipak J. Shah, Honeywell Technology Center, Honeywell Inc., 3660 Technology Dr., Minneapolis, MN 55418-1096 Dr. Gideon Shavit, Honeywell Inc., Commercial Buildings Group, 1500 West Dundee Road, Arlington Heights, IL 60004, , Charles E. Sherman, P.E., President, Energy Simulation Specialists, Inc., 64 E. Broadway Road, Ste. 230, Tempe, AZ 85282 Max H. Sherman, Ph.D., Lawrence Berkeley Laboratory, Bldg. 90, Rm 3074, University of California, Berkeley, CA 94720 Mike Shincovich, D.O.E. HR-822, Office of Admin. Services, 1000 Independence S.W. \#IF-039, Washington, D.C. 20585 Chris Shockman, Research Intelligent Buildings, Dept. of Construction Engineering and Management, Stanford University, Terman Engineering Rm. 396, P.O. Box 5127, Stanford, CA 94309 Chris Siebens, Manager-Marketing Programs \& Support, Jersey Central Power \& Light Comapny, 310 Madison Ave., Morristown, NJ 07962 Peter Simmonds , Advanced Technologies, Flack + Kurtz, Consulting Engineers, 475 Fifth Ave., New York, NY 10017 Bradford S. Simmons, Load Research Supervisor, San Diego Gas \& Electric, 101 Ash street, P.O. Box 1831, San Diego, CA 92112 St. Paul, MN 55102-1611 Al Smith, Director of Facility Management, St Joseph Regional Health Center, 2801 Franciscan Drive, Bryan, TX 77802-2544

487 Dennis A. Smith, P.E., C.E.M., Director-Energy Services, Atlanta Gas Light Company, P.O. Box 4569 , Atlanta, GA 30302-4569

488 Linda Smith, Staff Engineer, State of Colorado, Office of Energy Conservation, 112 E. 14th Avenue, Denver, CO 80203 
Robert C. Sonderegger, SRC Systems Inc., 1300 Clay Street, Ste. 850, Oakland, CA 94612

Prof. Ed Sowell, Dept. of Computer Science, California State University at Fullerton, Fullerton, CA 92634

492 G. F. Sowers, P.E., Senior Vice President, Law Companies Group, Inc., 114 Townpark Drive, Suite 250, Kennesaw, Georgia 30144-5599 Anthony J. Spata, P.E., Project Engineer II, Mcdonald's Corporation, Kroc Drive, Oak Brook, IL 60521 Donald H. Spethmann, P.E., HVAC Control Consultant, 636 Michelline, Northbrook, II 600 Lawrence G. Spielvogel, Lawrence G. Spielvogel Inc., 203 Hughes Road, King of Prussia, PA 194063785

496 Jeffrey D. Spitler, Ph.D., Assistant Professor, Mech Engrng and Aerospace Engmg, Oklahoma State University, 218 Engineering North, Stillwater, OK 74078-0545

497 Prof. Daniel Spreng, Dipl. Phys., M.Sc., Ph.D., Forschungsgruppe Energieanalysen, ETH Zentrum, ETL I 35, CH-8092 Zurich, Switzerland

498 John V.M. Stacey, Engineering Interface Limited, 2 Sheppard Ave. East, Ste. 200, Toronto, Ontario M2N 5Y7, Canada

499 Gene Stamper, 73 Cranford Pl., Teaneck, NJ 07666-4704

500 Leo Stambaugh, Executive Director, Texas Building Energy Institute, 10100 Burnet Road, CES-R7100, Austin, TX 78758

501 Dennis A. Stanke, The Trane Company, 3600 Pamel Creek Rd, La Crosse, WI 54601-7511

502 Roya Stanley, Iowa Dept. of Nat. Res., DNR Wallace Bldg., East 9th and Grand Ave., Des Moines, IA 50319-0034

503 Jay Stein, Senior Engineer, E Cube, Inc., 1900 Folsom, Ste. 112, Boulder, CO 80302

504 Samuel C. Steele, Synergic Resources Corporation, 118 Genesee Street, Geneva, NY 14456

505 Raymond Sterling, Ph.D., P.E., Dept of Civil and Mineral Engineering, Institute of Technology, 790 Civil and Mineral Engineering Building, Minneapolis, MN 55455

506 Franklin D. Stern, Research Associate, RCG/Hagler, Baily, Inc., P.O. Drawer O, Boulder, CO 803061906

507 Alan Stewart, Honeywell, Inc., 4732 Bentley Place, Duluth, GA 30136

508 Tom Stoffel Senior, Senior Scientist, National Renewable Energy Laboratory, 1617 Cole Boulevard, Golden, CO 80401-3393

509 John Stoops, Battelle PNL, PO Box 999 / MS K8-03, Richland, WA 99352

510 Ish Sud, Sud Associates P A, 1805 Chapel Hill Rd., Durham, NC 27707-1150

511 John Sugar, California Energy Commision, 1516 9th St., Mail Station 42, Sacramento, CA 95814

512 Larry Tanner, Sr. Fac. Engineer, Compaq Computer Corp., P.O. Box 692000, M 276, Houston, TX 77269-2000

513 Alan R. Tarrant, P.E., Director, Technology Applications, Lone Star Gas, 301 S. Harwood, Dallas, TX 75201

514 Z. Todd Taylor, K5-20, Energy Sciences Dept., Battelle PNL, PO Box 999, Richland, WA 99352

515 Kevin Yale Teichman, Ph.D., Office of Technology Transfer and Regulatory Support, U.S. EPA, H8105, 401 M Street, SW, Washington, DC 20460

516 Branislav Todorovic, Springer Fulbright honors Professor, University of Engr. Faculty, 27 Marto 80, Belgrade, Yugoslavia

517 Michael Totten, Senior Associate for Policy, International Institute for Energy Conservation, 420 C St., NE, Washington, DC 20002

518 Terry Townsend, Townsend Engineering, Inc., P.O. Box 23526, Chattanooga, TN 37422

519 Cedric S. Trueman, B.C. Buildings Corp, 3350 Douglas St., P.O. Box 1112 , Victoria BC V8W 2T4, Canada

520 Wayne C. Turner, Industrial Engineering and Management, Oklahoma State University, 322 Engineering North, Stillwater, OK 74078-0540

521 Emily K. Tuzson, Senior Energy Analyst, Energy Simulation Specialists, Inc., 64 E. Broadway Road, Ste. 230, Tempe, AZ 85282

522 Robert Tyls, C.P.E., AT\&T, Room 4EA134, One Oak Way, Berkeley Heights, NJ 07922

523 Tony Usiibelli, Commercial/Industrial Section Manager, Energy Office, State of Washington, P.O. Box 43165, Olympia, WA $98504-3165$

524 Al Utesch, 158 FM 1830, Argyle, TX 76226

525 Dr. Tanay Sidki Uyar, RETRU, Kocaeli University, Ant Park Yani 41300 Izmit, Kocaeli, Turkey

526 Pieter L. van der Mersch, P.E., Manager, Engineering, Dept. of Facilities Management, University of Colorado at Boulder, Campus Box 53, Boulder, CO 80309-0053

527 Alan J. Vanden Berg, Edison Electric Institute, 701 Pennsylvania Ave. NW, Washington, DC 20004-2608 
Malcom E. Verdict, Director, The Alliance to Save Energy, 1725 K. Street, Ste. 509, Washington, DC 20006-1401

Bruce Vincent, P.E., Demand Side Specialist, Sacramento Municipal Utility District, P.O. Box 15830, Sacramento, CA $95852-1830$

Gail D.A. Vitori, Administrative Director, Potential Building Systems, Inc., 8604 F.M. 969, Austin, TX 78724

Rebecca Vories, Infinite Energy, P.O. Box 1795, Denver, CO 80217

Paul C. Wacker, Building Controls Division, Honeywell, Inc., 1985 Douglas Drive MN10-1424, Golden Valley, Minnesota 55422-3992

David W. Wade, RDA Engineering, Inc., 134 South Avenue, Marietta, GA 30060

George N. Walton, Mechanical Engineer, Building and Fire Research Laboratory, National Institute of Standards and Technology, Gaithersburg, MD 20899-0001

C. M. Walton, Ernest H. Cockrell Centennial Chair in Engineering and Chairman, Department of Civil Engineering, College of Engineering, The University of Texas, Cockrell Hall, Suite 4.2, Austin, Texas 78712

Brent Wanggren, Master of science in Civil Engineering, Monitoring Center for Energy Research, Royal Institute of Technology, Brinellvagen 34, S-100 44 Stockholm, Sweden

\section{B. W. Ward, P.E., ASHRAE, 1791 Tullie Circle NE, Atlanta, GA 30329-2305}

Mashuri L. Warren, Ph.D., P.E., Product Manager, ASI Controls, 2202 Camino Ramon, San Ramon, CA $94583-1339$

Jim Washington, Wendell Campbell Associates, 1326 S. Michigan, Chicago, II

Monte Jack Waugh, Commonwealth of Virginia , Dept. of Health, Office of Water Programs, A.P. Hill Building, 102 N. Main Street-Third Floor, Culpepper, VA 22701-3085

William P. Welch, P.E., Sr. Energy Management Engineer, Eugene Water \& Electric Board, 500 East 4th Ave, P.O. Box 10148, Eugene, OR 97440-2148

Cynthia F. Wells, Manager, Resource Systems, R20B, Rockwell Space Operations Company, Rockwell International Corporation, 600 Gemini Avenue, Houston, TX 77058-2777

Bob Westby, NREL, 1617 Cole Blvd., Golden, CO 80401

Jeff Wheless, Systems Applications Engineer, Sclumberger Industries, 180 Technology Parkway, Norcross, GA 30092

Brian Wheppton, Projects Development, Officer Centre for Advanced Technology Education, Ryerson Polytechnic University, 350 Victoria St., Toronto, Ontario MSB 2K3, Canada

Ed White, P.E., Executive Director, The University of Texas Medical Branch at Galveston, Physical Plant Dept., Galveston, TX 77555-1016

Macauley Whiting, Box \#2980, Sun Valley, ID 83353

Mike Wiley, Alternative fuels and Recycling, General Services Commission, State Energy Conservation Office, P.O. Box 13047, Austin, TX 78711-3047

Charles Williams, Department of Environment, City of Chicago, Room 600A, 320 North Clark Street, Chicago, II 60610

Mike Williford, Asst., Texas Department of Criminal Justice, P.O. Box 99-Purchasing, Huntsville, TX 77342-0099

Shelley L. Wilson, Washington Associate, The Texas A\&M University System, The Capitol Hill Office Building, 412 Street, S.E., Washington, DC 20001

Frederick Winkelmann, Bldg. 90-3147, Lawrence Laboratory, Univeristy of California, Berkeley, CA 94720

Michael J. Witte, Ph.D., Research Engineer, ElectroCom GARD Ltd., 2070 Maple Street, Des Plaines, II 60018-3019

Jack S. Wolpert, Ph.D., President, E Cube, Inc., 1900 Folsom, Suite 112, Boulder, CO 80302

Dr. Kau-Fui Vincient Wong, University of Miami, Mechanical Engineering, P.O. Box 248294, Coral Gables, FL 33146

James E. Woods, Va Polytech Inst. \& State Un College, of Arch \& Urban Studies, 206 Washington St., Blacksburg, VA 24601-0527

David Wortman, P.E., Boulder Energy Associates, 1085 14th St., Ste. 1248, Boulder, CO 80302

Dr. Jonathan Wright, The University of Liverpool, Leverhulme Building, Abercromby Square, P.O. Box 147, Liverpool L69 3BX, Great Britain

Richard Wruck, Honeywell, 1500 W. Dundee, Arlington Heights, II 60004

Thomas P. Wutka, 130 Lost Acres Rd., North Granby, CT 06060-1313

Andrew J. Yager, Ph.D., Drammensveien 8, N-0255 Oslo, Norway

Fred Yebra, P.E., Energy Services Division, Environmental and Conservation Services Dept., City of Austin, P.O. Box 1088, Austin, TX 78767-8844 
563 C. James Yi, Ph.D., Director, Research and Deveopment, Johnson Controls, Inc., 507 East Michigan Street, Milwaukee, WI 53202

564 Robert E. Young, P.E., Advisor, Institutional Programs, Energy Programs \& Technology, Ministry of Energy, 56 Wellesley Street West, Toronto, Ontario M7A 2B7

565 Gren Yuill, Ph.D., Professor, Department of Architectural Engineering, The Pennsylvania State University, Room 213, Engineering "A", University Park, PA 16802

566 Nameys Zeltinsh, Prof. Dr. habil. sc. ing., Head of Emergy Efficiency Center, Institute of Physical Energetics, 21 Aizkraukles Str., Riga, LV-1006, Latvia

567 Radu Zmeureanu, Ph.D., Eng., Associate Professor, Centre for Building Studies, Concordia University, 1455 o., boul. de Maisonneuve W., Montreal, Quebec H3G 1M8 , Canada

568 Kim Zuhike, Director of Marketing and Sales Services, Wisconsin Power \& Light Company, P.O. Box 192, Madison, WI 53701-0192

$569 \quad$ William A. Zwack, Energetics, 7164 Gateway Drive, Columbia, MD 21046

570 Office of Assistant Manager for Energy Research and Development, DOE Oak Ridge Field Office, P.O. Box 2008, Oak Ridge, TN 37831-6269

571-572 OSTI, U.S. Department of Energy, P.O. Box 62, Oak Ridge, TN 37831

573 W. G. Phelps, Director, Safeguards \& Security Division, DOE-OR 